\title{
C. Sprachbewusstein, Verständigungsschwierigkeiten, Sprachdominanz und -konflikt
}

Während Teil A der Arbeit die offizielle Sprachen- und Schulpolitik behandelt, stellt Teil B dieser die Sprach- und Kommunikationspraxis im Alltag gegenüber. Dabei wurden etliche Kommunikationsformen und -medien einschließlich sprachlicher und außersprachlicher Elemente berücksichtigt. In Teil C sollen das Sprachbewusstsein der Westphalen im Allgemeinen, die Reflexionen der Zeitgenossen über die Sprachen und das Verhältnis der Sprachen zueinander im Mittelpunkt stehen. Es wird hinterfragt, ob die zu erwartenden Barrieren zwischen den französischen und deutschen Sprachgemeinschaften im Königreich Westphalen von den Zeitgenossen als Kommunikationshindernis wahrgenommen wurden; außerdem wird untersucht, inwieweit die verschiedenen Gruppen sich über ihre Sprachen identifizierten und voneinander abgrenzten.

Im Mittelpunkt stehen die Probleme, Streitigkeiten und Konflikte, die sich über die Sprachen anbahnten, da eine Analyse dieser Schwierigkeiten Rückschlüsse auf das Sprachdenken der Zeitgenossen erlaubt. Zudem reflektieren die Sprachprobleme und -konflikte das Selbstverständnis der verschiedenen Sprachgemeinschaften im Königreich Westphalen. Verschiedene Ebenen der Reflexionen über die Sprachen werden im Folgenden nebeneinander gestellt, um schließlich kritisch zu fragen, was es mit den offenen Konflikten im Königreich Westphalen auf sich hatte, bei denen Sprache(n) als Angelpunkt der Konflikteskalation benannt wurde(n).

Im ersten Abschnitt soll eine Annäherung an das Sprachdenken der Zeitgenossen erfolgen, während im zweiten Abschnitt unterschiedlich offensichtliche oder latente Situationen der Sprachdominanz dargelegt werden. Im dritten Abschnitt werden die offenkundigen Konflikte in der administration und am Hof untersucht.

Die Annäherung an das Sprachdenken der Zeitgenossen soll bei den Verständigungsschwierigkeiten und Übersetzungspannen beginnen, führt über den Umgang mit den Fremdwörtern der jeweils anderen Sprache sowie über die Angst, sich in der Fremdsprache fehlerhaft auszudrücken bis zum Bewusstsein für die Existenz von verschiedenen Niveaus der Sprachbeherrschung. Ferner wird das Sprachbewusstsein der Zeitgenossen über ihre Äußerungen hinsichtlich der unterschiedlichen Schwierigkeitsgrade der im Königreich Westphalen verwendeten Sprachen thematisiert.

Als weiterer Befund in der breiten Skala der Gegensätze über Sprachen im Königreich Westphalen werden auch einige Fälle von offensichtlicher oder 
latenter Sprachdominanz behandelt. Es geht insgesamt darum, die Situationen des Sprachkontakts zu beleuchten, die durch die Zeitgenossen problematisiert wurden, um die Wahrnehmung des Fremdsprachlichen durch die Westphalen zu ergründen. Dies könnte weiterführend auch Rückschlüsse auf ihre Fremdwahrnehmung insgesamt ermöglichen.

\section{Vom Sprachbewusstsein der Zeitgenossen}

\subsection{Unzulängliche Übersetzungen} und Sprachverständigungsschwierigkeiten

\subsubsection{Bewusstsein für Übersetzungsbedarf und Qualitätsmerkmale}

Häufig wird in den Polizei- oder Verwaltungsakten darüber berichtet, dass die Übersetzungsprozesse nicht ohne Fehler vonstatten gingen. Dieses Bewusstsein der Zeitgenossen über die Ungenauigkeiten, die sich bei einem Transfer von einer Sprache in die nächste ergaben, wird hier als ein Aspekt thematisiert, der über das Sprachbewusstsein Aufschluss gibt.

Vorweg kann festgehalten werden, dass das Bewusstsein für den Bedarf an Übersetzungen an sich schon eindeutig auf die Wahrnehmung von Sprache als Instrumentarium zur Verständigung unter den Zeitgenossen hinweist. Die Sprachenpolitik der westphälischen Obrigkeit gipfelte im Kern in einer weitgefassten Übersetzungspolitik. Die zweispaltige deutschfranzösische Ausführung des »Moniteur « ist ein Beweis dafür. Durch diese Übersetzungen im »Moniteur « entstanden jedoch viele Unstimmigkeiten in beiden Textversionen. ${ }^{1}$

Auch im Fall der Gesetzestexte zeigte sich bald nach Gründung des Königreichs Westphalen der Bedarf für eine Übersetzung des napoleonischen Zivilgesetzbuchs, die auch beim westphälischen Justizminister Siméon angefragt wurde:

Eine deutsche Übersetzung erschien ๖bei der noch zum größten Theil im Lande herrschenden Unkunde der französischen Sprache` als höchst nothwendig. Auf eine dahin an den Minister Simeon gerichtete Anfrage machte derselbe auf zwei Uebersetzungen von Daniels und Lassaux aufmerksam. Beide könnten nach Belieben gebraucht werden, doch solle derjenigen im einzelnen Falle den Vorzug gegeben werden, welche nach der Kenntniß des Richters von der französischen Sprache ihm am getreuesten den Sinn des Originaltextes im Deutschen wiederzugeben schiene, [so ein Erlass des Justizministers vom 14. Juni 1808]².

1 Siehe bereits oben im Kapitel B I. (Übersetzer, Dolmetscher).

2 GOECKE, Das Königreich Westphalen, S. 96. Vgl. ferner StA MR, Best. 75 Nr. 17, Befürwortung einer Verkaufsgenehmigung und einer Belobigung des Buchdruckers Krüger zu Marburg für ein neu erschienenes Buch über den Code Napoléon durch die Präfektur des Werradepartements, 1808; StA MR, Best. 75 Nr. 3251, Anweisung zur Auszahlung von 2040 Francs an den Bankier S. Heine 
Die Notwendigkeit einer solchen offiziellen Regelung zeigt an, dass es zu Anfang der westphälischen Herrschaft an einer zufriedenstellenden Übersetzung mangelte. Diese Schwäche versuchte man beim Justizministerium zu beseitigen:

Eine offizielle Uebersetzung, welche unter Aufsicht Simeons von westphälischen Rechtsgelehrten, von Leist u.a., verfertigt und bei Levrault in Straßburg gedruckt wurde, erhielt durch königliches Dekret vom 21. September 1808 alleinige Rechtsgültigkeit neben der französischen Ausgabe ${ }^{3}$.

Allerdings hatte man sich mit der Existenz dieser Übersetzung nicht aller Probleme entledigt:

Die deutsche Uebersetzung, welche den einzelnen Gesetzen, Dekreten u.s.w. gegenüber gedruckt wurde, ist oft ungenau, so daß in der That eine Erklärung des Justizministers vom 12. Januar 1811 nothwendig wurde, in der es hieß, >dass der französische Text der einzig offizielle und der deutsche Text nicht mehr als eine offizielle Uebersetzung ist und dass im Falle von Verschiedenheiten, Undeutlichkeiten oder Streitigkeiten immer der französische als Gesetz befolgt werden muß ${ }^{4}$.

Die Schwierigkeiten, durch die Übersetzung eine dem Original gleichwertige Version zu erreichen, mussten den Zeitgenossen ebenfalls bewusst werden und weisen auf einen anderen Aspekt ihres Sprachbewusstseins hin. Die Übersetzungen waren den Originaltexten unterlegen. Diese Ansicht teilte auch der kaiserliche Vertreter am westphälischen Hof, Reinhard, der über »die deutschen Uebersetzungen der Dekrete, [die] ungleichförmig und zuweilen ungenau « seien, klagte ${ }^{5}$.

Es dürfte anzunehmen sein, dass die Übersetzungsschwierigkeiten sich nicht allein auf die offiziellen Texte des westphälischen Staatsapparats beschränkten ${ }^{6}$. Zum Spottgedicht »Abschied von Cassel«, das 1813 wahrscheinlich vom ehemaligen Finanzminister Bülow als Satire auf König Jérôme geschrieben worden war, schreibt der Historiker Paul Zimmermann:

wegen des Vorschusses für den zum Studium des Code Napoléon nach Paris gesandten Staatsratsauditeur Boese, 1812.

3 Ibid., S. $96 \mathrm{f}$.

4 Ibid., S. 97; vgl. Le Moniteur westphalien, Nr.16, 2. Februar 1808, S. 67: Zirkularschreiben des provisorischen Ministers der Justiz und des Innern an die Präsidenten der verschiedenen Tribunalen, 23.1.1808; Reinhard, zitiert nach: TULARD, Siméon, S. 567.

5 Reinhard, zitiert nach: GoECKE, Das Königreich Westphalen, S. 113.

6 Zum Themenfeld der Übersetzung als Handwerk in historischer Perspektive vgl. SCHLIEBEN-LANGE, Das Übersetzungsbüro Dugas; ROCHE, »Völlig nach Fabrikenart«; DIES., Les traductions-relais; NOHR, Die französisch-deutsche "Übersetzungsmanufaktur «; ESPAGNE, Übersetzer in Paris und Leipzig; LÜSEBRINK, NOHR, REICHARDT, Kulturtransfer im Epochenumbruch; NOHR, Von Amberg bis Zweibrücken; BRAUN, Une tour de Babel?, S. 167-169. Weiterführend vgl. auch BACHMANN-MEDICK (Hg.), Kultur als Text. 
Die ursprüngliche Dichtung von Bülows war zum größeren Teile in französischer Sprache geschrieben. Um weiteren Kreisen verständlich zu werden, musste das Gedicht aber ganz in die deutsche Sprache übertragen werden. Das ist jedenfalls sehr bald geschehen; doch wissen wir nicht, von wem. Gewonnen hat es an dichterischem Werte weder durch die Übersetzung, die alle die feinen Anspielungen und Spitzen des Originals doch nur unvollkommen wiederzugeben vermochte, noch durch die Erweiterungen, die von den früheren Teilen doch nicht unbeträchtlich abstechen ${ }^{7}$.

Zwar stellt hier ein Historiker fest, dass der Übersetzungsvorgang trotz der Zusätze und Ergänzungen einen Verlust an Qualität und Präzision mit sich brachte, doch ist es naheliegend, dass auch diejenigen Westphalen, die beider Sprachen kundig waren, zum gleichen Schluss kommen konnten. Zudem erscheint die Bemerkung interessant, dass ein von einem Deutschsprachigen französisch verfasster Text besser war als die davon erstellte deutschsprachige Übersetzung, wobei wahrscheinlich nicht der ursprüngliche Autor die Übersetzung ins Deutsche besorgte.

\subsubsection{Verständigungsschwierigkeiten bei polizeilichen Untersuchungen}

Wie bereits festgestellt, hatten die Übersetzungsfehler, die beispielsweise durch den Vergleich des französischen Originaltexts und seiner deutschen Übersetzung im »Moniteur « den Westphalen offenkundig wurden, teilweise positive Auswirkungen: Einige der Zeitungsleser lernten aus den sprachlichen Unstimmigkeiten die Politik kritisch zu rezipieren.

Einen weniger positiven Aspekt der Folgen von Verständigungsschwierigkeiten und misslungenen Übersetzungsprozessen für die Westphalen stellen die polizeilichen Verfolgungen dar, die sich aufgrund von missverstandenen und falsch übersetzten Ausdrücken ergaben. Der Hannoveraner Bode wurde beispielsweise im März 1813 unter Arrest gestellt, "parcequ'il avoit dit en pleine rue, qu'il souhaitait, que tous les françois crevoint ${ }^{8}$. In eingehendem Verhör bestand Bode darauf, aufgrund folgender Wortverwechslung missverstanden worden zu sein:

La femme \& la servante de l'agent de police Schwarzbach affirment [avoir entendu le mot crever], mais le prevenu le nie. Il dit, que deux militaires françois avoient conduit un troisième, qui avoit eu l'air très-malade, \& que quelques passants avoient fait des rémarques de ce qu'on ne le portoit pas \& qu'il risqueroient de mourir sous leur mains, - / ce qu'on apelle en allemande d'un mot vulgaire: Krepiren / sur quoi il avoit répondu: qu'alors tous les malades qu'on transportoit de cette manière devoient

7 ZimmermanN, Graf Bülow, S. 52.

8 RNB St. Petersburg, F 993 Arch. Westf., K. 13, Nr. 7604-7687, hier Nr. 7641: Schreiben Nr. 94 P. S. von Frömbling und G. L. F. Grahn, Polizeikommissare in Hannover, an J. F. M. de Bongars, Generalinspektor der Gendarmerie mit der Hohen Polizei beauftragt, 5.3.1813. 
camper. Il prétend que les temoins avoient pris le mot camper ou campiren pour créver ou Krepiren ${ }^{9}$.

Ob nun Bode den französischen Militärs tatsächlich den Tod gewünscht oder lediglich angeregt hatte, sie sollten unverzüglich vor Ort Lager zum Ausruhen aufschlagen, ließ sich nicht endgültig feststellen ${ }^{10}$. Wegen des Zweifels am Sinn seines Geredes wurde er von den hannoverschen Polizeikommissaren für drei Tage inhaftiert. Wenn selbst Personen, die offensichtlich einem sprachlichen Missverständnis zum Opfer gefallen waren, verdachtshalber bestraft wurden, zeigt dies, dass die Verständigungsschwierigkeiten für die Westphalen durchaus unangenehme Folgen haben konnten.

Ein anderer Fall zeigt, wie wiederum die politische Polizei ihrem eigenen Eifer bezüglich der Sprachverständigung erlag, sich mühselig mit wortwörtlichen Übersetzungen plagte und dadurch in ihren täglichen Geschäften aufgehalten wurde. Der Pagenlehrer Zinserling berichtet in seinen »Westphälischen Denkwürdigkeiten« über einen Vorfall aus den Büros des Polizeichefs Berkagny, den Bezeichnungen aus dem Hannoverschen "Köther« und »Kothsassen« für »Menschen« - auslösten. Wie bereits im Kapitel B I. (Übersetzer, Dolmetscher) zitiert, wurde seitens der Polizei befürchtet, dass diese »denominations ignominieuses«, die wortwörtlich »un homme assis dans la boue«, eine »trace de l'ancien droit feodal« darstellten, die es nun zu bekämpfen gelte. Erst nach einer leidenschaftlichen internen Diskussion wurde vom Polizeichef hingenommen, dass die Bezeichnungen ethymologisch aus dem Slawischen stammten und ideologisch unbedenklich waren ${ }^{11}$.

Auf die Überwachung des deutschen Sprachgebrauchs durch die politische Polizei als ein Aspekt der latenten Sprachdominanz im Königreich Westphalen, den dieses Beispiel illustriert, kommt die Untersuchung später zurück. Es kann vorerst festgehalten werden, dass die politische Polizei mit der wortwörtlichen Übersetzung von "Köther» und »Kothsasse», die eine beleidigende Bedeutung im Französischen suggerierte, ihre Zeit unnötig verschwendete, da der eigentliche Sinn sich nur aus der Tradition heraus verstehen ließ und eine etymologische Ergründung erforderte. Zinserling wollte zudem mit der Erwähnung dieser Anekdote wahrscheinlich deutlich machen, welche Verlangsamungen die sprachlich bedingten Verständigungsschwierigkeiten im Behördengang verursachen konnten. Er wollte wohl auf die Ineffizienz und Lächerlichkeit des Vorgangs hinweisen:

9 Ibid.

10 Über die Wohltätigkeit der Hannoveraner, die ebenso den Franzosen wie den anderen Soldaten galt, ist bereits im Kapitel B V. (Zinngießer Taberger) berichtet worden.

11 ZINSERLING, Denkwürdigkeiten, S. $43 \mathrm{f}$. 
selbst ein angesehener Gelehrter wie J. von Müller, der um den Erhalt der Universitäten im Königreich Westphalen kämpfte, musste zu Rate gezogen werden, um darüber zu entscheiden, ob nun »Köther « eine herabwürdigende, menschenverachtende Bezeichnung sei, weil sie sich eventuell vom Kot der Köter ableitete.

Aus den Übersetzungsschwierigkeiten und -ungenauigkeiten ergab sich einerseits insgesamt ein Potential für Staatskritik und ein Handlungsspielraum für manche Westphalen. Andererseits wurden die Übersetzungsschwierigkeiten und Sprachmissverständnisse aufgrund fehlerhafter Übersetzungsprozesse in manchen Situationen auch zu einer Belastung. Der Schluss liegt daher nahe, dass die gelegentlich überlieferten Übersetzungsschwierigkeiten, die sicherlich von den Zeitgenossen in einem viel breiteren Umfang erfahren wurden, zu einem wesentlichen Aspekt ihrer Wahrnehmung der jeweilig anderen Sprache werden konnten. Den Westphalen musste bewusst werden, dass es ein schwieriges Unterfangen war, die $\mathrm{Nu}$ ancen respektive die Genauigkeit einer Sprache bei der Übersetzung in die andere $\mathrm{zu}$ erhalten.

\subsection{Umgang mit Fremdwörtern und Französisierung des deutschen Sprachgebrauchs}

Bereits im Kapitel über die Bittschriften (B III.) zeigte sich die Tendenz, in deutschsprachigen Schreiben, die die Westphalen an ihre Obrigkeit richteten, französische Fremdwörter zu verwenden. Dies könnte als eine Anpassung an die neuen Verhältnisse gedeutet werden, als ein Versuch, die westphälische Herrschaft durch die Verwendung ihres Wortschatzes positiv zu stimmen. Diese teilweise minimalen Französisierungsmerkmale erstreckten sich auch auf andere überlieferte Quellensorten. Selbst die gedruckten Quellen weisen eine Fülle solcher Stellen auf, in denen Fremdwörter den fremden Charakter der westphälischen Herrschaft zu betonen scheinen und französische Einschübe im Text, durch den lateinischen Schriftzug graphisch abgesetzt, die neue Realität der Westphalen reflektieren. An anderen Stellen werden Anekdoten, die besonders lebhaft und authentisch wirken sollten, mit einem zitierten Ausspruch in französischer Sprache aufgelockert ${ }^{12}$.

Interessanterweise beschränkt sich diese Übernahme französischer Termini im deutschen Textfluss nicht ausschließlich auf Schriftstücke aus dem Verwaltungsbereich. Es fällt auf, dass gerade für die Wiedergabe von Emotionen französische Einsprengsel benutzt wurden. Wenn der Zeitgenosse F. Müller im Rückblick über die damaligen wirtschaftlichen Zustände berichtet, erwähnt er Staatsbeamte, die ab 1811 ihre Gehälter nur noch

12 Der Zeitgenosse Nagel verwendet zuweilen französische Aussprüche, um seine Anekdoten lebhafter zu vermitteln. Vgl. NAGEL, Kriegsbilder aus der Heimath, u.a. S. $124,127,128$. 
zur Hälfte bezogen, und Rechnungen, die nur zu einem Drittel beglichen wurden:

Und dieser offenkundigen Misère gegenüber mussten wir das lächerliche Schauspiel einer öffentlichen Verbrennung aller englischen Waaren erleben. [...] Viele wollten denn auch behaupten, die Sache sei nicht so ernstlich gewesen, wie es den Anschein hatte. Die Kaufleute hätten sich gegen ein gutes Doucheur mit den Polizeiagenten verständigt und schlechtere inländische Waare ausgeliefert. Nur der Form halber seien einige englische Stücke darunter gewesen ${ }^{13}$.

Die Missstände werden als »Misère« beschrieben, die Bestechung ist ein "Doucheur». Auch im "Moniteur» findet sich das Fremdwort "Douceur» im Kontext einer Anzeige wieder ${ }^{14}$. Durch die Bezeichnung der Missstände und der Bestechungspraktiken in französischer Sprache wurde stilistisch der Entrüstung darüber Nachdruck verliehen. Es erscheint nicht zufällig, dass die Missstände und die Bestechungspraktiken in der westphälischen Verwaltung auf Französisch benannt werden, um so eine Verbindung mit der Sprache der Herrschaft herzustellen und den Franzosen die Korrumpierbarkeit zuzuschreiben.

Das Sprachbewusstsein der Zeitgenossen schloss ein, dass einer Sprache bestimmte Eigenschaften anhafteten. So lässt der Autor der burlesken Satire »Humoristische Reise durch ein hochseliges Königreich« seinen Antihelden sagen: "Mein Erstaunen ist nur in französischer Sprache zu beschreiben ${ }^{15}$. Hier spiegelt sich eventuell ein im 18. Jahrhundert konstruierter Nationalcharakterzug wider, der die Franzosen feminisierte ${ }^{16}$ : War das $>$ schwache Geschlecht nicht emotionaler angelegt und der Antiheld Hilarius deswegen geneigt, auf Französisch seinen Emotionen freien Lauf zu lassen? In der Vorstellung der Zeitgenossen über die Franzosen griffen jedenfalls bereits ab dem 18. Jahrhundert die Geschlechter- und Nationalcharaktere ineinander.

Die Vorstellung, bestimmte Gefühle oder Befindlichkeiten könnten nur in einer bestimmten Sprache gebührend ausgedrückt werden, spricht dafür, wie eng sich die Zeitgenossen den Sprachen, die sie beherrschten, verbunden fühlten und wie sie sich über diese definierten.

Wie nicht anders zu erwarten, soll Französisch nach Angabe von Keim als Fachsprache insbesondere in die Gastronomie, meist in der Form von Pleonasmen, eingezogen sein:

In der Sprache der Niederhessen, insbesondere in ihren verschiedenen Dialekten, hinterlässt die westphälische Zeit ihre Spuren. Der Prozess der sprachlichen `Eindeutschung`setzt sich fort. Dabei wird ursprünglich Fremdes mit Eigenem im Wort verbunden oder gar durch Eigenes verdoppelt. Die Karmenaden und Friggedellen, auf dem Weg >ins Grüne` im Frieggedellenbiedel verpackt, mögen ebenso als Beispiele

13 MÜlLeR, Kassel seit siebzig Jahren, Bd. 1, S. $33 \mathrm{f}$.

14 Le Moniteur westphalien, Nr. 255, Oktober 1811.

15 Hilarius, Humoristische Reise, S. 181.

16 Vgl. OwZAR, Fremde Herrschaft, S. $78 \mathrm{f}$. 
dienen, wie der Schardenggaarden, den man sonntags mit seiner Schwidde aufsucht. Serviette und Couvert für Gedeck dringen aus der französisch bestimmten gastronomischen Fachsprache in die deutsche Alltagssprache vor. Aus dem Serviertuch, das die Bedienung chez la main trug, machten die Kasseläner Schisslameng ${ }^{17}$.

Diese Ausdrücke sind als symptomatische sprachliche Interferenzen und Entlehnungen auf der Wortebene zu erkennen, die als Nebenerscheinung des Sprachkontakts unter der westphälischen Herrschaft zu werten sind ${ }^{18}$.

Bereits zum Ende des 18. Jahrhunderts wurden im Gegenzug Sprachreinigungs- und -bereicherungstendenzen in Deutschland sichtbar, die sich gezielt gegen die Dominanz des Französischen in der höfischen, diplomatischen und gelehrten Welt richteten ${ }^{19}$. Mit einiger Sicherheit kann angenommen werden, dass spätestens nach 1813 eine Abwehr gegenüber französischen Fremdwörtern als Gegenreaktion zur vorherigen Aneignung und Assimilation derselben auftrat ${ }^{20}$. Die Gründungswelle von Sprachgesellschaften zum Erhalt der deutschen Sprache nach 1813 zeugt von diesem Abwehrphänomen, das später abebbte, bevor die Bewegung in den 1840er Jahren wieder erstarkte ${ }^{21}$.

Die Feststellung, dass die Zeitgenossen wahrscheinlich verstärkt französische Wörter verwendeten, stellt nur einen Aspekt dar, entscheidend ist jedoch auch, ob diese Bemühungen auch Beachtung fanden. Die politische Polizei war jedenfalls der Ansicht, dass die Verwendung von Fremdwörtern in einem zeitgenössischen Text auf eine tendenziöse Intention hinweisen könnte. Ein geographisches Werk von Caspari erregte beispielsweise wegen eines Fremdworts die Aufmerksamkeit der Polizei:

Ayant parcouru cet ouvrage je n'ai rien trouvé qui puisse mériter une suppression, de sorte que le mot équivoque Spolien dont se sert cet auteur à l'occasion des objets qui

17 KeIM, »Savoir vivre«, S. 152.

18 Vgl. LANDWEHR, Geschichte des Unsagbaren, S. 127. Systematische Erhebungen, die in einem quantitativ-lexikalischen Ansatz erlauben, differenzierte Ergebnisse vorzustellen, sind für die vorliegende Untersuchung nicht angestellt worden. Eine lexikalische Bestandsaufnahme, die zeigen könnte, ob die Tendenz im Vergleich zur zweiten Hälfte des 18. Jh. zu- oder abnehmend war, wäre eine interessante Aufgabe für eine linguistisch angelegte Arbeit.

19 Die Sprachreinigungstendenzen richteten sich allerdings im Laufe des 18. Jh. zunehmend gegen das Lateinische bzw. gegen die Archaismen und Regionalismen im Deutschen, mehr als gegen die französischen Fremdwörter. Vgl. u.a. WELLER, Französischunterricht in Deutschland, S. 626-628; KRAMER, Das Französische in Deutschland, S. 117.

20 Eine Einschränkung dieser These erfordert die Feststellung von Keim im Fall der Marke Westphälischer National-Kaffee, der zwar 1815 mit der Umbenennung zum Germanischen Kaffee eindeutig germanisiert wurde, jedoch graphisch noch lange die französisch-westphälische Prägung mit dem lateinischen Schriftzug beibehielt. Vgl. KeIM, "Savoir vivre«, S. 151.

21 Vgl. u.a. KIRKNESS, Zur Sprachreinigung, S. 237-242, 247-252; FlAMM, Eine deutsche Sprachakademie. 
ont été le fruit des victoires de l'Empéreur Napoleon le Grand n'est en derniere analyse qu'une affectation d'exprimer dans un terme etranger ce qu'en termes propres on appele Beute, Erbeutung c.a. acquisition faite par droit de guerre qui n'est contesté par personne. J'ai l'honneur de joindre à ce sujet l'extrait d'un dictionnaire latin art. $\underline{\text { Spolium }}^{22}$.

In diesem Fall war das Thema Kunstraub, je nach Perspektive, an sich schon sensibel, weil es eine Kritik an der Eroberungspolitik Napoleons beinhalte$t^{23}$. Die lateinische Sprache, als eine den Polizeibeamten weniger vertraute Sprache, erweckte eventuell eher ihr Misstrauen. Einige Situationen sind überliefert, in denen die lateinische Sprache bei Protesten gegen die westphälische Herrschaft bevorzugt wurde und von den Polizeibeamten unverstanden blieb ${ }^{24}$. Auch Scheller bestätigt mit seinen Versen, dass die französischen Einwanderer der Beherrschung der lateinischen Sprache in der deutschen Bildungswelt mit Misstrauen begegneten ${ }^{25}$.

Die oben zitierte Stellungnahme des Generalpolizeikommissars Boehmer zum Fremdwort »Spolien«, die den Autor des Werkes entlastete, erfolgte jedenfalls nach einer Anfrage aus Kassel zu jener fraglichen Passage im Buch. Die politische Polizei war gegenüber dem Sprachgebrauch und der implizierten Kritik, die sich in der Wortwahl widerspiegeln könnte, sehr wachsam. "Spolien« als "mot équivoque», als zweideutiger Ausdruck aufgespürt, wurde schließlich durchgelassen. Offensichtlich befürchteten die Polizeibeamten in Kassel, mit dem lateinischen Fremdwort würde mehr Kritik ausgedrückt als mit dem deutschen Terminus. Die Tatsache, dass sich das Wort im deutschen Textfluss absetzte, könnte mit der Absicht verbunden gewesen sein, eine Sprache zu wählen, die für viele unverstanden blieb und dadurch kodiert und kryptisch wirkte. Erzeugte nicht etwa das lateinische Wort »Spolien« in Bezug auf die Kriegsführungspraxis Napoleons, der sich selbst in seiner Herrschaftslegitimation und durch seine Zeremonien in Verbindung mit der antiken Welt setzte, einen brisanten Widerspruch, der die

22 RNB St. Petersburg, F 993 Arch. Westf., K. 7, Nr. 3569-3617, hier Nr. 3596: Schreiben Nr. 1018 P. G. von G. W. Boehmer an J. F. M. de Bongars, 11. 3. 1812.

23 Zum Thema Kunstraub unter Napoleon vgl. TitTMAnN, Rechtliche Bemerkungen; DUNCKER (Hg.), Eines hessischen Gelehrten Lebenserinnerungen; WeSCHER, Kunstraub; SAVOY, Patrimoine annexé; HeIMSOTH, »Was Bonaparte gestohlen, können die Preußen wiederholen«; EBELING, LEBEN, Die Kunstpolitik Napoleons; SMIDT, Der Kunstraub in Kassel.

24 Vgl. PRÖHLE, Die Fremdherrschaft, S. 9f.; GOECKE, Das Königreich Westphalen, S. 132; KLEINSCHMIDT, Aus Braunschweigs westfälischer Periode, S. 742. Im Kapitel B IV. (Karikaturen) wurde die Unschlüssigkeit des Polizeikommissars Haas über eine lateinische Losung erwähnt.

25 Vgl. SCHELLER, Jeromiade, S. 47. 
Illegitimität Napoleons, des "Caesars«, wie er gelegentlich durch die Zeitgenossen bezeichnet wurde, besonders heraushob ${ }^{26}$ ?

Wie auch immer die Verwendung von Fremdwörtern im Kern gemeint war, ob als Loyalitätserklärung gegenüber der neuen Herrschaft oder als Kritik, als Betonung des Fremdheitscharakters oder als Vorwurf der Illegitimität, die Fremdwörter blieben nicht unbeachtet. Ihre Verwendung fiel auf, wurde in Frage gestellt und interpretiert.

Wenn dies auf die Schriftsprache zutrifft, dann wahrscheinlich auch auf die mündliche Verständigung der Westphalen. Mit dem Einfließenlassen von französischen Fremdwörtern in den Redefluss beabsichtigten die Zeitgenossen mitunter zu imponieren. So wird in der burlesken Satire »Humoristische Reise« dem naiven und opportunistischen Helden vor seiner Abreise in die Residenz von seiner Mutter der folgende Rat gegeben, der, wenn auch fiktiv, doch die Beweggründe einiger Zeitgenossen reflektieren hilft:

Sey daher einschmeichelnd gegen die Höhern, beinahe gnädig-herablassend gegen Deines Gleichen, und gegen Geringere kannst Du nicht stolz genug seyn; - das alles wirkt, und du Wirst bald als ein nobler Mann ausgezeichnet werden, besonders wenn Du nun auch recht viel französische Brocken in Deine Rede wirfst, sobald Du genöthigt bist, deutsch zu sprechen; nun, und dass Du Dir keine Mühe geben wirst, diese Bauernsprache richtig sprechen zu wollen, das versteht sich von selbst ${ }^{27}$.

Die Aussage der Mutter lässt folgende Vermutung zu: Das Imponier- und Einschüchterungsgehabe, das sich durch das Einflechten von "französischen Brocken « in die deutsche Sprache offenbarte, könnte nicht einzig auf die Intention zurückzuführen sein, sich beim Fremdherrn einschmeicheln zu wollen. Er könnte ebenso den Deutschsprachigen, die das Französische gar nicht beherrschten, gegolten haben und musste nicht bedeuten, dass man sich die französische Sprache aneignen wollte; dieses Verhalten könnte vielmehr mit einer grundsätzlichen Abwehr gegen »diese Bauernsprache« gepaart gewesen sein. Das Quellenzitat suggeriert, wie kompliziert sich das Verhältnis zu der Fremdsprache gestalten konnte: Selbst von denjenigen, die sich den Anschein gaben, sich assimiliert zu haben, wurde die französische Sprache als Merkmal einer sozialen Abgrenzung benutzt. Über sie demonstrierten manche Westphalen ihre Überheblichkeit gegenüber Bevölkerungsgruppen, die der französischen Sprache nicht mächtig waren. Die Vorgabe, Französisch zu beherrschen, drängte sich den Westphalen als Machtdiskurs

26 Über die napoleonische Herrscherpräsentation unter Bezugnahme auf antike Referenzen vgl. den Tagungsbeitrag von L. Morenz, "Zwischen Adler und Biene. Napoleonische Herrschaftslegitimation in alten Spuren«, gehalten bei der Tagung "Antike(n)rezeption um 1800 « am 10.-11.02.2006, organisiert durch das Forschungszentrum Gotha für kultur- und sozialwissenschaftliche Studien der Universität Erfurt, in: H-Soz-u-Kult, [10.3.2006], http://hsozkult.geschichte.huberlin.de/tagungsberichte/id=1073 (22.8.2011).

27 Hilarius, Humoristische Reise, S. $52 \mathrm{f}$. 
auf: Die Sprachen spiegelten das Verhältnis zwischen Herrschenden und Beherrschten im zweisprachigen Gesellschaftskontext in einmaliger Weise wider.

Das Erscheinen eines französischen oder lateinischen Fremdworts, das durch den Kontrast der lateinischen und deutschen Schrift hervorstach, könnte man, um mit den Vertretern des "performative turn « zu sprechen, als eine Inszenierung im Text auffassen, der damit performativen Charakter annahm und zumindest für den Autor einen theatralischen Zug besaß und dramatische Folgen, wie die Gefahr einer Zensur, nach sich ziehen konnte ${ }^{28}$. Die Fremdwörter, wie das Beispiel der »Spolien« zeigte, blieben nicht unbeachtet: Sie wurden sehr wohl von den Zeitgenossen wahrgenommen und interpretiert. Auf der Suche nach dem Sprachverständnis und der Wahrnehmung von Sprachen durch die westphälischen Zeitgenossen stellt diese Feststellung einen interessanten Aspekt dar.

\subsection{Hemmungen, sich in der Fremdsprache auszudrücken}

Einen weiteren Aspekt im Umgang mit der Fremdsprache, der über das Bemerken von Fremdwörtern oder die stilistische Verwendung von Fremdwörtern hinausgeht, stellt die Hemmschwelle dar, sich in der Fremdsprache auszudrücken, die manche Zeitgenossen empfanden. Der Polizeiagent Waldhausen, der dem Generalpolizeikommissar Boehmer in Göttingen Berichte über den Zustand des Schulwesens in Osterode lieferte, sorgte sich beispielsweise darum, ob sein Französisch ausreichend sei. In dem Begleitschreiben von Boehmer an Bongars betonte Ersterer, Waldhausen hoffe wegen der Korrektheit und der Rechtschreibung seines Berichts auf die »indulgence de l'autorité supérieure ${ }^{29}$.

Vom Staatsrat wird oftmals berichtet, dass der Kontrast zwischen den französischen "gewandten Rednern" und den Deutschen, die »sich nur mangelhaft in der fremden Sprache auszudrücken wussten«, frappierend war $^{30}$. Tatsächlich soll der Innenminister, Graf von Wolffradt, Hemmungen empfunden haben, sich in der fremden Sprache auszudrücken ${ }^{31}$. Wer sich die französische Sprache in Auszügen angeeignet hatte, beherrschte

28 Vgl. Fischer-Lichte, Kolesch (Hg.), Kulturen des Performativen; FischerLiCHTE, Vom »Text« zur »Performance«; FisCHER-Lichte, HoRN (Hg.), Performativität und Ereignis; MARTSCHUKAT, PATZOLD (Hg.), Geschichtswissenschaft und »performative turn«; FISCHER-LICHTE, WULF (Hg.), Praktiken des Performativen; KRÄMER (Hg.), Performativität und Medialität.

29 Vgl. RNB St. Petersburg, F 993 Arch. Westf., K. 7, Nr. 3649-3688, hier Nr. 3683: Schreiben Nr. 1201 P. G. von G. W. Boehmer an J. F. M. de Bongars, 19. 5. 1812.

30 Vgl. KLEINSCHMIDT, Geschichte des Königreichs Westfalen, S. 33.

31 Vgl. ibid., S. 47 f.; vgl. ferner ThIMME, Die inneren Zustände, Bd. 2, S. 89. 
nicht sämtliche Finessen der Rhetorik ${ }^{32}$. Zu den beschränkten französischen Redetalenten der deutschsprachigen Staatsräte schreibt allerdings Zinserling zurechtweisend:

Der Gebrauch der Französischen Sprache im Staatsrathe konnte hier kein hinlänglicher Entschuldigungsgrund seyn, da diese Sprache Personen aus diesem Stande ohnehin geläufig seyn musste, und ein Jahr Uebung vollkommen hinreichte, um es in dem Mechanischen zu einiger Fertigkeit zu bringen ${ }^{33}$.

Was für die Deutschen, die sich mit Hilfe der französischen Sprache zu artikulieren versuchten, galt, traf sicherlich auch auf die Franzosen zu. Es dürfte anzunehmen sein, dass nach einigen Jahren im Königreich Westphalen ein Lernprozess auch für die französischen Zuwanderer einsetzte. Der anonyme Autor der Pasquille "Die entlarvte hohe und geheime Polizei des zerstörten Königreichs Westphalen" stellt fest, dass die Franzosen "größtenteils" auch die deutsche Sprache beherrschten: jedoch »wenn sie auch der teutschen Sprache ganz oder zur Hälfte, oder nur mittelmäßig mächtig waren, so redeten sie doch in der Regel nicht teutsch $\aleph^{34}$. Er urteilt über sie: »Sie verstehen und sprechen alle recht gut teutsch, selbst diejenigen, von denen ich Jahre lang keinen teutschen Laut gehört habe ${ }^{35}$. Der anonyme Autor wertet diese Zurückhaltung misstrauisch und vermutet darunter die Absicht, »unter diesem Deckmantel [...] unsre Gesinnungen, und im Ganzen die öffentliche, herrschende Meinung bei uns auszuspähen. Sie sahen es als ein Mittel an, uns treuherzig zu machen, und an ihnen keine Lauscher zu befürchten $«^{36}$. Der anonyme Autor, der 1814 so argwöhnisch gegen die Franzosen schreibt, war nicht gewillt, ihnen nachträglich zuzugestehen, dass sie vielleicht aus Angst, sich fehlerhaft in der Fremdsprache auszudrücken, zurückhaltend bei der Anwendung ihrer deutschen Sprachfertigkeiten waren. Dabei waren andere Zeitgenossen durchaus der Ansicht, dass das Erlernen der deutschen Sprache eine besondere Herausforderung darstellte. Wenn die Zeitgenossen das Erlernen der Sprachen gegeneinander abwogen, beurteilten sie Deutsch als eine schwer zu erlernende Sprache:

wehe dem Franzosen, der ohne Sprachlehrer Deutsch lernen soll! Wenn unsere Armeen für die westlichen Nachbarn so unüberwindlich gewesen wären, als unsere Sprachformen, so würden sie ohne die Allianz von einigen tausend Sprachmeistern niemals Sieger geworden $\operatorname{sein}^{37}$.

Auch der höchst motivierte Sprachlehrer Devoluet stellte bald nach seinen ersten Annäherungen an die deutsche Sprache fest: »Ces voyages m'ont

32 KLEINSCHMIDT, Geschichte des Königreichs Westfalen, S. 48.

33 ZINSERLING, Denkwürdigkeiten, S. 154.

34 AnOnymus, Die entlarvte hohe und geheime Polizei, S. 31.

35 Ibid.

36 Ibid.

37 NAGEL, Kriegsbilder aus der Heimath, S. $194 \mathrm{f}$. 
amené à Francfort en 1808. Je me mis à étudier l'Allemand, et je vis bientôt que l'étude de cette langue, la plus riche et la plus savante parmi les modernes, ne serait pas l'affaire de quelques années « ${ }^{38}$. Zum Sprachbewusstsein der Zeitgenossen zählte, dass sie sich der mit dem Erlernen einer Fremdsprache verbundenen Mühen bewusst waren.

\subsection{Bedauern über unzureichende Fremdsprachenkenntnisse}

Bereits in den Kapiteln über die Übersetzer und Dolmetscher (B I.) und den Spracherwerb (B II.) konnte angedeutet werden, dass deutsch-französisch Zweisprachige im Königreich Westphalen in der Minderheit waren, für sie aber allerhand offizielle und inoffizielle Übersetzungsaufgaben anfielen. Sie trugen weitgehend zur Sicherstellung der Kommunikation in dem neuen Staat bei. In der Tat war nicht jeder »mit einem Maulwerke seltener Art in beiden Sprachen ausgerüstet ${ }^{39}$.

Der Autor der Satire »Jeromiade« bestätigt, dass das Fehlen französischer Sprachfertigkeiten für strebsame Bürger zu einem Karrierehindernis werden konnte:

Auch N. N. N., ein grosser Mann -

Wenn's kam auf kleine Dinge an,

Und der der Anwäld Büberei'n

Bedekkte mit dem Mantel sein - [...]

Zog ein in Kassel, und verliess

$\mathrm{Zu} \mathrm{N.N.} \mathrm{N.} \mathrm{den} \mathrm{Bratenspiess.}$

Hätt er die Welsche Sprach' gekonnt,

Hätt' er sich besser dort gesonnt,

Und's wär gemacht aus ihm ein Ding,

Das auch mit hin nach Welschland ging ${ }^{40}$.

Es kann davon ausgegangen werden, dass die Beherrschung der französischen Sprache zu einem entscheidenden Faktor für eine Karriere im westphälischen Staatsapparat und in der Verwaltung wurde ${ }^{41}$.

Während einige Zeitgenossen Hemmungen hatten, sich wegen mangelnder Kenntnisse in der Fremdsprache auszudrücken, bedauerten andere offen unzureichende Fremdsprachenkenntnisse. In einem Bericht des Präfek-

38 GStA PK, V. HA, Nr. 2300, Akten der Generaldirektion des öffentlichen Unterrichts - Ansuchen um Anstellung als Lehrer der französischen Sprache, 18101813, Bl. 17 f.: Schreiben von Devoluet, Sprachlehrer in Kassel, an J. C. von Leist, Generaldirektor des öffentlichen Unterrichts, 24.1.1813.

39 ANONYMUS, Die entlarvte hohe und geheime Polizei, S. 59.

40 SCHELLER, Jeromiade, S. 32.

41 Vgl. GStA PK, V. HA, Nr. 2286, Gesuche um Anstellung bei den höheren Schulen, 1808-1813, Bl. 23: Attestation de parfaite connaissance \& prononciation de la langue française de C. von Villers, professeur à Gottingue, pour C. W. L. Bauermeister aus Nordheim, à l'adresse de J. C. von Leist, 27.7.1812. Vgl. auch die Kapitel B I. (Übersetzer, Dolmetscher) und B II. (Spracherwerb). 
ten des Elbdepartements, Graf von der Schulenburg-Emden, an den Innenund Justizminister Siméon vom 3. August 1808 lobt er die Qualitäten des Unterpräfekten in Stendal, des Grafen von der Schulenburg-Bodendorff, und äußert zugleich sein Bedauern über dessen unzureichende Kenntnisse der französischen Sprache: »[Il] est actif, laborieux [...]. Il est propre à toutes les affaires, et le seroit encore davantage, si la langue française lui etoit plus familière « ${ }^{42}$. Reinhard, der kaiserliche Vertreter am westphälischen Hof, macht ebenfalls zurückhaltende Bemerkungen über die Französischkenntnisse des westphälischen Innenministers Wolffradt: »er sei ein sehr rechtschaffener Mann, aber zu furchtsam und zu wenig geschickt, beherrsche auch die französische Sprache nicht genügend « ${ }^{43}$.

Das Klagen über die mangelnden französischen Sprachkenntnisse betraf jedoch nicht immer nur Dritte, manchmal wurde dies auch in eigener Sache bedauert:

Gestern Abend kam einer Namens Weichel im Gasthaus zum Ritter und erzahlte mit groster Freüde Bezeigung, was ihm ein französischer Courir welcher hier durch ging von der Armée erzahlt habe, nämlich, wegen den grosen Verlust an Menschen an Pferten extra, die Geselschaft welche meisten aus lauten Könglich. Beamten bestant nahm so ein herzliche Antheil daran, daß alle sagen wann uns Morizius französisch verstänte so könnten wir - <wans > auch mehrere Bouteillen Wein kostete die Interessanteste Nachrichten von der Armée immer durch dem durchpassirenten Courrire erfahren, - Sie nenen Interessanten Nachrichten, was zum Nachtheil der armée gesprochen wird, - so denken alle Marburger ${ }^{44}$.

Nicht immer wurde dieses Bedauern so ausdrücklich formuliert. J. Meyer stellte über seine Schwierigkeiten, bei seinem Verwandten N. Meyer, Lieferant der französischen Armee in Möllen, 1804 eine Anstellung zu finden, lapidar fest ${ }^{45}$ :

Da ich indeß die französische Sprache nicht erlernt hatte, so konnte mich Hr. Meyer in seinen Geschäften nicht gebrauchen, derselbe gab mir daher einige Thaler zur Rückreise, welche ich aber anzutreten keine Lust hatte, ich fasste vielmehr den Entschluß in Hamburg mein Glück zu versuchen ${ }^{46}$.

In deutschsprachigen Bittschriften entschuldigten sich die Bittsteller gelegentlich für den Gebrauch ihrer Muttersprache: »verzeihen, wenn ein aus

42 GStA PK, V. HA, Nr. 1338, Akte des Justizministeriums zu Kassel über den öffentlichen Geist in den Departements, 1808, Bl.21-24: Schreiben vom Grafen P. E. A. von der Schulenburg-Emden, Präfekt in Magdeburg, Elbdepartement, an J. J. Siméon, Innen- und Justizminister, 3. 8. 1808.

43 Reinhard, zitiert nach: THIMME, Die inneren Zustände, Bd. 2, S. 71. Vgl. auch DU CASSE (Hg.), Les Rois frères de Napoléon Ier, S. 371.

44 RNB St. Petersburg, F 993 Arch. Westf., K. 16, Nr. 9760-9796, hier Nr. 9796: Rapport Nr. 3 von C[erfy], Polizeiagent in Mission in Marburg, an J. F. M. de Bongars, 13.1.1813.

45 Weiterführend vgl. Clemens, Napoleonische Armeelieferanten.

46 MeYer, Kurze Erzählung, 1836, S. 2. 
Sr. Königl. Westphälischen Majestät Landen gebürtiger Unterthan es wagt hochdieselben in deutscher Sprache schriftlich zu beschweren ${ }^{47}$.

Im Gegenzug zu den Selbsteinschätzungen der Deutschen über ihre eigenen ungenügenden Französischkenntnisse wurden auch die mangelnden Deutschkenntnisse der französischen Einwanderer thematisiert. Cramer berichtet in seiner "Geschichte des Königreichs Westphalen« über eine Neujahrspredigt des Pastors Hellmuth aus dem Jahre 1808, der sich anspielungsreich und tadelnd über die Fremden äußerte, die unsere Sprache nicht kennen $^{48}$.

$\mathrm{Zu}$ den Reaktionen auf das Dekret vom 6. Juli 1808, das die Ernennung der Unterinspektoren und Oberförster regelte, schreibt der Historiker Willy Kohl: »Unter den Förstern war ein Franzose, des Granges, in Rosenburg, der es aber ablehnte, zum Oberförster befördert zu werden, weil er kein Deutsch konnte ${ }^{49}$.

Von denjenigen, die ihre ungenügende Beherrschung der jeweils anderen Sprache bereuten, mochten manche lückenhafte Fremdsprachenkenntnisse erworben haben, während sie anderen gänzlich fehlten. Ihr Klagen darüber und das dadurch offengelegte Empfinden der Zeitgenossen über mangelnde Fremdsprachenkenntnisse kann als Signal dafür gedeutet werden, dass hin und wieder Situationen eintraten, in denen die Sprachbarrieren zwischen den französischen und deutschen Sprachgemeinschaften als hinderlich empfunden wurden. Dieser Aspekt der Wahrnehmung von Fremdsprachen leitet zur Frage nach dem Sprachbewusstsein und Sprachdenken der Westphalen über.

\subsection{Bewusstsein für verschiedene Niveaus der Sprachbeherrschung}

Bereits aus dem Kapitel über Spracherwerb (B II.) wurde das Bewusstsein deutlich, dass eine Sprache erlernt werden muss und dies mit Mühe verbunden ist. Deswegen überrascht es nicht weiter, dass unter den Zeitgenossen das Bewusstsein für die Existenz von verschiedenen Graden der Sprachbeherrschung vorhanden war.

47 GStA PK, V. HA, Nr. 2030, Akte des Ministeriums des Innern, Pensions- und Gnadengesuche, 1807-1811: Schreiben von Tangermann, Ökonom, Belsdorf bey Alleringersleben, Elbdepartement, an die Regenten, 15.10.1807.

48 Vgl. CRAMER, Geschichte des Königreich Westphalen, S. 89, ferner S. 88-91.

49 KOHL, Die Verwaltung der östlichen Departements, S. 169f. Vgl. ferner über die émigrés der Französischen Revolution in Deutschland: HöPEL, MidDELL (Hg.), Réfugiés und Émigrés; RANCE, L’identité; DIES., La »référence allemande«; DIES., Mémoires de nobles émigrés; SCHÖNPFLUG, VOSS (Hg.), Révolutionnaires et Émigrés. 


\subsubsection{Sprachbeherrschung der "fremden« Sprache}

Der bereits zitierte Sprachlehrer Devoluet gab in einem Schreiben an den Generaldirektor des öffentlichen Unterrichts über sein Erlernen der deutschen Sprache an, dass er nach seiner Ankunft in Frankfurt am Main 1808 damit angefangen habe und bald feststellen musste, dass dies im Selbststudium nicht in ein paar Jahren getan sein würde ${ }^{50}$. Schließlich urteilte Devoluet um das Jahr 1810 herum über das von ihm erreichte Niveau in deutscher Sprache: "Au milieu de ces occupations j'avais appris l'Allemand, sans maître et d'une manière assez profonde. Je l'ecris mieux que je ne le parle ${ }^{51}$. Devoluet erging es so, dass er die studierte und selbsterlernte Fremdsprache besser schriftlich als mündlich beherrschte. Sicherlich machte nicht nur er diese Erfahrung; welchen Bereich man sich zuerst erschloss, war bestimmt vom Sprachlerntyp und den Lebensumständen abhängig, in denen die Fremdsprache erlernt wurde. Was die analphabetischen mehrsprachigen $>$ Ad-hoc -Dolmetscher betrifft (siehe Kapitel B I.), werden diese fast ausschließlich durch Immersion die jeweils andere Sprache erlernt haben.

Ein solches bain de langue wünschte sich ein französischer Vater für seinen in Deutschland geborenen Sohn. Der Geheimrat und Direktor des Akzisen- und Zollamts in Magdeburg, Roux, selbst seit 1776 aufgrund von "diverses circonstances, et entre'autres des liaisons de famille in Preußen ansässig, fragte am 4. Oktober 1807 für seinen 21-jährigen Sohn, der seit seinem dreizehnten Geburtstag in militärischen Diensten »au service de Prusse dans le Régiment d'infanterie du Duc de Brunswick« stand, ob man diesen so schnell wie möglich »en la même qualité dans un régiment au service de S. M. le Roi de Westphalie ou de S. M. L'empereur« anstellen könne. Er betonte: »et surtout s'il y a la moindre possibilité dans un régiment françois où il aurait le plus d'occasions de se perfectionner dans la langue française, la langue maternelle de son père, et de montrer s'il est digne d'être incorporé à sa brave nation $\aleph^{52}$.

Ein anderer Vater, der ebenfalls für seinen Sohn um eine Anstellung im westphälischen Militär bat, führte sogar in seiner Anfrage aus:

Mein ältester Sohn, der jetzt achtzehn Jahre alt ist, hat aus eigener Neigung den Soldatenstand gewählt. [Ich] bitte [...] meinem Sohne doch bey dem Königlich Westphälischen Militair die Anstellung als Lieutenant zu bewirken. [...] Die französische

50 GStA PK, V. HA, Nr. 2300, Bl. 17f: Schreiben von Devoluet an J. C. von Leist, 24. 1. 1813.

51 Ibid.

52 GStA PK, V. HA, Nr. 2030: Schreiben von de Roux, Geheimrat und Direktor des Akzisen- und Zollamts in Magdeburg, Elbdepartement, an die Regenten in Kassel, 4. 10. 1807. 
Sprache versteht er, aber er spricht sie, theils aus Blödigkeit, theils aus Mangel an Uebung noch nicht fertig ${ }^{53}$.

Das Urteil des Vaters fiel nicht gerade mild aus, immerhin stellte er eine Verbesserung durch die Praxis und das Überwinden der entsprechenden Hemmung in Aussicht. Der Schwierigkeit, sich in der französischen Fremdsprache gewandt auszudrücken, waren sich selbst Staatsräte bewusst ${ }^{54}$. Davon zeugt auch eine Angabe des westphälischen Pagen Lehsten-Dingelstädt, der in seinen Memoiren festhält:

Am 15. Mai 1808 begab sich König Jérôme über Göttingen [...] nach Braunschweig, Halberstadt und Magdeburg und kehrte am 25. Mai zurück. Von Lehsten begleitete ihn. [...] Daß allerorten große Empfangsfeierlichkeiten vorbereitet waren, ist verständlich, dass manche lächerliche Darstellung und Anrede vorfiel, insbesondere soweit die französische Sprache in Frage kam, erklärlich ${ }^{55}$.

Die Verlegenheit mancher Zeitgenossen, die Reden oder Ansprachen in französischer Sprache mit Repräsentationscharakter und Pomp halten sollten, mochte von gewandteren Betrachtern als lächerlich eingestuft werden, was ebenfalls vom damaligen Sprachdenken zeugt. Diejenigen, die die Sprachbeherrschung weiter gebracht hatten, amüsierten sich über die Mühen derjenigen, die am Anfang ihres Spracherwerbs standen. Eine Tendenz zum Vollkommenheitsanspruch war angelegt, obgleich die vielen französischen Sprachlehrbücher, "Anfangsgründe», Dolmetscher und Methoden zum Selbststudium oder zur begleitenden Stütze neben dem Privatunterricht, den erwachsenen Westphalen versprachen, zügig und ohne Schwierigkeiten Französisch zu vermitteln ${ }^{56}$. Zwischen dem Anspruch der Westphalen, den Versprechungen der Sprachlehrbücher und Sprachlehrer und der Realität entstand für viele ein Widerspruch. Trotz aller Sprachlehrbücher, die Erfolgserlebnisse in kürzester Zeit versprachen, wussten doch die meisten Zeitgenossen, dass zu einer gründlichen Beherrschung der frem-

53 GStA PK, V. HA, Nr. 1693, Verschiedene Anfragen und Correspondenzen (Eingaben von Städten, Bittschriften von Beamten und Privatpersonen betr. Unterstützungen, Anstellungen und Pensionen beim Innenministerium), 1807-1812, Bl. 82 f.: Schreiben von Böcler, Prediger in Blankenhagen bei Rostock, an G. A. von Wolffradt, Inneminister, 9.2.1811.

54 Vgl. Thimme, Die inneren Zustände, Bd. 2, S. 89.

55 [LEHSTEN-DingELSTÄDT], Am Hofe König Jérômes, S. 17.

56 Vgl. u.a. Trucheman, oder französischer Dollmetscher, mit der Aussprache, für Bürger und Bauern, Lüneburg ${ }^{2}$ 1804; C. M. von SERVAIS, Anfangsgründe der französischen Sprache, in einer faßl. Darstellung der einfachsten Regeln, mit einer Samml. von Wörtern, Gesprächen und Erzähl., Frankfurt a.M. 1805; Christian August Lebrecht KÄSTNER, Kunst in zwey Monaten französisch lesen, schreiben und sprechen zu lernen, Leipzig ${ }^{2} 1807$; Wie lernt man die französische Sprache ohne Lehrer in kurtzer Zeit verstehen, sprechen und schreiben? Ein Noth- und Hülfsbüchlein, Bremen 1809; Der aufrichtige Franzose, oder die Kunst in acht Tagen französisch sprechen zu lernen, München ${ }^{3} 1813$. Für weitere Titel vgl. das Kapitel B II.1. (Spracherwerb). 
den Sprache, sei es der französischen oder einer anderen, auch Mühe und Zeit gehörten. Anschaulich wird die Haltung zum Spracherwerb als langfristig angelegtes Projekt am Beispiel eines westphälischen Staatsgefangenen. Karl Wilhelm Freiherr von Willisen, im Oktober 1812 von der westphälischen Polizei verhaftet, brachte bis zu seinem Ausbruch am 1. Sept. 1813 fast ein Jahr auf dem Kastell in Kassel zu, weil er 1808 zu den Österreichern übergelaufen war, um gegen die »Westphälinger« zu kämpfen. Außerdem war er 1809 einige Tage an Schills Seite marschiert und war seiner Verpflichtung, sich als westphälischer Staatsbürger dem Militärdienst zu stellen, nicht nachgekommen ${ }^{57}$. Als Staatsgefangener erbat er sich zusammen mit anderen von Bongars Papier und Bücher zum Studieren in der Haft, was ihnen unter strenger Vorgabe an den Staatskommandanten im Kastell, jegliche Kommunikation untereinander oder mit der Außenwelt zu unterbinden, zugestanden wurde ${ }^{58}$. Als der Vernehmer der politischen Polizei im Kastell, der Jurist Rosenmeyer und der Leutnant Jungenbluth eine Inspektion des coffre den Willisen bei seiner Verhaftung bei sich führte, im Auftrag des Generalsekretärs der Hohen Polizei Schalch unternahmen, fanden sich darin einige politische und ökonomische Bücher. Ein Buch von Rehberg, aber auch englische und französische Bücher und viel "grimmsche Bücher " waren darunter ${ }^{59}$. In seinem Koffer fand sich außerdem eine »Griechische Grammatik von Bettmann«, »Schneiters griechisch-deutsches Handwörterbuch" und in der Truhe handschriftliches Material, das davon

57 Über Willisens Verhaftung berichtet Steffens, vgl. STEFFENS, Was ich erlebte, Bd. 6, S. 322. Vgl. RNB St. Petersburg, F 993 Arch. Westf., K. 18, Nr. $11398-$ 11 419, hier Nr. 11 399: Schreiben Nr. 453 P. S. von Moisez, Generalpolizeikommissar der Hohen Polizei in Halberstadt, an J. F. M. de Bongars, 3. 10. 1812; ibid., Nr. 11 400: Schreiben Nr. 453 P. S. von Moisez an J. F. M. de Bongars, 1. 10. 1812; ibid., Nr. 11 401: Schreiben Nr. 734 H. P. von F. T. de Guntz an J. F. M. de Bongars, 11. 9. 1812; ibid., Nr. 11 402, Signalement du baron de Willisen, 4.9.1812; ibid., Nr. 11 398: Konzept eines Geständnisses von K. W. von Willisen; RNB St. Petersburg, F 993 Arch. Westf., K. 18, Nr. 11 372-11 397, hier Nr. 11 394: Konzept eines Schreibens von K. W. von Willisen an J. F. M. de Bongars, o. Datum [vor Okt. 1812]; RNB St. Petersburg, F 993 Arch. Westf., Nr. [13 852], Registre des personnes arrêtées, 1812: Eintrag Nr. 65.

58 Vgl. RNB St. Petersburg, F 993 Arch. Westf., Nr. 13 848, Registre de correspondance du bureau de la police secrète, 1812: Schreiben Nr. 2042 von J. F. M. de Bongars, an Jungenbluth, Leutnant und Staatskommandant des Kastells, 19. 11. 1812; ibid.: Schreiben Nr. 2070 von J. F. M. de Bongars an Jungenbluth, 23. 11. 1812; ibid., Schreiben Nr. 2194 von J. F. M. de Bongars an Jungenbluth, 20. 12. 1812. Bongars verdächtigte Willisen, auch Mitglied des Tugendbundes zu sein. Vgl. RNB St. Petersburg, F 993 Arch. Westf., Nr. 13 848: Schreiben Nr. 2084 von J. F. M. de Bongars an V. von Höne, Kriegsminister in Kassel, 25. 11. 1812.

59 Vgl. RNB St. Petersburg, F 993 Arch. Westf., K. 18, Nr. 11372-11397, hier Nr. 11 388: Schreiben von J. P. R[osenmeye]r an Schalch, Generalsekretär der Generaldirektion der Hohen Polizei, 9. 10. 1812; ibid., Nr. 11 387: Inventar der Truhe von $\mathrm{K}$. W. von Willisen. 
zeugt, wie Willisen sich bemühte, außerdem Spanisch und Englisch zu lernen $^{60}$. Willisen, der sein Studium in Halle aufgegeben hatte, um Partei gegen Jérôme und Napoleon zu ergreifen, lernte dennoch fleißig weiter und es dürfte anzunehmen sein, dass er auch seine langen Stunden im Kastell zu Kassel mit Vokabellisten und Grammatikregeln zubrachte, wie dies aus dem Inventar seiner Truhe für die Zeit vor seiner Festnahme hervorgeht ${ }^{61}$.

Ein anderer Fall weist auf das latente Bewusstsein der Zeitgenossen hin, eine erworbene Fremdsprache müsse praktiziert werden, damit sie einem nicht verloren gehe. Über den Gefängniswärter des Zivilgefängnisses in Braunschweig, der mit dem entlaufenen Matrosen Williams aus Nordamerika ein vorläufiges Verhör führte, bevor dieser nach Kassel überstellt wurde, schrieb der Generalpolizeikommissar Guntz an Bongars:

j'ai l'honneur d'envoyer ci-inclus une Espece de Verbal, que le Geolier de la prison Civile, ayant été en Amerique et parlant encore quelques mots d'Anglois, a dresser sur le Matelot John Williams. Quoique cette piece n'ait point de validité, je l'ai jugé cependant à propos de la remettre entre les mains de Votre Excellence ${ }^{62}$.

Guntz betonte, der Gefangenenwärter Köhlert könne noch einige Worte auf Englisch stammeln und hätte sich deswegen in dem vorläufigen Verhör hervorgetan: Die unterschwellige Herablassung über die englischen Sprachfertigkeiten des Gefangenenwärters zeugt allerdings davon, dass er sich bewusst war, eine Fremdsprache müsse praktiziert werden. Möglicherweise erfolgte diese abschwächende Bemerkung, weil die englische Sprache - wegen der Kontinentalsperre und der Feindschaft Napoleons zu England - im

60 Vgl. RNB St. Petersburg, F 993 Arch. Westf., K. 18, Nr.11372-11397, hier Nr. 11 397: Verzeichniß der in den Koffer des K.W. von Willesen vorgefundenen Efecten durch J. P. Rosenmeyer und Jungenbluth unterschrieben; ibid., Nr. 11 378: Übungsblatt mit Grammatikregeln und Deklinationen in Altgriechisch; ibid., Nr. 11 379: Übungsblatt in Altgriechisch; ibid., Nr. 11 381: Übungsblatt in Englisch; ibid., Nr. 11 382: Übungsblatt in Altgriechisch; ibid., Nr. 11 389: Heft betitelt "Spanische Sprachlehre« angefangen in Berlin, 7. 5. 1808, fortgesetzt am 28. 5. 1811; ibid., Nr. 11 390: Vokabelnheft mit Altgriechisch, angefangen am 22.1., aufgehört am 17.2.1811; ibid., Nr. 11 395: u.a. griechische Vokabeln; ibid., Nr. 11 396: Heft mit Altgriechisch. Sein Verhör wurde von Bongars persönlich in französischer Sprache geführt. In einem Register der politischen Polizei, in dem Willisens Angaben eingetragen sind, steht, dass er neben der deutschen die französische, die englische und die lateinische Sprache beherrschte. Vgl. RNB St. Petersburg, F 993 Arch. Westf., Nr. [13 852]: Eintrag Nr. 65. Auch die Mutter Willisens, Friederike, beherrschte offenbar die französische Sprache, so die Bittschrift, die sie in Sorge für ihren "cecond fils« an Bongars richtete. Vgl. RNB St. Petersburg, F 993 Arch. Westf., K. 18, Nr. 11 398-11 419, hier Nr. 11 404: Gesuch von F. de Willisen an J. F. M. de Bongars, 10. 1812.

61 Vgl. ibid., Nr. 11 399: Schreiben Nr. 453 P. S. von Moisez an J. F. M. de Bongars, 3. 10. 1812.

62 RNB St. Petersburg, F 993 Arch. Westf., K. 17, Nr. 10 717-10 735, hier Nr. 10719 : Schreiben Nr. 586 P. G. von F. T. de Guntz, Generalpolizeikommissar der Hohen Polizei in Braunschweig, an J. F. M. de Bongars, 15.3. 1813. 
Königreich Westphalen das Gegenteil einer Prestigesprache darstellte, das heißt einer Sprache, mit der gesellschaftliches Ansehen erzielt werden konnte. Der Hinweis vom Polizeikommissar Müller, dass Köhlert "welcher als vormaliger Braunschweigischer Soldat mehrere Jahr in America gewesen, [...] dadurch die englische Sprache erlernt « $^{63}$ habe, enthält wie Guntz' Kommentar unterschwellig eine herabwürdigende bis abfällige Haltung gegenüber den Fremdsprachenkenntnissen Köhlerts, wahrscheinlich wegen des Umstands seines Erlernens der Sprache und seiner sozialen Herkunft. Guntz schränkte aufgrund der dürftigen Englischkenntnisse Köhlerts die Aussagekraft des Verhörs ein. Das erstellte Schriftstück stufte er als »Espèce de verbal« ein und nicht als vollwertiges Verhörprotokoll. Bongars bestätigte ihn insofern in dieser Ansicht, als er ihm zurückschrieb, dass das Dokument von Köhlert werde als Vorlage für die eigentlichen Verhöre dienen ${ }^{64}$.

Diesem Fall von Zweifeln an der Fremdsprachenbeherrschung Köhlerts kann ein anderes Beispiel gegenübergestellt werden, das zeigt, dass andere Zeitgenossen nicht zögerten, ihre mangelhaften Fremdsprachenkenntnisse selbst zu Lehrzwecken zu verwenden. Der Polizeiagent Waldhausen berichtete dem Generalpolizeikommissar Boehmer über die Situation am Gymnasium in Osterode:

On traite a la verité le français, mais le Directeur de même que le Conrecteur du college qui donnent ces leçons savent à peine les premiers élément de cette langue \& par consequent ne sont pas capable de l'instruire. Je suis trop peu Pedagogue pour pouvoir juger sur la Methode de l'instruction, mais les examens publics prouvent suffisament que les ecoliers n'en savent pas assez pour aller avec succés a l'accademie ${ }^{65}$.

Dass einige Französisch nur schlecht beherrschten und sich dennoch berufen fühlten, es zu lehren, zeigt, dass nicht jeder selbstkritisch mit dem eigenen Können in der Fremdsprache umgehen konnte und dass das Bewusstsein über divergierende Niveaus der Sprachbeherrschung nicht unbedingt immer vorhanden war ${ }^{66}$. Als Lehrfach hatte Französisch, wie die anderen modernen Sprachen auch, jedenfalls nicht den gleichen Stellenwert wie die geisteswissenschaftlichen oder naturwissenschaftlichen Fächer. Der bereits

63 Ibid., Nr. 10 720: Vorbemerkung vom Polizeikommissar Müller zum Verhör von J. Williams, 14.3.1813.

64 RNB St. Petersburg, F 993 Arch. Westf., Nr. 13 850, Registre de correspondance du Bureau de la police secrète, 2. 1.-18. 4. 1813: Schreiben Nr. 686 von J. F. M. de Bongars an F. T. de Guntz, 18.3.1813.

65 RNB St. Petersburg, F 993 Arch. Westf., K. 7, Nr. 3649-3688, hier Nr. 3684: Rapport Nr. 19 H. P. von Waldhausen, Polizeiagent in Osterode, an G. W. Boehmer, 18. 5. 1812 .

66 Vgl. das Beispiel der deutschsprachigen Pagenlehrer, die in Kassel in französischer Sprache unterrichteten: [LEHSTEN-DingELSTÄDT], Am Hofe König Jérômes, S. 4. 
zitierte Waldhausen schrieb zu seiner Vision von der Mädchenschule in Osterode:

L'école des filles est dirigé par la femme du receveur Jechter, il est tout simple qu'une femme seule ne peut pas suffire à tout les points d'une telle entreprise \& il serait a souhaiter que cette école fut changé dans un institut public ou les régents du college enseignasent la religion, l'histoire, Geographie \&c. tandis que la Directrice se chargerai de la langue française et des ouvrages du sexe ${ }^{67}$.

Der Direktorin der Mädchenschule Jechter, die bisher alle Fächer unterrichtet hatte, hätte Waldhausen gern die meisten Fächer abgenommen und sie namhaften männlichen Kollegen übergeben, bis auf das Französische und die häuslichen Arbeiten, die eine gut ausgebildete Dame unterrichten könne. Diese Vorstellung macht deutlich, dass Französisch neben der Hauswirtschaft als Unterrichtsfach in Waldhausens Aufzählung eine minderwertige Stellung einnahm ${ }^{68}$.

\subsubsection{Beherrschung der eigenen Sprache}

Im Übrigen wurde von Zeitgenossen auch die Erfahrung gemacht, dass sich innerhalb der deutschen Sprachgemeinschaft erhebliche Unterschiede der Sprachbeherrschung ergaben. Die Bedeutung mancher Mitteilungen blieb einer breiteren Öffentlichkeit verschlossen und konnte, aufgrund einer kryptischen Ausdrucksweise, nur von einer Minderheit verstanden werden. So schrieb der Unterpräfekt Piautaz aus Halle an den Präfekten des Saaledepartements über die Verbreitung eines in deutscher Sprache verfassten aufrührerischen Zettels, der vermeintlich von einem Studierenden der Theologie stammte, beruhigend: » $\mathrm{Da}$ dieser Zettel, der von wenigen gelesen und von manchen seines schwülstigen Stils halber nicht verstanden worden ist, keine ernsthaften Folgen haben können, verstehet sich von selbst « ${ }^{69}$. Ob der vermeintliche Theologiestudent seinen Zettel bewusst verklausuliert hatte oder unbewusst einen verschlüsselten Stil pflegte, ändert wenig an der Sache: Nur wenige waren in der Lage, seine antiwestphälische Kritik überhaupt zu verstehen. Der Quellenauszug ermöglicht es, die Aussage über die verschiedenen Grade der Sprachbeherrschung einer Fremdsprache zu re-

67 RNB St. Petersburg, F 993 Arch. Westf., K. 7, Nr. 3649-3688, hier Nr. 3684: Rapport Nr. 19 H. P. von Waldhausen an G. W. Boehmer, 18. 5. 1812.

68 Der Stellenwert von französischer Konversation und »Parliermethode« insbesondere in der Mädchenbildung hat weit zurückreichende Tradition, vgl. KALTZ, Der Fall Beaumont, S. 247, 256; vgl. ferner DoFF, Der Beitrag der neueren Fremdsprachen, S. $261 \mathrm{f}$. Über die Tendenzen zur Zurückdrängung von Frauen aus dem öffentlichen Leben und in die private Sphäre im 19. Jh. vgl. HAUSEN, Die Polarisierung der "Geschlechtscharaktere«; WUNDER, VANJA (Hg.), Wandel der Geschlechterbeziehungen; HAUSEN, Öffentlichkeit und Privatheit.

69 RNB St. Petersburg, F 993 Arch. Westf., K. 13, Nr. 7725-7761, hier Nr. 7754: Schreiben Nr. 960 Allg. Polizei von J. M. Piautaz, Unterpräfekt in Halle, Saaledepartement, an W.-C. Gossler, Präfekt in Halberstadt, Saaledepartement, 27. 1. 1813. 
lativieren. Selbst in Bezug auf die deutsche Sprache war durchaus das Bewusstsein für verschiedene Niveaus der Beherrschung vorhanden. Nach Stefan Brakensiek waren Sprecher mit dialektal und sozial unterschiedlich ausgeprägter Sprechweise und Schreibduktus zur gegenseitigen Verständigung darauf angewiesen, sich aufeinander zuzubewegen: »Voraussetzung für [ein] Geschäft auf Gegenseitigkeit bildete eine geglückte Kommunikation zwischen den einzelnen Dorfvorstehern und dem Amtmann. Dazu war es erforderlich, dass beide Seiten sich ernsthaft bemühten, die sprachlichen und mentalen Barrieren, die sich zwischen Bauern und Gebildeten erhoben, zu überwinden $\aleph^{70}$. Diese Feststellung relativiert das breite Niveauspektrum im Französischen in der westphälischen Gesellschaft und in der Verwaltungswirklichkeit.

Als Professor Tieftrunk in Halle Anfang 1808 versuchte, das Druckprivileg für die »Gazette politique de Halle« auf sich übertragen zu lassen, bezichtigte er den bisherigen Redakteur, F. W. Kolpatsky, die deutsche Sprache nur ungenügend zu beherrschen:

Le privilege d'ecrire et de rediger la gazette politique de Halle avec ses annonces se trouvois iusque ici dans les mains d'un ecriveur fort incapable. Il n'entent la langue et il est privé des toutes les arts pour servir a l'interét du Regime et du publique. C'est peutetre seulement par cela, qu'il ecrivoit quelques fois si scandaleusement, que les authorités françoises lui derfendoient la publication et le punissoient de prison $^{71}$.

Ob tatsächlich wegen seiner unzureichenden Beherrschung der deutschen Sprache oder aufgrund des Inhalts der "Gazette", jedenfalls wurde im darauffolgenden September das Druckprivileg für die genannte »Gazette« endgültig Professor Tieftrunk übertragen.

Auch der bereits erwähnte Sprachlehrer und Verfasser einer Lernmethode für die französische Sprache, Devoluet, der im Januar 1813 in Kassel für eine Reform des Fremdsprachenunterrichts in französischer Sprache beim Generaldirektor des öffentlichen Unterrichts vorsprach, gestand diesem in seiner Eingabe, die französische Sprache im Selbststudium erlernt zu haben, da er zunächst eine Ausbildung in lateinischer Sprache in Mâcon genossen habe:

À l'âge de 19 ans, je quittai Mâcon, ma ville natale, pour me fixer à Paris. Soutenu par mes parents, je me livrai à diverses études, notamment à celle du Barreau. Je fournissais quelquefois des articles au journal de Paris et au publiciste. C'est là que le hasard me fit tomber sous la main la grammaire française de Port-royal. Je la lu avec d'autant plus d'avidité, que tout ce qu'elle contenait me parut nouveau. Dans nos Collèges, on ne nous enseignait que le Latin; et si nous apprenions un peu de français, c'était simplement par les corrections de nos professeurs, et sans le secours d'une seule règle. Je

70 BRAKENSIEK, Fürstendiener - Staatsbeamte - Bürger, S. 347.

71 GStA PK, V. HA, Nr. 1881, Akten des Innenministeriums - Die öffentlichen Blätter im Saaledepartement, 1808-1813, Bl. 2: Schreiben des Professors Tieftrunk aus Halle, 29.3. 1808. 
fus frappé de mon ignorance et de l'insuffisance de nos études. Je fus même effrayé en songeant que déjà je m'étais livré au Public, sans autres armes qu'un peu de goût et de pratique; ce qui certes ne suffisait point pour être sur de la correction de son style.

Je me hâtai de remplir cette immense lacune, et deux années entières ne m’ont vu occupé que d'ouvrages sur notre langue, lus d'abord par nécessité et bientôt par goût ${ }^{72}$.

Diese Aussage legt nahe, dass notfalls selbst die Muttersprache wie eine Fremd- oder Zweitsprache im Selbststudium erlernt werden musste. Die Selbstverständlichkeit der Beherrschung der Muttersprache auf einem ansehnlichen Niveau war nicht unbedingt gegeben.

\subsubsection{Handschriftenvielfalt}

Ein weiterer, eher unvermuteter Aspekt der Sprachbeherrschung betrifft die Handschrift. Der bereits zitierte Prediger Böckler, der für seinen Sohn wegen einer Anstellung im westphälischen Militär beim Innenministerium anfragte, urteilte mit einiger Schärfe: »Seine Muttersprache schreibt er richtig; aber er schreibt keine schöne Hand « ${ }^{73}$. In diesem knappen Quellenzitat sind gleich zwei Informationen enthalten: Es war zum einen in den Augen der Zeitgenossen nicht selbstverständlich, die eigene Muttersprache korrekt zu schreiben und die noch im Entstehen begriffenen Standardisierungen der Rechtschreibung zu beherrschen ${ }^{74}$. Zum anderen stellte die Handschrift, mit ihrer mehr oder minder sozial ausgeprägten Graphie und Leserlichkeit, ein weiteres Element dar, das neben korrekter Rechtsschreibung das Niveau der Sprachbeherrschung ausmachte und ebenfalls wichtig zu sein schien ${ }^{75}$. Handschriften waren um 1800 offensichtlich soziokulturell, je nach Ausbildungsgrad und beruflicher Branche ausgeprägt, aber auch geschlechtsspezifisch markiert. Im »Burgschen Kurier. Im Gespräch mit einem Bauer von den neuesten Zeitgeschichten und Welthändeln« vom 4. März

72 GStA PK, V. HA, Nr. 2300, Bl. 17 f.: Schreiben von Devoluet an J. C. von Leist, 24. 1.1813.

73 GStA PK, V. HA, Nr. 1693, Bl. 82 f.: Schreiben von Böcler an G. A. von Wolffradt, 9.2.1811.

74 Zum Thema Standardisierung der deutschen und französischen Sprache vgl. BAlibar, Les Français fictifs; MATTHEIER, Nationalsprachenentwicklung; SETTEKORN, Sprachnorm und Sprachnormierung in Frankreich; MATTHEIER, Dialekt und Standardsprache; DERS., Standardsprache als Sozialsymbol; KRAMER, Das Französische in Deutschland, S. 61. Schulze erwähnt erste frühneuzeitliche Tendenzen zur Normierung der Sprachen, die bereits im 16. Jh. ansetzten. Vgl. SCHUlZE, Die Entstehung des nationalen Vorurteils, S. 45; NORTH, Das Reich als kommunikative Einheit, S. 240.

75 Hier sei auf den im Kapitel B III. (Bittschriften) erwähnten Fall von Lehmann verwiesen, der es nach einiger Zeit nicht mehr wagte, beim Generalinspektor der Gendarmerie Bongars eine Bittschrift in seiner Handschrift einzureichen, da dieser jene sofort erkannte, was sich auf den Antrag vermutlich negativ ausgewirkt hätte. 
1813, der ganz in volksaufklärerischer Tradition, die mediale Form des Dialogs zwischen einem Kurier und einem Bauer wählte, um seine ungebildete Leserschaft über die neueren politischen Nachrichten zu informieren, wurde der Hinweis »Nur leserliche Anzeigen werden aufgenommen!« für den Inseratenteil eingefügt ${ }^{76}$.

Als Piautaz, Unterpräfekt in Halle, Bongars ein Pamphlet, "qui est une parodie d'un Evangile, est a ce qui me semble l'ouvrage de quelque mauvais plaisant, et je n'y vois pas une tendance seditieuse, mais plutot la preuve du mauvais esprit de l'auteur« übersandte, fügte er zu seinen Mutmaßungen über den Autor hinzu: "L'ecriture fort mauvaise de l'original semble etre celle d'une femme de basse extraction, mais l'auteur meme ne manque pas d'esprit et doit etre recherché dans la Classe des personnes d'une bonne education ${ }^{77}$. Über die Handschrift meinte er eine Frau als Kopistin des fingierten Evangeliums zu erkennen und sah sich auch in der Lage zu behaupten, diese stamme aus den Unterschichten und sei von geringerem Ausbildungsniveau, währenddessen er den Inhalt jemandem von Bildung zuschrieb. Kalligraphie und Handschriften waren bei Piautaz offensichtlich beliebte Indizien bei seiner polizeilichen Ermittlungsarbeit im Auftrag von Bongars. So meldete er sich am gleichen Tag in einem anderen Fall beim Polizeichef und schrieb über die Ermittlungen zum Autor des am Haus des Professors Knapp angebrachten Pamphlets:

Je suis parvenu a me procurer sans bruit les ecritures de tous les Etudians de Halle, mais nous n'avons trouvé aucun, qui nous a pu donner un soupçon, qui auroit pu se justifier.

76 RNB St. Petersburg, F 993 Arch. Westf., K. 13, Nr. 7725-7761, hier Nr. 7734. Über die Schriften der Volksaufklärung vgl. für die zeitgenössischen Werke: BECKER, Versuch über die Aufklärung des Landmannes; DERS., Noth- und Hülfsbüchlein; DOHM, Über Volkskalender; ZERRENNER, Volksaufklärung. Weiterführende Beiträge aus der Forschung: Herrmann (Hg.), »Die Bildung des Bürgers«; VIERHAUS, Aufklärung et monde populaire; BÖNING, Das Intelligenzblatt als Medium der praktischen Aufklärung; FREVERT, »Tatenarm und gedankenvoll«?; GRosse, Salzmanns »Der Bote aus Thüringen«; BÖNING, SIEGERT (Hg.), Volksaufklärung; BÖNING, Zeitungen für das »Volk«; DERS., »Ist das Zeitungslesen auch dem Landmanne zu verstatten?«; MIX, Lektüre für Gebildete und Ungebildete; LÜsEBRINK, MOLLIER, Les almanachs populaires; BÖNING, Aufklärung auch für das »Volk«?; DERS., Das Private in der Aufklärung; LÜSEBRINK, MOLLIER (Hg.), La perception de l'événement dans la presse; LÜSEBRINK, Archive der Fremdwahrnehmung, S. 133 f.; SCHEEL, BöNING (Hg.), Der Höhepunkt der Volksaufklärung; KRETSCHMANN (Hg.), Wissenspopularisierung; LÜSEBRINK, MIX (Hg.), Les lectures du peuple. Weiterführend ein Beitrag zur Revision der Volksaufklärung-Forschung, vgl. PETRAT, Der Kalender im Hause des Illiteraten und Analphabeten.

77 RNB St. Petersburg, F 993 Arch. Westf., K. 13, Nr. 7725-7761, hier Nr. 7744: Schreiben von J. M. Piautaz an J. F. M. de Bongars, 7.2. 1813. Das `Evangelium wurde anonym im Briefkasten bei der Post ohne Adressaten abgegeben, was die Absicht deutlich macht, es der Obrigkeit zukommen zu lassen. 
Il est assez probable, que l'ecriture est de la main d'un homme attaché au commerce et nous avons déjà trouvés quelque soupçons assez propres pour fixer notre attention et pour diriger les recherches ultérieures ${ }^{78}$.

Piautaz revidierte seine Ansicht über den Autor des Pamphlets, das er zunächst wegen seines schwülstigen Stils einem Theologiestudenten zugeschrieben hatte, nachdem die Überprüfung der Handschriften aller Hallenser Studenten nichts ergeben hatte: Er sah nun ganz deutlich in der Handschrift einen Mann, der in der Handelswelt tätig sei. Selbst anonyme Schreiben konnten aufgrund der soziokulturellen Zuschreibung über den Inhalt, den Schreibduktus, aber auch aufgrund der Handschrift nicht lange die Anonymität ihrer Autoren vor der Polizei schützen. Aus den zitierten Beispielen geht gleichzeitig auch die Schriftfixiertheit der westphälischen Gesellschaft hervor.

Im Teil B wurden bereits mehrfach polizeiliche Ermittlungen zitiert, die anonym verfasste Schriftstücke betrafen, in denen die Handschrift und ihre Kalligraphie sehr bald zur Enttarnung der Pamphletschreiber oder Denunzianten führte ${ }^{79}$. So schrieb Bongars dem Generalpolizeikommissar in Marburg im Februar 1813 fast mit einem tadelnden Unterton:

Vous me dites dans [votre] rapport que cette lettre [Lettre anonyme qui renferme des avis importants, dont vous me donnez en meme tems communication] doit <être> d'une main connue. Si vous en connoissez l'écriture il ne peut pas vous devenir difficile à en reconnoitre l'auteur, vous voudrez donc bien me le nommer par le retour du Courier ${ }^{80}$.

Den Aspekt der unterschiedlichen Beherrschung der Muttersprache, ob in der Sprechweise, im Schreibduktus oder in der Schreibweise, sollte man nicht unterschätzen oder nur als eine Sache der ungebildeteren Zeitgenossen kennzeichnen. Als ein Dekret über den Gebrauch der deutschen und fran-

78 RNB St. Petersburg, F 993 Arch. Westf., K. 13, Nr. 7725-7761, hier Nr. 7750: Schreiben von J. M. Piautaz an J. F. M. de Bongars, 7.2. 1813. Piautaz bemühte sich auch im Laufe der Ermittlungen um die Entzifferung bzw. Enträtselung des Inhalts des »schwülstigen « Pamphlets und gab Bongars zu bedenken: »j'ai d'ailleurs fait le possible pour completter avec verité le sens de cet Ecrit, mais je n'ai pu parvenir a trouver quelques mots avec sureté. La poesie, qui est a la fin de cet Ecrit est tirée d'un poéme de Klopstock, intitulé /Schlachtgesang/ qui se trouve dans le premier Volume des poesies de cet auteur, Edition de Leipzig de 1798 pag. 255. - J'ai completté autant qu'il m’étoit possible le sens de cet ecrit et cet Essai est joint a cette lettre«.

79 Im Online-Kapitel über das Medium »Brief« z.B. im Rahmen der analysierten Affäre Kocken und Bielstein, http://halshs.archives-ouvertes.fr/PLCINAPOLEON (1.1.2013), im Kapitel B I.1.4. (Übersetzer, Dolmetscher) in der Affäre Rau.

80 RNB St. Petersburg, F 993 Arch. Westf., Nr. 13 850: Schreiben Nr 244 von J. F. M. de Bongars an F. J.H. von Wolff, Generalpolizeikommissar der Hohen Polizei in Marburg, 5. 2. 1813. 
zösischen Sprache bei den öffentlichen Verhandlungen im März 1808 im Staatsrat zur Debatte stand, berichtete einer der Staatsräte an König Jérôme:

La langue allemande est la langue naturelle et par conséquence la plus commune des peuples soumis à Votre obéissance. Cependant quatre à cinq dialectes différens et tous fort irréguliers sont répandus dans les diverses parties de Vos Etats, sans qu'on puisse justement déterminer, quel est celui de ces dialectes qui a le plus de faveur et qui en mérite d'avantage.

Le doute est tel à cet égard, que les hommes les plus instruits dans vos conseils reçoivent et se renvoyent réciproquement le reproche de ne pas savoir l'allemand, et qu'on ne peut obtenir une traduction du Bulletin des Loix qui réunisse deux suffrages $^{81}$.

Auch in Gelehrtenkreisen und in der oberen Verwaltungsebene hielten sich ausgezeichnete deutsche Muttersprachler gegenseitig vor, die deutsche Sprache nicht ausreichend zu beherrschen.

\subsubsection{Idealfall: Vollkommenheit in der Fremdsprache}

Besonders rühmlich und außergewöhnlich erschien es den Zeitgenossen, wenn man es in einer Fremdsprache zu einer fast vollkommenen Beherrschung brachte. Dr. Theodor Kühne, nach eigenen Angaben Professor der abendländischen Sprachen in Marburg, gab Wolffradt, dem Innenminister, hinsichtlich seiner italienischen Sprachkenntnisse an: »Wahre Kenner der italienischen Dichtkunst versichern mich in ihren Antworten, dass ich durch die Bekanntmachung meiner Poesien einer deutlichern Beweis von fremder Sprachkenntniß gebe, als je ein Deutscher bisher gethan habe ${ }^{82}$.

Auch Professor Villers, der von einem seiner früheren Göttinger Studenten, Bauermeister aus Nordheim, um eine Referenz gebeten worden war, schrieb in seiner »Attestation de parfaite connaissance \& prononciation de la langue française«:

Monsieur [...] Bauermeister, de Nordheim, ayant suivi cet été mon cours de Littérature française, j'ai eu occasion de me convaincre, en causant avec lui dans cette langue, non-seulement qu'il en avait une exacte et parfaite connaissance grammaticale, mais encore qu'il la parlait avec un très bon accent, d'une manière coulante, aisée, et tout-à-fait nationale, de manière qu'on le prendrait facilement pour un français natif; ensorte qu'à cet égard, je le juge tout aussi propre qu'un français à enseigner la langue française dans une Ecole; tandis que je l'encrois beaucoup plus capable par ses bonnes études grammaticales et par l'avantage qu'il a de posséder les deux langues ${ }^{83}$.

81 GStA PK, V. HA, Nr. 571, Das Dekret des Königs Jérôme über den Gebrauch der deutschen und französischen Sprache bei den öffentlichen Verhandlungen, März 1808, Bl. 1: Bericht an den König Jérôme, 19.3.1808.

82 StA MR, Best. 75 Nr. 156, Akten des Innenministeriums über die Universität von Marburg: Schreiben von T. Kühne, Professor abendländischer Sprachen in Marburg, an G. A. von Wolffradt, 16. 10. 1810.

83 GStA PK, V. HA, Nr. 2286, Bl.23: Attestation de parfaite connaissance et prononciation de la langue française de C. de Villers pour C. W. L. Bauermeister à l'adresse de J. C. von Leist, 27. 7. 1812. 
Die perfekte Beherrschung einer Fremdsprache setzte sich im Urteil Villers' aus genauen grammatikalischen Kenntnissen, einer sehr guten Aussprache und einem ungehemmten und souveränen Redefluss zusammen.

\subsection{Umgang mit den Sprachen vom Feind und Wertungen über die Sprachen}

Um einen Einblick in das Sprachbewusstsein der Zeit zu gewinnen, empfiehlt es sich, den Blick nicht allein auf das Verhältnis zwischen der französischen und deutschen Sprache zu richten, sondern auch auf den Stellenwert, den weitere Sprachen im westphälischen Kontext erlangen konnten. Der Drang der Westphalen, sich im letzten Jahr des Bestehens des Königreichs Westphalen Grundkenntnisse der russischen Sprache anzueignen, wurde bereits angesprochen. Ihre Bemühungen, sich mit russischen Wörtern und Wörterbüchern auszustatten, waren nicht zuletzt von abfälligen Bemerkungen über diese Sprache durch die Polizeibeamten begleitet. Ihre Einstellung zur russischen Sprache ging so weit, darin »russische Schmierereyen ${ }^{84}$ oder $"$ mots barbares ${ }^{85} \mathrm{zu}$ erkennen. Die Geringschätzung einer Sprache, die einem sehr fremd klang ${ }^{86}$, bestätigt die Aussage des Offiziers Lehsten-Dingelstädt, der über seinen Austausch mit einem russischen Gefangenen im Kontext des russischen Feldzugs berichtet:

Beim Regiment waren mehrere Polen, welche der russischen Sprache kundig waren. Durch sie wurde die Aussage der Gefangenen bekannt. Ein Korps, meist aus Russen bestehend, habe sich über Großenhain zurückgezogen. >Mein Gefangener ließ mich bitten, ich solle ihn nicht fortschicken, ich sei ein so guter Offizier, da ich ihm mein Tuch zum Verbinden gegeben habe, er wolle mir dienen. Doch was sollte ich mit ihm beginnen, da ich kein Russisch verstand und seine Wunde nicht unbedeutend war. Es tat mir leid. Doch musste ich ihn mit den anderen transportieren lassen. [...] Was aus den armen Gefangenen wurde, weiß ich nicht ${ }^{87}$.

Die Auffassung, man könne mit einem Diener, dessen Sprache man nicht sprach, wenig anfangen, selbst wenn er einem dankbar ergeben war, ist bezeichnend. Auch erwecken einige Aussagen von Zeitgenossen den Eindruck, dass eine Sprache, die man nicht beherrschte, einen unheimlichen Charakter annehmen konnte. Der westphälische Pfarrer Gehren, als Staatsgefangener nach Mainz verbracht, schrieb von dort aus drei Briefe: "Ein französischer Brief wurde an den Hrn. Präfekt Jean Bon de St. André, ein deutscher an den Hrn. Stadtmaire Makke zu Maynz und ein dänisch-deutscher an meine Gat-

84 RNB St. Petersburg, F 993 Arch. Westf., K. 14, Nr. 7952-7997, hier Nr. 7975: Schreiben von J. M. Piautaz an den Maire in Halle, 2. 2. 1813; vgl. ibid., Nr. 7977: Schreiben Nr. 71 von J. M. Piautaz an W.-C. Gossler, Februar 1813.

85 RNB St. Petersburg, F 993 Arch. Westf., Nr. 13 850: Schreiben Nr. 946 von J. F. M. de Bongars an Frömbling und G. L. F. Grahn, 12.4. 1813. Vgl. ferner zu den Vorstellungen von minderwertigen Sprachen REINHARD, Sprachbeherrschung, S. 8.

86 Zum Topos des Fremden als Barbar ohne Sitten und Sprache vgl. ibid., S. 8 f.

87 [LEHSTEN-DingelstäDT], Am Hofe König Jérômes, S. 108. 
tin zu Felsberg geschrieben ${ }^{88}$. Alle Briefe wurden durchgelassen, nur beim dritten "mußte der dänische Theil, so unschuldig auch dessen Inhalt war, in deutsch umgewandelt werden - >weil der Hr. Aufseher der holländischen Sprache sich nicht völlig gewachsen fühle « ${ }^{89}$. Der Pfarrer lässt seinen Leser Anteil haben an seiner Belustigung über den Aufseher, der Dänisch mit Holländisch verwechselt und so tut, als ob er schon Holländisch könne, nur nicht genügend für den Brief Gehrens.

Zeitgenössische Bemerkungen über das Russische, aber auch über das Englische fallen ebenfalls durch ihre Abwertung auf. Wer über Sprachkompetenzen in englischer Sprache verfügte, konnte von der Obrigkeit stigmatisiert werden: Die Hohe Polizei vermutete hinter solchen Fähigkeiten oft einen Werber für englische Militärdienste oder einen Spion. Durch die Kontinentalsperre und die Opposition Englands gegen die napoleonische Expansionspolitik war das Verhältnis zu allem Englischen und Englischsprachigen angespannt; zudem hatten sämtliche mächtige Opponenten des Königreichs Westphalen aus dem Hannoverschen, wie der Graf von Münster, aber auch der Herzog von Braunschweig-Oels, im Jahr 1809 nach England übergesetzt. Von dort aus, sowie von Helgoland, wurde der Krieg gegen Napoleon organisiert, mitunter durch die Anwerbung von Männern im Königreich Westphalen, die bereit waren, gegen Napoleon zu kämpfen ${ }^{90}$. Im Königreich Westphalen lebten auch, noch aus dem vorangegangenen Jahrhundert, ehemalige Soldaten des Fürsten von Hessen-Kassel, die dieser in englische Militärdienste vermittelt hatte und die zum Teil wegen ihrer Beteiligung am Amerikanischen Bürgerkrieg über englische Sprachkenntnisse verfügten ${ }^{91}$.

$\mathrm{Zu}$ westphälischer Zeit wurden das Englische und das Russische im Allgemeinen eher gering geschätzt, weil die Abneigung gegenüber diesen ausländischen Mächten teilweise auf deren Sprachen projiziert wurde.

Die Vorurteile, beispielsweise über die Schwierigkeit, die Vollkommenheit und die Vielfalt einer Sprache, reflektieren ebenfalls das Prestige oder den Stand einer Sprache in dem jeweiligen Zeitalter, in der jeweiligen Gesellschaft. Sie gehen teilweise auf tradierte Diskurse über die Sprachen zurück,

88 GEHREN, Dreimalige Verhaftung und Exportation, S. 128.

89 Ibid., S. 129.

90 Vgl. u.a. Havemann, Das Kurfürstenthum Hannover, S. 24; KLEINSCHMIDT, Geschichte des Königreichs Westfalen, S.640; ThImmE, Die inneren Zustände, Bd. 1, S. 425-428; DERS., Die hannoverschen Aufstandspläne; MIERZINSKY, Unter Franzosenherrschaft, S. 10; LÜNSMANN, Die Armee des Königreichs Westfalen, S. 38; BreITENBORN, Die Grafschaft Wernigerode, S. $58 \mathrm{f}$. Zu den Auswirkungen der Kontinentalsperre gegen englische Waren vgl. u.a. DUfRAISSE, La contrebande; DERS., Französische Zollpolitik; DERS., Les transformations de l'appareil douanier.

91 Vgl. u.a. LosCH, Kfm. Hessen, S. 38; DERS., Soldatenhandel. 
wie auf diejenigen, die bereits im Zuge des Streites über die »Qualität der einzelnen Sprachen « durch die Humanisten entwickelt worden waren ${ }^{92}$.

Das Französische wurde auch im Laufe der westphälischen Herrschaft, je nach eingenommener Perspektive, unterschiedlich bewertet. Spätestens ab 1814 erfolgte eine Kehrtwendung in der Toleranz gegenüber dem Französischen ${ }^{93}$. Wie oben zitiert, bezeichnete man es gelegentlich als »Bauernsprache « ${ }^{94}$. Scheller erwähnt 1814 in den Versen seiner »Jeromiade« ein deutsch-französisches Wörterbuch in folgender Weise: »Ein Deutsche[s] Taschenwörterbuch/Mit Welsch gemischt « ${ }^{95}$. Im selben Werk hält Jérôme eine Rede »auf Fransch ${ }^{96}$. Das Französische als »Welsch» oder als »Fransch« zu bezeichnen, machte in aller Knappheit und ein wenig derb die Ansicht des Autors über diese Sprache deutlich. Das wechselnde Ansehen der Sprachen folgte sehr eng den politischen Entwicklungen.

\subsection{Zugang zur Fremdsprache}

Einerseits existierte offensichtlich das Bewusstsein dafür, dass eine Fremdsprache bis zur Vollkommenheit beherrschbar sei, wie im oben erwähnten und von Professor Villers gelobten Fall Bauermeister. Bemerkenswert ist andererseits, dass selbst für Personen mit keinen oder wenigen Kenntnissen einer Fremdsprache diese nicht durchweg ein unzugängliches Idiom darstellte, das für sie in seiner Bedeutung undurchdringbar bleiben musste. Der bereits zitierte Page und nachmalige westphälische Offizier LehstenDingelstädt schreibt über einen Konflikt unter Militärs, der sich in Folge einer Niederlage im Kriegsgeschehen vom Oktober 1813 ergab:

Da tritt der etwas berauschte polnische General auf General Wolff zu mit den Worten: >Vous vous êtes battus hier comme des gens... si mes braves Polonais n'avaient pas tenu forme, tout aurait été perdu<. [Es kam zu einer] Beschimpfung [und] rätselhafte[m Ausbruch].

Unschlüssig, was mit solchem Prahlhans anzufangen sei, waren viele unserer Leute, welche seine französischen Worte teils verstanden, teils erraten hatten, auf den Wall getreten, nahmen ihn auf die Schulter und wollten den Kerl in die Elbe werfen ${ }^{97}$.

Wie Lehsten-Dingelstädt weiter beschreibt, blieb dem westphälischen General Wolff nichts anderes übrig, um das Leben des betrunkenen und beleidigenden polnischen Generals vor der Rache des Militärvolks zu retten, als diesen zu einem Duell aufzufordern. Zur abschließenden Regelung des Konflikts wurde auf das Duell, das wegen der Betrunkenheit des Herausforderers

92 SCHulze, Die Entstehung des nationalen Vorurteils, S. 28.

93 Vgl. AnONYMus, Die entlarvte hohe und geheime Polizei, S. 142; SCHELLER, Jeromiade; Cramer, Geschichte des Königreichs Westphalen, S. 75.

94 Hilarius, Humoristische Reise, S. 53; SCHELlER, Jeromiade, S. 8.

95 SCHELLER, Jeromiade, S. 75.

96 Ibid., S. 88.

97 [LeHSTEN-DingelstäDT], Am Hofe König Jérômes, S. 135. 
für ihn nicht gut enden konnte, verzichtet und durch eine Entschuldigung ersetzt. Selbst einfache Soldaten, die wenige bis keine Kenntnisse der französischen Sprache hatten, konnten dennoch den Ausbruch des polnischen Generals verstehen, der sie auf Französisch in ihrer Tapferkeit beleidigte ${ }^{98}$. Dieses Beispiel sagt sehr viel über den Umgang mit Fremdsprachen aus: Selbst wenn man eine Sprache nicht kannte, versuchte man, sie zu verstehen. Die Zeitgenossen begegneten Fremdsprachen nicht, indem sie diese etwa als ein unzugängliches Sprachsystem betrachteten, das ihnen nur fremd bleiben konnte. Gegenüber Fremdsprachen reagierten die Zeitgenossen aktiv und versuchten durchaus aus der ihnen ungewohnten Sprache verständliche Ausdrücke oder Wörter herauszuhören, bei denen sie sich zutrauten, diese zu einem Sinn zusammenzusetzen. Sicherlich, wie der Fall des betrunkenen polnischen Generals erahnen lässt, stützten sie sich bei der Interpretation seiner Worte auf seine Mimik und Gestik. Die Vermutung liegt nahe, dass die anwesenden Soldaten mit besseren französischen Fremdsprachenkenntnissen schnell als Dolmetscher fungierten, um eine zügige kollektive Interpretation des beleidigenden Ausbruchs des polnischen Generals und eine passende kollektive Reaktion zu ermöglichen ${ }^{99}$. Eine weitere Situation, die diesmal nicht auf eine kollektive Erfahrung zurückgeht, sondern auf das Erlebnis mit einem Schriftdokument eines Einzelnen, des westphälischen Generalleutnants Ludwig Bödicker, untermauert diese Aussage. Der Militär befand sich in Gewahrsam im Kasseler Kastell und man brachte ihm eine "Petition« in französischer Sprache, die seine Frau offenbar unter Druck verfasst hatte. $\mathrm{Zu}$ seiner Reaktion auf das Schriftstück schreibt er:

Obschon ich wenig Französisch verstand, und von dem Antrag an meine Frau nichts wusste, wurde mir doch aus einigen mir gleich verständlichen Sätzen, der Inhalt des Briefes klar genug und versetzte mich in solche Wuth, dass ich dem Kommandant versicherte, einen jeden der mir einen solchen Antrag wiederholen würde, zu erwürgen ${ }^{100}$.

Dieses Beispiel bestätigt: Obwohl man eine Sprache nicht perfekt beherrschte, erschien sie einem nicht ganz unzugänglich und man traute sich zu, ihre Bedeutung annähernd zu verstehen.

Auch wenn eine gemeinsame sprachliche Verständigungsebene bestand, konnten sich in die Diskussion Unstimmigkeiten einschleichen, die den einen oder anderen Gesprächspartner zu einem Ausbruch in einer anderen

98 Weiterführend zum Ehrhandel und Duell vgl. FÜRBRINGER, Metamorphosen der Ehre; FrEvERT, Ehrenmänner; DINGES, Ehrenhändel; SCHREINER, SCHWERHOFF (Hg.), Verletzte Ehre.

99 An dieser Stelle kann an die im Kapitel B I. (Übersetzer, Dolmetscher) formulierte These der Existenz zahlreicher `Ad-hoc «-Übersetzer in der westphälischen Gesellschaft, hier >Ad-hoc -Dolmetscher, angeknüpft werden.

100 BÖDICKER, Die militärische Laufbahn 1788-1815 des Generallieutenants Ludwig Boedicker, S. 282. 
Sprache verleitete. Der anonyme Autor der »Garküche an der Fulde« berichtet im Jahre 1814 über ein solches Streitgespräch zwischen einem Franzosen und einem Deutschen, das sich im Gasthaus von Murry in Kassel ereignete, als er zufällig dort vorbeischaute:

Es entspann sich zwischen einem Franzosen und einem Teutschen das Tischgespräch über die Vorzüge der Stadt Paris vor allen andern Hauptstädten der Welt. Der Franzose übertrieb seine Vorliebe für Paris so sehr, dass er behauptete, wer diese Stadt nicht gesehen, sollte sich schämen zu sagen, daß er je gereiset hätte. Dieß verdroß meinen Landsmann, der sich auch ein wenig darauf einbildete, schon auf Reisen, wiewohl nicht in Paris selbst, gewesen zu seyn. Er ließ seinem Gegner in halb versteckten Worten merken, dass nur ein Franzose in seinem Dünkel so etwas behaupten könnte. Dieser fing Feuer, und löschte es, ehe mein Landsmann sich's versah, in dem Gesichte des letztern, welches er mit einem fliegenden Glas Wein zugleich begoß und leicht verwunderte. Der Beleidigte sprang auf und räschte sich - nur mit Worten; denn der Franzose hatte die Lacher - lauter Franzosen - alle auf seiner Seite, und von dem Wirth des Hauses - selbst auch ein Franzose - wäre eben so wenig Beistand zu erwarten gewesen ${ }^{101}$.

Ganz abgesehen davon, dass dieses Beispiel zum kulturellen Konflikt zwischen einem Deutschen und einem Franzosen bemerkenswert ist, weil der Deutsche versuchte, seine Stimme gegen eine gewaltige Tradition der Paris-Reiseliteratur zu erheben ${ }^{102}$, war seine Lage im Gasthaus schnell aussichtslos. Zu Anfang hatten offensichtlich die Streitenden problemlos eine gemeinsame Verständigungssprache gefunden. Bei der dominant französischsprachigen Klientel des Gasthauses Murry dürfte anzunehmen sein, dass es sich um Französisch handelte. Die gemurmelten »halb versteckten Worte«, wahrscheinlich in deutscher Sprache, waren es jedoch, die zur Eskalation des Streitgesprächs und zu der handgreiflichen Reaktion des Franzosen führten. Der Deutschsprachige wehrte sich zwar noch mit Worten, nur war es in diesem Moment unwesentlich, ob diese in deutscher oder

101 ANONYMUS, Die französische Garküche, S. $70 \mathrm{f}$.

102 Über den Paris-Mythos, der hier Auslöser des Streitgesprächs war, vgl. STIERLE, Der Mythos von Paris. Einige Beiträge von deutschsprachigen Parisreisenden unter der Französischen Revolution und im Übergang zum 19. Jh. vgl. CAMPE, Briefe aus Paris; Schulz, Ueber Paris und die Pariser; Kotzebue, Erinnerungen aus Paris; CRAMER, Individualitäten aus und über Paris; PINKERTON, Ansichten der Haupstadt der französischen Kaiserreiches; WEHLE, Vertraute Briefe; NIEMEYER, Beobachtungen auf einer Deportationsreise. Weiterführend vgl. auch satirische Beiträge der Reiseliteratur: BASSE, Reise-Scenen und Reise-Abentheuer. Über die Parisreisende und die Paris-Reiseliteratur vgl. HARPPRECHT, Des révolutionnaires allemands; REQUATE, Kommunikationswege und -bedingungen. Zum zeitgenössischen öffentlichen Diskurs über Kassel als »kleines Paris« vgl. ANONYMUS, Die französische Garküche. Weiterführend zur Thematik der Reiseliteratur vgl. BÖDEKER, Reisen; BREnNER (Hg.), Der Reisebericht; CHABAUd, COHEN (Hg.), Les guides imprimés; MERKel, Die Besichtigung von Kassel; LANDWEHR, Die Stadt auf dem Papier durchwandern; BAUERKÄMPER, BÖDEKER (Hg.), Die Welt erfahren, S. 301-320; GERSMANN, Ferne Welten, fremde Welten. 
französischer Sprache geäußert wurden: Die Franzosen waren in der Überzahl und überstimmten mit ihrem Gelächter den fluchenden Erniedrigten. Das Problem entstand in diesem Fall nicht aus den Sprachen, sondern ergab sich einmal aus der Arroganz eines Franzosen, der nicht dulden wollte, dass s sein Paris einer anderen Großstadt oder einem anderen Reiseziel in irgendeiner Weise nachstand, und zum anderen aus dem Insistieren eines Deutschen auf seine bürgerlichen Bildungserfahrungen. Diametral entgegengesetzte kulturelle Einstellungen prallten hier aufeinander. Jeder pochte unerbittlich auf die Allgemeingültigkeit seiner kulturellen Referenzen, wobei die Sympathie des anonymen Berichterstatters dem Deutschen gilt, der sich in der Auseinandersetzung immerhin auf die Verwendung von Wörtern beschränkte.

Diese Ausführungen haben insgesamt gezeigt, dass die Zeitgenossen die ihnen fremden Sprachen, ob sie diese gar nicht beherrschten oder beinahe perfekt, durchaus nicht als undurchdringliche Monolithen empfanden. Das Bewusstsein für verschiedene Niveaus der Sprachbeherrschung war ausgeprägt - eine Aussage, die sich jedoch von den Fremdsprachen der Westphalen auch auf ihr Verhältnis zu ihren Erst- oder Muttersprachen erweitern lässt. In der Einleitung zum Einstieg in die Sprachproblematik wurde die Co-Existenz von Extremen, vom hochstilisierten Sprachproblem bis zur Selbstverständlichkeit der mehrsprachigen Kommunikation, als paradoxe Situation oder als linguistisches Rätsel identifiziert. Die obigen Ausführungen zeigen, wie weitgehend selbstverständlich die Westphalen selbst mit Sprachen umgingen, die sie mangelhaft oder recht wenig verstanden.

\section{Von der Sprachdominanz des Französischen über das Deutsche}

Im Königreich Westphalen wurden die Spitzenämter im Staatsapparat und in der Verwaltung vornehmlich von französischen Migranten übernommen. $\mathrm{Da}$ die Staatsgründung außerdem unmittelbar auf die Expansionspolitik Napoleons zurückging, wurde die Herrschaftssituation von zeitgenössischen Stimmen oft als auferlegte Fremdherrschaft kritisiert. Die Historiographen im 19. Jahrhundert schlossen sich, teilweise unreflektiert, diesem Urteil an.

Es stellt sich die Frage, ob sich dieses Verständnis der neuen Herrschaftsverhältnisse als Fremdherrschaft auch in der Sprachenfrage widerspiegelte beziehungsweise ob die Dominanz einer Sprache von den Zeitgenossen so empfunden wurde. Es werden im Folgenden Situationen aufgezeigt und Reflexionen von Zeitgenossen herangezogen, die das Verständnis der Sprachenfrage im Königreich Westphalen als Sprachdominanz zu ergründen ermöglichen. 


\subsection{Offener Sprachkonflikt}

Es sind nur wenige Quellen über Situationen überliefert, in denen offenkundig die Sprachwahl zum Konflikt wurde, diese sind aber umso prägnanter.

Folgender Zwischenfall macht die Diskrepanz zwischen den Sprachen besonders deutlich. Der Kasseler Polizeiagent Würz berichtete am 24. April 1813 seinem Vorgesetzten:

Gestern früh ist in der Markt-Gasse ein Bürger und Schneidermeister nahmens Rosenbaum von einem französischen Soldaten um nachweisung seines Logis gefragt worden, worauf derselbe geantwortet hat, daß er kein französisch verstände, ein dazu gekommener französischer Officier gab ihm ein paar Ohrfeigen ${ }^{103}$.

Auffällig ist, dass der Polizeiagent wenig explizit macht, was der Anlass zu den Ohrfeigen gewesen sei. Wahrscheinlich galt die grobe Behandlung des einheimischen Schneidermeisters dessen bekundeter Unkenntnis der französischen Sprache. Zwar wurde der Geohrfeigte sicher nicht schwer verletzt, aber dieser Angriff auf seine Person zeigt die westphälischen Sprachverhältnisse in einem Ungleichgewicht. Die Gewaltanwendung eines Französischsprachigen gegenüber einem Deutschsprachigen, weil letzterer kein Französisch beherrschte, macht die Sprachenfrage zu einer gelegentlich gewalttätigen Angelegenheit. Die Tatsache jedoch, dass Würz sich nicht genötigt sah, die Ursache des Konflikts genauer zu erläutern, weil er wahrscheinlich davon ausging, die Evidenz des Affronts würde Bongars sofort verstehen, sagt auch etwas darüber aus, wie selbstverständlich das Dominanzverhältnis der französischen Sprache über die deutsche für die Zeitgenossen war. Solche Fälle von Gewalttätigkeiten und offenen Angriffen, die sich aufgrund der Sprachen ergaben, zeugen davon, welche Sprache man unter der westphälischen Herrschaft besser zu beherrschen hatte.

Der erste Teil dieser Arbeit über die staatliche Sprachenpolitik im Königreich Westphalen konnte deutlich machen, dass die Tendenz nicht in Richtung Oktroyierung der französischen Sprache ging. Sucht man nach den Nachteilen, die sich durch die Konkurrenz der Sprachen ergaben, wird man vor allen Dingen bei den eher tendenziösen zeitgenössischen Stimmen fündig, die wiederum ihren Widerhall bei den Historikern des 19. Jahrhunderts finden. Der anonyme Autor der Libelle "Die entlarvte hohe und geheime Polizei des zerstörten Königreichs Westphalen« war durchaus der Ansicht, dass sich ein Zwang zum Erlernen der französischen Sprache ergab:

In die entferntesten Provinzen, in die abgelegensten Gebirgsgegenden wurden Polizei-Verfügungen in französischer Sprache abgesandt, so daß es oft einer Nachfrage in dem ganzen weiten Bezirk bedurfte, bis man einen Dolmetscher fand, der nicht selten, gleich den Bedienten, Komplimente in Sottisen oder umgekehrt verwandelte, und bezeigte man dem französischen Polizeimachthaber seine Verwunderung

103 RNB St. Petersburg, F 993 Arch. Westf., K. 10, Nr. 5126-5159, hier Nr. 5129: Rapport von H. W[ür]Z, Polizeiagent in Kassel, an J. F. M. de Bongars, 24. 4. 1813. 
darüber, so gab er nur mit weniger Worten zu verstehen, daß dieses das beste Mittel wäre, in kurzer Zeit Französisch zu lernen ${ }^{104}$.

Diese Angaben sollten allerdings mit Vorsicht ausgelegt werden. Die Quelle muss um so mehr kritisch hinterfragt werden, als der anonyme Autor auch in anderen Passagen seiner Libelle diffamierende Angaben macht, deren Wahrheitsgehalt fragwürdig erscheint. Der Beitrag des anonymen Autors kann zur Enthüllungspublizistik gerechnet werden, die sich nach Auflösung des Königreichs Westphalen insbesondere über die Methoden der politischen Polizei empörte. Zusammen mit anderen Libellen ist sie äußeres Zeichen einer damals aktuellen gesellschaftlichen Debatte über die Fremdherrschaft und deren Polizei ${ }^{105}$. Interessanterweise scheint der Autor einen Enthüllungsprozess angestrebt zu haben, weil er die Abrechnung der wiederhergestellten Obrigkeiten der westphälischen Territorien $1814 \mathrm{mit}$ den kompromittierten Dienern der westphälischen Herrschaft als zu zögerlich empfand ${ }^{106}$. Der Verfasser war teils »Augenzeuge gewesen, teils bedankte er >einem glücklichen Zufall Aktenstücke, aus denen er Personalia, Techniken und Wirkungsradius der französisch-westfälischen Geheimpolizei rückhaltlos aufdecken konnte ${ }^{107}$. Seine Darstellung der westphälischen Verhältnisse wurde wegen ihrer tendenziösen Art zum Anlass für Gegenkritik von Zeitgenossen, die Berichtigungen für nötig hielten ${ }^{108}$. Der Ton der Schrift ist sicherlich tendenziös, jedoch bescheinigte ihr selbst ein Mitglied der Hohen Polizei den Wahrheitsgehalt der Informationen, auch wenn diese häufig in einem »Mischmasch von Wahrheit und Lüge« verhüllt seien ${ }^{109}$.

104 AnOnYmus, Die entlarvte hohe und geheime Polizei, S. $29 \mathrm{f}$.

105 Vgl. u.a. RiESENER, Polizei und Politische Kultur im 19. Jh., S. 42.

106 Vgl. ibid., S. VI.

107 SiEMANN, »Deutschlands Ruhe, Sicherheit und Ordnung«, S. 15.

108 Zeitgenossen vermuteten, dass das Wissen um Interna der westphälischen Hohen Polizei sich aus der Vertrautheit des Anonymus mit ihr ergebe. Der Autor sei vielleicht sogar jenen Opportunisten zuzurechnen, die, selbst kompromittiert durch ihre Enthüllungen, ihr westphälisches Engagement vertuschen wollten: «Zwar wird in vorliegender Schrift die vormalige geheime Policey zu Kassel, nebst ihren Agenten, nicht allerdings in dem schwarzen und grellen Lichte erscheinen, wie z. B. in der Schrift eines mir unbekannten Verfassers: entlarvte geheime Policey u.: dennoch befürchte ich nicht, daß man meine Erzählung bloß um deßwillen der Aufmerksamkeit weniger werth finden wird, weil ich die Policeyglieder nicht ganz von der Seite kennen zu lernen Gelegenheit hatte, wie dieser Verfasser, und weil ich es für unrecht halte, gegen irgend jemand, und wäre er auch mein erklärtester Feind und Verfolger, die ihm schuldige Schonung und Achtung zu verletzen«. GEHREN, Dreimalige Verhaftung und Exportation, S. V; vgl. WOLFF, Kurze Darstellung der Verwaltung der hohen Polizei, S. 5-11, 25, 65; vgl. ferner ZINSERLING, Denkwürdigkeiten, S. IV; CRAMER, Geschichte des Königreichs Westphalen, S. VIIIf.

109 WolfF, Kurze Darstellung der Verwaltung der hohen Polizei, S. 5, vgl. S. 12, 14; vgl. ferner AnOnYmus, Die französische Garküche, S. 48f.; THIMmE, Neue Mittheilungen, S. 111. 
Auch Pfarrer Gehren war vornehmlich wegen der Form und des Stils der Schrift kritisch, wobei er die Kritik an den Polizeidienern darin an sich berechtigt fand ${ }^{110}$. Was seine Kritiker in erster Linie empörte, war die Tatsache, dass ein Vertrauter der westphälischen politischen Polizei sich über sie ausließ, wie um das eigene Vergehen vergessen zu machen. Aufgrund der Einwände seiner Zeitgenossen kann den Aussagen des anonymen Autors eine Tendenz zur Übertreibung zugesprochen werden, freilich mit einem wahren Kern als Grundlage. Für den Fokus auf die Sprachenfrage erscheinen deswegen seine Angaben zwar nicht unbedingt 'wahrheitstreu<, jedoch signifikant für die öffentliche Debatte, die 1814 stattfand: Seine Unterstellungen lagen für manche Zeitgenossen durchaus im Bereich des Glaubwürdigen und des Vorstellbaren. Entgegen seiner Behauptung, die Polizei habe im Königreich Westphalen weitgehend auf zweisprachige Bekanntmachungen verzichtet, scheint, wie bereits erwähnt, eher die Bemühung vorhanden gewesen zu sein, für zweisprachige Bekanntmachungen zu sorgen, um den Westphalen nicht eine Entschuldigung für das Übertreten von polizeilichen Verordnungen aufgrund ihres Unverständnisses der französischen Sprache zu verschaffen.

Der Vorwurf, bei der Prozessführung werde die Übersetzung ins Deutsche für den Angeklagten und seine Verteidigung vernachlässigt, ist ein weiteres wiederkehrendes Motiv. Scheller beschreibt in seiner » Jeromiade« eine Situation aus Braunschweig, wo zu westphälischer Zeit ein aus Genf stammender Richter im Amt war:

Und sprach der Wirth darein ein Wort,

So trieb man ihn mit Degen fort,

Und lief er gleich zu Richtern hin,

Hatt' er der Sach' doch kein'n Gewinn,

Denn selber stellte sich zuhand,

Als ob er kein Wort Deutsch verstand,

Und stekkt' ihn oft noch obendrein

Zur Straf in einen Käfig ein,

Wozu denn Meister Peter Squenz

Als Polizei gab die Sentenz ${ }^{111}$.

In der hier dargestellten Situation stellt sich der französischsprachige Richter rücksichtslos taub gegenüber dem in deutscher Sprache vorgebrachten Anliegen des deutschsprachigen Wirts. Sicherlich gilt es zunächst, den

110 »So zahlreich auch die Schriften sind, welche seit Deutschlands Erlösung erschienen, und worin über den Unfug der Franzosen [...] bitter geklagt, die Französischen Policeydespotie scharf gerügt und die Agenten der Policeygerichte zum Gegenstande gerechter Ironie und Satire gemacht wurden: so wenig Schriften hat man doch noch, die eine treue und ausführliche Erzählung der Mißhandlungen enthalten, welche sich einzelne Opfer der geheimen Policey [...] gefallen lassen mußten«. GEHREN, Dreimalige Verhaftung und Exportation, S. III, vgl. S. IVf.

111 SCHELLER, Jeromiade, S. 164. 
Wahrheitsgehalt der Angabe anzuzweifeln, der leider nicht überprüfbar ist. Die Situation war jedenfalls für die Zeitgenossen sehr wahrscheinlich vorstellbar.

Ziemlich unsicher erscheint jedoch insgesamt die Angabe, die selbst von manchen Historiographen des 19. Jahrhunderts überliefert wurde, wonach Aufständische zum Teil zu Unrecht bestraft wurden, weil sie aufgrund ihrer deutschen Sprache nicht ausreichend vor dem Kriegsgericht, das aus französischsprachigen Vertretern bestand, angehört wurden:

Allein, da ein der deutschen Sprache, speziell des Dialekts der Landbevölkerung kundiger Richter oder Beisitzer bei dem Kriegsgericht bis ganz zuletzt sich nicht befand, sind augenscheinlich viele Irrthümer untergelaufen, und manche sind ganz unschuldig, - ein Gendarm hinten, einer vorn, oder auf Karren massenweise - zum Straftransport abgeführt worden ${ }^{112}$.

Situationen, in denen sich die Nicht-Beherrschung der französischen Sprache deutlich zum Nachteil der Angeklagten auswirkte, lassen sich aufgrund der weitgehend verschollenen Gerichtsakten nicht mehr belegen. Eine verfälschende, tendenziöse und antifranzösische Intention kann jedoch vermutet werden. So bezeugt zum Beispiel bei einer ähnlich gelagerten Situation der Ermittlung gegen aufständische Bauern aus der Gegend um Gifhorn der Dolmetscher Mierzinsky, dass die deutsch-französische Sprachbarriere zugunsten der Aufständischen benutzt wurde, um eine Milderung der ihnen angedrohten Strafe zu erzielen ${ }^{113}$. Mierzinsky bestätigt auch an anderer Stelle, dass es selbst bei Kriegsgerichten durchaus üblich war, Dolmetscher einzustellen ${ }^{114}$. Auch Pfarrer Gehren berichtet über seinen eigenen Prozess vor dem Kriegsgericht Ende Mai 1809, dass für eine Übersetzung ins Französische gesorgt wurde: „Der Vortrag geschah in deutscher Sprache; doch ließen sich einige der Hrn. Officiere die Hauptpunkte ins Französische übersetzen ${ }^{115}$. Sicherlich hätte sich der Verurteilte gewünscht, seine Stellungnahme wäre dem Gericht in vollem Umfang zugänglich gemacht worden. Somit war die Situation trotz erfolgter teilweiser Übersetzung eine, bei der die französische Sprache über die deutsche dominierte.

Bisher konnten auch etliche Situationen beschrieben werden, in denen die Beherrschung der französischen Sprache zu einem entscheidenden vorteilhaften Faktor in der Karriere einzelner Personen wurde. Demgegenüber konnten sich allerdings französische Sprachkenntnisse auch sehr nachteilig auswirken, wie folgendes Beispiel zeigt. Der westphälische Zeitgenosse

112 GoECKE, Das Königreich Westphalen, S. 23.

113 Vgl. MiERZINSKY, Unter Franzosenherrschaft, S. 38-40. Siehe auch Kapitel B I. (Übersetzer, Dolmetscher).

114 Vgl. [MiERZINSKY], Erinnerungen aus Hannover, 1843, S. 35.

115 GEHREN, Dreimalige Verhaftung und Exportation, S. 70, vgl. S. 68-73. 


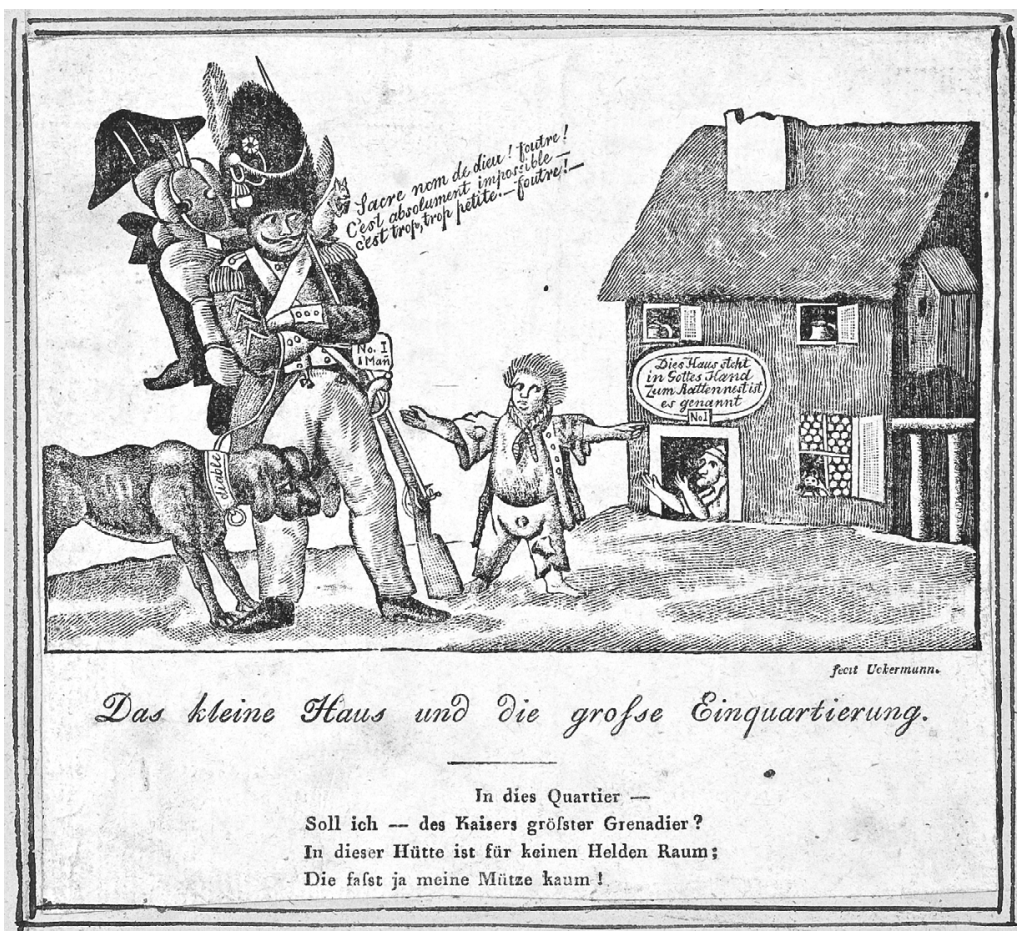

Abb. 29: Johann Immanuel Uckermann, Das kleine Haus und die große Einquartierung, Erfurt, Holzschnitt, 13,4×15 cm, Erfurt, Angermuseum, 5594b.

Nagel berichtet über das Prozedere der Einquartierung beim Anrücken der französischen Truppen in Halberstadt im Oktober 1806:

Mit einbrechender Dämmerung füllte sich die Stadt mit einrückenden Truppen zu Pferde und zu Fuße nach gerade dergestalt, dass am späten Abend auch die verborgendsten Winkelgassen aufgesucht werden mussten, und das war keine leichte Aufgabe, da nur selten sich noch ein Einwohner auf die offenen Straße wagte, am wenigsten Einer, der dem Franzosen in seiner Sprache Rede und Antwort geben konnten.

[...] Ein Glück war es, dass die Leute deutlich geschriebene Quartierbillete hatten, aus welchen ihnen bei Laternenschimmer die nöthige Nachweisung gegeben werden konnte. Wo sie aber eines Kundigen habhaft geworden waren, ließen sie ihn nicht wieder los; er mogte wollen oder nicht, er mußte mit ${ }^{116}$.

Dass die Beherrschung der französischen Sprache die einheimischen Halberstädter zwang, den französischsprachigen Soldaten beim Suchen ihres Quartiers zu helfen, ist ein weiteres indirektes Signal für die Machtstellung des Französischen über das Deutsche in der westphälischen Gesellschaft. 
Überheblichkeiten seitens eingewanderter Franzosen gegenüber den Einheimischen drückten sich nicht zuletzt sprachlich aus. Darüber berichtet Nagel erneut im Kontext der Einquartierungen in Halberstadt:

Es war gar nichts Seltenes, dass sie die Kost, welche jeder schlichte Deutschen von gesundem Appetit mit Wohlbehagen verzehrt haben würde, auf den Boden schütteten oder gar den Hausbewohnern samt dem Geschirre an die Köpfe warfen, mit dem Bedeuten: pour les cochons (Schweinefutter)! Auftritte der Art sind uns nicht bloß in der Heimath, sondern noch im Jahre 1808 auch jenseits des Rheins vorgekommen, wo das vormals deutsche Land dem französischen Kaiserreichen längst einverleibt war, zum Zeugnisse, dass der Nationalfranzose den deutschredenden Volksgenossen noch lange nicht als ebenbürtig ansah ${ }^{117}$.

Solche Situationen, in denen die Franzosen durch Verhalten, Gebärden und Sprache ihre Dominanz spüren ließen, wirken, selbst bei einer Sprachpolitik, die nicht auf die Oktroyierung der französischen Sprache ausgelegt war, ernüchternd und zeigen das tatsächliche ungleiche Verhältnis der Sprachen und ihrer Sprecher im Königreich Westphalen auf. Außerdem handelt es sich hier um einen der selten überlieferten Momente, in denen die Verzahnung von Sprache, Gestik und Mimik deutlich wird ${ }^{118}$.

Über die Sprachen wurde sozial Druck ausgeübt, wie der österreichische Diplomat Mettingh und seine Frau am westphälischen Hof ab 1813 in ihrer Isolation erfuhren: »Er und seine Gattin kamen sich vor, als lebten sie in einem Lande, in dem niemand ihre Sprache rede [...]. Man wußte, daß man nicht ungestraft mit ihm redete «119. Zwar wurden die Eheleute Mettingh nicht gefangen gesetzt, alle jedoch, die in Berührung mit ihnen kamen, hatten mit einer Bestrafung zu rechnen. Sie lebten mitten in der Hauptstadt des Königreichs Westphalen wie abgeschnitten von der Welt.

Bei aller anfänglich deklarierten Akzeptanz für die zweisprachige Situation im Königreich Westphalen wurde auch über die Sprachen Gewalt und Druck ausgeübt, was darauf hinweist, dass beide Sprachen nicht von gleicher Bedeutung waren. Der Umgang mit den Sprachen barg einen repressiven Charakter.

Eine Umkehrung erfolgte schlagartig mit der Auflösung des Königreichs Westphalens, wie Scheller in der »Apotheose« seiner Satire »Jeromiade« darlegt:

117 Ibid., S. 40. Vgl. ferner Hassenpflug, Jugenderinnerungen, S. 128f. Über Konflikte im Zusammenhang mit der Verpflegung bei Einquartierungen vgl. WÜRGLER, Wer hat Angst vor wem?, S. $155 \mathrm{f}$.

118 Auf die oben bereits zitierte Auseinandersetzung in einem Kasseler Gasthaus zwischen einem Deutschen und einem Franzosen über die Vorrangstellung von Paris als Reiseziel trifft diese Aussage ebenfalls zu. Vgl. ferner HASSENPFLUG, Jugenderinnerungen, S. 131.

119 KLEINSCHMIDT, Geschichte des Königreichs Westfalen, S. $567 \mathrm{f}$. 
Franzmann[s] selbst verzweifelt hier

$\mathrm{Zu}$ finden ferner noch Quartier

In Deutschland, und sein täglich Brodt,

Und singet seine grosse Noth: [...]

Désormais en notre langue

Qui peut faire une harangue

Sans peur d'être souffleté?

Qui peut porter la culture

Du grand peuple sans - lavure,

Sans fouet, sans coups de pied? [...]

$\mathrm{O}$ quel paradis perdu ${ }^{120}$ !

Wenn es Anfang 1813 noch möglich war, dass ein französischer Offizier auf offener Straße einen Kasselaner ohrfeigte, weil dieser keine Auskunft in französischer Sprache zu geben wusste oder die Anfrage in französischer Sprache nicht verstehen konnte, hatten sich diese von Scheller als »paradiesisch « für die Französischsprachigen beschriebenen Herrschaftsverhältnisse Ende 1813 umgekehrt und die Franzosen mussten sich nun selbst vor Ohrfeigen und Tritten vorsehen.

\subsection{Tilgung der deutschen Sprache oder Korrekturen am deutschen Sprachgebrauch nach den neuen Herrschaftsprinzipien?}

Folgt man den tendenziösen Angaben des anonymen Autors der Schrift »Die entlarvte hohe und geheime Polizei des zerstörten Königreichs Westphalen«, so war neben der eher auf Toleranz ausgelegten und auf eine gute Kommunikation zwischen den Sprachgemeinschaften im Königreich Westphalen bedachten offiziellen Sprachpolitik (Teil A) die Hohe Polizei insgeheim mit einem ganz speziellen Auftrag in Bezug auf die Sprachen versehen:

[ich] darf [...] nicht mit Stillschweigen übergehen, daß die Übermacht der Polizei sich nicht nur auf die Teutschen, sondern sogar auf die teutsche Sprache erstreckte: wäre nicht unglücklicher Weise für Westphalen nur der Ausschuß der französischen Nation zum Regieren hierher gekommen, so würde der bessere, solidere und fähigere Theil derselben wohl eingesehen haben, daß es sehr unklug war, einem eroberten und unterjochten Staate im ersten Anfange seine Sprache, seine gewohnten Titel und Schauspiele zu nehmen. Ein teutscher Philosoph sagt sehr richtig: >Wenn der Polnische Name und die polnische Sprache aus Europa vertilgt wird, so erregt dies mein Bedauern, weil ich kein großes Naturwerk, dergleichen eine Nation ist, gern zerstört sehe «. Trotz aller Vorliebe für das Vaterland der Teutschen, kann ich mit Recht dasselbe auf Teutschland anwenden. Es war aber Plan - und welch' ein Plan! - von Seiten der hohen Polizei, dieses Naturwerk niederzureißen, und nach und nach gänzlich aufzulösen $^{121}$.

120 SCHELLER, Jeromiade, S. $303 \mathrm{f}$.

121 AnONYMUS, Die entlarvte hohe und geheime Polizei, S. $28 \mathrm{f}$. 
Die in dieser Aussage enthaltene Behauptung ist zunächst schwer einzuordnen und erfordert Quellenkritik. Außerdem wird Sprache hier als Naturwerk dargestellt, die der Nation ihre Quintessenz verleihe, und nicht etwa als kulturelles Erzeugnis. Auf die dahinter verborgene Konstruktion von Sprache und deren Einfluss auf die vermeintlich nationalen Identitätsprozesse der verschiedenen Sprachgemeinschaften aus der Sicht der Zeitgenossen und Historiographen des 19. Jahrhunderts soll die Untersuchung später zurückkommen.

Wenn man versucht zu ergründen, wie die angebliche Verfolgung der deutschen Sprache durch die politische Polizei ausgesehen haben könnte, wird man auf die bereits wiedergegebene Erzählung einer Anekdote aus den Büros der Hohen Polizei durch den Pagenlehrer Zinserling zurückgeführt, die auf den ersten Blick belanglos erscheinen mag, jedoch der Angabe des oben zitierten anonymen Autors Sinn verleiht: Die Polizeibeamten machten sich Sorgen über die Bedeutung der Wörter »Köther« und »Kothsassen«, wenn mit diesen Bezeichnungen Menschen gemeint waren ${ }^{122}$. "Köther « und "Kothsasse" erschienen den französischsprachigen Polizeibeamten durch die wörtliche - und nicht etymologisch oder kontextabgeleitete - Übersetzung ins Französische eine menschenverachtende Bedeutung zu vermitteln und eine Missachtung von westphälischen Staatsbürgern zu implizieren. Wegen des allgemeingültigen Gleichheitsprinzips galt es schließlich auch, die Verwendung von nicht zeitgemäßen Termini im deutschen Sprachgebrauch zu unterbinden ${ }^{123}$. Die Motive für das Eingreifen der politischen Polizei in den deutschen Sprachgebrauch waren nicht in erster Linie auf eine grundsätzliche Bekämpfung der deutschen Sprache ausgerichtet, wie der oben zitierte anonyme Autor es glauben lassen möchte, sondern auf eine Kontrolle der Ideen, die durch die Sprache transportiert wurden. Im Sprachgebrauch sollte im Sinne des revolutionären Erbes des napoleonischen Kaiserreichs das Gleichheitsprinzip der neuen Gesellschaft betont werden. Hierin sollten sich die ersten Veränderungen im Denken der Westphalen manifestieren. Mit ihrer Zensur menschenentwürdigender Wörter beabsichtigte die Generaldirektion der Hohen Polizei, den Wortgebrauch im Sinne der neuen Staatlichkeit zu reformieren und Zeichen der alten Herrschaft zu tilgen. Sie machte sich zur Aufgabe, die Tauglichkeit der deutschen Sprache für die reformierten gesellschaftlichen Verhältnisse zu überprüfen.

122 ZinserLiNG, Denkwürdigkeiten, S. $43 \mathrm{f}$.

123 Die zentrale Bedeutung des Gleichheitsprinzips der westphälischen Staatsbürger kann durch die Lektüre des »Westphälischen Moniteur « bestätigt werden, vgl. Le Moniteur westphalien, Nr. 15, 31. Januar 1808, S. 59 f.: Königliches Dekret vom 23. Januar 1808, Von der Aufhebung der Leibeigenschafts-Rechte und Verbindlichkeiten; ibid., Nr.22, Dienstag, 16. Februar 1808, S. 87-90; ibid., Nr. 30, 6. März 1808, S. 120; ibid., Nr.31, 8. März 1808, S. 123 f.; ibid., Nr. 58, 10. Mai 1808, S. 235; ibid., Nr. 67, 31. Mai 1808, S. 264; ibid., Nr. 85, 12. Juli 1808, S. 346. 
Die Anekdote bezeugt, dass auf diese Weise eine latente Sprachdominanz im Königreich Westphalen ausgeübt wurde. Die Polizeibeamten, nur bedingt der deutschen Sprache mächtig, begegneten dieser Sprache mit Misstrauen. Die französische Sprache besaß somit eine entscheidende Definitionsmacht für die gesellschaftlichen Verhältnisse.

Die Umbenennung der Territorien im Königreich Westphalen wird gelegentlich als ein weiterer Schritt in Richtung Tilgung der alten Herrschaftsverhältnisse interpretiert. Von der Intention her wird vermutet, dass die alten Provinznamen verschwinden mussten, um die geschichtlichen Erinnerungen daran zu beseitigen und den "Staat ohne Vergangenheit « erstehen zu lassen ${ }^{124}$.

\subsection{Sprachliche Gegenoffensive der Deutschsprachigen}

Allerdings scheinen die sprachlichen Druckmittel die Denkweise der Westphalen nicht besonders tief beeinflusst zu haben, denn etliche Beispiele zeugen gerade vom sprachlichen Abwehrvermögen gegen Tendenzen zur sprachlichen Revision ihrer Denk- und Erinnerungskultur. So berichtet der von der politischen Polizei verfolgte Pfarrer Gehren, dass diese politische Polizei »Hohe Polizei« genannt und als solche gefürchtet werden wollte. Allerdings wurde sie von den Zeitgenossen häufig "geheime Polizei« genannt ${ }^{125}$. Die bereits im Kapitel über die Gerüchte erwähnten abwertenden Bezeichnungen für die unpopulären Gendarmen, die teilweise auf deutschen Wortspielen basierten, sind hier ebenfalls zu erwähnen. Die Westphalen wehrten sich durchaus mit sprachlichen Mitteln und persiflierten gern die neuen Herrschaftsverhältnisse.

In anderen Situationen bewirkten die sprachlichen Versuche der Obrigkeit, die alten Herrschaftszeiten als definitiv vergangen zu erklären, genau das Gegenteil des Erwünschten. So führt Scheller in seiner »Jeromiade« aus, dass die Betitelung des neuen Königs durch die Westphalen zum Teil satirisch neu interpretiert wurde. Über das Schloss zu Braunschweig, in dem Jérôme hin und wieder residierte, schreibt er:

Es ständ' auch oben schon am Schloss

Sein Namenszug H. N. Nr. gross

Und dikk gemacht sammt einer Kron',

Der spräche allen Geistern Hohn, [...]

(Doch gab's auch manche, welche standen

Und lasen, bis den Sinn sie fanden,

Der denn nach ihrer Meinung gar -

Hier Nisten Räuber, deutlich war.

125 GEHREN, Dreimalige Verhaftung und Exportation, S. 38. 
Auch sprach ein Bau'r mit kekkem Muth:

Düt het dog wol - Hei Nimt Rit - $\hat{u} t^{126}$ !

Wenn Jérôme auch als siegreicher Herrscher in Braunschweig aufzutreten vermochte, so wurde ihm der angestrebte Nimbus durch die neue Interpretation des Kürzels seines Namenszugs streitig gemacht. Der von seinen Untertanen erdichtete spöttische Sinnspruch zeigt ihren Eigensinn und ihre unterschwellige Kritik an seiner Herrschaft. Beim Betrachten der Buchstaben »H. N.« für »Hieronymus Napoleon« auf den westphälischen Münzen kam gelegentlich auch die Gleichsetzung mit Hans Narr heraus ${ }^{127}$. Der Spott rief eine kulturelle Referenz auf, die außerdem den meisten Franzosen verschlossen bleiben musste, denn welchem Franzosen sollte "Hans Narr « ein Begriff sein? Doch die Umwidmung der Inschriften durch die Westphalen beschränkte sich nicht auf ihr Staatsoberhaupt. So berichtet der anonyme Autor der "Garküche an der Fulde « über im Kern ähnlich herablassende und spöttische Umdichtungen der Kasseler. Der Hofbuchdrucker Collignon ließ sich einen imposanten Pavillon mit der Inschrift P. C. für seine Initialen in seinem Privatgarten errichten ${ }^{128}$ :

keiner ging vorbei, ohne diese zwei Buchstaben ganz anders zu deuten, als sie in gerader Beziehung auf den Anfangsbuchstaben des Vor- und Zunahmens des Eigenthümers zu verstehen waren. [...] Endlich löste den Neugierigen ein vorbeigehender Franzose - wahrscheinlich einst Ehrenmitglied der Akademie der Inschriften - dieses Räthsel, und las, indem er, den Blick auf das Belveder gerichtet, einen im Weg stehenden Bürger unsanft in die Seite stieß: Passe, Coujon! In diesem Sinne sahen auch die Franzosen aus dem Belveder heraus, die Teutschen aber in das Belveder hinein, und unter diesen mit einer Art von Schadenfreude - die Casselchen Buchdrucker, Buch- und Papierhändler, denen die königliche Hofbuchdruckerei ein Dorn im Auge war $^{129}$.

In diesem Quellenzitat wird die richtige Deutung der Inschrift einem Franzosen übertragen, was den Spott der Deutschen über Collignon noch verstärkt. Hier werden erneut die unsanften Manieren eines Franzosen gegenüber einem Deutschen kritisiert, die ersterer zudem mit einem Schimpfwort unterstrich: Insgeheim sollen die Deutschen außerhalb des Gartens die Beleidigung der Franzosen im Pavillon erwidert haben. Der Vorfall, wahrhaftig oder eingebildet, lässt ahnen, wie angespannt das Verhältnis zwischen den Sprachgemeinschaften in Kassel war. Die nicht verbalisierte Anwendung des gleichen Ausspruchs auf die Franzosen im Pavillon in der Anekdote sugge-

126 SCHELLER, Jeromiade, S. 187.

127 RNB St. Petersburg, F 993 Arch. Westf., K. 7, Nr. 3459-3485, hier Nr. 3477: Verhörprotokoll von J. J. Kocken, 15.1.1812.

128 Weiterführend über private Gartenkultur im Übergang vom 18. zum 19. Jh. vgl. MOlitor, Der Erbfeind im Garten; SARKowicz (Hg.), Die Geschichte der Gärten; VAN DÜlmEN, Das irdische Paradies; EGER (Hg.), Fort, fort, der Südost fliegt gerade über Wörlitz!

129 ANONYMUS, Die französische Garküche, S. 94. 
riert außerdem, dass die Kasselaner durchaus den Franzosen eine baldige Rückreise nach Frankreich wünschten. Sicher ist der Wahrheitsgehalt der Anekdote fragwürdig, jedoch liegt sie im Vorstellungsbereich und im Ausdrucksvermögen der Zeitgenossen.

Als im Jahr 1813 nach dem Rückzug aus Russland die Armee neu organisiert wurde, soll es nicht mehr viele Freiwillige gegeben haben, die sich als Stellvertreter von Konskribierten einziehen lassen wollten ${ }^{130}$. Die neuen Rekruten wurden von den Westphalen spöttisch »N Nur Nicht Nach Norden « " genannt, wegen der "viermaligen Anbringung des Anfangsbuchstaben von `Napoleon` auf ihren Rockschößen « ${ }^{131}$.

Angesichts der vielen Familien, deren Angehörige nicht vom Russlandfeldzug zurückkehrten, ist es faszinierend zu lesen, wie viel sarkastischen Humor die Westphalen sprachlich noch hervorbringen konnten ${ }^{132}$.

Pröhle berichtet seinerseits in seinen auf mündlichen Überlieferungen von Zeitgenossen basierenden "Episteln" über das Königreich Westphalen im Jahre 1858, dass der sprachliche Versuch der Franzosen, den Herzog Friedrich Wilhelm von Braunschweig zu erniedrigen und seine Herrschaftsansprüche ein für alle Male zu verleugnen, indem man ihm seinen ursprünglichen Titel aberkannte und ihn zu »Braunschweig-Oels" umtaufte, gänzlich fehlschlug: "So hat sich auch gerade an das Wörtchen Oels die Vorstellung von einem kostbaren Wundenöl und von einer unbeschreiblichen Vaterlandstreue gehängt ${ }^{133}$. Der Versuch der Herabwürdigung und der Erniedrigung über die Sprache scheiterte, weil die sprachliche Konnotation im Deutschen kurzerhand positiv besetzt wurde. Solche Nuancen in der Wahrnehmung von Sprache nachzuempfinden, blieb den französischsprachigen Staatsbeamten, die bewusst die Bezeichnung "BraunschweigOels« pflegten, mit großer Gewissheit verborgen und gerade dieses Fehlen eines muttersprachlichen Gehörs und der entsprechenden Feinfühligkeit machte ihr Vorhaben zunichte. Im Zusammenhang mit der Gewerbefreiheit und dem darüber aufkommenden Unmut der Zünfte erlangte das Wort »Patentmeister« eine andere Konnotation als von den Behörden intendiert: »Indessen wurde im Publikum die eigentliche Zunftehre fortwäh-

130 Vgl. SeVerin-Barboutie, Vom freiwilligen Söldner zum dienstpflichtigen Untertan, S. 123.

131 LynCKer, Historische Skizzen, S. 55; vgl. PlanerT, Alltagsleben und Kriegsnöte, S. 56. Das Spottbild "Nur Nicht Nach Norden« ist auch in der Karikatur "Die Waage« aus dem Jahre 1813/1814 festgehalten: CILlESSEN, REICHARDT u.a. (Hg.), Napoleons neue Kleider, S. $34 \mathrm{f} ., 278 \mathrm{f}$.

132 Vgl. Namentliches Verzeichniß; NiEMEYER, Trost und Erhebung; [MierZINSKY], Erinnerungen aus Hannover, 1843, S. 121 f.; MÜLLER, Kassel seit siebzig Jahren, Bd. 1, S. $54 \mathrm{f}$.

133 PrÖHLE, Die Fremdherrschaft, S. 19; vgl. Thimme, Die inneren Zustände, Bd. 1, S. 447. 
rend so hoch gehalten, dass die Benennung >Patentmeister für ein Schimpfwort galt, weil sie gleichbedeutend mit >Pfuscher` war « ${ }^{134}$. Wer die Macht besaß, die Gebrauchswörter einer Gesellschaft zu bestimmen, konnte dennoch die heimlich damit verbundenen neuen oder sich wandelnden Bedeutungen nicht verhindern. Damit hielt sich zumindest in diesem Punkt die Sprachdominanz des Französischen über das Deutsche in Grenzen. Die Beispiele zeigen auch deutlich, wie dynamisch die sprachlichen Prozesse aufeinander aufbauten und andere Bedeutungen in beiden Sprachen hervorrufen konnten.

\subsection{Deutsch als Gegensprache und als Nische für subversive Kommunikation}

Die mangelhaften Deutschkenntnisse einiger französischsprachiger Einwanderer wurden auch teilweise genutzt, um sich der deutschen Sprache als Gegensprache zu bedienen. Über sie konnte Staatskritik kommuniziert werden. Manchmal wurde ein so genannter »langage convenu « verwendet, wie es in einem Schreiben von Savigny an Hugo Bernard de Bassano Maret über die Westphalen hieß:

Le nombre des sociétés secrètes augemente de jour en jour; les affiliés, au moyen d'un langage convenu, se communiquent réciproquement, en public, leurs sentiments sur les événements politiques. Dans un repas donné, il y a peu de temps, à Magdebourg, on a bu à la santé de saint Pancrace qui, pour les initiés, était le prince Bagration, dont on célébrait l'heureuse retraite ${ }^{135}$.

Dabei diente in diesem speziellen Fall nicht die Verwendung der deutschen Sprache als Deckmantel für die verbotene und staatskritische Botschaft, sondern eine für die Beteiligten und Eingeweihten kodierte Anspielung. Durch die mangelhaften Deutschkenntnisse der oberen Staatsvertreter ergaben sich für die Westphalen Situationen, in denen die deutsche Sprache ihnen Handlungsspielräume und verdeckte Redefreiheit gewährte.

Über einen weiteren Fall, in dem ganz konkret die geringfügigen bis nicht-existenten Kenntnisse der deutschen Sprache der neuen Machthaber ausgenutzt wurde, wird von Thimme für Hannover berichtet. Zur Zeit der Angliederung an Frankreich wurde vor 1810 einmal ein Bote mit kompromittierenden Briefen festgehalten ${ }^{136}$. Die französischen Verwalter ließen den Polizeidirektor Heinrich August Meyer holen und ersuchten ihn, die Briefe vorzulesen. Meyer stellte bald fest, dass die Briefe die Handschrift des Grafen von Münster trugen. Er beschloss daraufhin, alle verfänglichen Schreiben

134 LYNCKER, Historische Skizzen, S. 47.

135 Savigny, zitiert nach: FABRE, Jérôme Bonaparte, S. 165.

136 Siehe dazu das Online-Kapitel über das Medium »Brief«, http://halshs.archivesouvertes.fr/PLCI-NAPOLEON (1. 1.2013). 
verschwinden zu lassen ${ }^{137}$. Nicht nur das Verständnis des Deutschen bereitete den französischen Machthabern Probleme, auch die deutsche Schrift stellte für die an lateinische Schriftzeichen gewöhnten Franzosen eine Hürde dar und bot dadurch Handlungsspielraum für Sympathisanten der alten Herrschaft. Die französischen Beamten konnten vielleicht Deutsch verstehen, es zu lesen stellte für sie jedoch wegen der deutschen Schrift ein großes Hindernis dar ${ }^{138}$.

Damit konnte die deutsche Sprache zum Teil zur Nische für antifranzösisch gesinnte Autoren avancieren. Dies bestätigt ein Schreiben Villers' an Henrich Steffens. Der Hallenser Professor berichtet über die verschiedenen Reaktionen deutschsprachiger Gelehrter seiner Zeit auf seine Schrift »Über die Idee der Universitäten «:

`Sie würden`, schrieb Villers, `verloren sein, wenn Sie nicht für Ihre Darstellung eine Sprache gewählt hätten, die dem Franzosen ein völlig unverständliches Sanscrit ist Ein Franzose glaubte, daß solche Ueberschwenglichkeiten gar keine politischen Einfluß haben könnten, und doch war diese kleine Schrift während der Jahre des Drucks ein beliebtes Handbuch der Studirenden und wirkte, ich darf es sagen, wenn auch nur unmittelbar auf wenige, doch mittelbar auf sehr viele junge Männer aller deutschen Universitäten. [Von Leist] sprach ebenfalls über diese Schrift, gestand, daß er, als er sie gelesen, erschrocken sei, und warnte mich, obgleich ich damals im Begriffe war, Halle zu verlassen und nach Breslau zu reisen. >Wir müssen`, sagte er, >die kleine Spur von Preßfreiheit, die uns übrig geblieben ist, durch die größte Vorsicht in der Benutzung derselben zu retten suchen ${ }^{139}$.

Die Verwendung der deutschen Sprache bot offensichtlich in bestimmten Fällen Gelegenheiten, die Achtsamkeit der Zensurbehörden zu umgehen ${ }^{140}$. Die Möglichkeit bei einer Unterredung von der gebräuchlichen Umgangssprache auf eine Zweitsprache zu wechseln, um diskret eine Botschaft

137 Vgl. Thimme, Die inneren Zustände, Bd. 2, S. 427.

138 Im Übrigen waren die Deutschen auch beim Lesen von der lateinischen Schrift angestrengt und verlasen sich dabei regelmäßig. Vgl. HASSENPFLUG, Jugenderinnerungen, S. 124.

139 Steffens, Was ich erlebte, Bd.6, S. 162 f. Weiterführend zum Thema Pressefreiheit vgl. GERSMANN, Im Schatten der Bastille, S. 33, 229, 236, 239; WILKE, Die Entdeckung von Meinungs- und Pressefreiheit als Menschenrechte.

140 Über das symbiotische Verhältnis von Zensoren und Zensierten und die Kulanz der Zensurbehörde gegenüber einigen Schriften, die sich in einem Grenzbereich der Staatskritik bewegten, vgl. GERSMANN, SCHROEDER, Zensur, Zensoren und Zensierte; GERSMANN, Literarischer Untergrund; DIES., Im Schatten der Bastille, S. 30, 32 f.; DIES., »police du livre, police de la librairie«. Als Zensoren tätig waren im Königreich Westphalen z. B. die Generalpolizeikommissare der Hohen Polizei, nachweislich Guntz und Wolff, aber auch Lehmann, vgl. Kapitel B III. (Bittschriften). Über die relativ große Freiheit, die die politischen Journale und die wissenschaftlichen Zeitschriften gegenüber der starken Einschränkung im Fall der Zeitungen genossen, vgl. FRATZKE-WEISS, Europäische und nationale Konzeptionen, S. 188; vgl. ferner WILKE, Medien- und Kommunikationsgeschichte um 1800, S. $47 \mathrm{f}$. 
geheim zu halten, war übrigens auch unter den Machthabenden geläufig. So berichtet Mierzinsky, der Autor der "Erinnerungen aus Hannover und Hamburg aus den Jahren 1803-1813«, wie Graf Pierre-François de Réal bei der Untersuchung gegen Louis-Antoine Fauvelet de Bourienne d'Aubignosc einen Hinweis in italienischer Sprache gab ${ }^{141}$.

Die deutsch-französische Diglossie im Königreich Westphalen betraf nur eine beschränkte Gruppe von Personen. Die französische Sprache besaß das höhere Sozialprestige: Die Bemühungen der Westphalen, Bittschriften in französischer Sprache einzureichen oder Französisch über Sprachlehrer oder mit Hilfe von Sprachlehrbüchern zu erlernen, haben dies hinreichend bewiesen. Diese Ausgangssituation war jedoch für die einsprachig Deutschsprachigen nicht unbedingt nur von Nachteil. Aus der Konkurrenz beider Sprachen konnten sich Situationen ergeben, in denen das nicht unmittelbare Verstandenwerden für die Deutschsprachigen eine Nische für ihre verdeckte Kommunikation darstellen konnte.

\subsection{Sprachfertigkeiten und Akzente in der Aussprache als Überführungs- und Tarnungsmittel der Polizei}

Fremdsprachliche Kompetenz war sicherlich nicht immer von Vorteil in der westphälischen Gesellschaft. Insbesondere die politische Polizei konzentrierte sich bei ihren Beobachtungen auf die Sprachkompetenzen der Verdächtigen, um Vermutungen und weitere Ermittlungen anzustellen. Wer Deutsch mit einem englischen Akzent sprach, erregte größeres Aufsehen. In einem Agentenbericht heißt es:

Der Herr mit dem gelblich melirten Rock, wovon ich in meinem Vorgestrigen sprach, ist nach Minden. Er spricht deutsch wie ein Engländer. Der Marqueur aus dem versicherte mir, er habe Guineen bei sich, und logire in Minden im goldenen Löwen, wohin er ihm die Adresse gegeben ${ }^{142}$.

Der englische Akzent bei der Aussprache des Deutschen erschien dem Polizeiagenten genauso relevant und verdächtig wie der Besitz fremder Währung oder wahrscheinlich der gelblich melierte Rock ${ }^{143}$.

In den Signalements und Steckbriefen der Polizei wurden die Sprachkenntnisse in einer eigenen Rubrik aufgeführt, neben physiologischen Angaben wie Gesichtszügen, Körpergröße oder besonderen Merkmalen - ver-

141 Vgl. [MiERZINSKY], Erinnerungen aus Hannover, 1843, S. $93 \mathrm{f}$.

142 WOLF, Kurze Darstellung der Verwaltung der hohen Polizei, S. $18 \mathrm{f}$.

143 Über die Kleidung als politisches Erkennungszeichen und Mittel zur Verstellung im Königreich Westphalen könnte eine weitere Fallstudie unternommen werden. Zum Thema weiterführend vgl. FEHLIG, Kostümkunde; DINGES, Der »feine Unterschied «; MEDICK, Eine Kultur des Ansehens; HagEMANN, Heldenmütter, S. 185 f.; MÜLLER, Kleider machen Nationen; WrIGLEY, The Politics of Appearances; Keller-Drescher, Die Ordnung der Kleider; Keupp, Macht und Mode. 
narbtes Gesicht, schiefe Körperhaltung, Frisur - und zivilbürgerlichen Angaben.

Akzente in der Aussprache konnten jedoch auch seitens der Polizei zum Zweck der Tarnung simuliert werden. Beispielsweise berichtet der Staatsgefangene Rudolf Zacharias Becker, wie er unauffällig von einem kaiserlichen Polizeibeamten von Gotha nach Magdeburg auf die Zitadelle geführt wurde: »wenn wir in eine Stadt kamen, und wo ausgestiegen wurde, sprach ich französisches Deutsch, um dem Wunsche meines Begleiters, daß unsre Reise im strengsten Incognito geschehen möge, zuvor zu kommen « ${ }^{144}$.

Tatsächlich wussten die Zeitgenossen um ihre dialektal oder fremdsprachlich bedingten Akzente und sahen sich gelegentlich vor, nicht aufgrund dessen erkannt zu werden. Der westphälische Soldat J. Meyer aus Dransfeld bestätigt in seiner "Erzählung«, er fürchtete sich, wegen seiner Aussprache überführt zu werden, als die russische Armee in Wilna anrückte, wo er schon seit einiger Zeit bei seinen jüdischen Glaubensgenossen Aufnahme gefunden hatte. Er zog deswegen vor, sich »taub und stumm anzustellen, wenn mich Soldaten etwas fragten ${ }^{145}$.

Teilweise dienten die Sprachkompetenzen der Kontrahenten - oder deren Mangel - zur Überführung bei Untersuchungen ${ }^{146}$. Der Göttinger Buchhändler Kuebler wurde bei seiner Aussage in einer Untersuchung damit konfrontiert, dass er wegen seiner Unkenntnis der französischen Sprache unmöglich die verbreitete falsche Nachricht von einem französischen Offizier, wie von ihm angegeben, erhalten haben könne, sondern diese selbst erfunden haben müsse ${ }^{147}$.

Glaubt man der Angabe des anonymen Autors der Schrift »Die entlarvte hohe und geheime Polizei des zerstörten Königreichs Westphalen«, so war der Einsatz ihrer deutschen Sprachkenntnisse durch die Polizeibeamten zuweilen sehr hinterlistig:

Übrigens mußte die Unkunde der teutschen oder französischen Sprache auch zu einem Vehikel der geheimen Polizei dienen. Die Franzosen hielten das teutsche Volk für unwissend genug, daß es kein Wort Französisch verstände, und wenn sie auch der teutschen Sprache ganz oder zur Hälfte, oder nur mittelmäßig mächtig waren, so redeten sie doch in der Regel nicht teutsch. Unter diesem Deckmantel suchten sie unsre Gesinnungen, und im Ganzen die öffentliche, herrschende Meinung bei uns

144 BECKER, Leiden und Freuden, S. 16.

145 MEYER, Erzählung der Schicksale und Kriegsabentheuer, ${ }^{3} 1838$, S. 89.

146 Die Autoren des Pamphlets in Briefform, Kocken und Bielstein, die im OnlineKapitel über das Medium »Brief« erwähnt wurden, wurden z. B. aufgrund ihrer unverwechselbaren Umgangssprache erkannt, die sie selbst im Schriftlichen nicht verbergen konnten, http://halshs.archives-ouvertes.fr/PLCI-NAPOLEON (1. 1.2013).

147 Vgl. RNB St. Petersburg, F 993 Arch. Westf., K. 14, Nr. 8159-8260, hier Nr. 8245: Schreiben Nr. 314, von Mertens, Generalpolizeikommissar der Hohen Polizei in Göttingen, an J. F. M. de Bongars, 29.3.1813. 
auszuspähen. Sie sahen es als ein Mittel an, uns treuherzig zu machen, und an ihnen keine Lauscher zu befürchten. Daß sie größtentheils Teutsch verstanden und sprachen, ist durch die seit der zweiten Invasion der Kosacken hier zurückgebliebenen Franzosen erwiesen; ob aus Furcht, aus Mangel an Umgang mit ihren Landsleuten, oder aus Bedürfnis der Geselligkeit mit Teutschen, denen sie sich mehr, als vorher, zu empfehlen Ursache und guten Willen haben? Will ich nicht entscheiden, aber genug! Sie verstehen und sprechen alle recht gut teutsch, selbst diejenigen, von denen ich Jahre lang keinen teutschen Laut gehört habe ${ }^{148}$.

Diese Angabe ist sicherlich tendenziös, aber sie könnte doch einen wahren Kern enthalten, bedenkt man, dass die Spitzelarbeit der politischen Polizei stets eng an die Beherrschung fremder Sprachen geknüpft war. In Frankreich war dies schon Jahre zuvor von den zuständigen Organen leidvoll erfahren worden:

Das Übersetzungsbureau [des Auswärtigen Ministeriums in Paris] wurde gleichfalls [im Jahre 1799] aufgehoben und blos ein Uebersetzer angestellt; die Beamten des Departements sollten selbst die europäischen Sprachen kennen. Es war ein gefährliches Bureau gewesen. Die fremden Sprachen waren nicht die Liebhaberei der Franzosen, man hatte Ausländer anstellen müssen, und englische Spione waren auf diese Art in das Departement gelangt ${ }^{149}$.

$\mathrm{Ob}$ es um das Feststellen von besonderen Sprachfertigkeiten oder eines bestimmten Akzents auf Deutsch oder Französisch ging, die politische Polizei orientierte sich sehr stark an den Sprachfertigkeiten der Westphalen, um deren Identitäten zu ermitteln und auf deren zeitweilig Parteilichkeiten zurückzuschließen. Die Polizeiagenten selbst bedienten sich gern des Deckmantels der Sprach(un)kenntnis als Tarnungsmittel oder zur Überführung von vermeintlichen politischen Gegnern des westphälischen Staats.

Sprachen konnten im Königreich Westphalen durchaus ein Mittel der politischen Unterdrückung darstellen. Außerdem wird in Bezug auf das zeitgenössische Sprachbewusstsein deutlich, dass oftmals die Sprechweise und Aussprache einer Person von ihren Zeitgenossen als Indiz für deren Herkunft und Identität interpretiert wurde.

\subsection{Von den Vorzügen der Beherrschung der französischen Sprache}

Cassel nahm ein durchaus französisches Gepräge an, allerwärts hörte man französisch, las man nur französische Schilder, das fremde Volk tummelte sich dominirend einher, die Deutschen lernten bei den zahllos auftretenden Sprach- und Tanzmeistern französisch reden und tanzen; oberflächliche französische Institute thaten sich auf ${ }^{150}$.

148 AnOnymus, Die entlarvte hohe und geheime Polizei, S. 31.

149 LANG, K. Fr. Reinhard, S. $387 \mathrm{f}$.

150 KleINSCHMIDT, Die Eltern, S. 276; vgl. LYNCKeR, Historische Skizzen, S. 82. 
Die Umbruchstimmung, die der Historiker Kleinschmidt bei seiner Beschreibung Kassels im Jahre 1807 schildert, und die plötzliche Allgegenwärtigkeit der Franzosen und des Französischen legen die Vermutung nahe, dass die französische Sprache auf einmal einen besonderen Stellenwert in der westphälischen Gesellschaft erhielt, der einer Dominanzstellung nahe kam.

Eine fiktive Anekdote des satirischen Autors der »Humoristischen Reise« macht deutlich, wie die französische Sprache unmerklich die Oberhand gewann. Der naive Antiheld beschreibt seine Ankunft in Kassel wie folgt:

Endlich erreichten wir einen honetten Gasthof, und ein buntscheckiges Thier kam an den Wagen gerennt. Ich fragte den Menschen: sist er der Hausknecht, und kann ich hier ein honettes Quartier bekommen?

Der Mensch sah mich mit einem Blick an, als wenn er hätte sagen wollen - bête allemande! - wenn er so viel französisch verstanden hätte; indeß erwiederte er in schwäbischem Dialect: - Hausknechte haben wir hier nicht mehr; ich bin der Garçon, und werde sogleich den Portier befragen thun ${ }^{151}$.

Diese abwertende Reaktion gegenüber jemandem, der kein Französisch benutzte, selbst von einem, der wenig davon verstand, sagt viel darüber aus, wie sich die französische Sprache in vielen Lebensbereichen mit Definitionsmacht ausbreitete, womit solche Auftritte denkbar wurden, zumindest in der Hauptstadt Kassel ${ }^{152}$. Das fiktive Gespräch scheint die Befunde aus dem zweiten Teil zu bestätigen, dass die Westphalen auf vielerlei Art und Weise bereit waren, das Französische regelrecht aufzusaugen. Die Bittschriften in französischer Sprache und die Sprachlehrbücher zum Selbststudium sind die eine, die Aufnahme französischer Ausdrücke im deutschen Redefluss eine weitere Erscheinung. Die deutsche Sprache mochte noch geduldet oder akzeptiert werden, doch die Vorzüge, die sich aus der Beherrschung der französischen Sprache ergaben, bewirkten möglicherweise schleichend eine dominierende Stellung des Französischen über das Deutsche. Kenntnisse der französischen Sprache wurden beispielsweise zu einem entscheidenden Kriterium bei der Auswahl der westphälischen Deputierten ${ }^{153}$.

Gute Sprachkenntnisse in der französischen Prestigesprache galten als Einstellungsvoraussetzung in vielen anderen Bereichen ${ }^{154}$. Für Georg Friedrich von Martens' Beförderung zum Prorektor der Universität Göttingen war es sicherlich entscheidend, dass er »die französische Sprache vollkommen beherrschte und mit mehreren einflussreichen französischen Diplomaten bekannt war ${ }^{155}$. In Hannover erhielt der Kammermeister Christian

151 HILARIUS, Humoristische Reise, S. 116.

152 LÜDTKE, Einleitung: »Sicherheit« und »Wohlfahrt«, S. 8; vgl. ferner REINHARD, Sprachbeherrschung, S. 6, 34.

153 Vgl. GoECKE, Das Königreich Westphalen, S. 43.

154 Vgl. BRAKENSIEK, Fürstendiener - Staatsbeamte - Bürger, S. 144.

155 THImme, Die inneren Zustände, Bd. 2, S. 279. 
Ludwig Albrecht Patje aufgrund seiner französischen Sprachkenntnisse eine bedeutende Rolle bei der ersten französischen Besetzung seiner Stadt noch vor der westphälischen Zeit:

Der an der Spitze der Executiv-Commission stehende Kammermeister Patje, welcher sehr bald durch seine Geschäftsgewandtheit und die vollständige Beherrschung der französischen Sprache einen bedeutenden Einfluß erlangt hatte, suchte besonders darauf hinzuwirken, dass ein gutes Vernehmen mit den Einquartierten und namentlich den Officieren erstrebt wurde, indem er dadurch hoffte zur Erleichterung des Landes am ersten etwas zu erlangen ${ }^{156}$.

Auch andere Zeitgenossen teilten die Ansicht, dass, um einen guten Sekretär eines Verwaltungsbeamten abzugeben, die Beherrschung der französischen Sprache für die Deutschsprachigen entscheidend war: »Man muß Sorge dafür tragen, dass F. ein tüchtiges und uns ergebenes Subject zum Secretair bekomme, und dazu scheint mir keiner geschickter, als mein L.; er ist beider Sprachen mächtig, und ein sehr gewandter Mensch « ${ }^{157}$.

Ein weiteres fiktives Beispiel einer der Protagonisten der satirischen "Humoristischen Reise « verdient exemplarisch zitiert zu werden:

Mein Lehrling schoß mit freier Hand die Schwalbe in der Luft, in der Nacht aber auch die zahmen Reh, welche für Sr. Durchlaucht gestellt werden sollten, und daher wurde er stracks des Landes verwiesen. Wie ich nachher vernommen habe, war er in einem andern Lande, da er gut französisch sprach, als Kriegscommissär angestellt, und hatte, während die Menschen zusammen geschossen wurden, und besonders, da seine Magazine immer im Retiriren waren, sich so viel zusammen gerechnet, dass er nach beendetem Kriege Zehnten, und zuletzt sogar Klöster kaufte, als wodurch er ein grundreicher, und grundrechtschaffener, am Ende auch wohl gar ein grundgelehrter Mann geworden seyn soll ${ }^{158}$.

Wie sich skrupellose Menschen, die die französische Sprache beherrschten, bereichern konnten, legt diese burleske Satire nahe.

Die Erteilung von französischem Sprachunterricht durch einen Muttersprachler war sogar eine Tauschware, die man gegen Kost und Logis einwechseln konnte ${ }^{159}$. Im »Westphälischen Moniteur« erschienen des öfteren Stellenangebote für oder Stellengesuche von französischsprachigen oder zweisprachigen Personen ${ }^{160}$.

156 HausmanN, Erinnerungen, 1873, S. 44.

157 Vertraute Briefe, S. 4; vgl. ferner GStA PK, V. HA, Nr. 2286, Bl. 23: Attestation de parfaite connaissance \& prononciation de la langue française de C. von Villers pour C. W. L. Bauermeister aus Nordheim, à l'adresse de J. C. von Leist, 27.7. 1812.

158 Hilarius, Humoristische Reise, S. $81 \mathrm{f}$.

159 Vgl. Le Moniteur westphalien, Nr. 251, Beilage, 21. Oktober 1811. Vgl. bereits Kapitel B II. (Spracherwerb).

160 Vgl. ibid.; ibid., Nr. 254, Beilage, Oktober 1811; ibid., Nr. 265, Beilage, 6. November 1811; ibid., Nr.266, Beilage, 7. November 1811; ibid., Nr. 268, 8. November 1811; ibid., Nr. 270, November 1811. 
Aus dem Verhörprotokoll von Rau ergibt sich, dass dieser bereit war, eine angebliche Tätigkeit als Dolmetscher zwischen den französischsprachigen Truppen und den deutschsprachigen Einheimischen vorzutäuschen, um schneller eine Anstellung zu erhalten. Er produzierte sogar falsche Zeugnisse zur Beglaubigung seines Schwindels ${ }^{161}$. Dieser Fall sagt etwas über das Ansehen der Prestigesprache Französisch aus, mit der sich Rau schmückte und durch die er hoffte, schneller wieder in Dienst zu kommen.

Als der Autor der »Entlarvten hohen und geheimen Polizei des zerstörten Königreichs Westphalen« die Polizeiagentin Würtz porträtiert, zählt er auch die französische Sprache zu den Talenten, die ihrer Karriere zugute kamen:

Im Anfange des Jahrs 1812, also während der wichtigen Epoche der preussischen Monarchie, lebte sie mehrere Monate als heimliche Kundschafterinn zu Berlin, wo ihr eine ausgebreitete Bekanntschaft, die Kenntniss der französischen Sprache und ihre außerordentliche Gnade vorzüglich zu statten kamen ${ }^{162}$.

Selbst wenn die Beherrschung der französischen Sprache nicht unmittelbar zu einer Anstellung als Verwaltungsbeamter oder employé für den westphälischen Staat führen musste, konnten auch Opponenten der westphälischen Herrschaft erfahren, dass französische Sprachkenntnisse in ihren Auseinandersetzungen mit dem neuen Staatsapparat günstige Auswirkungen haben konnten. Der Pfarrer und Staatsgefangene Gehren bestätigt diese Erfahrung in seinen Memoiren. Als er sich in Gefangenschaft in Mainz befand, wurde er vom dortigen französischen Präfekten um einen Brief in französischer Sprache gebeten, in dem er um seine Rückkehr nach Hessen bitten sollte. Sieben Tage später erhielt er die Nachricht seiner bevorstehenden Freilassung. Sein westphälischer Leidensgenosse, der sich ebenfalls in französischer Gefangenschaft in der Zitadelle in Mainz befand, bedauerte jedenfalls bei dieser Nachricht, dass er wegen mangelnder Französischkenntnisse den Präfekten nicht so oft besucht habe wie Gehren es getan hatte ${ }^{163}$.

Diese Beispiele von Vorteilen, die Einzelpersonen aus ihren französischen Sprachkenntnissen zogen, erhärten die These von der Bevorzugung und Vorrangstellung der französischen Sprache in der westphälischen Gesellschaft und lassen sich auch auf die Wahrnehmungsmuster eines Kollektivs übertragen: Die Nachkommen der hugenottischen réfugiés in Halberstadt bezogen sich auf ihre französische Sprache und die Notwendigkeit ihres Erhalts, um unter der westphälischen Herrschaft das Recht zu bekommen, ihre religiösen Riten fortführen zu können und nicht mit der deutsch-reformierten Kirche zusammengelegt zu werden ${ }^{164}$. Bemerkens-

161 Vgl. RNB St. Petersburg, F 993 Arch. Westf., K. 21, Nr. 13 019-13 040, hier Nr. 13 021: Verhörprotokoll von F. Rau, 22.2. 1813.

162 ANONYMUS, Die entlarvte hohe und geheime Polizei, S. 84.

163 Vgl. GeHREN, Dreimalige Verhaftung und Exportation, S. $161 \mathrm{f}$.

164 Vgl. KoHL, Die Verwaltung der östlichen Departements, S. 91. 
wert ist, dass sie eher mit dem Erhalt ihrer französischen Sprache als mit der in Westphalen proklamierten Religionstoleranz argumentierten. Dies lässt vermuten, dass sie sich unter dem Vorwand des Spracherhalts eher Erfolg für die Fortführung ihres Kults versprachen.

Auf einer individuellen Ebene wurde dem westphälischen Offizier Lehsten-Dingelstädt beim Rückzug vom Russlandfeldzug aufgrund seiner Sprachkenntnisse in Deutsch, Französisch und Italienisch die Führung von versprengten napoleonischen Truppen angetragen:

Hinter dem Dorf treffen wir auf versprengte italienische Truppen und alte Seesoldaten. [...] Da sie hörten, dass ich deutsch, französisch und auch etwas italienisch verstand und manchen zurechtwies, trat ein alter Marine-Sousoffizier, als es Tag wurde, zu mir heran: >Mon officier, prenez le commandement, sinon ca n'ira pas, il faut de l'ordre partout<.

Ein italienischer Offizier stellte sich gleichfalls sehr bereitwillig unter meinem Befehl. Wir lagerten beim nächsten Dorfe [...] Von Stunde zu Stunde wuchs die Schar. Auch mehrere höhere Offiziere fanden sich, denen ich das Kommando abtreten wollte, doch bestanden sie darauf, dass ich, da ich deutsch und französisch verstände, sie mindestens bis Torgau führe. Als wir wieder aufbrachen, war es mir gelungen, aus den wohl tausend Mann der verschiedensten Waffengattungen ein Korps zu bilden ${ }^{165}$.

Dieses Beispiel zeigt, dass die Mehrsprachigkeit in bestimmten Notsituationen selbst die Aufhebung der ansonsten schwerfälligen militärischen Hierarchie nach sich ziehen konnte.

Spätestens mit der Auflösung des Königreichs Westphalen Ende 1813 büßte jedoch die französische Sprache ihren hohen Rang ein. Diejenigen Verwaltungsbeamten, die zuvor gerade aufgrund ihrer Kenntnisse der französischen Sprache zu Staatsvertretern avanciert waren, erfuhren diese Veränderung am schmerzhaftesten. Ende 1813 waren Steinwürfe auf Fenster westphälischer Beamter durchaus üblich ${ }^{166}$. Uli Kahmann berichtet, wie dies auch beim Schneider Lemkuhl der Fall war, »weil er französisch sprach, mit den Douanen Umgang hatte und für sie arbeitete «167.

Im Königreich Westphalen mussten zwar nicht alle grundsätzlich Französisch sprechen lernen; eine derartige Sprachdominanz war eindeutig nicht die Praxis; allerdings lassen sich die Vorzüge, die sich aus der Beherrschung der französischen Sprache ergeben konnten, nicht leugnen, so dass von einer schleichenden Dominanz der französischen Sprache gesprochen werden kann.

165 [LeHSTEN-DingeLSTÄDT], Am Hofe König Jérômes, S. 133.

166 Vgl. HofFmanN, Aufrührer, Ruhestörer oder gute Patrioten?

167 Kahmann, Die Geschichte des J. F. A. Lampe, S. 342. 


\subsection{Beredsamkeit und Redekultur}

Ein weiterer Aspekt, der für eine schleichende Dominanz der französischen über die deutsche Sprache spricht, ist die rhetorische Gewandtheit, die die Französisch- und Deutschsprachigen in den Augen der Zeitgenossen zum Teil voneinander unterschied. Der Historiker Lyncker beschreibt mit einem eindrucksvollen Sprachbild, welche kulturellen Differenzen sich zwischen Franzosen und Deutschen in Bezug auf die Redekultur und den Schreibduktus sich im Königreich Westphalen zeigten:

Die Franzosen hatten alle jene hochtönenden hohlen Phrasen französischer Rhetorik mit herübergebracht, wie sie in der Kaiserzeit in Paris blühten und welche einem deutschen Ohr so höchst widerwärtig klangen. In ihren Reden und Schriften stürzten Worte und Sätze schwadronirend und lärmend übereinander wie die Wellen eines Wasserfalles, so dass Einem beim bloßen Ansehen oder Anhören ganz schwindlich wurde ${ }^{168}$.

Auch die Zeitgenossen berichten über die Diskrepanz zwischen der rhetorischen Leichtigkeit der Franzosen und der Schwerfälligkeit der Deutschen, die auf andere Traditionen der Redekultur zurückzuführen seien. Exemplarisch können hier die Urteile der Zeitgenossen über die Erfahrungen in den Reichsständen angeführt werden. Bereits über die Reichsständeeröffnungsrede von Jérôme wurde von einem anonymen Autor in seinem Artikel "Regierungs-Geschichte des Königreichs Westphalen" in einer Zeitung aus dem Jahre 1810 betont: "Eine solche Rede stach sehr gegen die sonst übliche Kanzleisprache ab; und ihr Eindruck auf die Reichsstände war sichtbar « ${ }^{169}$.

Siméon selbst plädierte bei seiner Ansprache vor den Reichsständen für mehr Beredsamkeit in der Gerichtsbarkeit, um die bevorstehende Reform der Justiz zu unterstützen:

Indeß die deutsche Literatur mit der Literatur aller Nationen um den Vorzug buhlt, ihre Dichter, Geschichtsschreiber und Schriftsteller preißt, wie sollte sie nicht auch Redner haben? Bemächtigen Sie sich des bisher fehlenden Ruhms der gerichtlichen Beredsamkeit. Sollte sie zuweilen ins weitläufige gehen, immer ist sie kürzer als die schriftliche Verhandlung. Eine Nation, welche mehr denkt und weniger leicht sich bewegt, als die, bei welchen die Redekunst in verjährter Uebung ist, wird den Misbräuchen des mündlichen Vortrags leichter entgehen und nur seine Vortheile genießen ${ }^{170}$.

Dieser von Napoleon gesandte französischsprachige Verwaltungsbeamte des Königreichs Westphalen zeigte sich rhetorisch herausfordernd, um die deutschsprachigen westphälischen Staatbürger aus ihrer Reserve zu locken

168 LYNCKER, Historische Skizzen, S. $82 \mathrm{f}$.

169 ANONYMUS, Regierungs-Geschichte, S. 229; vgl. OWZAR, Schlendrian, S. 308.

170 Siméon, zitiert nach: ANONYMUS, Regierungs-Geschichte, S. 230. Vgl. auch CrAmer, Geschichte des Königreichs Westphalen, S. 160 f. 
und einen Wandel ihrer Redekultur herbeizuführen ${ }^{171}$. Die Schwerfälligkeit, die Siméon den Deutschen vorwarf, scheint auch mit den Erfahrungen der westphälischen Abgeordneten selbst übereinzustimmen. Das Fehlen von Debatten- und Parlamentskultur in den westphälischen Reichsständen wurde in der Forschung mehrfach bestätigt. Herbert Obenaus bezeichnet die Reichsständemitglieder als die $» 100$ Stummen ${ }^{172}$. Der zeitgenössische Jurist Cramer beschreibt in aller Ausführlichkeit die schockierten und empörten Reaktionen der Reichsstände auf eine vom Finanzminister Malchus, allerdings auf Deutsch, gehaltene Rede:

So endete die Sitzung zur Zufriedenheit des Staats-Raths [Malchus], und mit seltsamen Gesichtern schritten, nach erhaltenem so scharfen Verweise die Gruppen der Reichsstände den vom Orangeriesaale zur Stadt führenden Berg hinan, indem sie sich die vernommenen Worte wiederholten, und überlegten, was wohl zu ihrer Ehrenrettung zu beginnen sey. Man versammelte sich, hierunter zu berathschlagen, bei dem Präsidenten der Stände und fasste den Entschluß, zuerst durch eine Deputation sich vom Staats-Rath Malchus eine Abschrift der gehaltenen Rede zu erbitten, und, wenn man diese erhalten, durch eine zweite Deputation sich bei dem Minister Simeon über den ehrenrührigen Inhalt derselben zu beschweren. - Manche Mitglieder zweifelten, ob Malchus ihnen auch sein oratorisches Werk, seine Philippika, so geben würde, wie er sie gehalten habe, indem man es seiner politischen List wohl zutraute, dass er manche harte Ausdrücke mit milderen vertauschen dürfte ${ }^{173}$.

Des weiteren wurde Malchus von den Abgeordneten angelastet, beim Deklamieren seiner "Strafpredigt« sichtlich viel Freude gezeigt zu haben ${ }^{174}$. Die Gegenstrategie der Deputierten, diese in ihren Augen unsägliche Rede in schriftlicher Form zu verlangen, um sie als Beweismaterial gegen Malchus anzuführen, ist bezeichnend für ihr Festhalten an der Schriftlichkeit. Siméon, dem die Deputierten ihren Ärger über Malchus' Rede antrugen, reagierte selbst "als gewandter Staatsmann « darauf ${ }^{175}$. Cramer berichtet über Siméons Versprechungen:

Mit französischer Leichtigkeit deutete er das Vertrauen des Königs zur Reichsversammlung an, versicherte, wie jener mit Erstaunen ihre Klagen über die wider seinen Willen vom Rapporteur des Staats-Raths erlittenen Beleidigungen hören würde. Auf das Genaueste sollte Malchus Rede geprüft werden, hätte er auf irgend eine Weise seinen Auftrag und seine Befugniß überschritten, hätte er die Reichstände in der

171 Tittmann bekennt im Vorwort zu seinem »Handbuch für westphälische Notarien« auch sein Vorhaben, zu einer »Verbesserung des Geschäftsstyls der Deutschen« beizutragen. Vgl. Handbuch für westphälische Notarien, S. VIII.

172 OBENAUS, zitiert nach: HECKER, Napoleonischer Konstitutionalismus, S. 146.

173 CRAMER, Geschichte des Königreichs Westphalen, S. 252.

174 Ibid., S. 252. Ein Historiker, der seine Aussage zum Teil auf mündliche Überlieferungen stützen konnte, berichtet, dass Malchus, nicht so sehr wegen seiner Rede, sondern weil er nach Ablehnung seines eingebrachten Grundsteuergesetzes »im Zorn über diese unerhörte Anmaßung, sehr beleidigende, die Würde der Stände verletzende Reden hatte laut werden lassen «, so unpopulär bei den Reichsständemitgliedern wurde. LYNCKER, Historische Skizzen, S. $75 \mathrm{f}$.

175 CrAmER, Geschichte des Königreichs Westphalen, S. 253. 
Heiligkeit ihrer Person gefährdet oder beleidigt, so solle er gewiß bestraft werden, und so die Versammlung jede ausgezeichnete Satisfaktion erhalten. Für den Augenblick aber mögte man sich um so mehr beruhigen, da er den Ständen ein dreifaches Versprechen geben könne: theils wolle er den Vorfall sogleich unmittelbar an den König berichten, eine getreue Uebersetzung der Malchusschen Rede beifügen und sich von dem Könige weitere Verhaltungs-Befehle erbitten; theils verspräche er den Ständen dahin zu wirken, dass der Staats-Rath Malchus, der zu ihrer Unzufriedenheit Veranlassung gegeben, nie wieder in ihrer Mitte als Rapporteur des Staats-Raths auftrete, theils solle die Rede nicht so, wie sie gehalten sey, sondern mit Hinweglassung aller etwas anstößiger und beleidigender Stellen im Moniteur abgedruckt werden. Und über solche Versicherungen hoch erfreut schieden die Deputierten von dannen, ohne je wieder etwas weiteres von der ganzen Angelegenheit zu erfahren ${ }^{176}$.

Cramers Ansicht nach hätte die vor Siméon aufgetretene Abordnung darauf bestehen sollen, dass die Malchus'sche Rede in vollem Umfang abgedruckt werde, "wie sie gehalten sey, indem der Nation, deren Abgeordnete sie wären, das kein Geheimniß bleiben dürfte, was in den öffentlichen Sitzungen der Reichsstände verhandelt wäre [...], so aber trugen die schön klingenden Worte des Ministers [Siméon] den Sieg davon ${ }{ }^{177}$.

Die ganze Angelegenheit um die Reform des Malchus'schen Steuergesetzes sorgte damals für großen Unmut und rief sogar eine Flugschrift hervor $^{178}$. In der Forschung zum Parlamentarismus dient die Ablehnung des Malchus'schen Steuergesetzes durch die Reichsstände als Angelpunkt für das Urteil über diese Versammlung, da das Gesetz zu den wenigen zählte, die die westphälischen Reichsstände zurückwiesen ${ }^{179}$. Die Pointe, auf die Cramer zum Schluss anspielt, ist, dass Siméon selbst Malchus zu der deutschsprachigen Rede geraten haben soll. Malchus sollte »mit deutscher Derbheit das [...] sagen, was mit französischer Leichtigkeit hätte [nur] angedeutet werden « können ${ }^{180}$. Während die eingangs angeführte französischsprachige Grabrede Siméons fast den ehrwürdigen deutschen Ton traf, verwendete Malchus' deutschsprachige Rede vor den Reichsständen die französische Dreistigkeit. In ihrer konstruierten Rollenzuweisung hätte die Erzeugung von Gegensätzen nicht eindeutiger sein können. Schenkt man Cramer Glauben, nach Abzug des überspitzten Gegensatzes zwischen tugendhafter deutscher Sprache und zwar rhetorisch brillanter, aber hinterlistiger französischer Sprache, so war der Kontrast zwischen dem derben Redestil des deutschsprachigen Ministers und dem höflichen und leichten Redestil des französischsprachigen Ministers nicht allein den kultu-

176 Ibid., S. $253 \mathrm{f}$.

177 Ibid., S. 254.

178 Vgl. Gedanken über die Natur und Gränzen des Königreichs Westphalen; vgl. ferner darüber CrAMER, Geschichte des Königreichs Westphalen, S. 255; HECKER, Napoleonischer Konstitutionalismus, S. 153. Vgl. unter den Schriften von Malchus: MALCHUS VON MARIENRODE, Über die Verwaltung der Finanzen.

179 Vgl. HeCKer, Napoleonischer Konstitutionalismus, S. $153 \mathrm{f}$.

180 CRAMER, Geschichte des Königreichs Westphalen, S. 255. 
rell bedingten Gewohnheiten der Redekultur anzulasten. Mit diesem offenbar den Zeitgenossen allgemein bekannten Unterschied zwischen den Staatsräten wurde zudem höchst strategisch umgegangen. Die Strafpredigt ließ die westphälische Regierung den Abgeordneten der Reichsstände von einem deutschsprachigen Vertreter in deutscher Sprache erteilen, während die Deutschsprachigen von Siméon dazu ermuntert wurden, der französischen »Nationalstärke« der brillanten Redekultur nachzueifern ${ }^{181}$. Wurde die deutsche Sprache dafür funktionalisiert, Unannehmlichkeiten zu verkünden, während die französische Sprache eine positive Rolle behielt, zeigt dies, dass beide Sprachen, selbst wenn nicht direkt von einer offiziellen Sprachdominanz des Französischen über das Deutsche ausgegangen werden kann, in ihrer Rollenaufteilung in bestimmten Gesellschaftsbereichen nicht auf dem gleichen Stand waren.

Auf die Gewichtung beider Sprachen in Verwaltung und Regierung soll die Untersuchung noch kommen, aber selbst im Staatsrat soll der Kontrast zwischen den französischen "gewandten Rednern" und den Deutschen, die "sich nur mangelhaft in der fremden Sprache auszudrücken wussten «, aufgefallen $\operatorname{sein}^{182}$.

Unabhängig davon, ob die französische und die deutsche Sprache verwendet wurde oder die Deutschsprachigen sich in französischer Sprache gegenüber den Französischsprachigen artikulieren mussten, waren offensichtlich die französische Sprache und ihre Sprecher positiver besetzt.

Nicht allein auf die Beherrschung der fremden französischen Sprache kam es an, sondern auch auf die Beredsamkeit. Dies bestätigt Wolffradt in seinen »Denkwürdigkeiten «: »[Belastend war das] vis-à-vis von französischen Ministern, die nicht allein Sache und Sprache in ihrer Gewalt hatten, sondern die durch ihre Talente und Beredsamkeit in den französischen legislativen Versammlungen geglänzt hatten und auch hier wieder glänzten ${ }^{183}$. Die Franzosen hatten nun mal den Erfahrungsvorsprung der Französischen Revolution, schien der Minister mit Neid festzustellen ${ }^{184}$. Die Überlegenheit der Franzosen in ihrer Redekultur wurde offenbar gelegentlich seitens der Deutschsprachigen als erdrückend oder erniedrigend erfah-

181 Ibid., S. 171.

182 KLEINSCHMIDT, Geschichte des Königreichs Westfalen, S. 33 f., vgl. auch S. 47 f.

183 Wolffradt, zitiert nach: ThIMME, Die inneren Zustände, Bd. 2, S. 89. [WolfFRADT], Denkwürdigkeiten, S. $65 \mathrm{f}$.

184 Weiterführend zur Redekultur unter der Französischen Revolution vgl. SCHLIEBEN-LANGE, Schriftlichkeit und Mündlichkeit; HunT, The Rhetoric of Revolution. Insbesondere Schlieben-Lange hat auf verschiedene Topoi in diesem $\mathrm{Zu}$ sammenhang hingewiesen, unter anderem den Topos in der deutschsprachigen Literatur, wonach die Französische Revolution sich im Medium der Mündlichkeit vollzogen habe. Vgl. SCHLIEBEN-LANGE, DRÄXLER, Die Französische Revolution und das deutsche Sprachdenken, S. $11 \mathrm{f}$. 
ren. Die Beredsamkeit der Französischsprachigen imponierte offensichtlich auch und es soll nicht an Bereitschaft seitens der deutschsprachigen Westphalen gefehlt haben, ihre Redekultur zu verändern. Scheller schreibt dazu ironisch, wenn er über die Harzreise Jérômes berichtet:

Und Ehr' genug an allen Orten [...]

Und Deutsch' und Welsche Reden halten,

Die war'n aus Weidenholz gespalten

Im Winter schon am Ofen heiss,

Und biegsam, dünn, und blau und weiss,

Und so mit Lügen angemacht,

Als hätt' ein Anwald sie erdacht,

Der, wo die Wahrheit nichts gewinnt,

Auf Lügen und - Rechtsmittel sinnt:

Queerfeldein in das Banngehag

Des Löwen, das er sein itzt nannte,

Und wo man ihn zu sehen brannte

Mit eines Glühwurms - heissem Feuer,

Und wo itzt war die Freude theuer,

Die kam aus reinem Herzen her,

Und nicht befohlen von ein'm Maire ${ }^{185}$.

Die Anpassungsversuche der deutschsprachigen westphälischen Staatsbürger an die französische Beredsamkeit betrachtet Scheller rückblickend mit gebührender Skepsis:

Die alle machten ihren Bükkling,

Und sodann traten wieder Rükkling,

Nachdem man halbe Wort' gesprochen

Und manche Red' war abgebrochen,

Die man schon lang mit Angst und Schweiss

Hatt' eingelernt beim Ofen heiss ${ }^{186}$.

Die Aufforderung der Französischsprachigen an die Deutschsprachigen, ihre angeblich schwerfällige Rede zu verbessern, sowie der Versuch, ihnen eine andere Kultur des Sprechens aufzunötigen, können als eine auf den ersten Blick zwar unauffällige, dennoch frappierende Variante von schleichender Sprachdominanz gewertet werden.

\subsection{Französisierung des öffentlichen Raumes}

\subsubsection{Offizielle Straßen- und Ortsumbenennung}

Direkt mit der Gründung des Königreichs Westphalen und mit der Einteilung in neue Verwaltungseinheiten nach dem Vorbild der französischen

185 SCHELLER, Jeromiade, S. 80. Über die Reden in französischer Sprache anlässlich des Einzugs Jérômes in Braunschweig liefert Scheller ebenfalls Verse. Vgl. ibid., S. 88.

186 Ibid., S. 95. 
Departements wurde eine Französisierung des öffentlichen Raumes selbst offensichtlich. Scheller dichtet 1814 dazu:

Voraus schon war das Königreich Westfalen sammt dem Mahnerteich Im weiland Hochstift Hildesheim Gemahlt mit Farb' und Gummischleim, Getheilt in Präfecturen gar

Nach seinen Wässern hell und klar.

Die Katten sammt den alten Sassen

Sich sollt'n Westfalen nennen lassen,

Nach Gallischer Gelehrsamkeit,

So hoch berühmet weit und breit

Und in der Zeitung ausposaunt ${ }^{187}$;

Die Namensgebung der Departements folgte den Namen der Flüsse. Die Landstriche wurden umbenannt und damit die Inbesitznahme durch die Franzosen signalisiert. Der Historiker Kleinschmidt erkennt in den Maßnahmen, welche die alten Provinznamen verschwinden ließen, die Intention, »die geschichtlichen Erinnerungen zu verwischen ${ }^{188}$.

In Kassel weitete sich die französisierende Umbenennungspolitik auf die Straßen- und Ortsnamen aus ${ }^{189}$. Die Stadtviertel, die zuvor in Alt- und Neustadt eingeteilt waren, wurden zum Kanton der Unterstadt und Kanton der Oberstadt beziehungsweise zum ersten und zweiten Kanton umgetauft, als habe das Alte der "Altstadt « nicht mehr zu bestehen ${ }^{190}$. Das Schloss Wilhelmshöhe wurde nun in Napoleonshöhe umbenannt ${ }^{191}$; aus dem Wilhelmsthal wurde Katharinenthal ${ }^{192}$; der Friedrichsplatz wurde zum Ständeplatz ${ }^{193}$ und der Königsplatz wurde zum Napoleonsplatz sowie mit der entsprechenden Bronzebüste versehen ${ }^{194}$.

In den Versen Schellers wird der Umstand für eine solche Umbenennung nachgedichtet, denn Namensgebung und -veränderung wurden zudem in Feierlichkeiten eingebettet, so anlässlich der Thronbesteigung Jérômes:

187 Ibid., S. 9.

188 KLEINSCHMIDT, Die Eltern, S. 274.

189 Vgl. Bulletin des Lois, 1808-1812, Nr.63, Dekret vom 31. Okt. 1808, S. 274276. Zum Thema Straßennamenumbenennung weiterführend vgl. BAYER, Französisch-deutsche Straßenschilder; KRAMER, Straßennamen in Köln; DERS., Französische Straßennamen; DerS., Das Französische in Deutschland; GerSMAnN, Der Streit um die Straßennamen.

190 Vgl. KLEINSCHMIDT, Geschichte des Königreichs Westphalen, S. 32.

191 Vgl. LYNCKER, Historische Skizzen, S. 89.

192 Vgl. ibid.; GOECKE, Das Königreich Westphalen, S. 49.

193 Vgl. LYNCKER, Historische Skizzen, S. 90; KLEINSCHMIDT, Das Königreich Westphalen, S. 20.

194 Vgl. ANONYMus, Die französische Garküche, S. 14; LYNCKER, Historische Skizzen, S. 90; KirCHEISEN, König Lustig, S. 74. 
Und hielten Reden, dass es brummte,

Und Jerum fast darob verstummte.

Doch hat er, da man abgebrochen,

In Welscher Zung' also gesprochen:

,Ich will Euch mich zu lieben zwingen!

>Und was ich will soll mir gelingen

Und dies kam in die Zeitung h'nein,

Dass drob sollt Alt und Jung sich freun.

Zur Wilhelmhöh' gings nun hinauf,

Wo Jerum hemmte seinen Lauf,

Und sprach: ^Hier steh’ mein Königsthron,

`Hier auf der Höh' Napoleon!

>Wer Wilhelmshöh' sie nennet wieder,

>Den schiess' ich als Aufrührer nieder ${ }^{195}$ !

Jérômes Drohgebärde und die Androhung der Todesstrafe für die Nennung des alten Namens Wilhelmshöhe ist historisch nicht nachweisbar und entspricht sicherlich nicht der Realität. Die Übertreibung durch den satirischen Autor der » Jeromiade « weist darauf hin, wie hoch sensibel die offizielle Umbenennungspolitik in den Augen der Zeitgenossen war.

Zieht man die Ausführungen des satirischen Autors der »Humoristischen Reise " heran, so bemühten sich die einheimischen Kasselaner angeblich nicht einmal, die neuen Straßennamen auszusprechen. Vielmehr ignorierten sie stillschweigend die neue Namensgebung:

Eine neue Verlegenheit [erfuhren wir]! Keine Straße hatte ihren Namen mehr, und die alten Einwohner der Stadt, welche wir befragten, wo man nach der und der Straße (der neuen Taufe) komme, gestanden keine Rede, und gingen mit einem mitleidigen Blick an uns vorüber ${ }^{196}$.

Die »Verwirrung bis zur Unkenntlichkeit der Straßen« soll sich auch nach Auflösung des Königreichs Westphalen fortgesetzt haben, so der anonyme Autor der "Garküche an der Fulde«, der sich ebenfalls mit dem Thema beschäftigt:

Bediente sich der öffentliche Ausrufer während der französischen Regierung des französischen Namens einer Straße, so hatte man Mühe, ihren ursprünglich teutschen Namen herauszufinden, und jetzt, da der alte teutsche Namen wieder ausgesprochen wird, muß man doch auch, um sich zu orientieren, den französischen $\mathrm{zu}$ Hülfe nehmen. [...] An manchen Ecken der Straßen sah man den alten teutschen Namen ausgewischt und einem neuen französischen entgegen, so wie es jetzt wieder umgekehrt der Fall ist ${ }^{197}$.

Die Quellenzitate widersprechen sich zum Teil und übertreiben sicherlich: Als gemeinsame Konstante inszenieren sie die Verwirrung, die durch die Umbenennungen entstand. Man kann vermuten, dass die Straßen- und

195 SCHELLER, Jeromiade, S. $27 \mathrm{f}$.

196 Hilarius, Humoristische Reise, S. 119 f.

197 ANONYMUS, Die französische Garküche, S. 37. 
Ortsumbenennungen eventuell einige Westphalen irritierten; ganz sicher kann jedoch davon ausgegangen werden, dass nach 1813 das Thema zu einem Kanon der Enthüllungspublizistik wurde.

\subsubsection{Umbenennungen auf Privatinitiative}

Im Fall der Hauptstadt Kassel fällt jedoch insbesondere auf, dass die Französisierung des öffentlichen Raumes durch Umbenennungen nicht allein auf staatliche Maßnahmen zurückging: »Cassel nahm ein ganz französisches Gepräge an, überall hörte man französisch, überall sah man französische Ladenschilder mit den hochtrabendsten Aufschriften « ${ }^{198}$. Dies bestätigt ein Zeitgenosse, der als Kind um 1807 in Kassel lebte und seine Erinnerungen daran im Nachhinein aus dieser Kinderperspektive niederschrieb:

Doch dauerte es gar nicht lange, so machte sich ein ganz anderes Leben [in Kassel] bemerkbar. [...] Mit Mühe buchstabirten wir die französischen Aufschriften der Schilder über die vielen neuen Läden zusammen; entziffern konnten wir sie freilich nicht und nur die ausgelegten Waaren gaben den Ausschlu $3^{199}$.

Die Französisierung des öffentlichen Raumes durch zugezogene Kaufleute, Restaurateure und dergleichen war offensichtlich so massiv, dass die Kasseler Kinder ihre Spielgewohnheiten anpassten und gemeinsam spielerisch die Ladenaufschriften entzifferten.

Dass diese Veränderungen in erster Linie die Städte und insbesondere die Hauptstadt Kassel betrafen, macht der Historiker Philipp Losch deutlich:

Französisch [...] war [...] die Sprache des Siegers [...]. Das eigentliche Land blieb von dieser Französisierung im allgemeinen weniger berührt, in den Städten und namentlich in der Hauptstadt machte dagegen das Franzosentum reißende Fortschritte, und binnen kurzem war die ehemalige Residenz des alten Kurfürsten, der seine Untertanen so ängstlich vor dem gallischen Wesen bewahrt hatte, nicht mehr wiederzuerkennen ${ }^{200}$.

Diese Aussage wird jedoch durch den Befund aus dem Unterkapitel über die französischen Privatlehrer (B II.1.1.) relativiert, da diese nicht ausschließlich in Kassel zu finden waren. Festzuhalten bleibt, dass das Bild von "Cassel à la française " offensichtlich auch eine Folge der Privatinitiative einzelner Bürger war, die ihren Ladenaufschriften oder Gasthöfen einen französischen Klang verleihen wollten. $\mathrm{Zu}$ den Namensgebungen der Gasthäuser werden insbesondere beim anonymen Autor der "Garküche" aufschlussreiche Angaben gemacht. Ein neues Kaffeehaus in Kassel, das Kaffeehaus Jérôme, erfreute sich besonderen Zulaufs, angeblich schon allein wegen des Patronyms des Königs: »Bei Jerome in der Königsstraße war der Platz gar zu

198 KleINSCHMidT, Geschichte des Königreichs Westphalen, S. 31; vgl. DerS., Die Eltern, S. 276.

199 MÜLLER, Kassel seit siebzig Jahren, Bd. 1, S. 11.

200 LosCH, Kfm. Hessen, S. 51. 
beschränkt. [...] Schon der Name Jerome war einladend, und die Franzosen ließen es sich bei Jerome dem Zweiten so gut schmecken, als ihre vornehmeren Landsleute bei Jerome - dem Ersten am Hofe ${ }^{201}$. Diese Aussage spricht für die Anziehungskraft der neuen Benennungen, die den neuen Herrschaftsverhältnissen und der allgemeinen Beachtung, die sie erfuhren, Rechnung trugen. Über die bereits bei Anbruch der neuen Herrschaft bestehenden Einrichtungen schreibt Lyncker zusammenfassend:

Eines Tages machte [...] der Inhaber des `Hessischen Hofes` ein `Hôtel de Westphalie` aus seinem Hause; die den Franzosen anstößige Firma `Hof von England kehrte sich in ein >Hotel de Paris` um und das Gasthaus `zum Kurfürsten`nahm die Bezeichnung $>$ Hotel rouge $<\mathrm{an}^{202}$.

Ein Problem, das aus den vielen Umbenennungen hervorging, findet sich auch in der burlesken Satire von Nicolai wieder:

Die erste Unannehmlichkeit, welche ich in der Residenz durch meinen Bedienten, von welchem ich überzeugt seyn musste, dass er besser wäre wie das beste Adressbuch, hatte, war die, dass ich erst den guten Gasthof nicht finden konnte, den ich suchte. Denn die Gasthöfe hatten bei dem neuen Herrn ihre Schilder verändert, und da gab es denn jetzt kein >deutsches Haus < keinen >Gasthof zu allen Nationen >herrschaftliche Schenke`mehr. Das alles war jetzt Hôtel, und die Aushängeschilder sogar hatten sich zu der Mantelträgerei müssen anpinseln lassen ${ }^{203}$.

Die Anpassung der Namen der Gasthäuser an die neuen politischen Verhältnisse zieht der Autor ins Lächerliche - sie symbolisiert jedoch die allgemeine politische Aufbruchstimmung und ermöglicht, den Umfang der allgemeinen Französisierung des öffentlichen Lebens und die dahinter verborgene graduelle Sprachdominanz durch das Französische aufzuzeigen.

\subsubsection{Französisierung der Personennamen und der Amtstitel}

Einige gingen mit der Französisierung so weit, dass sie ihre eigenen Personennamen französisierten. Im Kapitel B III. (Bittschriften) war die-

201 ANONYMUS, Die französische Garküche, S. 71. Dieses Beispiel passt hervorragend auf die von Schwerhoff vorgeschlagene Forschungsfrage in Bezug auf die Medialität von Räumen: »In einem doppelten Sinn wäre nach der Medialität der untersuchten Räume zu fragen. Einmal sind sie durch ihre Bauweise, ihre Zugänglichkeit, ihre Ausstattung und ihre Ausmalung selbst Bedeutungsträger, semiotische Objekte, eben Kommunikationsmedien, die den Besuchern bestimmte Botschaften [...] vermitteln sollten. [...] Tavernen [...] in Form von Wirtshausschildern, Wappen, Fensterscheiben etc. symbolisch besetzte Elemente, die das Gebäude selbst zum Medium von Traditionsvermittlung machen. Zweitens wäre dann nach den Kommunikationsmedien zu fragen, die in den jeweiligen Räumen dominierten«. SCHWERHOFF, Kommunikationsraum Dorf und Stadt, S. $143 \mathrm{f}$.

202 LYNCKER, Historische Skizzen, S. 89; vgl. KirCHEISEN, König Lustig, S. 85; FABRE, Jérôme Bonaparte, S. 163.

203 Hilarius, Humoristische Reise, S. $115 \mathrm{f}$. 
ses Phänomen der Anpassung an die neuen Herrschaftsverhältnisse schon erwähnt worden.

Viele wurden freiwillig oder durch die Verwaltungsbehörden kurzerhand von »Wilhelm « auf "Jean" umgetauft, wobei sich die Frage stellt, wie die neue Herrschaft sich in den Zivilbüchern zurechtfinden wollte und die Herkunft ihrer Staatsbürger bei Bedarf nachverfolgen konnte, wenn die Menschen so leichtfertig ihre Taufnamen wechseln konnten ${ }^{204}$. Selbst eine Person englischer Herkunft wie der Matrose John Williams ging in die Akten der westphälischen Polizei als »Jean Ulms« ein, mit der Besonderheit, dass er im französischsprachigen Schreiben des Polizeichefs durchaus "John Williams" sein durfte, während er im deutschsprachigen Schreiben des Generalpolizeikommissars Guntz zu deutsch-französisch »Jean Ulms« wurde ${ }^{205}$. Selbst Jérômes Hofmaler François-Joseph Kinson oder Kinseon aus Brügge wurde kurzerhand vom Pagen Lehsten-Dingelstädt in seinen Memoiren $\mathrm{zu}$ »Quinçon« französisiert, als passe er so besser in die Kasseler Verhältnisse ${ }^{206}$.

Über den Verlust ihrer Taufnamen beklagten sich auch einige Zeitgenossen, wie der Metropolitan Gundelach aus Zierenberg im Fuldadepartement im Rahmen seiner Predigt beim Klassenkonvent der Landprediger der Departements hessischer Herkunft im Sommer 1810 in Oberlistingen:

Damals waren wir Unterthanen eines Fürsten, mit dessen Verlust wir auch sogar unsern Namen verloren haben, der uns sehr gelinde und väterlich regierte [...], aber jetzt sind wir Unterthanen eines fremden Regenten, eines fremden Volks, dessen Sprache wir nicht einmal verstehen, dessen Sitten uns fremd sind, von dem wir unser Schicksal zu erwarten haben ${ }^{207}$.

Die Titel der Verwaltungsbeamten, aber auch der niederen Chargen im öffentlichen Leben wurden in der Regel französisiert ${ }^{208}$. Dieses Phänomen wird teilweise in der Anekdote aus der burlesken Satire von Nicolai reflektiert, die bereits oben zitiert wurde, in der dem Antihelden bei seiner Ankunft in Kassel ein »Garçon « statt eines Hausknechts begegnet ${ }^{209}$. Lyncker beschreibt ähnliche Tendenzen, gerade im niederen Hofstaat und im wei-

204 Diese Tendenz zur Französisierung der Taufnamen selbst seitens der Beamten steht im Widerspruch zu dem gleichzeitig aufkommenden statistischen und demographischen Erfassungsdrang und zur Entwicklung von Instrumentarien zur besseren Polizeiüberwachung. Vgl. DENIS, Une histoire de l'identité.

205 RNB St. Petersburg, F 993 Arch. Westf., K. 17, Nr. 10 717-10 735, hier Nr. 10719 : Schreiben Nr. 586 P. G. von F. T. de Guntz an J. F. M. de Bongars, 15. 3. 1813; vgl. ibid., Nr. 10721.

206 [LEHSTEN-DingELSTÄDT], Am Hofe König Jérômes, S. 30; vgl. FRÖHLICH, Théâtre Royal, S. 171; NiCOUD, Auf der Leinwand und in Marmor, u.a. S. 65.

207 Gundelach, zitiert nach: ANONYMUS, Die entlarvte hohe und geheime Polizei, S. 162, vgl. S. 161.

208 Vgl. AnONymus, Die entlarvte hohe und geheime Polizei, S. 30.

209 Vgl. Hilarius, Humoristische Reise, S. 116. 
teren Umkreis der Bediensteten am Hof, sich mit pompösen französischen Titeln zu schmücken, die imponieren sollten. Einige Beispiele von Titeln, welche aufgrund ihres Klangs und ihrer Länge "allein schon einem deutschen Ohr Respect einflößen mussten «, führt er $\mathrm{an}^{210}$ :

Das französische garçon d'attelage aux écuries de S. M. le Roi de Westphalie klang freilich anders als das anspruchlose Prädicat >Wagenknecht $\measuredangle$. Der palafrenier de S. M. le Roi de Westphalie dünkte sich mehr als der Thürsteher eines deutschen Fürstenhauses. An der Stelle des Lichtkämmerers spreizte sich ein chef de l'éclairage du palais de S. M. le Roi. Ein Gehülfe des Hühnerstopfers unterzeichnete: premier aide de l'engraisserie royale und ein Schreiber des Intendanten Laflèche glaubte es sich selbst schuldig zu sein, seinem unbedeutenden Namen den langen Titel eines commis de l'intendance générale de la maison de S. M. le Roi de Westphalie nachzusetzen. Ueberhaupt durfte der Zusatz de S. M. le roi ou de la reine de Westphalen nicht fehlen, wenn irgend eine Berichtigung vorhanden war, sich desselben zu bedienen; wo die Berichtigung fehlte, zog man sie an den Haaren herbei. Der Koch des General Reubel nannte sich z. B. cuisinier de son Excellence le Gouverneur Reubel, général de division et aide de Camp de S. M. le Roi de Westphalie $e^{211}$.

Auch dem naiven Antihelden von Nicolai in der "Humoristischen Reise« wird von seiner fürsorglichen und zeitgeistbewussten Mutter vor der Abreise in die Residenz empfohlen, bald einen langen Titel anzunehmen ${ }^{212}$.

Über die Vorliebe einiger Westphalen, sich anlässlich der neuen Herrschaft einen neuen Namen zu geben, berichtet außerdem der anonyme Autor der »Entlarvten hohen und geheimen Polizei des zerstörten Königreichs Westphalen«. Über den Polizeiagenten Cerf, genannt Cerfy, weiß er auszuführen:

An dem ganzen Schurken war nur eine komische Seite, dass er nemlich Cerf hieß, und nicht Hirsch - nach seinem ursprünglichen Namen. Hirsch schien selbst darüber $\mathrm{zu}$ erröthen, was Cerf gethan hatte und zu thun im Stande war. So weit reichte die Umschaffung der Namen bei der französischen Armee, vom Marschall an bis auf den gemeinsten Spion ${ }^{213}$ !

Seinen Angaben zufolge wurde insbesondere im Militär die Französisierung der bürgerlichen Namen praktiziert, um die Anpassung an die neuen Herrschaftsverhältnisse zu akzentuieren. Diese Praxis scheint an sich nicht neu gewesen zu sein. Wolffradt berichtet in seinen "Denkwürdigkeiten« über einen französischen Emigranten aus dem Elsass am Braunschweigischen Hof, Montjoie, der auch Frohberg genannt wurde ${ }^{214}$.

Manche Französisierungen von Familiennamen gingen auf die Schwierigkeiten zurück, welche die französischen Einwanderer mit der Aussprache deutscher Familiennamen hatten: »Leste - so nannte der König immer

210 LYNCKER, Historische Skizzen, S. 88.

211 Ibid.; vgl. KIRCHEISEN, König Lustig, S. 86.

212 Vgl. HILARIUS, Humoristische Reise, S. 52.

213 ANONYMUS, Die entlarvte hohe und geheime Polizei, S. 113.

214 [WOLFFRADT], Denkwürdigkeiten, S. 394. 
v. Lehsten $\aleph^{215}$. Die Französisierungstendenzen der Zeitgenossen beschränkten sich sicherlich nicht nur auf die Familiennamen. Die Memoiren, die zur westphälischen Zeit entstanden, sind reichlich mit französischen Einsprengseln versehen ${ }^{216}$.

Wenn die deutschen Familiennamen freiwillig oder aus staatlicher Veranlassung französisiert wurden, erscheint jedoch interessant, dass sich auch die Franzosen über ihre Namen und Titel anpassten und dies durchaus die Aufmerksamkeit der Zeitgenossen auf sich lenkte.

\subsubsection{Eindeutschung von Personennamen und Persiflage}

Im Gegenzug zu diesen staatlichen und nicht-staatlich betriebenen Französisierungsmaßnahmen fällt auf, dass auch eine Art Verdeutschung der französischen Einwanderer stattfand. Jérôme versah seine Günstlinge gern mit deutschen Adelslehen und -gütern und auch mit den dazugehörigen Titeln. Die arrivierten Franzosen zeigten Gefallen daran, sich über ihre neuen Namen und Titel westphälisch zu assimilieren. Da sie der neuen Staatsgründung zum Teil ihren neuen unverhofften Wohlstand verdankten, überrascht die ostentative Annahme ihrer neuen Namen nicht weiter. Losch schreibt dazu retrospektiv:

Die meisten dieser Franzosen wurden übrigens durch Titelverleihungen zum Schein deutsch frisiert, da Jerome nach seines Bruders Vorbild in seiner Umgebung eine neue Aristokratie zu schaffen suchte, die allerdings kein langes Leben hatte. Von all den Grafen und Baronen von Wellingerode, Bernterode, Marienrode, Retterrode, Freudenthal, Riede, Keudelstein, Hoene usw. ist längst keine Spur mehr vorhanden. Nur ein Name hat sich in den Gothaischen Kalender gerettet und existiert noch fort. Die Nachkommen des Pierre Alexandre Le Camus leben noch heute als preußische Grafen von Fürstenstein in Schlesien ${ }^{217}$.

Über die Titelvergabe innerhalb der Hofgesellschaft machte man sich auch seinerzeit lustig, weil die französischen Günstlinge Hofnamen annahmen und sich damit zierten, aber oft selbst kaum in der Lage waren, diese auszusprechen ${ }^{218}$. Oder man spielte kritisch darauf an, dass die neuen Titel der französischen Emporkömmlinge bloß leere Versprechungen darstellten:

So ward nun Allix auf der Stell'

Gemacht zum Graf im eignen Fell,

Und zwar genant von Freudenthal,

Dieweil war Freude überall.

Doch ist er in dem ganzen Land

Nur Graf von Jammerthalgenannt,

215 [LEHSTEn-DingelSTÄDT], Am Hofe König Jérômes, S. 10.

216 Die Bedeutung dieses Phänomens ist schwer ohne einen Vergleich mit der Zeit vor 1807 und nach 1813 und ohne eine systematische syntaktische Erhebung einzuschätzen. Vgl. z. B. HAUSMANN, Erinnerungen, 1873, S. 43 f.

217 LosCH, Kfm. Hessen, S. 53.

218 Vgl. KIRCHEISEN, König Lustig, S. 77. 
Und dazu Königs-Lieutenant,

Der's Stellvertreten bass verstand ${ }^{219}$.

Die spöttische Umtaufe scheint nicht allein auf Schellers Reimbedürfnis zurückzugehen, sondern tatsächlich zu westphälischer Zeit Verbreitung gefunden zu haben. Interessant ist in dieser Hinsicht auch zu verzeichnen, dass nach 1813 eine Eindeutschung der französischen Überbleibsel der westphälischen Herrschaft stattfand. In seiner »Jeromiade « verwendet beispielsweise deren Autor Scheller eine breite Palette von Namen für das ehemalige Staatsoberhaupt König Jérôme. Dabei pflegt er insbesondere die französische Variante mit den Akzenten zu meiden. Der abgesetzte Monarch heißt da »(Herr) Jerum «, sogar gelegentlich »Jerum Malapart« oder auch »Jerom « aber niemals französisch » Jérôme «220.

Die Eindeutschung von französischen Termini und die Wortspiele mit diesen eingedeutschten französischen Ausdrücken stellen eine interessante Erscheinung dar, die die Fähigkeit der Zeitgenossen zeigt, der Allgegenwärtigkeit des Französischen satirisch zu begegnen und es sich so anzueignen. Wer spielerisch mit der französischen Sprache umging, konnte diese nicht nur als bedrückend empfinden. Die bereits oben erwähnte latente Sprachdominanz war eine komplexe und sicherlich auch sehr subjektive Angelegenheit. Wenn die Sprachdominanz durch das Französische und die Franzosen in bestimmten Situationen als durchgreifend empfunden wurden, so waren die Westphalen auch in der Lage, sich sprachlich zu wehren. Ihre Kritik artikulierte sich zum Teil ganz konkret in einer spöttischen Umwandlung eines unbeliebten französischen Wortes. Über ein Tedeum, das gegen Ende der westphälischen Herrschaft als Reaktion auf die kriegerischen Auseinandersetzungen oftmals verordnet wurde, brachte der Autor der "Jeromiade " folgendes Wortspiel in seinen Versen zustande, das unter den Zeitgenossen gängig gewesen zu sein scheint: »Wenn's nach dem Treffen hiess ein Dreh-um «221. Dem Tedeum vermochte Scheller wirklich nichts Gutes abzugewinnen: »Was man auch nannt' ein Te-dreh-um, Und öfters Te Diabolum ${ }^{222}$. Zu den letzten Reaktionen Jérômes auf die bevorstehende Auflösung der westphälischen Herrschaft zählt Scheller:

Schon commandirt' er ein Te Deum,

Doch es erfolgt ein lustig Dreh-um,

Als siebzehn Landwehrmänner kamen

Dahergesprengt in Gottes Namen.

Ihm blieb im Hals's Te Deum stekken,

Als man begann 's Gewehr zu strekken ${ }^{223}$.

219 SCHELLER, Jeromiade, S. 280.

220 Ibid., S. 152.

221 Ibid., S. 190, vgl. S. 201.

222 Ibid., S. 246.

223 Ibid., S. 252. 
Der Einfallsreichtum Schellers zur Persiflage eines französisch-kaiserlichen Brauchs korrespondiert mit der Unbeliebtheit, mit der die staatlich einberufenen Tedeum im Jahre 1813 von der westphälischen Bevölkerung aufgenommen wurden. Thimme berichtet, wie die Hannoveraner während eines Gottesdienstes schlagartig ihre Kirche verließen, als man zum Tedeum übergehen wollte ${ }^{224}$. Deswegen dürfte anzunehmen sein, dass auch die Westphalen über die Tedeums sprachlich ihren Spott ausschütteten und nicht allein Scheller im Jahre 1814. Über die Eindeutschung von französischen Termini und Ausdrücken und die anspielungsreichen Wortspiele, die damit entstehen konnten, eröffnete sich für die Westphalen eine Möglichkeit zur Persiflage der Sprachdominanz.

\subsection{Bereitschaft zur Aneignung der französischen oder deutschen Sprache}

$\mathrm{Zu}$ den Indizien, die dafür sprechen, dass das Verhältnis der deutschen und französischen Sprache im Königreich Westphalen auf eine Dominanz des Französischen über das Deutsche hinauslief, zählt sicherlich, dass die Bereitschaft zur Aneignung der französischen Sprache bei Deutschsprachigen offenbar weit ausgeprägter war als die Bereitschaft von Französischsprachigen zum Erlernen der deutschen Sprache. Im ersten Gesang der "Jeromiade « wird dieses Ungleichgewicht in der Bereitschaft zum Erwerb der Sprache der Anderen sehr gerügt:

Im voraus hatten wir, o Schmach!

Verlernt zu sprechen Deutsche Sprach', Und waren durch Sprechmeisterlein Gelehrt zu schwatzen zierlich fein Mit Nas' und Gaum ein Mengelmus, Das selbst der Kaiser Carolus Der Gross' die Bauernsprache nannte, Und sie von seinem Hof verbannte, Ein Schnack zweideutig, arm, voll Zoten, Und von der Dichtkunst streng verboten, Voll Misslaut, sonder Saft und Kraft, Drum leicht gelernt und angeschafft, Damit der Welschling sonder Müh' Fand' Atzung- Weg- und Weiber- hie, Die er ansonst nicht finden könnte, Weil die Natur ihm nicht vergönnte $\mathrm{Zu}$ lernen eine andre Zunge, Als die gefasst der kleine Junge! So musst' man uns das Fransche lehren, Damit wir Frankenknechte wären, Und unsre Weiber ihre Metzen, Und man uns könnt' nach Willkür hetzen ${ }^{225}$.

224 Vgl. Thimme, Die inneren Zustände, Bd. 2, S. $191 \mathrm{f}$.

225 SCHELLER, Jeromiade, S. 8. 
Die Trägheit der französischen Einwanderer bezüglich des deutschen Spracherwerbs wird hier argwöhnisch beklagt und bespöttelt, während demgegenüber betont wird, dass die Deutschsprachigen durchaus bemüht waren, sich in der französischen Sprache zu verständigen. Ein anderer Zeitgenosse, der weniger scharf urteilt, hebt jedoch mit einiger Übertreibung ebenfalls die große Bereitwilligkeit der Deutschen hervor, die französische Sprache zu erlernen:

Ueberdies fanden die Franzosen bei ihrer Ankunft schon viele, die von jeher die größte Vorliebe für sie gezeigt, die ihre Cultur, ihre Sprache und Sitten angenommen hatten, denen es schwer wurde, die Sache ihres Volks zu ihrer eigenen zu machen, und die es daher mitten in dem blutigen Kampfe für Freiheit und Selbstständigkeit nicht über sich bringen konnten, sie für Feinde anzusehen ${ }^{226}$.

Bereits im Kapitel B II. (Spracherwerb) konnte deutlich gemacht werden, wie die deutschsprachigen Westphalen sich bemühten, die französische Sprache zu erlernen. Einige solcher Bemühungen machte der Autor der »Jeromiade« zum Gegenstand seiner spöttischen Verse, so bei seiner Beschreibung der Aufnahme Jérômes durch die Braunschweiger ${ }^{227}$.

Über den allgemeinen Umschwung zugunsten der französischen Sprache berichtet auch der zeitgenössische Marburger Historiker Johann Friedrich Ludwig Wachler, nicht allein für das Königreich Westphalen:

Auch fingen Einige an, ihre herrliche, reiche, mannhafte, hochgebildete und hoher Fortbildung fähige Muttersprache zu verachten und zu vernachlässigen. Französisch lernten Alte und Junge; französisch sprechen und schreiben können, galt bey Vielen als höchste Empfehlung. Die flachen, schaalen Reimereien der Franzosen wurden mit Bewunderung von Leuten, die vornehm und geschmackvoll hießen, erhoben; und unsere vaterländische Dichter voll Kraft und Gehalt als Halbwilde herabgesetzt. In den Rheingegenden hörte der Reisende zu seinem Erstaunen mehr Französisch als Teutsch sprechen; und in den Unterrichts-Anstalten der ehrwürdigen Hanse-Städte an der Ostsee sollte auf höchsten Befehl die edle Muttersprache durch die französische verdrängt werden ${ }^{228}$.

Wachler beanstandete vor allen Dingen, dass das Interesse für die französische Sprache bei den Deutschsprachigen mit der Missachtung der eigenen Sprache einherging. Ein Bericht des Präfekten des Leinedepartements, Friedrich Alexander Freiherr von Hövel an Siméon bestätigt die Offenheit der Deutschsprachigen für die französische Sprache, die von den Franzosen nicht erwidert wurde:

Les Allemands conaissent assez generalement la langue et la littérature françoises ils imitent les modes de cette nation et ses usages. Ils voïagent beaucoup en France,

226 WAGENER, Das Königreich Westphalen, S. 27.

227 Vgl. SCHELLER, Jeromiade, S. 93, 159.

228 [Johann Friedrich Ludwig WACHLER], Ernste Worte der Vaterlandsliebe an Alle, welche Teutsche sind und bleiben wollen, o.O. November 1813, zitiert nach: SPIES (Hg.), Die Erhebung gegen Napoleon, S. 344. 
et il n'y a pas peut-etre une assertion plus vraïe que celle que les principes ont fraié le chemin aux François à l'influence qu'ils ont en Allemagne aussi bien que leurs armes. - j'ose donc dire que les Allemands jugent les françois avec le moins de prevention possible entre deux nations differentes. Les françois au contraire qui ignorent ordinairement l'allemand me paraissent plus sujets de juger les allemands moins equitablement: et je ne cacherai pas que c'est ça qu'on leur reproche le plus. Pour le reste les préjugés nationaux ne restent que rarement sans influence quelconque. Il est par exemple tres naturel que chaque nation desire de voir emploier chez elle le moins des etrangers poissibles. On ne se cache pourtant pas en Westphalie qu'on y a besoin d'un certain nombre des françois pour faire aller et introduire les formes françoises; et la remarque generale que les nations ne sont jamais jalouses des etrangers d'un merite reconu et distingué qu'on fait entrer chez elles, est encore un fois prouvée par les dispositions qu'on trouve chez nous ${ }^{229}$.

Die Aufgeschlossenheit der Deutschsprachigen gegenüber der französischen Sprache kontrastiert in diesem Quellenzitat mit der Sturheit der Franzosen, die für gewöhnlich weder die deutsche Sprache beherrschten noch die Offenheit besaßen, sich in ihrer Begegnung mit Deutschen von nationalen Vorurteilen zu lösen. Nach Ansicht des Präfekten Hövel stellte die Beherrschung einer fremden Sprache, selbst in Grundzügen, einen wesentlichen Zugang zu einer anderen Kultur dar und denjenigen, die sich gegen das Erlernen einer anderen Sprache versperrten, blieb auch die dazugehörige Kultur unzugänglich. Wie Hövel, der vor der Anstellung von inkompetenten Franzosen in der Verwaltung warnt, beklagten sich Zeitgenossen über die Franzosen, die Ämter im neuen Verwaltungsapparat bekleideten, ohne dabei Anstrengungen zu zeigen, Grundkenntnisse der deutschen Sprache zu erwerben ${ }^{230}$. Auch die Historiker wissen über unzählige Franzosen zu berichten, die sich nicht einmal bemühten, Deutsch zu erlernen ${ }^{231}$. Dass »die fremden Sprachen [von jeher] nicht die Liebhaberei der Franzosen « gewesen sind, wird für das revolutionäre Zeitalter in einem anderen Kontext als beständiges Merkmal beschrieben ${ }^{232}$.

Einige Beispiele können jedoch herangezogen werden, die dieses pauschale Urteil und die damit verbundene Beschränktheit der Franzosen abmildern. Der Staatsgefangene Becker berichtet über einen Franzosen, der mit ihm um die 20 bis 25 Verhöre in der Zitadelle in Magdeburg führte:

Allein schon beym dritten oder vierten lebte in mir die Hoffnung wieder auf, daß meine Unschuld über die wider mich bey dem französischen Gouvernement ange-

229 GStA PK, V. HA, Nr. 1338, Bl. 25-30: Bericht von F. A. Freiherr von Hövel, Präfekt in Göttingen, Leinedepartement, an J. J. Siméon, 4. 8. 1808.

$230 \mathrm{Vgl}$. AnONYmus, Die entlarvte hohe und geheime Polizei, S. 30, 42; [MIERZINSKY], Erinnerungen, 1843, S. 54; Hellmuth, zitiert nach: CRAMER, Geschichte des Königreichs Westphalen, S. 88 f.; Reinhard über Siméon, zitiert nach: THIMME, Die inneren Zustände, Bd. 2, S. $69 \mathrm{f}$.

231 Vgl. Thimme, Die inneren Zustände, Bd. 2, S. 260; vgl. ferner KirCHEISEN, König Lustig, S. 77, 86, 96; KoHL, Die Verwaltung der östlichen Departements, S. 36.

232 LANG, K. Fr. Reinhard, S. 387 f. 
brachte Verläumdungen obsiegen könne: weil ich in meinem Inquirienten einen sehr rechtschaffenen Mann erkannte, der mit der strengsten Gewissenhaftigkeit in Beobachtung seiner Amtspflicht Liebe zur Wahrheit und Gerechtigkeit verband, und dabey hinreichende Kenntniß der deutschen Sprache und Literatur besaß, um den Gegenstand der Untersuchung im rechten Lichte zu sehen ${ }^{233}$.

Beckers Vorstellungen stimmen mit den schon eben zitierten des Präfekten Hövel überein: Das Bemühen um sprachliche Verständigung in einer fremden Sprache war in den Augen der Zeitgenossen ein wichtiger Schritt hin zu gegenseitiger Verständigung und Achtung.

Ein anderer Franzose, der seine Anstrengungen beschreibt, die deutsche Sprache zu erlernen, ist der bereits zitierte französische Sprachlehrer Devoluet. In seinem Brief, der durch seine Länge und Ausführlichkeit als Quelle den Rang eines Selbstzeugnisses verdient, bezeugt er viel Interesse am Erlernen der deutschen Sprache ${ }^{234}$. Er bestätigt jedoch auch, dass das Französische in Kassel dominierte: "Au milieu de ces occupations j'avais appris l'Allemand, sans maître et d'une manière assez profonde. Je l'ecris mieux que je ne le parle. Je n'ai pu m'exercer dans une ville où tout le monde parle français ${ }^{235}$.

Das Ungleichgewicht im Interesse für die Sprache der anderen ist ein Hinweis darauf, dass die französische und die deutsche Sprache nicht den gleichen Stand in der westphälischen Gesellschaft hatten und eine latente Sprachdominanz des Französischen über das Deutsche allgemein spürbar war.

\subsection{König Jérôme und seine deutschen Sprachkenntnisse}

Ein Aspekt, der in Bezug auf das Sprachenverhältnis im Königreich Westphalen als äußerst negativ von den Zeitgenossen empfunden wurde, war die fehlende Beherrschung der deutschen Sprache durch das Staatsoberhaupt, König Jérôme selbst. Auf den Antrag auf Beibehaltung der deutschen Sprache durch einen Ausschuss von westphälischen Deputierten in Paris im Dezember 1807 erwiderte Jérôme, »wegen der Sprache wollte er, so schwer dies sei [...], willfahren und er selbst würde binnen drei Jahren Deutsch lernen was er nie wahr gemacht hat! «36

233 BECKER, Leiden und Freuden, S. 60.

234 Vgl. GStA PK, V. HA, Nr. 2300, Bl. 17 f.: Schreiben von Devoluet an J. C. von Leist, 24. 1. 1813.

235 Ibid. Über die Dominanz des Französischen in Kassel schreibt Lyncker angesichts der zahlreichen französischen Einwanderer: »Kein Wunder, wenn man in der Residenz schon nach Verlauf eines Jahres außerhalb der Familienkreise fast mehr französisch als deutsch reden hörte«. LYNCKER, Historische Skizzen, S. 88.

236 KLEINSCHMIDT, Geschichte des Königreichs Westfalen, S. 10; vgl. ferner LYNCKER, Historische Skizzen, S. 82; FABRE, Jérôme Bonaparte, S. 73. 
Trotz seines Versprechens sollte er jedoch nie die Neigung verspüren, Deutsch zu erlernen. Dies wurde von seinen Untertanen durchaus wahrgenommen und erzeugte bei ihnen Unsicherheit und Verärgerung. In den Berichten einiger Verwaltungsbeamter über die öffentliche Meinung wird das Unbehagen der westphälischen Staatsbürger über die Verständigungsschwierigkeiten mit ihrem Monarchen regelmäßig wiedergegeben. Im Bericht des Präfekten des Werradepartements vom Juli 1808 heißt es explizit:

On reconnoit généralement les bontés et les vues justes du Roi, et on manifeste le désir qu'il soit en rélation plus proche avec ses sujets; ce désir est occasioné par l'usage qui existoit jadis, que chaque sujet pouvoir s'adresser au souverain et démander une audience chez lui. Les gens du peuple se plaignent qu'ils ne pourront parler avec le Roi, faute de connaître la langue françoise $e^{237}$.

Auch der Präfekt in Heiligenstadt meldete ähnliche Hoffnungen der Bewohner des Harzdepartements:

ein Fürst aus ihrer Nation <wäre ihnen> nicht so lieb gewesen, als ein französischer Prinz. [...] Nur das bedauern die Unterthanen, daß sie demselben diese Gesinnungen nicht in ihrer Nationalsprache zu erkennen geben können; indessen <freuen > sie sich der Hoffnung, diesen Wunsch in der folge erfüllt zu sehen, da die Meinung allgemein ist, daß Seine Majestät die deutsche Sprache erlernt ${ }^{238}$.

Gerade in diesem Bericht wird vermittelt, dass die Westphalen bereit waren, die neuen Herrschaftsverhältnisse zu akzeptieren und die französische Nation zu verehren. Ihr einziger Zweifel an der westphälischen Verfassung soll allein in den Verständigungsschwierigkeiten mit ihrem Staatsoberhaupt gelegen haben. Quellenkritisch muss dahingestellt bleiben, ob der Präfekt nicht den apolitischen Charakter seiner administrés forciert hat, um selbst einen guten Eindruck in Kassel zu hinterlassen.

Wenn sich anfänglich die Kritik in der Form einer Sorge oder einer Hoffnung auf baldiges Erlernen der deutschen Sprache durch das Staatsoberhaupt äußerte, so wurde aufgrund der Nichteinlösung von Jérômes Versprechen die zeitgenössische Kritik immer lauter ${ }^{239}$. Reinhard, der Vertreter des Kaiserreichs Frankreich am westphälischen Hof, soll geäußert haben: »Der König [hat] sich [nicht] damit beschäftigt [...], sich die deutsche Sprache anzueignen, und verweigert ihr also ihren schönsten Triumph $\aleph^{240}$. Napoleon scheint ebenfalls diese Ansicht geteilt zu haben, denn er ließ sei-

237 GStA PK, V. HA, Nr. 1338, Bl. 6-17: Bericht von G. J. G. A. von Reimann, Präfekt in Marburg, Werradepartement, an J. J. Siméon, 16. 7. 1808.

238 Ibid., Bl. 36-45, Bericht von A. H. von Trott zu Solz, Präfekt in Heiligenstadt, Harzdepartement, an J. J. Siméon, Aug. 1808.

239 Vgl. die bereits oben zitierte Predigt des Pfarrers Gundelach aus dem Jahre 1810: zitiert nach: ANONYMUS, Die entlarvte hohe und geheime Polizei, S. $161 \mathrm{f}$.

240 Reinhard, zitiert nach: GOECKE, Das Königreich Westphalen, S. 113. 
nem Bruder im Jahr 1811 bestellen, er bedauere, dass Jérôme »sich nicht mehr verdeutsche ${ }^{241}$.

Ein anderer Zeitgenosse, der Jurist Cramer, schreibt in seiner »Geschichte des Königreichs Westphalen« über den König Jérôme und seine Sprachkompetenzen:

Die Rede des Königs [bei der Eröffnung der Reichsstände] ward mit der lebendigsten Bewegung und mit allgemeinen Beifall aufgenommen (ob sie gleich von dem Drittheil der Repräsentanten verstanden wurde; denn sie ward, da der König der Deutschen Sprache nicht mächtig war, und die Sprache seines Volkes nie zu lernen sich die Mühe gab, in Französischer Zunge gesprochen) ${ }^{242}$.

Die Kritik am König trifft hier sicherlich auch die beifallgebenden Vertreter der Reichsstände, die der unverstandenen Ansprache zugejubelt haben sollen. Rückblickend wurde jedoch in erster Linie König Jérôme zur Last gelegt, er habe sich um den Erwerb von deutschen Sprachkenntnissen nicht ernsthaft bemüht. Dieses Urteil über ihn avancierte gar in der Memoirenliteratur, die nach 1813 erschien, zum Topos. Es ist auch wieder Cramer, der die fehlende Nähe zwischen Monarch und Untertanen im Zuge der Harzreise des Königs von 1811 unter anderen auf die »Unkunde der Sprache« zurückführt:

Der Weg gieng über Göttingen, Salzgitter, Braunschweig, Blankenburg, Halberstadt, Magdeburg, Halle, Nordhausen, zurück nach Napoleonshöhe bei Cassel, wo der König den 25sten wieder eintraf. Bewillkommnungsreden und Aufzüge, Illuminationen usw. Doch nirgend fand man eine Spur von dem schönen Wunsche der wechselseitigen Annäherung des Regenten und der Unterthanen; jede vortheilhafte Wirkung der Anwesenheit des Königs wurde vernichtet unter dem Gewirr des zahlreichen Gefolges, durch die Unkunde der Sprache, durch die Gesetze der Hofsitte, durch das aus denselben hervorblickenden Mißtraun und durch die Eile der Reise ${ }^{243}$.

Kritisch zeigt sich auch Scheller in seinen Versen, obgleich er über Ausbrüche des Königs in deutscher Sprache durchaus zu berichten weiß:

So fuhr Herr Jerum frisch darein,

Indem er von sich weg ihn stiess:

'Sweik, icke wille nickes wiss',

,Denn icke lustik lebe will!

So sprach Herr Jerum oft und viel

Und's horcht' mit Lust aufs Hohoho!

Der König aus Ajaccio ${ }^{244}$.

Über den selbstgewählten Spitzname des Königs Jérôme, König »Lustig«, kann vielerorts nachgelesen werden. Ihm wird, humorvoll wie er war, fol-

241 Reinhard, zitiert nach: KLEINSCHMIDT, Geschichte des Königreichs Westfalen, S. 438.

242 CRAMER, Geschichte des Königreichs Westphalen, S. 86.

243 Ibid., S. 97 f.

244 SCHELLER, Jeromiade, S. $184 \mathrm{f}$. 
gender Spruch zugesprochen: " Lustig aujourd'hui<, disait-il parfois en prononçant 〉loustic«, 〉lustig demain, lustig toujours « ${ }^{245}$. Dass Jérôme sich wegen einer der wenigen deutschsprachigen Floskeln, die er beherrschte, den Spitznamen verdiente, erwähnt auch Kircheisen: » $\mathrm{Zu}$ den wenigen Brocken, die Jerome von unserer Sprache angenommen hat, gehört das Wort `Lustig، oder wie man es französisch ausspricht `Loustic . Er führte es gern im Munde, und deshalb hat man ihn im Volksmund `König Lustig`getauft $\aleph^{246}$.

Das Thema des Umgangs Jérômes mit der deutschen Sprache zeigt sich durchgehend als besonderer Kristallisationspunkt der Meinungen über ihn: Scheller geht in seinen Versen dazu über, Jérôme doch deutsche Aussprüche anzudichten. So lässt er ihn einige Brocken Deutsch sprechen, als er auf den Spruch eines "Hexenmeisters" reagiert, den dieser in lateinischer Sprache gesprochen hatte ${ }^{247}$ :

,Was spräk sie da?^ hob Jerum an.

O wie erschrak der Zaubermann,

Als hier ging betteln seine Kunst!

Doch fast' er sich, und sprach: >Mit Gunst,

>Ich las nur her ein Zauberspruch. [...]

Er sprachs, und reicht' den Becher dar,

Den Jerum nahm, obgleich er zwar

Nur wenig von der Sprach' verstund,

Und satzt' den Becher an den Mund ${ }^{248}$.

Der Jérôme, den Scheller 1814 beschreibt, spricht die deutsche Sprache nur rudimentär und überrascht damit seine Untertanen, die nicht einmal davon ausgingen, ein Hörverständnis des Deutschen bei Jérôme vorzufinden. Des Weiteren gibt der Autor eine Unterredung zwischen dem König und seinem Leibarzt in Braunschweig zum Besten, als seine Jérômefigur sich im Schloss zu Braunschweig von Geistern verfolgt glaubt:

Und mit ein'm Ach und O begann

Ein' Welsche Zwiesprach' alsodann,

Die mit viel Wunderns mächtig gross

Zuletzt auf Deutsch also sich schloss:

245 FABRE, Jérôme Bonaparte, S. 124.

246 KIRCHEISEN, König Lustig, S. 96. Interessanterweise wird in französischen Herkunftswörterbüchern zu »loustic« meist erwähnt, dass der Ausdruck seit 1762 vom Deutschen, wahrscheinlich von den schweizerischen Regimenten, wo der "lustig" ein »bouffon « - Possenreißer - war, ins Französische übernommen wurde. Damit hat die Bezeichnung nicht alleine eine wortwörtliche Bedeutung; auch die abgewandelte Bedeutung im Französischen trifft auf den Charakter zu, der Jérôme allgemein zugesprochen wird. Es ist nicht mehr auszumachen, ob das Spöttische im doppelten Sinn, das durch die Verwendung des Spitznamens König Lustig erzeugt wurde, auch der Bevölkerung bewusst war. Ein Nebenprodukt der vorliegenden Untersuchung: PAYE, »loustic«.

247 Vgl. SCHELLER, Jeromiade, S. $193 \mathrm{f}$.

248 Ibid., S. 194, 196. 
〉O grosser König, eile fort

$>$ Mit mir aus diesem Geisterort! [...]

>Top! Sprach Jerom, du bist mein Mann,

>Ich nehm' dich zu mein'm Leibarzt an ${ }^{249}$.

Herausragend scheinen die deutschen Sprachkenntnisse des Königs in Schellers Vorstellung nicht gewesen zu sein. Die Bemühung, Jérôme deutsch sprechen zu lassen, rührt möglicherweise von den gleichen Sorgen und dem gleichen Unverständnis her, wie es die Westphalen den Berichten der oben genannten Präfekten zufolge zeigten, weil ihr Monarch kein Deutsch zu erlernen vermochte. Bei Scheller erscheint bemerkenswert, dass Jérôme Deutsch in einer recht umgangssprachlichen Variante spricht: möglicherweise ein verdeckter Hieb auf Jérômes soziale Herkunft.

Während die »kleinen Leute« die Möglichkeit des direkten Austausches durch Audienz bei ihrem neuen Monarchen vermissten ${ }^{250}$, bedauerten ihrerseits die zeitgenössischen Gelehrten und Historiker, dass Jérôme dadurch wichtige deutschsprachige literarische Meisterwerke entgingen: "Jerome selbst lernte nicht deutsch, wie wir oben schon einmal berührt haben; also werden ihm persönlich wohl auch die Schriften Göthes fremd geblieben $\operatorname{sein} \aleph^{251}$.

Und »daß der König dieses im Herzen Deutschlands gelegenen Landes selbst die Sprache seiner Untertanen nicht verstand «, kann Losch auch nicht einleuchten ${ }^{252}$. Der Topos des faulen Königs Jérôme, der kein Deutsch lernen wollte, ist in der Historiographie zum Königreich Westphalen gut vertreten:

Wie er selbst einmal sagte, fühlte er sich ganz als Franzose und haßte die Deutschen und Deutschland und dachte wohl aus diesem Grunde und, da er faul war, nicht dran, Deutsch zu lernen, wie er es doch vor Übernahme der Herrschaft versprochen hatte ${ }^{253}$.

249 Ibid., S. 197-199. Als Leibärzte Jérômes waren zum einen der Franzose Jean Garnier und zum anderen Abraham Zadig tätig. Hier wird wahrscheinlich Letzterer gemeint sein. Vgl. AN Paris, $\mathrm{BB}^{11}$ 68, Demandes d'autorisations pour entrer ou rester au service des puissances étrangères, décret du 26.8.1811, Royaume de Westphalie, Henry-Coll, Dossier Garnier; GOECKE, Das Königreich Westphalen, S. 132; KLEINSCHMIDT, Geschichte des Königreichs Westfalen, S. 57; KiRCHEISEN, König Lustig, S. 59; LOTZE, A. T. Zadig.

250 Gleichwohl demonstrierte Jérôme durchaus Volksnähe: Er hielt pompöse Begnadigungszeremonien $\mathrm{ab}$ und begab sich auch unter seine Untertanen, wie in Marburg oder bei seiner Harzreise. Außerdem setzte er sich für die Öffnung der königlichen Parkanlagen um Schloss Napoleonshöhe für die Öffentlichkeit ein. Vgl. Kapitel B III. (Bittschriften).

251 GOECKE, Das Königreich Westphalen, S. 148.

$252 \mathrm{LOSCH}, \mathrm{Kfm}$. Hessen, S. 51.

253 KIRCHEISEN, König Lustig, S. 96. 
Sicherlich wurde nicht allein Jérôme angelastet, kein Deutsch gelernt zu haben. Anderen hohen Persönlichkeiten der westphälischen Herrschaft wurde dies auch zum Vorwurf gemacht: »König Jerome und manche der höchsten Staatsbeamten [waren und blieben] des Deutschen gänzlich unkundig [...] weder Jerome noch ein Siméon, Eblé usw. habe sich die geringste Mühe gegeben, das Deutsche zu erlernen ${ }^{254}$. In dieses Urteil stimmt auch Kircheisen mit ein: »Ebensowenig wie der König daran dachte, Deutsch zu lernen und sich mit deutschem Wesen zu befreunden, hielt es auch seine Umgebung für nötig, sich der Sprache des Landes zu bedienen « ${ }^{255}$. Hier wird der fehlende Vorbildcharakter des Monarchen kritisiert.

Über Siméon schreibt der westphälische Zeitgenosse Cramer: „So sprach Simeon zu den Reichsständen, deren Mehrzahl, da er in Französischer Sprache redete, gewiß nicht einmal den vollen Sinn der gleißnerischen Worte verstand; und schied dann in Glanz und Pracht aus der aufgehobenen Versammlung ${ }^{256}$.

Über die Sprachwahl vor den Reichsständen oder im Staatsrat, die auf Französisch fiel, unter anderem weil der König kein Deutsch sprach, haben viele Zeitgenossen ebenfalls zurückhaltende Kommentare abgegeben. Ein Historiker schreibt kritisch: »Im Staatsrat wurde nur Französisch gesprochen, und ein jeder, und wenn er auch noch so alt war, musste sich bemühen, sich in der fremden Sprache auszudrücken ${ }^{257}$.

Persönlichkeiten wie der Innenminister Wolffradt, deren Erstsprache Deutsch war, empfanden es zum Teil hemmend ${ }^{258}$, dass im Staatsrat Französisch gesprochen wurde ${ }^{259}$. War diese Hemmschwelle einmal überwunden, war die Kommunikation jedoch deswegen nicht schlechter:

Der König von Westphalen verlangte, dass man während der Deliberation frei und unumwunden reden solle. Dieses bediente ich mich dreist, sowie mancher Andere. Viel hatten wir Deutsche gegen uns; größtentheils ungewohnt, in einer so bedeutenden Versammlung in Gegenwart des Regenten, zu reden, und das in einer fremden Sprache, die den Wenigsten geläufig war, zumal die französische Geschäftssprache und das Alles vis-à-vis von französischen Ministern [...]. Dennoch hörte der König uns gerne, frug, wenn er uns nicht völlig verstand, bestimmter uns unsere Meinung $\mathrm{ab}$, und sicher oft trugen wir den Sieg davon. Wenn ich einmal in einer Angelegenheit, die nicht zu meinem Ressort gehörte, nicht sprach, so forderte der König mich ausdrücklich dazu auf; er glaubte, dass ich einiges Talent besäße, ihm die Sache in der Kürze klar und deutlich vorzustellen ${ }^{260}$.

254 Thimme, Die inneren Zustände, Bd. 2, S. 259.

255 KIRCHEISEN, König Lustig, S. 86.

256 Cramer, Geschichte des Königreichs Westphalen, S. 173.

257 KirCHEISEN, König Lustig, S. 86.

258 Vgl. [WOLFFRADT], Denkwürdigkeiten, S. 65.

259 Vgl. KLEINSCHMIDT, Die Eltern, S. 274.

260 [WOLFFRADT], Denkwürdigkeiten, S. 65 f. 
Mit diesen Ausführungen zeichnet Wolffradt das Bild eines verständnisvollen und um Kommunikation bemühten Königs und mildert damit sein Bild eines an der deutschen Sprache Desinteressierten. Sicher muss quellenkritisch dahingestellt bleiben, ob Wolffradt die eigenen Möglichkeiten der Einflussnahme auf den König im Rahmen der Diskussionen des Staatsrats nicht übertreibt. Aber auch der Staatsrat Heister bestätigt das Bild eines einfühlsamen und geduldigen Jérôme gegenüber den sich schwerfällig in französischer Sprache artikulierenden Staatsräten:

Der König habe jederzeit den Vortrag der Redner im Staatsrate mit Aufmerksamkeit angehört, auch wenn dieser wegen der mangelnden Übung in der französischen Sprache etwas schwerfällig geworden sei. In solchen Fällen habe Jerome selbst den Redner ermahnt, sich Zeit zu nehmen, weil von geborenen Deutschen eine vollkommene Fertigkeit in jener Sprache nicht zu verlangen sei ${ }^{261}$.

Nach Aussage eines anderen Zeitgenossen kann von der mangelnden Bereitschaft Jérômes, die deutsche Sprache zu erlernen, durchaus nicht auf dessen Einstellung zu den Deutschen im allgemeinen geschlossen werden:

Ganz mit Recht macht man dem König den Vorwurf, daß er es nicht der Mühe wert gehalten hat, Deutsch zu erlernen, obgleich er den Deutschen in allem den Vorzug gegeben. Fast alle Franzosen aus seiner nächsten Umgebung entfernte er. Selbst die Kränkung durch Dörnberg brachte ihn nicht von den deutschen Kavalieren zurück, und er würde dies noch mehr getan haben, wenn ihm nicht vom Kaiser von Zeit zu Zeit Franzosen zugeschickt worden wären, und diese musste er behalten. Eine Ausnahme bildet allein der Graf Fürstenstein, früher Le Camus. Er aber hat sich durch seine Vermählung mit einer Gräfin Hardenberg völlig naturalisiert und ist auch später stets in Deutschland geblieben ${ }^{262}$.

Wie weit Jérôme in seinen alltagsbezogenen deutschen Sprachkompetenzen tatsächlich gekommen ist, lässt sich nicht mehr ausmachen. Bei allen zeitgenössischen Kommentaren zu seinen geringfügigen oder nichtexistenten deutschen Sprachkenntnissen wird jedoch deutlich, dass den Westphalen dieses Thema wichtig war. Viele der Memoirenschreiber hatten offensichtlich erwartet, der König werde sich um den Erwerb deutscher Sprachkenntnisse bemühen - und wurden darin enttäuscht. Dies zeugt davon, dass es im Königreich Westphalen nicht gelang, ein Gleichgewicht zwischen den zwei Hauptsprachen herzustellen. Die Westphalen mussten im Laufe der westphälischen Herrschaft am Beispiel ihres Königs erfahren, dass das Erlernen der deutschen Sprache nicht so bedeutsam war wie das Erlernen der französischen Sprache. Indirekt reflektierte die Lebensweise des Königs eine ablehnende Haltung gegenüber der deutschen Sprache, die für die Zeitgenossen eine Dominanz des Französischen über das Deutsche nahe legte. So wurden überspitzte Urteile von Historikern möglich, wie dasjenige von Lyncker:

261 Thimme, Die inneren Zustände, Bd. 2, S. 89.

262 [LEHSTEN-DingELSTÄDT], Am Hofe König Jérômes, S. 30. 
Ein so wunderbares Bild, als die Straßen von Cassel, der Hauptstadt des tapfern Kattenstammes, in dieser Zeit darboten, konnte kaum in Träumen übertroffen werden. Ein fremdes Volk, das anders sprach und anders dachte, das anders fühlte, anders liebte, anders sang und anders tanzte, tummelte sich dominirend darin umher ${ }^{263}$.

\section{Von Sprachbarrieren und sprachlich bedingten Konfliktsituationen}

Wie schwerwiegend bei der beschränkten Anzahl an deutsch-französischen Zweisprachigen mit ausgeglichenen Sprachkenntnissen die Sprachbarrieren für die Kommunikation in der westphälischen Gesellschaft insgesamt waren, lässt sich nur annähernd rekonstruieren. Allerdings wird bei einigen überlieferten Ausnahmesituationen deutlich, dass die deutsch-französischen Sprachbarrieren von dramatischer Folge sein konnten, wie sich beim Brand des landschaftlichen Hauses in Hannover am 8. Januar 1809 zeigte: »durch die zwischen den löschenden Bürgern und dem französischen Militair, wegen Unkunde der Sprache, gleich Anfangs vorgefallenen Unordnungen, [wurde] dem Feuer bedeutenden Vorschub [gegeben] «264. Auch beim Schlossbrand in Kassel am 23. November 1811 begünstigten die Verständigungsschwierigkeiten die Ausbreitung des Feuers. Quellenkritisch könnte jedoch offen gelassen werden, ob nicht die vermeintlichen Verständigungsschwierigkeiten für den Raub von königlichen Gütern herhalten mussten, der beim Schlossbrand verstärkt zu beobachten war $^{265}$.

Wenngleich weniger dramatisch als bei Naturkatastrophen oder Bränden, stellten sich die Sprachbarrieren dennoch auch in anderen Angelegenheiten als entscheidender Störfaktor dar. Für den demokratischen Ablauf der Diskussionen und Stimmenabgaben im Parlament hatten die Sprachbarrieren hemmende und negative Auswirkungen. Der Jurist Cramer berichtet über die Reaktion eines Mitglieds der Reichsstände:

Ein Mitglied der ständischen Versammlung gestand nämlich, dass er von allen den dort [in französischer Sprache] gehaltenen Reden und vorgeschlagenen Gesetzen nichts verstehe, dass er aber wohl ahnde, die getroffenen Maaßregeln führten zum Unglück des Landes. Um nun von seiner Seite das Gewissen rein zu erhalten, höre

263 LYNCKER, Historische Skizzen, S. 84.

264 [MIERZINSKY], Erinnerungen aus Hannover, 1843, S. 53.

265 [LEHSTEN-DingELSTÄDT], Am Hofe König Jérômes, S. 62; vgl. HePPE, Das Schloß der Landgrafen von Hessen, S. 291. Eine Fallstudie über die Auswirkungen und die Thematisierung des Schlossbrandes wäre interessant, da der Verlust dieses deutschen Kulturguts sich teilweise in einer national konnotierten Berichterstattung niederschlug und zudem durch eine darauf folgende Umzugskette in Kassel die Miet- und Besitzverhältnisse der Kasselaner durcheinander brachte. 
er nach dem, was gesprochen und verhandelt würde, gar nicht hin, sondern gebe ein für alle mal eine verneinende Kugel bei der Stimmensammlung ${ }^{266}$.

Die Strategie dieses Reichsständemitglieds, wegen des sprachlichen Unverständnisses sicherheitshalber kategorisch alles abzulehnen, wirkte sicher ernüchternd für die Ausübung der konstitutionellen Monarchie, die das Königreich Westphalen zu sein anstrebte - eine Schlussfolgerung, die Cramer, quellenkritisch gesehen, geneigt war, seinem Leser vorzuschlagen $^{267}$.

Auf der Suche nach Situationen, in denen die Sprachbarrieren von Bedeutung waren und negative Auswirkungen hatten, fallen jedoch nicht nur die deutsch-französischen Sprachbarrieren auf. Die innerhalb der deutschen Sprachgemeinschaft existierenden Sprachbarrieren scheinen ebenfalls beachtlich gewesen zu sein. Der westphälische Fahnenflüchtige Johann Friedrich Ruthe aus Hildesheim verlief sich beispielsweise in der Gegend bei Bernburg, wo er eigentlich den Weg zur Elbe und dann nach Berlin finden wollte, weil er die Leute, die er nach dem Weg fragte, schlicht nicht verstehen konnte ${ }^{268}$. Ähnlich erlebten es Bauern, die 1809 von ihren Verbündeten mit der Verantwortung für einen Aufstand allein gelassen wurden:

Le chef des cuirassiers, qui avait jugé opportun d'attendre le résultat de la rencontre pour se lancer dans la bagarre, fut invité à ramener son détachement au régiment, tandis que les paysans criaient, dans leur patois, inintelligible pour tout le monde, que les cuirassiers étaient leurs complices et qu'il fallait les arrêter aussi ${ }^{269}$.

Ihre Versuche, gerecht behandelt zu werden, fanden kein Gehör, weil sie aufgrund ihres Dialektes nicht verstanden wurden und man deshalb ihren Protest einfach ignorieren konnte.

Die hohe Relevanz dieser innerdeutschen Sprachbarrieren betont auch der Historiker Brakensiek in seiner Untersuchung über lokale Beamte in niederhessischen Kleinstädten. Zu den Voraussetzungen für eine geglückte Kommunikation zwischen den einzelnen Dorfvorstehern und Amtmännern zählt er auf: »Dazu war es erforderlich, dass beide Seiten sich ernsthaft be-

266 CRAMER, Geschichte des Königreichs Westphalen, S. 229. Über eine ähnliche Abwehrstrategie von zwei Bauern aus den Werra- und Saaledepartements, die aufgrund ihres sprachlichen Unverständnisses der Gesetzesvorlagen systematisch eine verneinende Kugel bei Abstimmungen abgaben, berichtet Thimme. In dieser Anekdote, die in der "Minerva" erschien, könnte allerdings Propaganda gegen den Parlamentarismus im westphälischen Staat und gegen die französische Sprache erkannt werden. Vgl. Thimme, Die inneren Zustände, Bd. 2, S. 94. Zum Mitspracherecht der Reichsstände vgl. u.a. OwZAR, Schlendrian, S. 305.

267 Über die Arbeitsweise der westphälischen Repräsentativvertretung vgl. HECKER, Napoleonischer Konstitutionalismus, S.139-146; KNÖPPEL, Verfassung und Rechtswesen, S. 28.

268 Vgl. RuTHE, Auf der Flucht vor den Strickreitern, S. 45.

269 FABRE, Jérôme Bonaparte, S. 138. 
mühten, die sprachlichen und mentalen Barrieren, die sich zwischen Bauern und Gebildeten erhoben, zu überwinden $\aleph^{270}$. Tatsächlich häufen sich in den zeitgenössischen Schriften die Angaben über die auf deutschen Territorien vorzufindenden Dialekte ${ }^{271}$. Über das Trugbild eines homogenen Heiligen Römischen Reichs deutscher Nation mit einer Einheitssprache Deutsch urteilt der Autor der »Humoristischen Reise«, Nicolai, ironisch:

Schon [bald] wirst Du die grobe Lüge des >reich` zugestehn; noch gröber aber erscheint die Lüge, wenn Du Deutschland als >ein Reich verstehe ich nemlich eine Einheit. Findest Du diese aber im deutschen Reich? - Auf meinen Reisen durch Deutschland traf es sich einmal, dass ich an einem Tage, ehe ich noch Nachtquartier genommen hatte, die Ländchenzippel von fünf verschiedenen deutschen Potentaten passirte, und mit einer Gießkanne hätte man in fünf Landen den Wunsch um Regen aufheben können. Ich fand da fünf verschiedene Uniformschnitte, die Kokarden nicht zu vergessen, fünf verschiedene Dialecte, fünf verschiedene Geldcourse, fünf verschiedene Arten von Großprahlerei und Verhöhnung des Nachbars, und fünf verschiedene, jedoch unschädliche, politische Systeme ohne Basis. Hiernach also ist Deutschland wohl eben so wenig ein Reich, als die Ruinen von Herkulanum und Pompeji Städte sind ${ }^{272}$.

Die Dialekte werden neben anderen Faktoren als eine Komponente dargestellt, die der Einheit des Reiches zuwiderlief. Von dieser Satire über die Reichsgedanken einiger seiner Zeitgenossen zum Plädoyer für die Etablierung einer Nationalsprache sind es nur wenige Schritte.

Nuanciert werden muss diese Aussage wiederum durch den Befund, dass sprachliche Verständigungsschwierigkeiten nicht immer als problematisch empfunden wurden. An einer anderen Stelle seiner $» H u m o r i s t i s c h e n ~ R e i-$ se« schildert der Autor eine gelungene Kommunikationssituation, die über Gebärdensprache zustande kam ${ }^{273}$.

Im Gegensatz zu dem, was der Deserteur Ruthe erlebte, wurden sprachliche Verständigungsschwierigkeiten nicht zwangsläufig als Mobilitätshindernis an sich erfahren. Das Beispiel des schon erwähnten Matrosen Williams zeigt dies deutlich: Er zog, ohne ein Wort Deutsch oder Französisch zu sprechen, auf der Suche nach einer Hafenstadt durch Deutschland, wo er Arbeit zu finden hoffte. Seine Verständigungsschwierigkeiten stellten für ihn weder ein Mobilitätshindernis noch ein maßgebliches Handicap $\operatorname{dar}^{274}$.

270 BRAKENSIEK, Fürstendiener - Staatsbeamte - Bürger, S. 347.

271 Vgl. Hausmann, Erinnerungen, 1873, S. 44f.; Hilarius, Humoristische Reise, S. 116; SCHELLER, Jeromiade, S. 186f., 204, 297.

272 Hilarius, Humoristische Reise, S. $15 \mathrm{f}$.

273 Vgl. ibid., S. 127.

274 Vgl. RNB St. Petersburg, F 993 Arch. Westf., K. 17, Nr. 10 717-10 735, hier Nr. 10 719: Schreiben Nr. 586 P. G. von F. T. de Guntz an J. F. M. de Bongars, 15.3. 1813; ibid., Nr. 10 720: Vorbemerkung vom Polizeikommissar Müller zum Verhör von J. Williams, 14.3.1813. 
Bevor auf die Konfliktsituationen, die unmittelbar sprachlich bedingt waren, eingegangen wird, sollte erwähnt werden, wie kulturelle oder sozial bedingte Unterschiede zwischen Personen über die Sprachen hervorgehoben und betont werden konnten. Dies kann anhand einer Anekdote aus den »Erinnerungen « eines zeitgenössischen Hannoveraners veranschaulicht werden. Er berichtet über die Gesellschaften, die General Louis-Alexandre Berthier, der napoleonische Vertreter in Hannover vor der Übernahme des Hannoverschen durch das Königreich Westphalen, auf dem dortigen Schloss veranstaltete: »[Sie] wurden besonders gemieden und fast nur von zweideutigen Frauenzimmern besucht ${ }^{275}$. Über das Auftreten eines solchen »zweideutigen Frauenzimmers« gibt er belustigt einen Wortwechsel zwischen der Dame und einem Diener wieder: "Als eine von diesen bei der Tafel einst von einem alten zur Aufwartung befohlenen Hoflakai verlangte: `Donnez-moi une cuillère`, antwortete dieser: >Ach! Sie kann ok mit de Furschette freten $«^{276}$. Die schlagfertige Entgegnung des erfahrenen Hoflakaien in seinem Hannoverschen Dialekt auf die affektiert französisch redende Dame deutscher Erstsprache lässt ahnen, wie viele Möglichkeiten den Zeitgenossen offen standen, Konflikte durch einen abrupten und/oder dialektalen Sprachwechsel oder einen Wechsel zu einem anderen Soziolekt zu regeln. Der Hoflakai antwortete auf Deutsch unter Verwendung eines französischen Fremdworts und zeigte sich gegenüber der Dame auf diese Art herablassend: Er bedeutete ihr indirekt, wie lächerlich es sei, ihn auf Französisch anzureden, da er selbst Französisch in seinen Grundzügen beherrsche und ihre Tischmanieren zu ihrem beabsichtigten stilvollen Auftreten nicht passen würden. Das Ganze erhielt durch den gewählten Soziolekt »freten « für »fressen « statt dem neutralen Wort »essen « - sowie den Dialekt den Charakter einer rüden Zurechtweisung, die seine grundsätzliche Missachtung des getadelten »Frauenzimmers « verriet, womöglich wegen dessen Anwesenheit am Tisch des französischen Herrschaftsvertreters. Der Gegensatz zwischen dem Hoflakai und der Dame spiegelt sich in ihrem Austausch wider. Der latente Konflikt wurde durch die Sprachwahl deutlich und kam sprachlich in aller Knappheit des Wortwechsels zum Ausbruch. Die Wiedergabe der Anekdote durch Hausmann suggeriert zumindest diese Interpretation.

Die Sprachfronten im Königreich Westphalen verliefen nicht eindeutig, wie vielleicht auf den ersten Blick zu vermuten ist, zwischen zugewanderten französischsprachigen und einheimischen deutschsprachigen Westphalen. Eine solche vereinfachende Sichtweise würde unter anderem die zahlreichen regionalen Dialekte übergehen. Das Gebiet des Königreichs Westphalen 
war schließlich so weiträumig, dass die Existenz zahlreicher innerdeutscher Sprachbarrieren für die Untersuchung relevant ist ${ }^{277}$.

Die sprachlichen Gemeinsamkeiten und Differenzen in der westphälischen Gesellschaft richteten sich nicht unbedingt nach den nationalen Sprachgemeinschaften. Mancher in seinem Dialekt sprechende Bauer musste eher damit rechnen, von seinen deutschsprechenden Mitbürgern nicht verstanden zu werden als diejenigen Franzosen, die in sechs Jahren westphälischer Herrschaft kein Wort Deutsch lernten und sich auf die französische Sprachkompetenzen der höfischen Kreise aus vorwestphälischer Tradition verlassen konnten. Es liegt die Vermutung nahe, dass die regionalen Sprachbarrieren in der Alltagspraxis einen weitaus bedeutenderen Anteil darstellten als die Barriere zwischen französischen >Muttersprachlern` und französischsprachigen deutschen Muttersprachlern.

Die nachfolgenden Beispiele verdeutlichen, wie Sprache und Sprachwahl zum Konfliktauslöser werden konnten. Die Sprachverständigungsschwierigkeiten sollen dazu beigetragen haben, dass die Hannoveraner sich gelegentlich widerspenstig verhielten, was ihre Einquartierungspflicht von französischem Militär anging: "Ein Teil der Misshelligkeiten mag auch auf die Schwierigkeit der Verständigung zwischen den Hannoveranern und den fremdländlichen Soldaten zurückzuführen sein «, schreibt Thimme und zieht zum Vergleich das Beispiel von Lüneburg heran, wo eine bessere Verständigung gewährleistet war und damit auch weniger Konflikte entstan$\operatorname{den}^{278}$. Wie bereits im Zusammenhang mit den privaten Bemühungen der Westphalen um französischen und später russischen Spracherwerb festgestellt werden konnte, erkannten die Deutschen, dass zur Vermeidung von Verständigungsschwierigkeiten und zum friedvollen Auskommen mit den Franzosen oder mit den Russen die Aneignung der jeweiligen Sprachen gehörte. Ohne dass man sich Lynckers Schlussfolgerung anschließen muss, erscheint seine Feststellung eines Ungleichgewichts zwischen den Sprachgemeinschaften trotz der Übertreibung im Kern doch richtig:

Den Franzosen fiel es gar nicht ein, Deutsch zu lernen; auch wagte Niemand sich zu erbieten, denselben Unterricht in der deutschen Sprache zu geben, während die maîtres de langue française sich zu Dutzenden ankündigten und die Buchhandlungen fast nur noch alte und neue Erzeugnisse der französischen Literatur offerirten. So bequemten sich denn die Deutschen, französisch zu lernen, da die Franzosen, trotz des königlichen Versprechens, nicht Deutsch lernen mochten.

Mit dieser friedfertigen Lösung des Sprachconflictes allein war jedoch das Glück Westphalens noch nicht gegründet ${ }^{279}$.

277 Vgl. Goecke, Das Königreich Westphalen, S. 23; THIMme, Die hannoverschen Aufstandspläne, S. 283; KirCheISEN, König Lustig, S. 86; Henne, Innere Mehrsprachigkeit; UlBRICH, Die Bedeutung der Grenzen, S. 156.

278 Thimme, Die inneren Zustände, Bd. 2, S. 394.

279 LYNCKER, Historische Skizzen, S. $84 \mathrm{f}$. 
Wie gestaltete sich nun konkret das Zusammenleben der französischsprachigen Einwanderer und der deutschsprachigen Einheimischen in Streitfällen, selbst wenn letztere mehrsprachig oder geneigt waren, sich an die neuen Herrschaftsverhältnisse anzupassen?

\subsection{Deutsche und französische Sprachgemeinschaften in Kassel}

In vier Stationen soll im Folgenden das Zusammenleben der deutschen und französischen Sprachgemeinschaften mit besonderem Fokus auf Kassel untersucht werden. Zu Anfang soll die Frage nach der Präsenz und der Akzeptanz der französischen und der deutschen Sprache zur königlichen Bibliothek führen. Von dort aus wird ein Einblick in das Theaterleben und insbesondere in die Streitkultur der deutschen und französischen Zuschauer im Théâtre royal genommen. Als weitere Lebenssphäre werden die westphälischen Behörden behandelt sowie die Umsetzung beziehungsweise Abweichung von der Sprachregelung von 1809. Als letzte Station wird dann der Hofgesellschaft besondere Aufmerksamkeit gewidmet werden.

\subsubsection{Streit um die Sprache der Bücher in der königlichen Bibliothek}

Der anonyme Autor der Pasquille »Die entlarvte hohe und geheime Polizei des zerstörten Königreichs Westphalen« berichtet über den angeblichen Ausbruch des Registrators der Kasseler Bibliothek gegenüber einem employébei der Generaldirektion der kaiserlichen Domänen, Thannenberg, der zu einer Denunziation führte. Der Dissens entfachte sich über die Proportionen der französisch- und deutschsprachigen Literatur im Bestand der Bibliothek:

Der Registrator, ein Teutscher, [Herr Enzeroth], soll sich nemlich an den Kaiserl. französischen Schreiber, [Herr Thannenberg], der ein bestimmtes Buch von ihm verlangte, mit folgender unerhörten Antwort versündt haben: >Mein Herr! Wir haben hier nur teutsche Bücher, wird sind Teutsche hier, hier giebt es keine französischen Bücher . Darüber wurde denunziirt und - Enzeroth kann noch von seltener Rechtspflege, von großem Glücke sagen - zwei Mal ein Protokoll aufgenommen. Der Beklagte läugnete es aus dem Grunde, dass er sich lächerlich würde gemacht, und sich selbst widersprochen haben, weil die Bibliothek weit mehr französische, als teutsche Bücher enthielte. Doch wäre er damit nicht losgekommen, wenn der Herr Bibliothekar Murhardt in dem ihm abgeforderten Berichte - ein Beweis, dass man dem Hrn. Enzeroth zu Leib und Brode wollte, nicht zu seinem Vortheil gesprochen, und unter andern ihm nicht das Zeugniß gegeben hätte, dass er nichts weniger als verdächtig oder gefährlich wäre. Hierauf wurde die Klage erst ad Acta geschrieben und die ganze Sache unterdrückt ${ }^{280}$. 
Wenn der Bericht zutrifft, entsprang möglicherweise der Ärger des denunzierten Enzeroth dem Sachverhalt, dass die Literatur im Allgemeinen kaum zu den Bildungsstützen der neuen Kasseler Hofgesellschaft zählte ${ }^{281}$. Reinhard soll auch Goethe gemeldet haben:

Im Uebrigen gehe es uns hier gut genug. Der Kaiser ist, der König scheint mit mir zufrieden. Von der Literatur lebe ich hier ziemlich abgesondert. Für den alten Kurfürsten standen seit der Revolution Bücher in einer Kategorie mit runden Hüten und Pantalons, und an unserm jungen Hof ist der Refrain: >Nous ne lisons guères ${ }^{282}$.

Jérôme wurde sogar nachgesagt, als einziges Buch in seinen sieben Jahren in Kassel die Memoiren einer Maitresse Ludwigs XIV. aus der königlichen Bibliothek ausgeliehen zu haben. Es soll außerdem überlegt worden sein, die königliche Bibliothek in einen Tanzsaal umzuwandeln, mit multifunktionalen Seitenkämmerchen, ganz dem schlechten Leumund des westphälischen Hofes entsprechend. Der hessische Gelehrte Ludwig Völkel berichtet darüber:

Die Bücher wollte man mit Tapeten bedecken, aus den Abteilungen oben und unten, wo die Säulen stehen, kleine Zimmer machen. Wirklich nahm der Schreiner schon die Masse; die edlen Hofherren schritten auf und ab die Länge und Breite. Einer sogar, welcher wissen wollte, was in dem mathematischen Saale neben der Bibliothek wäre, fragte, ob die Instrumente nicht in der Küche zu brauchen wären ${ }^{283}$.

Bemerkenswert erscheint hier, wie das Bildungsdefizit der französischen Einwanderer in ihrem Umgang mit der königlichen Bibliothek hochstilisiert wird. Der Plan einer Umwidmung der Bibliotheksräume zu geselligen Zwecken wurde nicht ausgeführt, doch im Zusammenhang mit den Umbauarbeiten für das Ständepalais sollen dennoch viele Bücher gelitten haben: »Fingerdick bedeckte der Staub die auf der Erde liegenden Bücher", und die Maurer richteten im Bibliothekssaal die Steine her ${ }^{284}$. Bücher wurden nicht zuletzt im entstehenden Chaos entwendet ${ }^{285}$. Diese entrüsteten Ausführungen von Zeitgenossen und Historikern in ihrem Gefolge legen nahe, dass es um viel mehr ging als um eine Konkurrenz zwischen französisch- und deutschsprachiger Literatur in Bezug auf die Bibliothek und die Literatur: Nämlich, dass unter der westphälischen Herrschaft diametral entgegengesetzte Vorstellungen von Bücherpflege und vom Umgang mit Bildungsgütern aufeinanderprallten. Der soziokulturelle Kontrast zwischen den Gebildeten unter den Kasselanern und einigen arrivierten bildungslosen

281 ThIMME, Die inneren Zustände, Bd. 2, S. $316 f$.

282 Reinhard, zitiert nach: GOECKE, Das Königreich Westphalen, S. 146.

283 DUNCKER (Hg.), Eines hessischen Gelehrten Lebenserinnerungen, S. 273.

284 Ibid., S. 280; vgl. S. 281.

285 Thimme, Die inneren Zustände, Bd. 2, S. 319. Weiterführend zum Thema Kunstraub vgl. u.a. Die Beraubung des Museums zu Kassel; WESCHER, Kunstraub; SAVOY, Patrimoine annexé. 
französischen Zugewanderten durchzieht alle überlieferten Anekdoten über die königliche Bibliothek ${ }^{286}$.

Bezüglich der polizeilichen Ermittlung gegen Enzeroth lässt sich nicht eindeutig sagen, ob die oben erwähnte ablehnende Reaktion gegenüber der französischen Sprache und Literatur der Wahrheit entsprach oder lediglich vom Denunzianten erfunden wurde. Die westphälische Polizei entschied sich jedenfalls gegen die weitere Verfolgung von Enzeroth. Unabhängig davon wie der Sachverhalt lag, war die vermeintliche Reaktion des Bibliotheksregistrators zumindest in der Fantasie des Denunzianten denkbar und für die westphälische Polizei eine Untersuchung wert. Es scheint, dass die Spannung zwischen den Sprachgemeinschaften im Königreich Westphalen, also zwischen den französischen Einwanderern und den deutschsprachigen Einheimischen, derart anwachsen konnte, dass der ganze Vorfall der Polizei plausibel erschien. Über die Sprachen zu streiten, in denen die Bücher geschrieben wurden, und darüber seine Abneigung gegenüber der Sprachdominanz des Französischen im öffentlichen Leben zum Ausdruck zu bringen, gehörte durchaus in den Bereich des Vorstellbaren.

\subsubsection{Kasseler Streit- und Theaterkultur}

Exemplarisch sollen im Folgenden zwei Eklats im Théâtre royal in Kassel analysiert werden, die dazu dienen sollen, nach der Rolle der Sprachen in der Konflikteskalation zu fragen ${ }^{287}$. Außerdem soll durch diese beiden Streitfälle im Rahmen von Theatervorführungen und durch einen Exkurs über das Kasseler Theaterleben eine Bestandsaufnahme der sprachlichen Verfasstheit der bürgerlichen Theaterkultur erfolgen: Wie lebten die deutsche und die französische Sprachgemeinschaft in der westphälischen Hauptstadt? Lässt sich aus diesen beiden kurzen Einblicken in das Théâtre royal ein Neben-, Mit- oder eher Gegeneinander ermitteln?

\subsubsection{Vorspann: Zwei Streitfälle im Théâtre royal}

In den Polizeiakten finden sich mehrere Berichte über einen Streit im Théâtre royal zu Kassel, der sich im Februar 1813 abspielte. Bei der Vorstellung am 6. Februar 1813 ereignete sich im parterre noble ein heftiger Wortwechsel zwischen Perrey, chef de la porcelaine du roi und G. Zirges, employé dans les bureaux de la haute police. Am 8. Februar erstattete der Kasseler Polizeipräfekt Mercier Polizeichef Bongars Bericht darüber:

286 In französisch- und deutschsprachige Benutzer der königlichen Bibliothek zu Kassel vermittelt folgende Archivakte einen kleinen Einblick: StA MR, Best. 75 Nr. 1286, Generaldirektion des öffentlichen Unterrichts - Leihgesuche und Ausleihgenehmigungen (Bibliothek zu Kassel), 1810-1813.

287 Vgl. LYNKER, Das Theater in Kassel; FrÖHLICH, Théâtre Royal. 
Il résulte des dépositions [...] du Sr. Zirges, et des Srs. Bony \& Bouvrant Maitres d'hôtel de la Maison du Roi et Zeisse employé à l'intendance du trésoir [...]: que le Sr. Perrez s'étant porté brusquement sur un banc du parterre où se trouvoient placés le Sr. Zirges et une Dame Haberkorn enceinte, qui par ce mouvement a tombé de côté; que le Sr. Perrez, comme voulant la retenir, l'a saisie par son Schall, et que cette action interprétée d'une toute autre manière par le Sr. Zirges qui connaît cette dame, lui a fait lâcher les mots de polisson ou conduite polissonne; qu'alors le Sr. Perrez a saisi au collet le dit Sr. Zirges qui a riposté par un coup de canne là, les voies de fait ont cessé, et les dits Srs. Perrez et Zirges se sont retirés chez eux sur l'ordre de votre E. ${ }^{288}$.

Der Streit wurde offensichtlich durch ein Gerangel um Sitzplätze und durch ein Missverständnis über eine unbeholfene Geste ausgelöst, die aus der Perspektive der einen unanständig gewesen sei, aus der Perspektive der anderen jedoch eine Hilfestellung darstellen sollte. Am Streit scheinen etliche Theaterbesucher beteiligt gewesen $\mathrm{zu}$ sein, obwohl die Variationen in der Schreibweise der Familiennamen aufgrund der oben beschriebenen Tendenzen zur Französisierung und Eindeutschung von Namen über die genaue Anzahl Unklarheit herrschen lassen.

Bemerkenswert erscheint, dass keine Angaben darüber gemacht werden, in welcher Sprache der Wortwechsel stattfand. Die Akte zum Vorfall ermöglicht jedoch, die unterschiedlichen Sichtweisen der Beteiligten zu berücksichtigen, um sich den Vorgang zu verdeutlichen. Polizeikommissar Lang berichtete Mercier am 7. Februar über den Verdruss eines Beteiligten:

[Perrez] se plaignoit des mauvais procédés d'un jeune homme qui étoit resté à sa place. [...] Il déclara [...] être Chef de la Porcelaine de la Maison du Roi et ajouta qu'il vouloit se placer prés de la Loge de Mr. Dalmbert mais que le jeune homme dont sagit le reteint par le collet pour l'en empecher et l'insulta du mot de Polison en lui donnant un coup de poing.

Pendant ces entrefaites, S.E. Mr. le Général de Bongars vint prés de nous pour connoitre les auteurs de ce trouble qui avoit attiré l'attention et les régarde de tout le spectacle, il lui en fut rendu compte.

S. E. m'ordonna de faire sortir aussitôt du Parterre le jeune homme qu'on accussoit être l'agresseur et Elle fut très surprise de reconnoitre en lui un des Employés de ses Bureaux nommé Joerges ou Torerges ${ }^{289}$.

Zirges oder Joerges war also neben Perrey der zweite Unruhestifter im Zuschauerraum des Théâtre royal an jenem Abend. Perrez oder Perrey fühlte sich keineswegs schuldig, sondern vielmehr von dem jungen Mann ungerecht behandelt. Eine wesentliche indirekte Information besteht darin, dass zwischen den Handlungen auf der Bühne die Zwischenhandlungen im Zuschauerraum für kurze Zeit die Aufmerksamkeit der Theaterbesucher auf

288 RNB St. Petersburg, F 993 Arch. Westf., K. 17, Nr. 10 736-10 759, hier Nr. 10748 : Schreiben Nr. 1341 von P. Mercier, Polizeipräfekt in Kassel, an J. F. M. de Bongars, 8.2.1813.

289 Ibid., Nr. 10 751: Schreiben Nr. 61 von H. Lang, Polizeikommissar in Kassel, an P. Mercier, 7.2.1813. 
sich lenkten und alle Blicke sich zum parterre noble wendeten. Eine Zwietracht im Parterre lenkte vom Bühnengeschehen ab und wurde zum Spektakel für alle. Nun griff Polizeichef Bongars persönlich ins Geschehen ein und wies die Streitenden aus dem Theater. In seinem Bericht führte Lang zudem eine Liste von Zeugen an, deren Aussagen teilweise noch ausstanden: Es waren Beauny, maître d'hôtel de la maison du roi, Zeise, employé à l'intendance du trésor, wohnhaft in der Rue Denis beim Schuhmacher Mühlbein, und Emanuel Dalmbert, der zwar alles von seiner Loge aus beobachtet hatte, jedoch wünschte, nicht in die Affäre hineingezogen zu werden ${ }^{290}$. Sich direkt an die schwangere Frau Haberkorn zu wenden, um ihre Version des Vorfalls zu erhalten, kam dem Polizeikommissar allerdings nicht in den Sinn. Währenddessen wurde noch am gleichen Tag Beauny, auch manchmal Bony geschrieben, vom Polizeikommissar Lang angehört:

Est comparu Monsieur Beauny, [...] étant arrivé un peu tard au spectacle il fut obligé de se tenir de bout attendu qu'il se trouvoit beaucoup de monde au Parterre ou il cherchat a se placer, mais qu'ayant remarqué qu'a droite du dit Parterre et devant la Loge de Mr. Dalmbert il y avoit encore deux places non occupées il chercha à passer pour s'y placer, qu'un nommé Mr. Perrey [...] le suivit de près pour occuper la seconde place encore vacante, qu'à peine le comparant étoit assi qu'il entendit derriere lui un jeune homme qui traita à plusieurs reprises le dit Sr. Perrey de Polison, il se retourna pour voir ce qui resulteroit de cette insulte, il vit que Mr. Perrey pris ce jeune homme au Collet pour le faire sortir ${ }^{291}$.

Beauny soll nicht bemerkt haben, wie Perrey die schwangere Dame umgestoßen hatte. Bouverain, ebenfalls befragt, bestätigte Beaunys Angaben ${ }^{292}$.

Die Aussage macht nebenbei deutlich, dass ein reges Kommen und Gehen im Zuschauerraum auch nach Beginn der Vorstellung üblich war. Der pünktliche Einlass war offensichtlich nicht sehr streng geregelt und die $\mathrm{Zu}$ schauer drängten sich zum Teil stehend im Parterre, darunter auch hochschwangere Frauen ${ }^{293}$.

Zirges, selbst einer der Unruhestifter, gab zum Vorfall an:

[Il] déclare - qu'il étoit placé au parterre contre la Loge de Mr. Dalmbert ayant à sa Gauche le Sr. Zeige, Employé à l'Intendance du Trésor et a coté de ce dernier se trouvoit une Dame de sa connoissance, nommé Haberkorn, qui est Enceinte d'aumoins sept mois; qu'entre les deux pieces un individu portant Lunette, chercha a prendre devant lui une place qui se trouvoit vacante et qu'au même moment un autre individu qu'il ne connoissoit pas mais qu'il a appris depuis être Mr. Perrey, chef de la

290 Vgl. ibid.

291 Ibid., Nr. 10 752: Anhörung der Zeugen Beauny und Bouverain, maîtres d'hôtel de la maison du roi, durch H. Lang, 7. 2. 1813.

292 Vgl. ibid.

293 Über geregelten Einlass und Ruhe im Parkett vgl. u.a. CORVIN, Dictionnaire encyclopédique du théâtre; BRAUNECK (Hg.), Theaterlexikon. 
Porcelaine de la Maison du roi, vouloit enjamber la Banquette sur laquelle il étoit debout pour se placer à coté de l'individu à Lunette, dont il est question ${ }^{294}$.

Mit dieser Ausführung wird deutlich, dass die Kasseler Theatergemeinde nicht so überschaubar war, dass alle einander kannten. Man fand seinen Platz im Théâtre royal neben Vertrauten, Bekannten und Unbekannten. Zum Vorfall fuhr Zirges fort:

Le comparant ayant remarqué que Mr. Perrey placoit son pied entre la Dame Haberkorn et le Sr. Zeise d'une manier si forte que cette Dame Tomba entre les deux Banquettes et que Mr. Perrez qui probablement vouloit retenir la dite Dame empoigna son chaal; a cette occasion le Comparant avoie avoir dit à Mr. Perrez qu'il se conduisoit d'une manière Polisonne, celui ci offensé de ce propos voulut donner un coup de point au comparant qui chercha à le parrer en lui disant qu'il ne faloit pas faire de bruit qu'il alloit sortir avec lui, Mr. Perrez le prit au Collet et le comparant ayant cherché à se dégager lui appliqua un Coup de Canne sur l'épaule.

Mr. Perrey ayant été invité par la Gendarmerie de sortir du Par terre, j'ai resté à ma place jusqu'au moment ou le commissaire de police, provis. ma invité de sortir également.

Le Sr. Zirges propose comme témoins de tout ce qui s'est passer, Mrs Mrs Knippel, Brigadier de la Gendarmerie, Mr. Zeise Employé au trésor et le fils de Mr. Schöne demeurant rue royale 295 .

Obgleich der Vorfall viele Zuschauer fand und breite Aufmerksamkeit erregte, waren die Beteiligten offensichtlich bemüht, nicht aufzufallen oder gaben nachträglich vor, dies angestrebt zu haben. Zirges gibt zumindest an, dass er seinem Opponenten gesagt haben soll, "qu'il ne faloit pas faire de bruit ${ }^{296}$. Ob die Ruhe der Theaterbesucher dabei gewahrt oder dem eigenen Ansehen nicht geschadet werden sollte, wird aus der Angabe nicht deutlich. Polizeikommissar Lang machte jedenfalls trotz der Anregung von Zirges keine Anstände, die Zeugenbefragung um die von diesem erwähnten Personen zu erweitern. Vielmehr suchte er nochmals den Nachbarn der Dame Haberkorn auf, um die Umstände des Streites zu erforschen:

Zeise, Employé à l'intendance [...] n'a pas vu que la Dame Haberkorn soit tombée entre les deux Banquettes mais bien sur lui, puisqu'il étoit placé a côté d'elle et que Mr. Perrey avoit occasionné cette chute. Voulant à toute force se placer sur la Banquette devant nous ${ }^{297}$.

»Sur lui«, »devant nous«, der Perspektivwechsel bei seiner schriftlichen Wiedergabe in indirektem Stil des ihm mündlich vorgetragenen Streit-

294 RNB St. Petersburg, F 993 Arch. Westf., K. 17, Nr. 10 736-10 759, hier Nr. 10750 : Anhörung von G. Zirges, employé in den Büros des Polizeichefs J. F. M. de Bongars, durch H. Lang, 8.2. 1813.

296 Ibid.

297 Ibid., Nr. 10 753: Anhörung von Zeise, employé à l'Intendance, durch H. Lang, 8.2. 1813 . 
verlaufs gelang Lang in diesem Fall nicht ganz ${ }^{298}$. Bongars seinerseits verlangte vom Polizeipräfekten, dass der angesehene Staatsbürger Emanuel Meyer D’Alembert, auch Dalmbert genannt, zum Vorfall angehört wurde ${ }^{299}$. Das Protokoll seiner Anhörung, die wenig Neues hervorbrachte, die Beleidigungen bestätigte und den Austausch von Schlägen allerdings ausließ, lieferte Mercier dem Polizeichef am 14. Februar nach ${ }^{300}$.

Zehn Tage darauf ereignete sich erneut ein Vorfall im Théâtre royal, der ebenfalls in die Polizeiakten einging. Die Berichterstattung durch den diesmal bei der Anhörung der Zeugen beteiligten Polizeikommissar Berger gab folgende Auskunft:

[Ci-jointes les] déclaration[s] relativement à l'affaire qui ou pour mieux dire, le différent qui a eû lieu au spéctacle le Lundi 15 [février 1813] entre deux officiers grenadiers gardes et le Commissaire de police soussigné. Savoir.

$1^{\circ}$ Le Sr. [Marius] Salze, [Inspecteur du Garde Meuble de la Couronne], declare que $[\ldots]$, m'étant trouvé à la Comedie au partire noble, et ayant pris place sur un des bancs ayant à ma droite Monsr. Braun, seller, à ma gauche, Monsieur Berger, commissaire de police, [à la] $1^{\mathrm{er}}$ entracte sans quitter nos places pour parler avec les personnes qui se trouvoient devant nous. Deux officiers à notre insue ce sont emparés de ma place et de Celle de Monsr. Braun ${ }^{301}$.

Bei diesem Vorfall müsste es dem Polizeikommissar durch seine direkte Verwicklung in das Geschehen ein Leichtes gewesen sein, die Wahrhaftigkeit der zu Protokoll gegebenen Schilderung zu überprüfen. Salze oder Berger - der Perspektivwechsel ist durch den Sachverhalt nicht leicht nachzuvollziehen - fuhr fort:

Alors Monsieur Berger lui ayant dit qu'elles s'étoient ces fonctions dans ce moment et qu'il l'assuraoi que c'étoit bien la ma place. Il lui a repondu impertinement, je ne vous crois pas plus vous que Monsr. et n'a pas voulu ceder à nos prières. [Pour finir, Berger lui céda sa place].

$2^{\circ}$ Le Sr. <Chretien Friederic $>$ Braun fils - [Sattler in Kassel],

Ich bezeuge ebenfalls, daß sich die obenbemerkte Sache ganz so zugetragen hat, und ich dieselbe Worte des Herren Polizey-Commissair Berger als die der beyden Herrn Grenadier Offiziere gehört habe [...].

$3^{\circ}$ Le Sr. $<$ Hugues $>$ Fogere, [attaché aux Ecuries de la maison du Roi],

il est vrai que Messieurs Braun et Salze estois possesseurs des places qu'ils m'ont $<$ paru $>$ reclamés ${ }^{302}$.

298 Weiterführend über die mehrfachen Übersetzungsvorgänge, die bei einem Zeugenverhör und seiner Protokollierung anfielen, vgl. u.a. ULBRICH, Zeuginnen und Bittstellerinnen; DIES., Shulamit und Margarete, S. 179.

299 Vgl. RNB St. Petersburg, F 993 Arch. Westf., K. 17, Nr. $10736-10$ 759, hier Nr. 10 749: Schreiben Nr. 303 von J. F. M. de Bongars an P. Mercier, 9. 2. 1813.

300 Vgl. ibid., Nr. 10 747: Schreiben Nr. 1366 von P. Mercier an J. F. M. de Bongars, 14. 2. 1813; ibid., Nr. 10 754: Anhörung von E. de Meyer D’Almbert, Hofbankier, durch P. Mercier, 14.2.1813.

301 Ibid., Nr. 10 743: Anhörung durch L. M. A. Berger, Polizeikommissar in Kassel, 18.2. 1813.

302 Ibid. 
Besonders bemerkenswert erscheint an dieser Stelle des Protokolls von Berger, dass er einen Sprachwechsel innerhalb des Dokuments vollzog, angepasst an die Sprachen der jeweiligen Zeugenaussagen ${ }^{303}$. Als vierter Zeuge sollte der »sous-chef de Division à la secrétairerie d'Etat" noch angehört werden:

\section{$4^{\circ}$ Le Sr. <Joseph> Bouisson,}

Je soussigné déclare qu'il est en ma connoissance que M. M. Braun, Salze et Berger, Commissaire de police étant assie au partierre noble du spectacle deux officiers dont les noms me sont inconnues, ces deux derniers se sont emparés des deux places de Mr. Mre. Salze et Braun [et ont] fait beaucoup de difficultés à les leur rendre, que quant à la conversation qui a eu lieut entre le Commis ${ }^{\text {re }}$ de police et les deux officiers, je ne l'ai point comprise attendu que je ne connais point la langue allemande. [...] Boüillon ${ }^{304}$.

In allen Quellenzitaten fällt die sprachliche Anpassung an die neuen Herrschaftsverhältnisse durch die Französisierung der Vor- und Nachnamen auf. Wie bereits bei den Orts- und Personennamen erwähnt, vollzog sich offensichtlich über die gesamte Zeit der westphälischen Herrschaft ein sprachlicher Transfer von deutschen oder französischen Termini in die jeweils andere Sprache. Auch die Anhörungsprotokolle zu den beiden Theatervorfällen demonstrieren diese markante Tendenz der Aneignung der anderen Sprache bei gleichzeitiger Abgrenzung ihr gegenüber.

In den zitierten Auszügen zu den Theatervorfällen fallen zudem Einschübe der zentralen Begriffe auf, die im Rahmen der Ermittlung auftauchten und zum Teil im deutschen Textfluss französisiert wurden, wie »Banquette«. Es entstehen auch Mischformen, die frei aus beiden Sprachen entstanden, wie im Fall des zentralen »chaal« für Deutsch »Schal« der Dame Haberkorn.

Was die Sprachen angeht, fällt außerdem insbesondere bezüglich des zweiten Vorfalls auf, dass allen Angaben zufolge Bouillon oder Bouisson, nur Französisch sprach, Berger und Salze zweisprachig waren oder zumindest neben der deutschen Sprache auch genügend Kenntnisse in der französischen Sprache besaßen, so dass ersterer seinen Bericht in französischer Sprache verfassen konnte und letzterer seine Stellungnahme in französischer Sprache zu formulieren in der Lage war; über Braun kann vermutet werden, dass er kein Französisch beherrschte.

Berger spielte in dem Streit eine vierfache Rolle: Er war einer der Kontrahenten, setzte sich mit seiner Autorität als Polizeikommissar für die Regelung des Konflikts in dessen Verlauf ein, übernahm dabei dolmetschende

303 Für das Rheinland betonte Stein, dass die Führung einer Verwaltungsakte in französischer und deutscher Sprache eine Seltenheit darstellte. Vgl. STEIN, Sprachtransfer durch Verwaltungshandeln, S. 280.

304 RNB St. Petersburg, F 993 Arch. Westf., K. 17, Nr. 10 736-10 759, hier Nr. 10 743: Anhörung durch L. M. A. Berger, 18.2.1813. 
Funktionen und fungierte schließlich als Herrschaftsvertreter, der über die Aussagen der Streitenden Protokoll führte ${ }^{305}$.

Distanziert man sich vom Vorfall und vom Parterre, wo fünf Leute sich um vier Sitzplätze stritten und einige weitere um sie herum Zeugen waren, stellt sich nicht unberechtigterweise die Frage, in welcher Sprache die Komödie auf der Bühne an diesem 15. Februar 1813 gespielt wurde ${ }^{306}$. Wäre sie nämlich in deutscher Sprache aufgeführt worden, hätte Bouillon oder Bouisson wenig von ihr verstanden; war sie in französischer Sprache, was anzunehmen ist ${ }^{307}$, dürfte der Sattler Braun wenig verstanden haben ${ }^{308}$. So blieb ihm wahrscheinlich auch die Zeit, sich in den Streit mit den deutschsprachigen Offizieren einzubringen.

\subsubsection{Theatervorführungen in Kassel: Sprachen und Geschmack}

Die scheinbare Selbstverständlichkeit, mit der Deutsch- und Französischsprachige unabhängig von ihren Sprachfertigkeiten im Théâtre royal miteinander verkehrten und stritten, sollte nicht darüber hinwegtäuschen, dass die Sprache der Theatervorführungen durchaus von Belang für die Zuschauer war, auch wenn Mimik, Gestik, Statisten, Effekte und Kulissen dazu beigetragen haben können, die Zuschauer unabhängig von ihrer Sprachbeherrschung und der ihnen gelegentlich nicht zugänglichen Bühnensprache für das Spektakel zu interessieren.

Zinserling thematisiert in seinen »Denkwürdigkeiten" direkt das Problem der Theatervorführungen in französischer Sprache, deren Text dadurch nicht allen im Publikum verständlich war ${ }^{309}$. Dabei erwähnt er die konvergierenden Faktoren, einschließlich des Sprachverständnisses, die dazu beitrugen, dass das französische Theater in Kassel nicht gleichermaßen von allen angenommen wurde:

Die fremden Deutschen, die sich in Kassel niederließen, von welchen sie herkamen, [hatten] nur Theater im gewöhnlichen Deutschen Geschmack gesehen. Eine Revolution des Geschmacks unter dieser Klasse von dem Französischen Theater, konnte

305 Dieses Beispiel unterstützt den Befund im Kapitel B II. (Spracherwerb), der die Selbstverständlichkeit der Übersetzungsprozesse im Vorfeld des tatsächlichen schriftlichen Verwaltungshandelns herausstellte, so dass in den Polizeiprotokollen selten dokumentiert wird, wer welche Sprache tatsächlich beherrschte und in welcher Sprache aussagte.

306 Über den Spielplan des Théâtre royal in Kassel vgl. FrÖHLICH, Théâtre Royal, S. 171-177.

307 Über die Französisierung des Theaterangebots in Kassel berichtet u.a. ausführlich der Pagenlehrer Zinserling vgl. ZINSERLING, Denkwürdigkeiten, S. 118-137.

308 Vgl. MATTHEIER, Französisch verdrängt Deutsch?, S. 34.

309 Über das Projekt der Französisierung via Theaterprogramm in den annektierten Städten Mainz und Turin vgl. MARKOVITS, »S'approprier les mœurs, les habitudes et la langue française«. 
kein Einsichtsvoller erwarten. Die alten Vorurtheile, der Mangel an Kenntniss der Französischen Sprache und Litteratur, der Franzosenhass und die mit ihm verschwisterte Germanomanie, so wie die Blössen, die das Französische Theater in mehreren Stücken gab, legten einer solchen Revolution unübersteigliche Hindernisse in den Weg $^{310}$.

Einige regelmäßige Kasseler Theaterbesucher sollen sogar »Hass gegen das Französische Theater « empfunden haben ${ }^{311}$, was sich, Zinserling zufolge, unter anderem aufgrund der Zusammenstellung der Schauspielertruppen erklären ließe. Einige »Schauspieler und besonders Schauspielerinnen [verdankten] ihren Ruf nach Kassel nicht ihrem Verdienste, sondern einer besondern Rücksicht [und Hof-Protektionen] «312. Die Abneigung gegenüber dem Theater in französischer Sprache erklärt sich sicherlich auch aus der Verbindung zum Theater in deutscher Sprache: »Diejenigen Deutschen, die ihre Nerven im Deutschen Drama stärker als im Französischen Drama erschüttert gefühlt hatten, triumphirten nun über die Schwäche des Französischen Theaters«, räumt auch Zinserling ein ${ }^{313}$.

Es ist anzunehmen, dass sich einige von der französischen Sprache abgestoßen fühlten, wenn schon die französische Musik von Musikern der königlichen Kapelle und manchen Zuhörern teilweise als Zumutung empfunden wurde $\mathrm{e}^{314}$ :

Auf dem Theater herrschte natürlich die Französische Musik, und die Musiker der Kapelle wussten ihre Verzweiflung nicht stark genug auszudrücken, dass sie dazu verdammt waren, ihre Talente zur Ausführung Französischer Musik missbrauchen zu müssen ${ }^{315}$.

Die Abneigung mancher Kasselaner gegenüber französischsprachigen Theatervorführungen und der Musik französischer Komponisten wird als eine generelle Abwehrhaltung und gereizte Empfindlichkeit gegen das Französische und die Franzosen erkennbar.

Es war nach Zinserlings Aussagen jedoch nicht nur die Tatsache, dass die Theatervorführungen meist in französischer Sprache stattfanden. Einige Schauspieler, wie Bourdais, leisteten ihren Part sogar mit einem provenzalischen Dialekt, auf Grund dessen sie zuvor von der Pariser Komödie verwie-

310 ZINSERLING, Denkwürdigkeiten, S. 137.

311 Ibid., S. 138.

312 Ibid., S. 136.

313 Ibid., S. 134.

314 Vgl. ibid., S. 140-144; vgl. FreI-HAUENSCHILD, Eine europäische Kulturhauptstadt, S. 97.

315 ZINSERLING, Denkwürdigkeiten, S. $141 \mathrm{f}$. 
sen worden waren ${ }^{316}$. Zinserling stellt jedoch über die allmähliche Erziehung des Kasseler Theaterpublikums positiv fest:

Indessen fanden sich doch unter den jungen Leuten und denen, die, durch ihre Verhältnisse mit dem Hofe, mit der Französischen Sprache vertraut geworden waren, mehrere, denen nach und nach die Augen aufzugehen anfiengen. Diese jungen Leute, einige Franzosen und wenige Deutschen Kenner bildeten ein Publikum, das in der letzten Zeit schon einige Feinheiten des Pariser Publikums zeigte. Nur weniger Jahre hätte es noch bedurft, um diesem Publikum Konsistenz und Einfluss zu verschaffen ${ }^{317}$.

Erst durch die Verbindung zum Hofe, die damit vorhandene positive Einstellung und das Erlernen der französischen Sprache konnte sich, Zinserling zufolge, bei einigen geneigten Zuschauern allmählich ein Interesse und eine Empathie für das französische Theater herausbilden.

\subsubsection{Zusammenleben der Sprachgemeinschaften in Kassel: Indizien aus den beiden Theaterstreiten}

Insgesamt suggeriert die durch die beiden besprochenen Streitfälle erfolgte Bestandsaufnahme der sprachlichen Verhältnisse im Theater in Kassel, dass einige Kasselaner vielleicht weniger ins Theater gingen, um Zuschauer der Komödie auf der Bühne zu sein, als vielmehr um am gesellschaftlichen Leben im Zuschauerraum teilzuhaben und sich notfalls mit ihren Nachbarn zu streiten. Das Theatererlebnis scheint durch die Ereignisse im Zuschauerraum an Attraktivität gewonnen zu haben.

Das Protokoll der Anhörung zu dem Vorfall liefert durch seinen Wechsel von der deutschen zur französischen Sprache und zurück zur deutschen Sprache, je nach aussagender Person, exemplarisch ein Beispiel für die Kommunikation in der westphälischen Gesellschaft, in der die tatsächliche Diglossie auf der individuellen Ebene nur einige wenige betraf und sich das Leben dennoch mit dem Nebeneinander der französischen und der deutschen Sprache gestalten ließ. Insbesondere der erste Fall gibt ein Rätsel auf, was die Praxis der sprachlichen Verständigung in der Kasseler Gesellschaft betrifft: Die Polizeiprotokolle werden so geführt, als lebten die Kasselaner in allgemeinem sprachlichen Einvernehmen und es wird nicht mehr thematisiert, wer welche Sprache sprach oder beherrschte $e^{318}$. Die Selbstverständlichkeit des Zusammenlebens der verschiedenen Sprachgemeinschaf-

316 Vgl. ibid., S. 123. Von der Relevanz der Varietätenvielfalt des Französischen, die die französischen Einwanderer mitbrachten, zeugt die Existenz eines spezifisch darauf aufgebauten Sprachwörterbuchs aus dem Jahre 1804, vgl. Wörterbuch für die französische Aussprache, [1804].

317 ZINSERLING, Denkwürdigkeiten, S. $137 \mathrm{f}$. In diesem Quellenzitat lässt sich der Topos von Kassel als »kleinem Paris« erkennen. Vgl. ANONYMUS, Die französische Garküche.

318 Vgl. BURKe, Küchenlatein, S. 16; MATTHEIER, Französisch verdrängt Deutsch?, S. 34 . 
ten, insbesondere in Kassel, wird an diesen Theaterstreitigkeiten deutlich: Alle akzeptierten, dass monolinguale Deutschsprachige sich unter den $\mathrm{Zu}$ schauern einer Theatervorführung in französischer Sprache befanden.

In beiden Streitfällen waren Vertreter der Ordnungskräfte unmittelbar in den Streit involviert. Beim ersten Mal war sogar Polizeichef Bongars persönlich in das Geschehen verwickelt, aber auch der Gendarmeriebrigadier Knippel; beim zweiten Mal spielte der Polizeikommissar Berger eine entscheidende Rolle. Nicht sicher ist, ob diese Herrschaftsvertreter nur zu ihrem eigenen Vergnügen anwesend waren oder amtshalber im Zuschauerraum ihre Plätze einnahmen ${ }^{319}$. Im königlichen Dekret vom 27. Januar 1808 über die Organisation der Polizei in der Stadt Kassel war eindeutig geklärt, dass die »Theater-Polizei« zum Ressort des Polizeipräfekten gehöre, »in so fern sie auf die persönliche Sicherheit und auf die zu Verhütung unangenehmer Vorfälle, und Aufrechthaltung guter Ordnung, sowohl im Innern als von Außen zu treffenden Maaßregeln Beziehung hat « ${ }^{320}$. Wenn sich Polizeichef Bongars, wie beim zweiten Streitfall beschrieben, direkt in das Theaterleben einmischte, so war sein Vorgänger Bercagny nicht weniger eng an das kulturelle Leben in Kassel gebunden: Er agierte zu verschiedenen Zeiten seiner Präsenz in Kassel als Intendant des königlichen Theaters ${ }^{321}$. Der Pagenlehrer Zinserling schreibt dazu:

Bloss während der kurzen Zeit, in welcher Berkagny Intendant des Theaters war, bemerkte man Geschmack und Konsequenz in der Auswahl der Stücke, so wie auch seine Sorgfalt in der Strenge sichtbar war, mit der über die Nachlässigkeiten der Akteurs, die Kapricen der Aktricen und den Eigenwillen der Musiker wachte. Berkagny

319 Auch der westphälische Staatsgefangene Gehren berichtet, dass er bei seiner Ankunft in Mainz in Begleitung von Gendarmen zunächst auf den dortigen Polizeikommissar warten musste, der sich auf einer Theatervorstellung befand, um die Zuweisung zu einem Gefängnis zu erhalten. Vgl. GeHrEn, Dreimalige Verhaftung und Exportation, S. 114. In Kassel musste der Polizeipräfekt zeitweilig die Polizeikommissare an ihre Pflicht erinnern, sich bei den Theatervorstellungen abzuwechseln. Vgl. GStA PK, V. HA, Nr.693, Akte der Hohen Polizei im Königreich Westfalen, Juni 1812-Mai 1813: Rundschreiben Nr. 665 von P. Mercier, Polizeipräfekt in Kassel, an die Polizeikomissare in Kassel, 20. 10. 1812; ibid., Rundschreiben Nr. 1084 von P. Mercier an die Polizeikomissare, 23. 12. 1812; vgl. ferner ibid., Rundschreiben Nr. 701 von P. Mercier an die Polizeikommissare, 26. 10. 1812.

320 Le Moniteur westphalien, Nr. 17, 4. Februar 1808, S. 67: Königliches Dekret über die Organisation der Polizey in der Stadt Cassel, 27. Januar 1808, Art. 7; vgl. auch im Katalog zur Ausstellung »König Lustik!?» den Hinweis auf ein »Réglement général pour les Théâtres de Sa Majesté le Roi de Westphalie, arrêté par S. Ex. M. le Surintendant des Spectacles de Sa Majesté, le 16 Septembre 1812«, vgl. König Lustik!?, S. 99.

321 Vgl. AnOnymus, Die entlarvte hohe und geheime Polizei, S. 45 f.; Thimme, Die inneren Zustände, Bd. 2, S. 179. 
hatte unendlich viel Geist und Geschmack, und die Kenner beklagten das sehr, dass er nur so kurze Zeit die Direktion des Theaters hatte ${ }^{322}$.

Neben der künstlerischen Leitung des königlichen Theaters soll Bercagny auch für qualitativ hochwertige Theaterkritiken im Feuilleton des »Westphälischen Moniteur « verantwortlich gewesen $\operatorname{sein}^{323}$. Die Polizei übernahm offensichtlich auch Aufgaben wie die Gestaltung des Theaterlebens, vorab durch die Intendanz und danach durch Theaterrezensionen. Dazu kam die Zensur und die Polizeiüberwachung im Zuschauerraum, wobei auch das Gerede der Komödianten und Musiker während der Proben in ihrer Kontrollsphäre lag ${ }^{324}$.

Gleich ob sich die Ordnungsträger zum eigenen Vergnügen im Theater befanden oder dienstlich dort waren, sie setzten sich jedenfalls spätestens zu Beginn des Streits als Amtsträger für die Wiederherstellung der Ruhe ein, selbst wenn sie durchaus wie beispielsweise Berger auch Schwierigkeit hatten, sich durchzusetzen.

Insgesamt geben diese Ausführungen über das Kasseler Theaterleben einen interessanten Einblick in das Zusammenleben der französisch- und der deutschsprachigen Gemeinschaft bei kulturellen Anlässen auf der einen Seite und in die Vergnügungs- und Arbeitskultur von Herrschaftsvertretern und Staatsbürgern auf der anderen Seite. Nicht alle Zuschauer kannten sich beim Namen, jeder verfügte über sein eigenes Netzwerk an Bekannten und dennoch lebten sie nah beieinander und erlebten die gleichen Theatervorführungen, ungeachtet ihrer sprachlichen Fähigkeiten und ihrer Möglichkeiten, den Inhalt der Vorstellungen verstehen zu können.

Tatsächlich legen die »Denkwürdigkeiten" des Pagenlehrers Zinserling nahe, dass die Zuschauer eventuell aufgrund des regelmäßig wiederholten Theaterprogramms leichter Zugang zu den fremdsprachigen Aufführungen erhielten: "Opern, wie Une folie, Adolphe et Clara, Picaros et Diego u.s.w. wird man nie zu hören müde, und sie gefielen, der häufigen Wiederholung ungeachtet, auch in der Unvollkommenheit, mit der sie in Kas-

322 ZINSERLING, Denkwürdigkeiten, S. 132.

323 Vgl. ibid., S. 134f.; Le Moniteur westphalien, Nr. 159, 17. November 1810, S. 701, 703 f.: "Le sacrifice d'Abraham " im Théâtre royal. Bedauerlicherweise sind die Feuilletons des »Westphälischen Moniteur«nicht kontinuierlich überliefert.

324 Am 15. Sept. 1813 meldete der Polizeiagent Würz: »Von einem sicheren Mann weiß ich, daß das Orchester im Königl. Theater bey den Proben von Politischen Neuigkeiten unterhält, wobey die Braunschweiger sich hervor thun, und hauptsächlich der Violoncellist Heiligengirt». RNB St. Petersburg, F 993 Arch. Westf., K. 19, Nr. 11 919-12 074, hier Nr. 12 024: Rapport von H. W[ür]Z an J. F. M. de Bongars, 15.9.1813. Weiterführend über das symbiotische Verhältnis von Zensoren und Zensierten vgl. u.a. GERSMANN, SCHROEDER, Zensur, Zensoren, Zensierte. 
sel gegeben werden konnten $\aleph^{325}$. Hier spricht Zinserling zwar Opern an, die für gewöhnlich seltener in deutscher Sprache aufgeführt wurden. Die Tendenz zur Wiederholung dürfte jedoch auf Komödien und Dramen ebenso zugetroffen haben. Sicherlich war es für das Verständnis der Handlungen und Dialoge durch die Zuschauer, deren Erstsprache nicht Französisch war, sehr förderlich, wenn die Stücke wiederholt wurden, außerdem gewöhnte man sich daran und die Stücke gefielen den Zuschauern aufgrund des Wiedererkennungseffekts schon an sich ${ }^{326}$. Zinserling begrüßte auch die regelmäßige Wiederaufnahme des gleichen Theaterstückes:

[Es empfiehlt] sich, in einem kleinen Cirkel von klassischen Stücken herumzudrehen [...]. Die Kenner finden sich bei einem solchen Verfahren befriedigt, und dem Publikum wird auf diese Weise durch die beständige Wiederholung klassischer Stücke der ächte Geschmack angebildet ${ }^{327}$.

Der Hang zur Wiederholung resultierte jedoch nicht unbedingt aus der Rücksicht auf die Zuschauer, deren Erstsprache nicht Französisch war, sondern gehörte auch in französischen Städten zur Praxis. Der Langeweile, die sich dadurch bei regelmäßigem Theaterbesuch einstellen konnte, wurde wahrscheinlich damit begegnet, dass in der Wiederholung gelegentlich Improvisationen entstanden:

Bourdais glänzte vorzüglich in der Rolle des valet fripon. Eine unerschöpfliche Laune, ein unnachahmliches Mienenspiel und ein Fondsvon Witz, der ihn zuweilen verleitete, Calembourgs zu improvisiren, machten ihn in diesen Rollen unübertrefflich. Man sage was man wolle von der Einförmigkeit der Pasquins, Frontins und Carlins der Französischen Komödie. Wie geht es zu, dass diese Rollen von einem Schauspieler, wie Bourdais, dargestellt, nach unendlichen Wiederholungen derselben Stücke noch immer gefallen ${ }^{328}$ ?

Insgesamt mögen die Wiederholungen im Theaterrepertoire und die Treue des Publikums, das sich darauf einließ, sich das gleiche Stück mehrmals anzuschauen, zum Teil erklären helfen, dass auch Personen ohne oder mit geringen französischen Sprachkenntnissen sich französische Theatervorführungen ansahen ${ }^{329}$. Die beiden exemplarisch ausgewerteten Fälle zur Streitkultur des Publikums anlässlich von Theatervorführungen wecken

325 ZINSERLING, Denkwürdigkeiten, S. 121. Die Liste der französischen Schauspieler im Théâtre royal von Kassel und in anderen Ensembles findet man u.a. im »Almanach royal« sowie im »Hof- und Staats-Handbuch des Königreichs Westphalen«: Vgl. Almanach royal de Westphalie, 1811, S. 342-344; Almanach royal de Westphalie, 1813, S. 386; Hof- und Staats-Handbuch, 1811, S. 339-341.

326 [WOLFFRADT], Denkwürdigkeiten, S. 382.

327 ZINSERLING, Denkwürdigkeiten, S. 133. Er bedauerte sogar, dass dies nicht stärker beim Theater in Kassel geschah.

328 Ibid., S. 123.

329 Allerdings sprechen die Angaben Fröhlichs nicht dafür, dass das Theaterrepertoire viele Wiederholungen enthielt. Vgl. FrÖHLICH, Théâtre Royal, S. 177. 
jedenfalls Interesse für das Theaterleben in Kassel. Um die beiden Streitfälle besser zu kontextualisieren, ist ein kleiner Exkurs notwendig.

\subsubsection{Theaterleben in Kassel und in der Provinz}

Widersprüchliche Angaben in Quellen und Literatur verhindern eine eindeutige Aussage darüber, welche Sprache bei den Theatervorführungen überwiegend benutzt wurde. Der anonyme Autor der Schrift »Die entlarvte hohe und geheime Polizei«, der die westphälische Herrschaft in vielerlei Hinsicht kritisiert, klagt auch darüber, dass »einem eroberten und unterjochten Staate im ersten Anfange seine Sprache, seine gewohnten Titel und Schauspiele« genommen wurden und dass "Schauspielen in der Muttersprache « zu verlieren für die Westphalen ein Drama darstellte ${ }^{330}$. Auch der Zeitgenosse F. Müller schreibt, dass es 1810 lediglich ein »französisches Theaterpersonal [gab] - ein deutsches gab es nicht « ${ }^{331}$. Ferner räumt er ein, dass es zu diesem Zeitpunkt keine deutsche Theatertruppe mehr gab: » $\mathrm{Zu}[\mathrm{m}$ Theater] waren die tüchtigsten Kräfte herangezogen. Aber leider war es nur eine französische Anstalt; ein deutsches Theater gab es in Kassel nicht mehr ${ }^{332}$.

Im Widerspruch dazu schreibt der westphälische Page Lehsten-Dingelstädt in seinen Erinnerungen: »Abends [nach der Eröffnung der Reichsstände am 2. Juli 1808] war Freitheater. Es wurde Don Juan deutsch gegeben. Es bestanden damals in Kassel zwei Schauspielertruppen, eine deutsche und eine französische, welche täglich abwechselten « ${ }^{333}$. Der Historiker Kircheisen spricht seinerseits von zwei bis drei wöchentlichen Aufführungen im königlichen Theater in französischer Sprache, wenn der König auf seinem Schloss residierte ${ }^{334}$. Dem Historiker Rudolf Goecke nach erhielt die französische Theatertruppe aufgrund der Qualität ihrer Aufführungen hohen Zulauf, selbst von einheimischen Deutschen, die nicht der französischen Sprache mächtig waren:

Man erfreute sich in Cassel, Magdeburg und anderswo an der Aufführung französischer Stücke durch französische Truppen um so lieber, da ihre Leistungen wohl durchschnittlich besser waren, als die trotz Schiller und Göthe immerhin noch in ihren Anfängen befindliche deutsche Schauspielkunst sie bieten konnte ${ }^{335}$.

330 AnOnYmus, Die entlarvte hohe und geheime Polizei, S. 29.

331 MÜLLER, Kassel seit siebzig Jahren, Bd. 1, S. 30.

332 Ibid., S. 43.

333 [LEHSTEN-DinGELSTÄDT], Am Hofe König Jérômes, S. 18. Fröhlich erläutert, dass die deutsche Schauspieltruppe unter der Leitung von Reichhardt im Laufe des Jahres 1808 allmählich von einer französischen Schauspieltruppe abgelöst wurde. Vgl. FrÖHLICH, Théâtre Royal, S. 165f., 177, 181.

334 Vgl. KirCHEISEN, König Lustig, S. 136.

335 GOECKE, Das Königreich Westphalen, S. 148. 
Der Klage über die schlechten Leistungen der deutschen Schauspieltruppen im Allgemeinen schließt sich der ehemalige westphälische Innenminister, Wolffradt aus der Retrospektive an:

Im Jahre 1806, zur Zeit der französischen Occupation, sah ich in Berlin, an den wenigen Abenden, die ich Zeit hatte das Schauspiel zu besuchen, nur Uebersetzungen von französischen Opern ausführen, deren Darstellung unendlich unter dem war, was ich von der trefflichen französischen Truppe in Braunschweig gesehen hatte. Das Radicalübel bei uns liegt in Hochderoselben richtigen Bemerkung, dass die gute Lebensart und der seine Conversationston nicht bei uns, wie in Frankreich, bis zu denjenigen Classen herabgedrungen ist, aus denen die Schauspieler gewöhnlich hervorgehen ${ }^{336}$.

Der Pagenlehrer Zinserling lobt am französischen Theater gegenüber dem deutschen die klare Trennung der Gattungen, was auf die Spielqualität der einzelnen spezialisierten Schauspieler einen positiven Einfluss habe ${ }^{337}$. Ihm zufolge hatte speziell in Kassel »das Ballet [...] mit der Komödie einen gleichen Grad von Vollkommenheit erreicht « ${ }^{338}$.

Neben dem staatlichen Theatervergnügen, mehrheitlich in französischer Sprache, hielt sich jedoch auch ein deutschsprachiges Theaterangebot in Kassel ${ }^{339}$. Zinserling schreibt dazu: »Durch den Hass gegen das Französische Theater und durch die Begierde, etwas fürs Herz zu haben, erhielt sich ein so genanntes Deutsches Liebhaber-Theater « ${ }^{340}$. Über die Qualität dieses Amateurtheaters lästert er allerdings:

Leute, die in bürgerlichen Verhältnissen standen, und weder Studien noch feine Erziehung hatten, machten die Mitglieder dieser ehrenwerthen Truppe aus, in der ein Mensch, den die Natur zum Schönschreiber und Buchhalter bestimmt hatte, den Ton angab. Wie sich der Mittelstand an solchen jammervollen Darstellung der Kotzebuischen Meisterwerke ergötzen konnte, war kein Räthsel, aber dass selbst Staatsräthe und andere Personen vom Range solche Vorstellungen mit ihrer Gegenwart beehren und Geschmack daran finden konnten, war ein neuer Beweis, wie selten der gute Geschmack in Deutschland selbst unter den höheren Ständen und wohin die Germanomanie zu führen im Stande sey ${ }^{341}$.

Es erscheint bemerkenswert, dass sogar in Kassel einige Stücke von Kotzebue für die deutschsprachige Gemeinschaft gespielt wurden, denn andern-

336 [WOLFFRADT], Denkwürdigkeiten, S. $382 \mathrm{f}$.

337 Vgl. ZiNSERLING, Denkwürdigkeiten, S. 118.

338 Ibid., S. 126. Einschränkend traf er dieses Urteil nur in Bezug auf die unausgewogene Gewichtung der Dramen und Kömodien im gesamten Repertoire (S. 133) und die Abwanderung der Schauspieler vom Stadttheater zum Hoftheater (S. 139f.): »Durch die [...] Vorstellungen [am Hoftheater] litt gewöhnlich das Theater in der Stadt, auf welchem man, in Abwesenheit der vorzüglicheren Subjekte, oft Lükkenbüsser gab «.

339 Weiterführend vgl. MÖLLER, Das Theater als Vermittlungsinstanz bürgerlicher Werte.

340 ZINSERLING, Denkwürdigkeiten, S. 138.

341 Ibid., S. $138 \mathrm{f}$. 
orts im Königreich Westphalen waren solche Theateraufführungen verboten $^{342}$. Der Historiker Goecke berichtet beispielsweise, wie in Halberstadt ab April 1812 selbst Schillers Theaterstücke unter Zensur gerieten und wegen ihres satirischen Charakters und ihrer Gefährlichkeit für die öffentliche Ruhe in die Nähe von Kotzebues Werken gerückt wurden ${ }^{343}$. Eine gewisse Diskrepanz im Theaterrepertoire scheint sich zwischen Hauptstadt und Provinz ergeben zu haben.

Durch das obige Quellenzitat wird außerdem deutlich, dass die Theaterbesuche der Kasselaner, ob sie dem französischsprachigen oder deutschsprachigen Theaterangebot der Stadt galten, einer Parteiergreifung gleich kamen, unabhängig von der Qualität der Inszenierung. Der Gang ins deutsche Theater verband sich mit Staatskritik und das Besuchen französischsprachiger Theaterstücke durch Deutschsprachige bedeutete durchaus auch eine indirekte Loyalitätsbekundung an die neuen Herrschaftsverhältnisse.

Unabhängig davon, ob nun die Aufführungen mehrheitlich in französischer Sprache stattfanden, kann festgehalten werden, dass das Theater besonders in Kassel einen außerordentlichen Stellenwert nicht allein als Vergnügungsort und als Ort der Kommunikation, sondern auch als politisches Bekenntnis genoss. König Jérôme legte sehr großen Wert auf das Theater und scheute daher auch nicht die Ausgaben dafür. Der anonyme Autor der Schrift »Die entlarvte hohe und geheime Polizei« weiß, dass »die Polizei und das Theater die zwei kostspieligsten Branchen der Staatsausgaben « waren ${ }^{344}$. Kircheisen nennt Zahlen: "Das Theater in Kassel kostete den König nicht weniger als 500000 Franken im Jahre. Die Ausgabe stand in keinem richtigen Verhältnis zu den Gesamteinnahmen des kleinen Staates « ${ }^{345}$. Dieser Schwerpunkt in den Staatsausgaben und der Aufschwung des Theaterlebens unter Jérôme wurden auch mit der Errichtung eines neuen Theatergebäudes erkennbar:

Da das kleine Theater in der Löwenburg den Ansprüchen des Königs nicht genügte, so ließ Jerome an der auf der Anhöhe vor dem Marstall liegenden Allee ein neues Theater errichten, in das man vom östlichen Flügel des Schlosses Napoleonshöhe aus durch einen gedeckten Gang gelangen konnte.

342 Ein Hinweis vom westphälischen Justizminister an den Grafen von Fürstenstein, in seiner Zuständigkeit als ministre secrétaire d'état et des relations extérieures für die Beziehungen mit dem Fürstentum Waldeck und Pyrmont verantwortlich, zeigt, dass im Königreich Westphalen auch das Theaterleben im nahen Ausland exakt beobachtet wurde. Siméon meldete, dass in Pyrmont mit dem Wohlwollen des Fürsten von Waldeck im August 1810 von Kotzebue »Schaden ohne Noth, und Noth ohne Schaden« gezeigt wurde. Vgl. SML, A/3441/2009, Schreiben von J. J. Siméon an den Grafen P. A. von Fürstenstein, 21. 8. 1810.

343 Vgl. GoECKE, Das Königreich Westphalen, S. 148.

344 ANOnYmus, Die entlarvte hohe und geheime Polizei, S. 50.

345 KIRCHEISEN, König Lustig, S. 135; JÄGER, BURMEISTER, Das Königreich Westphalen, S. 12. 
In sehr kurzer Zeit und mit ungeheurem Kostenaufwand war das Gebäude aufgeführt worden ${ }^{346}$.

Andernorts sah die Erneuerung des Theaterlebens unter der westphälischen Herrschaft etwas anders aus, so in Halle, wo aus der Universitätskirche zunächst ein Heumagazin wurde und schließlich ab Sommer 1811 ein Theater ${ }^{347}$. Der Zeitgenosse Steffens berichtet anekdotenreich:

ich fand mich allerdings verletzt durch die gegenwärtige Benutzung derselben. Es war ein Gefühl, welches ich mit dem Volke theilte; ich vernahm darüber eine Aueßerung, die seltsam genug war. Die Schauspielergesellschaft hatte Halle verlassen. Während der Theater-Saison drohte der Komet von dem dunklen heißen Himmel herunter, bliebe aber noch nächtlich sichtbar, während das Theater öde und verschlossen dastand. >Wie ist das? $<$ hörte ich ein Weib zum andern sagen, >die Komödianten sind weg, und der Komödien-Stern ist noch immer da? ${ }^{348}$.

Steffens wollte wahrscheinlich mit dieser Anekdote kritisieren, dass mancher Hallenser in kürzester Zeit die vorwestphälische Verwendung des Kirchengebäudes, das nun als Theater diente, aus seinem Gedächtnis verdrängt hatte. Wenn auch die Wiederbelebung des Theaterlebens mancherorts auf einige Westphalen schockierend wirken konnte ${ }^{349}$, wenn damit die Zweckentfremdung und Entweihung eines geistlichen Gebäudes verbunden war, so wurde die Erneuerung des Theaterangebots selbst für diejenigen Staatsbürger sichtbar, die nicht ins Theater gingen. Wie bereits erwähnt, zeigte sich in Kassel die Pracht des neuerrichteten königlichen Theaters vor dem Marstall sowohl durch die Innendekoration des Zuschauerraums als auch durch seine Fassade ${ }^{350}$.

Was die Stücke betraf, wurde offensichtlich auch die Art der Inszenierungen radikal erneuert und die Kasselaner wurden reichlich mit Effekttheater bedient. Der Page Lehsten-Dingelstädt berichtet in seinen Erinnerungen jedenfalls, dass manche Oper den jugendlichen Pagen wegen der vielen Kunstgriffe (artifices) besonders imponierte und nahe ging:

Einen großen Genuß bereiteten den Pagen die schönen Vorstellungen, welche der berühmte Franconi aus Paris mit seiner Gesellschaft und seinen herrlich abgerichteten Pferden wiederholt gab. In einer Oper: La chasse de Henri IV. wurde auf dem Theater selbst eine Parceforcejagd aufgeführt. Dabei wurde in der Mitte der Bühne eine Felsschlucht dargestellt. Ein zahmer Hirsch soll von vielen Reitern mit der Meute gejagt werden. Mehrmals läuft er über die Bühne, Hunde und Reiter folgen. Endlich steht er auf der Felskante. Er zögert ein wenig. Der Ruf der Meute kommt näher. Da setzt

346 KirCheISEN, König Lustig, S. 136; vgl. Zinserling, Denkwürdigkeiten, S. 139f.; vgl. FREI-HAUENSCHILD, Eine europäische Kulturhauptstadt, S. 96. Eine Darstellung der Löwenburg findet man in: König Lustik!?, Kat. 191.

347 Vgl. STEFFENS, Was ich erlebte, Bd. 6, S. $264 \mathrm{f}$.

348 Ibid., S. $265 \mathrm{f}$.

349 Bei der oben zitierten Anekdote lässt sich der Topos der westphälischen Herrschaft als "zivilisatorischer Bruch" erkennen. Vgl. ferner KLEINSCHMIDT, Geschichte des Königreichs Westfalen, S. 449.

350 Vgl. KirCHEISEN, König Lustig, S. 136. 
er über eine wohl sechs fuß breite Kluft, die Hunde und Reiter wagen gleichfalls den Sprung ${ }^{351}$.

Das Theaterleben wurde durch den Einsatz von Effekten bei der Inszenierung spektakulärer als zuvor. Richtet man dabei erneut den Fokus auf die Zugänglichkeit des französischsprachigen Theater- oder Opernangebots für die nicht französischsprachigen Westphalen, so kommt man nicht umhin festzustellen, dass solche sensationsheischenden Theaterprogramme bei einem Publikum, das aus Französisch- und Deutschsprachigen bestand, besonders angebracht sein musste, da die effektreichen Darstellungsweisen vielleicht einen Weg darstellten, das Problem der Sprachbarriere im Publikum zu umgehen.

Tatsächlich scheinen nicht allein die importierten Theaterprogramme aus der französischen Hauptstadt eindrucksvoll in der Gestaltung gewesen zu sein. Pagenlehrer Zinserling schreibt dazu:

Was der [Theater]direktion gewöhnlich an Geist und Geschmack abgieng, ersetzte sie durch ihre Sorgfalt für die Pracht der Dekorationen und des Kostums, und von dieser Seite fiel das Theater gewöhnlich den durchreisenden Fremden in die Augen ${ }^{352}$.

Das pompöse Theaterleben entfaltete sich nicht nur auf der Bühne oder im Zuschauerraum, auch der Einzug in das und der Auszug aus dem Theater erlangten fast rituellen Charakter ${ }^{353}$, so der Historiker Kleinschmidt:

Fuhr oder ritt der Hof aus, so verband sich damit stets ein prächtiger Aufzug, [...] die Fahrt ging meist nach Napoleonshöhe und Katharinenthal oder ins Theater; wohin es aber auch war, dort wartete schon eine Abteilung Garde zu Fuß, und es waren Maßregeln getroffen, die jedem Unbefugten eine Annäherung an die Allerhöchsten Personen unmöglich machten. Nach Schluß des Theaters wurden alle Logen und das Parterre so lange abgesperrt, bis sich der Hof entfernt hatte: alles dies bot einen augenfälligen Gegensatz zu dem schlichten Hofe Friedrich Wilhelms III. und zu seinem Vertrauen in die Unterthanen ${ }^{354}$.

Nicht allein die Vorführungen an sich scheinen die Zuschauer zu ihrem Theaterbesuch animiert zu haben, sondern auch der damit verbundene Pomp und das mondäne Leben, die unter Jérôme besonders gepflegt wurden, wie Kircheisen bestätigt:

351 [LEHSTEN-DingelstÄDT], Am Hofe König Jérômes, S. 64; vgl. LYNCKER, Historische Skizzen, S.31f. Dies wird dadurch bestätigt, dass der Architekt Leo von Klenze seine Pläne modifizieren musste, um eine geräumigere Bühne zu schaffen, die sich auch für größere Aufführungen eignete, vgl. FrEI-HAUENSCHILD, Eine europäische Kulturhauptstadt, S. 96.

352 ZINSERLING, Denkwürdigkeiten, S. 135.

353 Das Theatervergnügen gehörte im Übrigen nicht allein zum Nachtleben, auch tagsüber wurden Vorstellungen gegeben. Vgl. [LEHSTEN-DingELSTÄDT], Am Hofe König Jérômes, S. 5 f.

354 KLEINSCHMIDT, Geschichte des Königreichs Westfalen, S. 79. 
Gegen acht Uhr abends erschienen die Minister, die höheren Beamten, das diplomatische Korps, die Offiziere, überhaupt die Geladenen. Ein jeder war bemüht, wie der König es liebte, größte Pracht zu entfalten. Die Herren erschienen in glänzenden Uniformen, mit allen ihren Orden angetan, und die Damen in den entzückendsten neuesten Toiletten, die sie meist in Paris hatten anfertigen lassen ${ }^{355}$.

Versucht man sich eine Vorstellung vom Treiben und vom Gesellschaftsleben im Zuschauerraum zu machen, das, den beiden Streitfällen nach, für die Theatergänger einen entscheidenden Teil des abendlichen Geschehens darstellte, wird der Gegensatz zwischen dem königlichen Theater auf Napoleonshöhe und dem königlichen Stadttheater deutlich ${ }^{356}$. Während in ersterem eine strikt reglementierte Sitzordnung herrschte ${ }^{357}$, gab es im Stadttheater offensichtlich zeitweilig ein großes Durcheinander ${ }^{358}$.

Das Theater war sicherlich aber auch deshalb bei einem breiten Publikum beliebt, weil Jérôme zu manchen Vorstellungen freien Eintritt gewährte ${ }^{359}$. So gesehen war das Theater eine Vergnügung für alle interessierten Bürger Kassels. Es wurde deswegen sogar als »ein wichtiger Ort der Begegnung zwischen Herrscher und Residenzbevölkerung « angesehen ${ }^{360}$. Ein Schreiben der Polizeiagentin Gall-Bessalié an den Polizeichef Bongars gibt darüber Auskunft, wie die Kasselaner sich um Theaterkarten bemühten und lässt erahnen, wie sich die Gesellschaft des Stadtheaters zusammensetzte. Am 16. März 1813 bat die Polizeiagentin mit folgenden Argumenten um die Zustellung von Theaterkarten:

E. Excellense halten zur $<$ Gna $>$ de, wan ich so dreist bin um die vernehre erhaltung, der bis für anfang diese Monats, durch Ihrer $<$ Gna $>$ de erhaltenen Teatre biliets ganz unterthänig zu bitten, die hohen <...ischten $>$ E. Excellense wurden es rechtfertigen, das ich irgend ein Mittel habe mus, um hi und da wo es nöhtig tuth bekantschaften anknüpfen zu könen, und diese bekanten gewiser maßen gegen mir zu verflichten; fühle depensen bin ich nicht imstande zu machen, mit hin wahr ein Teatre biliet bis itzt noch immer etwas, was ich mit anstand einer Tame de Scharge, einem Maitre d'autel oft<er> den auch in der bergerlichen Clase, anbiten konte, dahelt üblen einflus hat es für mich, weil alle diejenige die sie bis itzt von mir erhilten, nicht glauben, das ich keine mehr habe, sondern die eine die ander einer beneidet, und es mir versagt sie jener zu geben. Wodurch aus den Freunden, nur Feinde entstehen, überzeige von der Gnade E. Excellense lebe ich in der Hoffnung, das Sie meine unterthänige Bitten

355 KirCheisen, König Lustig, S. 136. Ebenfalls viel Pomp entfaltete Napoleon in Sachen Theater. So zum Beispiel im Rahmen des Erfurter Fürstentages im Oktober 1808. Vgl. [LEHSTEN-DingELSTÄDT], Am Hofe König Jérômes, S. 20.

356 Vgl. FrÖHLICH, Théâtre Royal, S. 177.

357 Vgl. [Lehsten-DingelstäDT], Am Hofe König Jérômes, S. 5 f.; KirCHEISEN, König Lustig, S. 136.

358 Dies betrifft insbesondere die Präsenz von Frauen bei den Theatervorstellungen. Vgl. KirCHEISEN, König Lustig, S. 137.

359 Vgl. LYNCKER, Historische Skizzen, S. 91; KirCHEISEN, König Lustig, S. 18; KeIM, "Savoir vivre«, S. 138

360 JÄGER, BURMEISTER, Das Königreich Westphalen, S. 12. 
Begnadigen verden, mir dieses für mich so zweckmäßige Mittel verner zu kommen zu laßen, und habe die Gnade zu sein E. Excellence ${ }^{361}$.

Aus einem späteren Schreiben der Polizeiagentin vom 9. April 1813 wird deutlich, dass Gall-Bessalié die Theaterkarten zum einen vergab, um ihr Netz aus ahnungslosen Informanten und Bespitzelten an sich zu binden, und zum anderen selbst ins Theater ging, um dort Bekanntschaften zu machen:

E. Excellense halten zur $<$ Gnade $>$, wen ich noch mals mich erdreiste, um die vernere Erhaltung, meines sonst gehabten Teaterbiliets untertähnig zu bitten, es geschiht wahrlich nicht, aus hang zum Vergnügen, aber E. Excellense könne nicht glauben, wie sehr es mir schuldet, und alle damals dadurch erworbenen Freunde, zu meiner jetzige Freunde macht, so manche Bekantschaft die ich theils selbst ins Teatre machte, theils durch das biliet mir herschafte, ist itzt unterbrochen ${ }^{362}$.

Diese Ausführungen der Polizeiagentin zeigen, dass sich über die Vergabe der Theaterkarten freundschaftliche oder klientelistische Beziehungen entwickelten. Wenn man sich ein Bild vom Theaterleben in Kassel machen möchte, führt dies weit über die Vorkommnisse im Innern des Theaters hinaus. Auch was sich im Vorfeld des Theaterlebens an zwischenmenschlicher Kommunikation ergab, wie durch die Verteilung der Theaterkarten, liefert interessante Indizien für das Zusammenleben der Sprachgemeinschaften in Kassel und verdient beachtet zu werden.

Die beiden Standorte, das königliche Stadttheater am Königsplatz in Kassel und das königliche Theater auf Napoleonshöhe, führten dazu, dass häufig Schauspielertruppen mit ihren Requisiten durch die Stadt zogen. Dadurch war das Theater auch für die Kasselaner, die es nicht besuchten, im Stadtbild präsent. Kircheisen schreibt über die Erscheinungen des Theaterlebens außerhalb der Räumlichkeiten des Theaters und der Spielzeiten im engen Sinn:

Hielt sich der König im Schlosse auf, fanden wöchentlich zwei bis drei Aufführungen statt. Schon vom Morgen an herrschte dann auf der nach Kassel führenden Straße reichbewegtes Leben, denn Schauspieler, Schauspielerinnen, Tänzer und Tänzerinnen sowie Dekorationen und Kostüme wurden in vielen Wagen aus Kassel herbeigeführt ${ }^{363}$.

Das Theater zog auf die Straße und wurde zum Tagesspektakel schon lange vor der Abendvorführung. Aber auch der Nachhall der Theatervorführungen scheint nicht unbedeutend gewesen zu sein: »In dem auf der Plantage

361 RNB St. Petersburg, F 993 Arch. Westf., K. 16, Nr. 9797-9817, hier Nr. 9805: Rapport von Gall-Bessalié, Polizeiagentin in Kassel, an J. F. M. de Bongars, 16. 3. 1813.

362 Ibid., Nr. 9800: Rapport von G.[all-Bessalié] an J. F. M. de Bongars, 9. 4. 1813.

363 KIRCHEISEN, König Lustig, S. 136; vgl. FrÖHLICH, Théâtre Royal, S. 182 f.; FrEIHAUENSCHILD, Eine europäische Kulturhauptstadt, S. 96. 
neuerbauten Theater fanden allabendlich Vorstellungen statt. Am Tage setzte dann der Hof selbst das Komödienspiel nach allen Richtungen fort. Es sollen dabei mancherlei Abenteuer vorgekommen sein « ${ }^{364}$.

Die Auflösung der Trennung zwischen Bühne und Zuschauerraum, zwischen Schauspielern und Theaterbesuchern und der theatralische Durchzug der Schauspielertruppen mit Requisiten durch die Stadt, die das weitgefasste und facettenreiche Theaterleben in Kassel kennzeichnen, könnten möglicherweise auch als ein Erbe der Französischen Revolution angesehen werden. Der Kommentar von Hans-Jürgen Lüsebrink über eine Inszenierung von »Brutus« legt dies zumindest nahe:

L'abolition symbolique de la séparation entre scène et parterre, acteurs et spectateurs, passé et présent, action sur scène et réactions du public, dont témoignent de nombreux comptes-rendus des représentations de la pièce, renvoie de même à l'imaginaire patriotique qui est habité par la vision d'une fusion de toutes les classes et de tous les états de la société en un corps uni et enthousiaste ${ }^{365}$.

Die Kasseler Gesellschaft zeigt sich bei allen revolutionären Zügen, die ihr nach dieser Definition zu eigen waren, in sehr streng getrennte Welten geteilt. Das Nebeneinander der Sprachgemeinschaften und Schichten bedeutete noch lange nicht ihre Verschmelzung, auch wenn man den Blick auf das Theaterleben in einem weitgefassten Sinne richtet. Es scheint von einer außerordentlichen Durchlässigkeit bei gleichzeitiger strenger Trennung geprägt gewesen zu sein: das Theater als Institution in der Stadt auch außerhalb der Räumlichkeit Theater präsent; die Französisch- und Deutschsprachigen Seite an Seite im Zuschauerraum; Theatervergnügen als kulturelles Angebot für alle Schichten; höfisches Zeremoniell in nächster Bürgernähe, aber mit strenger Abgrenzung ${ }^{366}$.

Richtet man den Fokus auf die Sprachen, so kann zusammenfassend festgehalten werden, dass genauso überraschend wie die Anwesenheit von Deutschsprachigen ohne französische Sprachkenntnisse bei französischsprachigen Theaterstücken die Duldung und Existenz eines teilweise relativ kritischen Theaterlebens in deutscher Sprache in der Hauptstadt gelten kann, das aufgrund des Schutzes durch die deutsch-französische Sprachbarriere ein Schattendasein führen konnte. Deutschsprachige saßen ne-

364 MÜlLER, Kassel seit siebzig Jahren, Bd. 1, hier S. 34.

365 LÜSEBRINK, Brutus, idole patriotique, S. 293. Wenn man betrachtet, dass zu vorwestphälischer Zeit der hessische Fürst Wilhelm IX. das Beifallklatschen im Theater untersagen ließ, weil dies als Ausdruck revolutionärer Gesinnung gelten könne, so waren ähnliche Partizipationsmöglichkeit der Zuschauer, die unter Jérôme galten, durchaus »revolutionär«. Vgl. WeIDEMANN, Fr. W. A. Murhard, S. 7.

366 Was das Theaterpersonal selbst angeht, wird durch die Zeitgenossen über Schauspieler berichtet, die sich in kürzester Zeit von Statisten zu Hauptdarstellern hocharbeiteten. Vgl. ZINSERLING, Denkwürdigkeiten, S. 127. 
ben Französischsprachigen in der gleichen Theatervorstellung. Wenn es zu Handgreiflichkeiten kam, fanden sich auch unter ihnen ein paar Zweisprachige, die zur weiteren Streiteskalation beitragen oder sich für das Schlichten des Streites einsetzen konnten. Diese Form des Nebeneinanders mehr als des Miteinanders, die für das Theater über die zwei eingangs analysierten Streitfälle dokumentiert ist, dürfte auch das sonstige Zusammenleben der verschiedenen Sprachgemeinschaften in Kassel geprägt haben.

\subsubsection{Von den Sprachkonflikten in der administration}

Die im ersten Teil vorgestellte Regelung über die Verwendung der französischen oder der deutschen Sprache in der administration, die in der Form eines Beschlusses am 21. März 1808 in die Akten des Staatsrats eingegangen ist und nicht mehr öffentlich gemacht wurde ${ }^{367}$, löste bei aller Klarheit dennoch gelegentlich Konflikte über die zu wählende Sprache für die Kommunikation innerhalb der Behörde aus.

\subsubsection{Distanzierung von der offiziellen Sprachregelung in der administration}

Vorgesehen war, dass die Verhandlungen im Staatsrat und die Kommunikation der Ministerien untereinander auf Französisch geführt wurden, während die Verhandlungen mit der Ständeversammlung auf Deutsch abzulaufen hatten ${ }^{368}$. Die Präfekten standen an der Schnittstelle zwischen den französisch- und deutschsprachigen Verwaltungsbereichen. Der gesamte Schriftverkehr mit den untergeordneten Behörden verlief auf Deutsch, während sie sich selbst an die Minister in französischer Sprache zu wenden hatten: "Die gesamte Lokalverwaltung bis zu den Präfekten einschließlich bediente sich der deutschen Sprache«, betont der Historiker Kohl ${ }^{369}$. Auch die Gerichte, Friedensrichter und Notare arbeiteten in deutscher Sprache ${ }^{370}$. Was die einzelnen Verwaltungsbereiche angeht, sollte beim Kronschatz und in den Büros der Ministerien und Staatsräte sowie bei den Generaldirektionen auf Französisch kommuniziert werden ${ }^{371}$. In der Armee wurde Französisch zur Kommandosprache; die Gardekorps kommunizierten in fran-

367 Vgl. GStA PK, V. HA, Nr. 571: Beschluss Nr. 33 vom König Jérôme, 21. 3. 1808; GOECKE, Das Königreich Westphalen, S. $148 \mathrm{f}$.

368 Vgl. KleinsChmidT, Geschichte des Königreichs Westfalen, S. 33; THIMmE, Die inneren Zustände, Bd. 2, S. 259.

369 KoHL, Die Verwaltung der östlichen Departements, S. 37; vgl. GoECKE, Das Königreich Westphalen, S. 149.

370 Vgl. GStA PK, V. HA, Nr. 571: Beschluss Nr. 33 vom König Jérôme, 21. 3. 1808.

371 Vgl. ibid.; KoHL, Die Verwaltung der östlichen Departements, S. 37; THIMME, Die inneren Zustände, Bd. 2, S. 259. 
zösischer Sprache, aber die Linientruppen bedienten sich der deutschen Sprache $^{372}$.

Obgleich eine Regelung über französisch- und deutschsprachige Bereiche in der Verwaltung getroffen worden war, fiel die Praxis zum Teil ganz anders aus. So berichtete Reinhard über eine Umfrage, die er unter den westphälischen Staatsräten über die offizielle Sprache ihres Landes durchgeführt hatte, nach Paris:

Ils m'ont répondu que c'était la langue allemande, puisqu'elle était employée dans les tribunaux et les administrations, puisque le texte allemand du code Napoléon était déclaré code du royaume. Toutefois, dans trois ministères au moins, toutes les affaires se traitent en français, les discussions du conseil d'État ont lieu en français, la rédaction des décrets est française, les traductions allemandes sont sans uniformité et souvent inexactes ${ }^{373}$.

Auch an den Ausführungen im Bericht des Staatsrats, aus dem der Beschluss über die Sprachregelung in der westphälischen Verwaltung hervorgegangen war, wird deutlich, dass die Sprachwahl ein Herd für Konflikte unter den Verwaltungsbeamten darstellte. Der Berichterstatter teilte die an ihn herangetragenen Vorstellungen mit, die für eine tiefergehende und weiter gefasste Einführung der deutschen Sprache als Verwaltungssprache plädierten, selbst in den Ministerien. Er riet dem König davon ab, in diese Richtung einzulenken, denn mit einer allgemeinen und ausschließlichen Verwendung der deutschen Sprache in der Verwaltung befürchtete er, eine schwer überwindbare Barriere zwischen dem Königreich Westphalen und dem Kaiserreich Frankreich zu schaffen ${ }^{374}$. Zwei der Ministerien waren tatsächlich in deutscher Hand, was nach und nach offenbar zu einer Distanzierung von den Vorschriften führte, jedenfalls was die Sprache der Kommunikationen unter den Staatsbeamten anging:

Man [hat] sich keineswegs strikt an die Vorschriften [der königlichen Entscheidung vom 21. März 1808] gehalten. Die Minister von Wolffradt und von Bülow und die unter dem letzteren stehenden Generaldirektionen erliessen z. B. ihre Reskripte an die Provinzialbehörden grossenteils in deutscher Sprache, gestatteten diesen auch die Einsendung deutscher Berichte. Am 16. Januar 1809 schrieb der Minister Wolffradt an die Präfekten: >Um Ihnen einige Erleichterung bei dem Geschäftsbetrieb zu gewähren, will ich Ihnen die Abfassung Ihrer Schreiben an mich in deutscher Sprache nachlassen, insofern der Gegenstand allgemeine Landesadministration [...]; jedoch darf der jedem Schreiben zur Seite gesetzte Inhalt in keiner anderen als der französischen Sprache sein. Auf alle übrigen Gegenstände, namentlich den Kultus, Hospitäler und milde Unterstützungen, Gesundheitspolizei, öffentlichen Unterricht, Künste

372 Vgl. Thimme, Die inneren Zustände, Bd.2, S. 150; LÜnSmann, Die Armee des Königreichs Westphalen, S. 11.

373 Reinhard, zitiert nach: TULARD, Siméon, S. 567.

374 Vgl. GStA PK, V. HA, Nr. 571: Bericht an den König, 19.3. 1808. 
und Statistik findet dies aber keine Anwendung; vielmehr müssen diese nach wie vor ganz in französischer Sprache gehalten sein $\varsigma^{375}$.

Die Frage, welche Bereiche der Verwaltungsgeschäfte tatsächlich von der französischen Sprache beherrscht waren oder doch in deutscher Sprache abgehandelt wurden, artete offenbar in den Augen einiger Staatsbeamter zu einer Art Wettkampf der Sprachen aus. Schenkt man zeitgenössischen Angaben Glauben, waren die verschiedenen Administrationsbranchen entweder der deutschen oder der französischen Partei zugeneigt, was sich zum Teil in der Sprachwahl für die interne Kommunikation und für den intraministeriellen Schriftverkehr widerspiegelte.

Das Finanzministerium wurde jedenfalls als »un des fiefs du parti allemand « angesehen ${ }^{376}$. Auch über das Innenministerium urteilt Fabre: »Confié aux Allemands du haut en bas de la hiérarchie, le service de l'Intérieur était, de tous, le plus suspect et le plus hostile à la haute police, demeurée entre des mains françaises ${ }^{377}$. Dieser deutschen Partei wurde die französische Partei gegenübergestellt: »Le parti français avait, aussi, ses citadelles: les Affaires étrangères, la Justice, la Police et la Guerre « ${ }^{378}$. Über dieses ausgeprägte Parteiendenken ist folgende Äußerung von Reinhard überliefert:

Es widerstreben [...] die Nationalitäten der Verschmelzung, die verschiedenen Beamten verhehlen ihre Abneigung gegen einander nicht, und Deutsche arbeiten den Zielen der Franzosen so entschieden entgegen, dass auch zweckmäßigen Schöpfungen die Anerkennung nicht zu Theil wird ${ }^{379}$.

Diese Gegenüberstellung der Franzosen und der Deutschen in der Verwaltung und die Kämpfe um die Durchdringung der einzelnen Geschäftsbereiche durch die deutsche oder französische Sprache gingen offensichtlich bis zur Anstiftung von Intrigen:

Der französische Clique am Hofe war Graf Bülow längst ein Stein des Anstoßes, in der gehässigsten Weise wurde seine Thätigkeit kritisiert, und die Intriguen gegen ihn ruhten auch nicht nach der Abreise seines speziellen Verleumders Jollivet. [Bülow hatte Jérômes Vertrauen;] [...] gern verzieh er ihm hierfür, dass Bülow bei Besetzung von Ämtern die Deutschen bevorzugte ${ }^{380}$.

\subsubsection{Zweisprachigkeit und Rekrutierungspolitik}

An Bercagnys westphälischer Karriere lässt sich nachzeichnen, wie sehr die französisch-kaiserliche Gesinnung sich auch in der Bevorzugung von

375 Thimme, Die inneren Zustände, Bd. 2, S. 260; vgl. KoHL, Die Verwaltung der östlichen Departements, S. 37.

376 FABRE, Jérôme Bonaparte, S. 113.

377 Ibid., S. 113.

378 Ibid., S. 116.

379 Reinhard, zitiert nach: HavemanN, Das Kurfürstenthum Hannover, S. 49.

380 KLEINSCHMIDT, Geschichte des Königreichs Westfalen, S. 410. 
französischsprachigen Personen bei der Rekrutierung von Untergebenen bemerkbar machte. Schon bei der Wahl Bercagnys zum Präfekten des Elbdepartements, die durch die Königin während ihrer Regentschaft in Abwesenheit Jérômes besonders unterstützt wurde, fielen folgende Argumente ins Gewicht: „Sie [die Königin] befürchtete, dass die Minister widersprechen würden, aber so fügte sie hinzu: '... es ist endlich Zeit, sie $\grave{a}$ la française tanzen zu lassen, denn französisch ist unsere Verfassung « ${ }^{381}$. Und als Bercagny dann sein Amt als Präfekt antrat, leitete er unverkennbar Maßnahmen ein, die von seiner Präferenz für die Franzosen zeugten: Als Bercagny »endlich zur allgemeinen Freude der Casseler - nicht aber der Magdeburger - den Ruf als ElbePräfekt erhielt, [fing er dort] so streng $[\ldots]$ an [...], z. B. durch Verabschiedung aller Präfectur-Offizianten, die nicht Französisch verstanden u.s.w. $\aleph^{382}$ Bercagny musste allerdings bald erkennen, dass diese plötzliche Französisierungsmaßnahme des Verwaltungspersonals Nachteile barg: "Der neue Präfekt sah sich bald veranlasst, da er über keine deutschen Sprachkenntnisse verfügte, für Magdeburg einen Unterpräfekten ausnahmsweise und entgegen der Verwaltungsbestimmungen, die besagen, daß der Präfekt im Departementshauptort gleichzeitig die Geschäfte eines Unterpräfekten für den betreffenden Distrikt zu führen hat, zu beantragen $\aleph^{383}$.

Das Problem der staatlich erwünschten Zweisprachigkeit und der nicht unbedingt damit einhergehenden Fachkompetenz für die betreffenden Verwaltungsämter entwickelte sich zu einem Reizthema unter den Zeitgenossen, welches das Parteiendenken und die Frontstellung zwischen Französisch- und Deutschsprachigen in der administration verschärfte. Reinhard gab nach Paris zu bedenken: »Die Auswahl der Verwaltungsbeamten und anderer Angestellten beschränkt sich in vielen Zweigen auf die geringe Zahl derjenigen, welche beide Sprachen sprechen und schreiben ${ }^{384}$. Damit beschrieb er das in seinen Augen existierende Defizit, dass den sprachlichen Kompetenzen für einen Posten in der Verwaltung vor den fachlichen der Vorrang gegeben wurde.

Napoleon selbst hatte zum Aufbau des neuen Verwaltungsapparats empfohlen, Zweisprachige vorzuziehen: "Nöthig wird sein, daß Sie sich einen Sekretär verschaffen, der sehr gut deutsch versteht, und beschäftigen Sie sich damit, mir ein paar Elsässer von hervorragendem Verdienst vorzu-

381 KoHL, Die Verwaltung der östlichen Departements, S. 36.

382 ANONYMUS, Die entlarvte hohe und geheime Polizei, S. $45 \mathrm{f}$.

383 KoHL, Die Verwaltung der östlichen Departements, S. 36. Die vermeintlich stärkere Französisierung des Verwaltungshandelns nach Einsetzung von Bercagny als Präfekt im Elbdepartement untersuchte zuletzt Todorov. Vgl. TODOROV, La division cantonale dans le royaume de Westphalie; DERS., Die Rationalität der Verwaltung.

384 Reinhard, zitiert nach: GoECKE, Das Königreich Westphalen, S. 113. 
schlagen, welche geeignet sein würden, Sie in Ihrer Verwaltung zu unterstützen $\aleph^{385}$. Allerdings riet Napoleon zudem, bei der Rekrutierung der Verwaltungsbeamten besonders auf die Beseitigung der » eitlen und lächerlichen Standesunterschiede« « zu achten. Dies war jedoch nur schwer mit der gewünschten Zweisprachigkeit zu vereinbaren. Obgleich Napoleon empfahl, wegen der Verwirklichung des Gleichheitsprinzips Leute aus dem Bürgertum für die Präfektenstellen zu nehmen, musste ihm Jérôme antworten, »es würde ihm sehr schwer werden, aus dem dritten Stand Kandidaten hierfür zu wählen, da der größte Theil dieser Leute wenig unterrichtet sei und die französische Sprache nicht verstehe ${ }^{386}$. Als am darauffolgenden 4. und 10. Januar 1808 die Präfekten- und Unterpräfektenstellen besetzt wurden, wurden ausschließlich Deutsche ausgewählt, jedoch mehrheitlich aus dem Adel, deren Repräsentanten mit der französischen Sprache eher vertraut waren ${ }^{387}$. Napoleon warnte zudem seinem Bruder vor den französischen Einwanderern: „n'employez aucun Français sans mon autorisation $\ll^{388}$. Die Befürchtung, inkompetente respektive politisch vorbelastete Personen könnten im westphälischen Verwaltungsapparat Anstellung finden, wurde deutlich ausgesprochen ${ }^{389}$.

Dem französischen Kaiser war bewusst, dass sich die neue Herrschaft auf gewandte Zweisprachige stützen musste, um ihre Verwaltung zu etablieren. Trotz dieses Bewusstseins haperte es bei der Realisierung, so das Urteil Reinhards: "Placer sur un trône allemand un prince français de sa maison fut sans nul doute la première erreur de Napoléon. L'entourer de conseillers, dont Siméon, qui ne parlait pas allemand, en était une autre « ${ }^{390}$.

Das Dilemma mit der Zweisprachigkeit war sicherlich groß: Auf der einen Seite erschien es angebracht, Zweisprachige für die Besetzung der Verwaltungsämter zu bevorzugen, andererseits war die Sprachkompetenz nicht bei allen mit der Fachkompetenz für den Posten gepaart. Außerdem wurde

385 Napoleon, zitiert nach: GOECKE, Das Königreich Westphalen, S. 37; vgl. KLEINSCHMIDT, Geschichte des Königreichs Westfalen, S. 4.

386 GOECKE, Das Königreich Westphalen, S. 61.

387 Vgl. GOECKE, Das Königreich Westphalen, S. 61; HeCKER, Napoleonischer Konstitutionalismus, S. 139-146.

388 Napoleon, zitiert nach: FABRE, Jérôme Bonaparte, S. $72 \mathrm{f}$.

389 Napoleon sollte im Laufe der westphälischen Herrschaft verschiedene Initiativen ergreifen, um die Herkunft der aus Frankreich eingewanderten Franzosen, die in westphälischen Diensten standen, zu überprüfen. Vgl. u.a. AN Paris, $\mathrm{BB}^{11} 72$, Notes et renseignements sur plusieurs français qui demandent l'autorisation, d'entrer ou de rester au service du roi de Westphalie, année 1812-1813, sousdossier Westphalie. So auch im Hofstaat Jérômes, vgl. [LEHSTEN-DINGELSTÄDT], Am Hofe König Jérômes, S. 61.

390 Reinhard, zitiert nach: TulaRD, Siméon, S. 567. 
gelegentlich vor oder nach der Anstellung festgestellt, dass die Anwärter auf Verwaltungsämter die Zweitsprache nur ungenügend beherrschten ${ }^{391}$.

Die Bemühungen, Zweisprachige zur Führung der Staatsgeschäfte zu rekrutieren, beschränkten sich zudem mehr auf die subalternen Posten. So war die obere Verwaltungsebene eher mit Amtsträgern aus Frankreich besetzt, die mehrheitlich keine deutschen Sprachkenntnisse mitbrachten. Über Siméon bemerkt der Historiker Jean Tulard: »Au milieu d'un personnel corrompu (Bercagny, Lecamus), Siméon fut vite isolé. Son ignorance de la langue contribua encore à aggraver son isolement « ${ }^{392}$. Nach seinem Urteil war die allmähliche Isolierung von Siméon nicht zuletzt sprachlich bedingt.

\subsubsection{Sprachwahl in der Amtskorrespondenz Wolffradts}

Die Sprachwahl für die interne Kommunikation der Staatsbeamten und der Verwaltungsbehörden ist sicherlich ein Thema, das sehr nuancierte Beobachtungen erfordert. Bei einer systematischen Erhebung der Sprache, in der die Verwaltungsschreiben aufgesetzt wurden, ergibt sich ein sehr weites Spektrum von abweichenden bis regelgerechten Praktiken. Durch ihre strenge Beachtung der Sprachregelung zeichneten sich beispielsweise der Finanzminister Bülow und der Innenminister Wolffradt aus: Sie korrespondierten meist auf Französisch miteinander, obgleich Französisch für beide eine Zweitsprache war ${ }^{393}$. Auch einige andere Beamtenpaare kommunizierten nach Vorschrift auf Französisch, selbst wenn dies ihrer gemeinsamen deutschen Erstsprache zuwiderlief und die Wahl der deutschen Sprache selbstverständlicher hätte erscheinen können.

Anhand der Korrespondenz des Innenministers Wolffradt, der vom 31. Dezember 1808 bis einschließlich Oktober 1813 im Amt war, kann exemplarisch dargelegt werden, wie, teils nach Vorschrift und teils davon abweichend, die Wahl einer Sprache für die Kommunikation zwischen den Staatsbeamten getroffen wurde ${ }^{394}$. Die Handhabung der offiziellen Sprach-

391 Vgl. die Fälle von Dörr und Reitsch z. B. GStA PK, V. HA, Nr. 1693, Bl. 54: Schreiben von G. A. von Wolffradt an J. A. Morio, Kriegsminister, 25.7.1810; ibid., Bl. 55: Schreiben von J. P. Reitsch, Sergent bei den westphälischen Linientruppen in Wolfenbüttel, an G. A. von Wolffradt, 27.5.1810; RNB St. Petersburg, F 993 Arch. Westf., K. 5, Nr. 2570-2612, Nr. 2522: Schreiben Nr. 647 von F. T. de Guntz an J. F. M. de Bongars, 7. 7. 1812. Vgl. ferner ThimME, Die inneren Zustände, Bd. 2, S. 379f., 167.

392 Tulard, Siméon, S. 559.

393 Vgl. KoHL, Die Verwaltung der östlichen Departements, S. 36. Diese Feststellung Kohls sollte jedoch durch einige Ausnahmen eingeschränkt werden: Vgl. GStA PK, V. HA, Nr. 1693, Bl. 89 f.: Schreiben Nr. 2349 von L. F. V. H. Graf von Bülow, Finanzminister, an G. A. von Wolffradt, 16.4.1811.

394 In Beamtenkorrespondenzen können teilweise stark individualisierende Tendenzen für die Anreden und Grußformeln sowie für den Schreibduktus festgestellt werden. Diese Tendenzen betreffen eher äußere Merkmale der Korrespondenzen 
regelung durch diesen deutschsprachigen Minister, der, wie schon erwähnt, nicht verhehlte, mit der französischen Sprache seine Schwierigkeiten zu haben, erscheint zur Veranschaulichung besonders geeignet.

Mit Merveldt, deutschsprachigem Generalrequetenmeister am westphälischen Hof von Januar 1810 bis 1812, der ebenfalls Französisch sprach, korrespondierte Wolffradt in französischer Sprache ${ }^{395}$. Diese Sprachwahl könnte sich aus der gelegentlichen Einbeziehung des Königs in die Begnadigungsverfahren erklären, die dem Generalrequetenmeister unterstanden.

Als der Präfekt des Werradepartements Berlepsch am 12. Juli 1809 dem Innenminister Wolffradt über die »surveillance des rédacteurs des journaux politiques « schrieb, tat er dies in französischer Sprache ${ }^{396}$. Die Sprachwahl dieser beiden Beamten war allerdings nicht stringent: Kurz zuvor hatte der Innenminister dem Präfekten eine Antwort in französischer Sprache zu einem Schriftstück desselben in deutscher Sprache gegeben ${ }^{397}$. Damit signalisierte er wortlos, dass die französische Sprache sich für den Austausch zwischen Staatsbeamten empfahl, um der offiziellen Sprachregelung gerecht $\mathrm{zu}$ werden. Im April 1809 schrieb Wolffradt erneut dem gleichen Präfekten des Werradepartements über die Schule in Spangenberg in französischer Sprache ${ }^{398}$. Der Innenminister scheint überhaupt ein strenger Hüter der offiziellen Sprachregelung gewesen zu sein. Mit dem Magdeburger Präfekten Graf von der Schulenburg-Emden ${ }^{399}$, mit dem Präfekten des Saale-

als den Inhalt der Briefe, der eher konventionell blieb. Vgl. BRAKENSIEK, Fürstendiener - Staatsbeamte - Bürger, S. 289. Vgl. dazu auch z. B. die Korrespondenz des Präfekten des Werradepartements Trott zu Solz und vom Generalpolizeikommissar Wolff: PAYE, Die Polizei, S. 96.

395 RNB St. Petersburg, F 993 Arch. Westf., K. 2, Nr. 214-219, hier Nr. 218: Schreiben von P. von Merveldt, Generalrequetenmeister, an G. A. von Wolffradt, 30.11. 1812. Mit dem französischsprachigen Kriegsminister Höne, geborener Sahla, Justizminister Siméon und Staatssekretär und -minister des Äußeren, Graf von Fürstenstein, geborener Lecamus, aber auch mit den Chefs der Hohen Polizei, Bercagny und dann Bongars, hat Wolffradt selbstredend auf Französisch korrespondiert, da es der Vorschrift entsprach und diese die deutsche Sprache nicht beherrschten.

396 Vgl. Sta MR, Best. 75 Nr. 185, Akten des Innenministeriums über die Schulanstalten im Werradepartement, 1809-1813: Schreiben Nr. 2089 von F. L. von Berlepsch, Präfekt in Marburg, Werradepartement, an G. A. von Wolffradt, 12.7. 1809.

397 Vgl. GStA PK, V. HA, Nr. 1977, Akte des Ministeriums des Innern, Buchhändler und Buchdruckereien, 1807-1811, Bl. 52: Schreiben Nr. 546 von G. A. von Wolffradt an F. L. von Berlepsch, 08. 03. 1809.

398 StA MR, Best. 75 Nr. 185: Schreiben Nr. 984 von G. A. von Wolffradt an F. L. von Berlepsch, 18.4.1809.

399 Im Zeitraum von März bis August 1809 sind mehrere Schreiben des Innenministers an den Präfekten in französischer Sprache überliefert, worunter sich auch Rundschreiben an die Präfekten befinden. Vgl. Lha S-A, Wernigerode, B 18 I. 139., Akten der Elbdepartementpräfektur über den Esprit public, 1809; StaM, A I P, Nr. 247, Akten des Magistrats über die gerichtliche Polizei und Instruktion 
departements Wilhelm-Christian Gossler ${ }^{400}$ und mit dem Generaldirektor des öffentlichen Unterrichts J. von Müller ${ }^{401}$ kommunizierte er ebenfalls in französischer Sprache. Bei einigen Staatsbeamten wie dem Kasseler Präfekten Friedrich von Reineck zeigte er mehr Geduld und schrieb abwechselnd auf Französisch und auf Deutsch, wobei das Deutsche abweichend von der offiziellen Sprachregelung überwog, näher an einer ungekünstelten und ungezwungenen Form der Kommunikation zwischen zwei Deutschsprachigen $^{402}$. Wenn man weitere Stichproben aus den Korrespondenzen

der peinlichen Sachen und Bestimmung wegen der korrektionellen Strafen gegen Vagabunden, Bettler und anderes Gesindel, 1809; Lha S-A, Wernigerode, B 18 I. 4. 1180., Akten der Elbdepartementpräfektur über die französischen Kirchenund Schulbediensteten zu Magdeburg, 1808. Einmal weicht der Innenminister von der offiziellen Sprachregelung ab und wendet sich in deutscher Sprache an den Präfekten, vgl. Lha S-A, Wernigerode, B 18 I. 198., Akten der Elbdepartementpräfektur über die Zivilgendarmerie, 1809, Bl. 45: Schreiben von G. A. von Wolffradt an Grafen P.E. A. von der Schulenburg-Emden, 10. 10. 1810. Dieses Schreiben antwortet auf eine Anfrage in deutscher Sprache des Präfekten an den Innenminister, vgl. ibid., Bl. 41 f.: Schreiben von P.E. A. von der SchulenburgEmden an G. A. von Wolffradt, 22.9. 1810.

400 Vgl. Lha S-A, Wernigerode, B 26 II. Rep. 28., Nr. 4, Akten der Saaledepartementpräfektur über die Einsendung der öffentlichen Blätter und Journale an die Generaldirektion der Hohen Polizei in Kassel, 1808. Auch Gossler antwortet gelegentlich dem Innenminister in französischer Sprache, vgl. Lha S-A, Wernigerode, B 26 II. Rep. 28., Nr. 4, Bl. 60: Schreiben Nr. 114 von W.-C. Gossler an G. A. von Wolffradt, 26. 2. 1809. Und gelegentlich auch in deutscher Sprache: Vgl. GStA PK, V. HA, Nr. 1977, Bl. 51: Schreiben Nr. 1507 von W.-C. Gossler an G. A. von Wolffradt, 1.3. 1809.

401 Vgl. StA MR, Best. 75 Nr. 194, Akten des Innenministeriums über die Einrichtung einer Katholischen Schule in Kassel sowie Bestellung und Besoldung der Lehrer, 1808-1810; StA MR, Best. 75 Nr. 185; StA MR, Best. 75 Nr. 154, Akten des Innenministeriums über den öffentlichen Unterricht - Lehrerbesoldung im Fuldadepartement, 1808-1813; StA MR, Best. 75 Nr. 180, Akten des Innenministeriums über den öffentlichen Unterricht - Bericht über den Zustand sämtlicher Gymnasien, Lyzeen und Bürgerschulen im Fuldadepartement, 1809-1812; StA MR, Best. 75 Nr. 1284, Akten der Generaldirektion des öffentlichen Unterrichts - Besoldung des Registrators Entzeroth, 1808-1810.

402 Im Zeitraum von Januar bis November 1812 sowie von Januar bis April 1813 sind mehrere Schreiben der beiden in deutscher Sprache überliefert, vgl. StA MR, Best. 75 Nr. 56, Akten des Innenministeriums über die Präfektur in Kassel, Fuldadepartement, 1809-1813; StA MR, Best. 75 Nr. 182, Akten des Innenministeriums über den öffentlichen Unterricht - Eintauschung und Ausbau des gräflich von malsburgischen Hauses in Kassel zum Lyzeum,1810-1812; StA MR, Best. 75 Nr. 196, Akten des Innenministeriums über die Dotierung des Kasselschen Schulfonds mit einem Teile des Vermögens der aufgehobenen Hof- und Garnisonskirche zu Kassel, 1810-1813; StA MR, Best. 75 Nr. 199, Akten des Innenministeriums über die Einrichtung und Reparatur der Garnisonschule in Kassel sowie Bestellung und Besoldung der Lehrer; StA MR, Best. 75 Nr. 1298, Akten der Generaldirektion des öffentlichen Unterrichts über die Schulanstalten in Cassel, 1812-1813; StA MR, Best. 75 Nr. 246, Akten des Innenministeriums über den Brand des Schlosses in Kassel; StA MR, Best. 75 Nr. 184, Akten des 
des Innenministers Wolffradt heranzieht, so fällt auf, dass er sich beispielsweise mit dem Nachfolger J. von Müllers, dem Generaldirektor des öffentlichen Unterrichts, Leist, durchweg in deutscher Sprache schriftlich austauschte, obwohl er noch am 16. Januar 1809 betonte, über das Ressort des öffentlichen Unterrichts sollte weiterhin in französischer Sprache berichtet werden ${ }^{403}$. Auch mit dem Finanzminister Malchus verkehrte Wolffradt, entgegen der Vorschrift für diese ministeriale Ebene, in deutscher Sprache, obwohl Malchus nicht zuletzt aufgrund seiner pfälzischen Herkunft zweisprachig war ${ }^{404}$. An den Innenminister wandte sich der zweisprachige Marburger Generalpolizeikommissar Wolff ebenfalls in deutscher Sprache ${ }^{405}$.

Der Briefwechsel Wolffradts mit dem Präfekten F. W. Frantz, der von Oktober 1808 bis 1812 in Göttingen für das Leinedepartement und ab 1812 in Hannover für das Allerdepartement zuständig war, war sprachlich gesehen eher unstetig. Frantz schrieb ihm sowohl in französischer als

Innenministeriums über die Entschädigungsforderung des Bürgers Lippert wegen der Abtretung seiner Wohnung in den Hallen am Napoleonsplatz in Kassel, 1812; StA MR, Best. 75 Nr. 200, Akten des Innenministeriums - Unterhaltung der Freischulen in Kassel sowie Bestellung und Besoldung der Lehrer, 18111813. Gelegentlich schreibt Reineck jedoch Wolffradt auf Französisch. Genauer betrachtet, schreibt er sogar einen Tag auf Französisch und am nächsten auf Deutsch, vgl. Sta MR, Best. 75 Nr. 56: Schreiben von Freiherrn F. von Reineck an G. A. von Wolffradt, 22.4.1813. Aus der Reihe fällt auch ein Schreiben in französischer Sprache über die Ernennung eines neuen Polizeikommissars in Kassel, vgl. Sta MR, Best. 75 Nr. 259, Akten des Innenministeriums - Ernennung der Polizeikommissare im Fuldadepartement, 1808-1813: Schreiben Nr. 1158 von G. A. von Wolffradt an F. von Reineck, 5.3.1813. Als Reineck Präfekt in Braunschweig wurde, setzte sich der Schriftverkehr z.T. in französischer Sprache fort, vgl. HStAH, Hann. 52, Nr. 135, Akten des Innenministeriums über verschiedene Gegenstände betr. die Hohe Polizei, vorwiegend aus den Departements der Leine und der Ocker, 1808-1813, Bl. 72: Schreiben von G. A. von Wolffradt an F. von Reineck, Präfekt in Braunschweig, Ockerdepartement, 12.8. 1813.

403 Vgl. GStA PK, V. HA, Nr. 1693; StA MR, Best. 75 Nr. 194; StA MR, Best. 75 Nr. 1284; StA MR, Best. 75 Nr. 183, Akten des Innenministeriums über den öffentlichen Unterricht - Organisation des Schulwesens in Kassel sowie Ernennung des Lehrpersonals am Lyzeum und an der Bürgerschule, Fuldadepartement, 1811-1813; StA MR, Best. 75 Nr. 196, Akten des Innenministeriums - Dotierung des Kassel'schen Schulfonds mit einem Teil des Vermögens der aufgehobenen Hof- und Garnisonskirche zu Kassel, 1810-1813; StA MR, Best. 75 Nr. 197, Akten des Innenministeriums über den öffentlichen Unterricht - Plan zur Errichtung einer israelitischen Töchterschule in Kassel, 1811; StA MR, Best. 75 Nr. 198, Akten des Innenministeriums über den öffentlichen Unterricht - Einrichtung einer Mädchenschule zu Kassel, 1808-1813; StA MR, Best. 75 Nr. 199; StA MR, Best. 75 Nr. 1283, Akten der Generaldirektion des öffentlichen Unterrichts - Personal- und Besoldungsetats der Bibliothek und des Museums in Kassel, $1808-1811$.

404 Vgl. StA MR, Best. 75 Nr. 182.

405 Vgl. StA MR, Best. 75 Nr. 260, Akten des Innenministeriums - Ernennung der Polizeikommissaren im Werradepartement, 1809-1813: Schreiben o. Nr. von F. von Wolff an G. A. von Wolffradt, 8. 1. 1810. 
auch in deutscher Sprache, wobei sich daraus kein System ableiten lässt ${ }^{406}$. Im Fall des Präfekten Trott, der anfänglich in Heiligenstadt für das Harzdepartement amtierte, von Juni bis August 1809 und bis Ende 1813 als Präfekt in Marburg für das Werradepartement fungierte, ist für die erste Zeit ein Schreiben Wolffradts in französischer Sprache überliefert ${ }^{407}$, aber aus seiner Amtszeit in Marburg liegen nur noch Schriftstücke in deutscher Sprache vor, wenngleich mit einigen französischen Termini ${ }^{408}$. Der Präfekt des Fuldadepartements von Juli/August 1808 bis Dezember 1811, Reimann, schrieb Wolffradt fast ausschließlich in deutscher Sprache ${ }^{409}$, ob-

406 Schreiben von Frantz in deutscher Sprache, vgl. HStAH, Hann. 52, Nr. 140, Akten des Innenministeriums über Anzeigen von aufrührerischen Bewegungen und Tumulten, 1813, Bl. 1 f.: Schreiben von Frantz, Präfekt in Hannover, Allerdepartement, an G. A. von Wolffradt, 17.4.1813; ibid., Bl. 11 f.: Schreiben von Frantz an G. A. von Wolffradt, 13.10.1813. Schreiben von Frantz in französischer Sprache, vgl. ibid., Bl. 5: Schreiben von Frantz an G. A. von Wolffradt, 30. 9. 1813; ibid., Bl. 17: Schreiben von Frantz an G. A. von Wolffradt, 17. 4. 1813. Wolffradt scheint auch gelegentlich in deutscher Sprache geantwortet zu haben, vgl. HStAH, Hann. 52, Nr. 2970, Akten der Präfektur des Allerdepartements über die Abreise der Behörden aus Hannover im Fall der Annäherung fremder Truppen, 1813: Schreiben von G. A. von Wolffradt an Frantz, 6. 4. 1813; HStAH, Hann. 52, Nr. 3026, Akten der Präfektur des Allerdepartements über verschiedenes Material der Hohen Polizei, 1810-1813: Schreiben von G. A. von Wolffradt an Frantz, 25. 7. 1813; GStA PK, V. HA, Nr. 1693, Bl. 37: Schreiben Nr. 1260 von G. A. von Wolffradt an Frantz, Präfekt in Göttingen, Leinedepartement, 17.5. 1809. Und wieder gelegentlich in französischer Sprache, vgl. HStAH, Hann. 52, Nr. 3026: Schreiben von G. A. von Wolffradt an Frantz, [12.-15].5. 1813.

407 Vgl. RNB St. Petersburg, F 993 Arch. Westf., K. 3, Nr. 375: Schreiben von A. H. von Trott zu Solz, Präfekt in Heiligenstadt, Harzdepartement, an G. A. von Wolffradt, 1.8.1809.

408 Vgl. RNB St. Petersburg, F 993 Arch. Westf., K. 10, Nr. 5673-5680, hier Nr. 5673; StA MR, Best. 75 Nr. 156, Akten des Innenministeriums - Universität von Marburg; Sta MR, Best. 75 Nr. 185, Akten des Innenministeriums über die Schulanstalten im Werradepartement, 1809-1813; GStA PK, V. HA, Nr. 1693.

409 Vgl. StA MR, Best. 75 Nr. 182; StA MR, Best. 75 Nr. 183; StA MR, Best. 75 Nr. 194; StA MR, Best. 75 Nr. 255, Akten des Innenministeriums - Konzessionsgesuche, Berichte über Unruhen bei der Abgabenerhebung und andere Polizeiangelegenheiten im Fuldadepartement; StA MR, Best. 75 Nr. 199; StA MR, Best. 75 Nr. 286, Akten des Innenministeriums über das Kastell in Kassel, 1809-1813; StA MR, Best. 76a Nr. 248, Akten der Präfektur des Fuldadepartements über den Brand im hiesigen königlichen Schlosse und die hierauf Bezug habende Verhandlungen, 1811; StA MR, Best. 75 Nr. 195, Akten des Innenministeriums über den öffentlichen Unterricht - Errichtung einer Artillerieschule in Kassel, 1810-1811; StA MR, Best. 75 Nr. 200; StA MR, Best. 75 Nr. 324, Akten des Innenministeriums über die Gendarmeriekaserne in Kassel, 1808-1813; StA MR, Best. 75 Nr. 256, Akten des Innenministeriums - Zeitungswesen im Fulda- und Werradepartement, 1808-1812; StA MR, Best. 75 Nr.265, Akten des Innenministeriums - Unterhaltung der Gefangenen im Fuldadepartement, 1808-1809. Lediglich ein Schreiben in französischer Sprache von Reimann, an den Innenminister adressiert, konnte bei den Sondierungen gesichtet werden. Vgl. StA MR, Best. 75 
gleich sich letzterer sowohl in französischer als auch in deutscher Sprache an ihn wandte ${ }^{410}$.

Was die weiteren Präfekten angeht, so waren die Schreiben des Präfekten Daniel Heinrich Delius, in den Jahren 1812 und 1813 in Göttingen, an den Innenminister in deutscher Sprache verfasst ${ }^{411}$. Ebenfalls verlief die Korrespondenz Wolffradts mit dem Präfekten Friedrich Christian Ludwig von Henneberg, in Braunschweig für das Ockerdepartement von 1808 bis 1812 amtierend, auf Deutsch ${ }^{412}$. Mit dem einstmaligen Unterpräfekten in Halle, Saaledepartement, Piautaz, der ab Mai 1813 in Kassel Präfekt wurde, korrespondierte Wolffradt auch auf Deutsch ${ }^{413}$. Mit dem Unterpräfekten in Goslar

Nr. 256: Schreiben Nr. 1967 von G. J. G. A. von Reimann an G. A. von Wolffradt, 17.3. 1809.

410 Schreiben von Wolffradt in französischer Sprache, vgl. StA MR, Best. 75 Nr. 255: Schreiben Nr. 4216 von G. A. von Wolffradt an G. J. G. A. von Reimann, Präfekt in Kassel, Fuldadepartement, 30. 11. 1810; ibid., Schreiben Nr. 2586 von G. A. von Wolffradt an G. J. G. A. von Reimann, 27. 8. 1810; StA MR, Best. 75 Nr. 199: Schreiben Nr. 1871 von G. A. von Wolffradt an G. J. G. A. von Reimann, 31. 12. 1809. Auf ein Schreiben des Innenministers Wolffradt in französischer Sprache erlaubte sich der Präfekt des Fuldadepartements sogar in deutscher Sprache zu antworten, vgl. GStA PK, V. HA, Nr. 1693, Bl. 72: Schreiben von G. A. von Wolffradt an G. J. G. A. von Reimann, 6.12.1810; ibid., Bl.71: Schreiben von G. J. G. A. von Reimann an G. A. von Wolffradt, 7. 1. 1811. Schreiben von Wolffradt in deutscher Sprache, vgl. StA MR, Best. 75 Nr. 199: Schreiben Nr. 3500 von G. A. von Wolffradt an G. J. G. A. von Reimann, 25.10.1810; ibid., Schreiben Nr. 4854 von G. A. von Wolffradt an G. J. G. A. von Reimann, 11.11.1811; ibid., Schreiben Nr. 3614 von G. A. von Wolffradt an G. J. G. A. von Reimann, 1. 11. 1810; ibid., Schreiben Nr. 3424 von G. A. von Wolffradt an G. J. G. A. von Reimann, 23.11.1809; ibid., Schreiben Nr.3621 von G. A. von Wolffradt an G. J. G. A. von Reimann, 29. 8. 1811; StA MR, Best. 75 Nr. 286: Schreiben Nr. 2879 von G. A. von Wolffradt an G. J. G. A. von Reimann, 9. 10.1809; ibid., Schreiben Nr. 3452 von G. A. von Wolffradt an G. J. G. A. von Reimann, 27. 11. 1809; StA MR, Best. 76a Nr. 248: Schreiben von G. A. von Wolffradt an G. J. G. A. von Reimann, 29.11.1811; ibid., Schreiben Nr. 5199 von G. A. von Wolffradt an G. J. G. A. von Reimann, 4. 12. 1811; ibid., Schreiben Nr. 5277 von G. A. von Wolffradt an G. J. G. A. von Reimann, 13.12.1811; StA MR, Best. 75 Nr. 195: Schreiben Nr. 4304 von G. A. von Wolffradt an G. J. G. A. von Reimann, 14. 12. 1810.

411 Vgl. HStAH, Hann. 52, Nr. 140, Bl. 13: Schreiben von D. H. Delius, Präfekt in Göttingen, Leinedepartement, an G. A. von Wolffradt, 20.10.1813; ibid., Bl. 18, Schreiben von D. H. Delius an G. A. von Wolffradt, 27. 10. 1813.

412 Vgl. StA MR, Best. 75 Nr. 56. Gleichwohl war Henneberg sicherlich ein ausgezeichneter Zweisprachiger, da er während der Präfekturzeit Bercagnys in Magdeburg, um dessen Unkenntnis der deutschen Sprache auszugleichen, dort als Unterpräfekt eingestellt wurde.

413 Vgl. StA MR, Best. 75 Nr. 56; StA MR, Best. 75 Nr. 199; StA MR, Best. 75 Nr. 200; StA MR, Best. 75 Nr. 1298, Akten der Generaldirektion des öffentlichen Unterrichts - Einrichtung und Ausbau der Halle am Napoleonsplatz in Kassel für die Bürgerschule, 1812-1813. 
verkehrte Wolffradt währenddessen zum Teil auf Französisch, obwohl dies nicht der Vorschrift entsprach ${ }^{414}$.

Man könnte die Sprache der Korrespondenz von beliebig vielen Beamtenpaaren in Betracht ziehen und würde viele Fälle finden, in denen diese abweichend von der offiziellen Sprachregelung sich auf eine Kommunikationssprache festlegten. Die westphälischen Beamten hielten sich nicht an die Vorgaben von 1808; dies hatten bereits die Aufforderungen Bercagnys an die Beamten gezeigt, sich gefälligst an diese Richtlinie zu halten, wie im ersten Teil B I.2. (Übersetzungspraxis) erwähnt.

Im Fall des Innenministers Wolffradt wurde die Wahl der einen oder der anderen Sprache, ob dies mit der offiziellen Sprachregelung konform war oder eine Distanzierung davon bedeutete, nicht direkt thematisiert. Man darf annehmen, dass die interne Regelung der beiden Staatsbeamten oder employés im gegenseitigen Einvernehmen oder sogar, noch wahrscheinlicher, unreflektiert erfolgte. Allerdings, selbst wenn die Sprachwahl nicht direkt thematisiert wurde, könnte die Entscheidung, auf ein französischsprachiges Schreiben in deutscher Sprache zu antworten oder umgekehrt, unausgesprochen von einer Verstimmung im Austausch zeugen.

\subsubsection{Sprachwahl von Beamten im Schriftverkehr mit zweisprachigen administrés}

Eine Akte ist in Bezug auf die Sprachregelung in der administration und die Interaktion mit den Administrierten besonders interessant und wird hier für die Argumentation herangezogen, obwohl sie von der Hauptstadt in die Provinz führt. Sie betrifft die französischsprachigen Kirchendiener und Schulbediensteten in Magdeburg und im Elbdepartement, die Nachkommen von Hugenotten waren, und befindet sich in den Präfekturakten des Grafen von der Schulenburg-Emden ${ }^{415}$. Auf ein in französischer Sprache verfasstes Schreiben der französischen Prediger und Kirchenbediensteten, in dem sie ihre ökonomischen Schwierigkeiten darstellten, die auf ausstehende Gehälter zurückgingen, antwortete der Präfekt stur in deutscher Sprache ${ }^{416}$.

414 Vgl. HStAH, Hann. 52, Nr. 140, Bl. 7: Schreiben von Kerl, Unterpräfekt in Goslar, Ockerdepartement, an G. A. von Wolffradt, 24. 10.1813. Dabei antwortete der Unterpräfekt auf ein Rundschreiben vom 19. 10. 1813, das bei ihm in französischer Sprache eingegangen war.

415 Weiterführend über die Magdeburger reformierte Gemeinde vgl. u.a. TolLIN, Geschichte der Französischen Colonie von Magdeburg; FISCHER, Die französische Kolonie zu Magdeburg.

416 Vgl. Lha S-A, Wernigerode, B 18 I. 1180., Bl. 1 f.: Schreiben der Prediger und des Gemeinderats der französisch-reformierten Gemeinde in Magdeburg an Grafen P.E. A. von der Schulenburg-Emden, 29.3.1808. Die Antwort des Präfekten in deutscher Sprache, vgl. ibid., Bl.3: Schreiben vom Grafen P.E. A. von 
Im Dezember 1808 wandte sich der seit Oktober neu eingestellte Prediger Dihm junior mit einer ähnlichen Gehaltsanforderung wiederum an den Präfekten, zuerst in französischer und daraufhin in deutscher Sprache ${ }^{417}$. Es ist nicht klar, was der Prediger damit erreichte und in welcher Sprache die Antwort verfasst war, falls er vom Präfekten eine auf seinen Antrag erhielt.

Die Prediger beharrten jedenfalls auf der Verwendung der französischen Sprache auch bei ihren späteren Schriftwechseln mit dem Präfekten Graf von der Schulenburg-Emden. Im April 1809 baten sie ihn, bei seinem Vorgesetzen um eine Gehaltserhöhung für sie vorzusprechen ${ }^{418}$. Die Sprache, in der der Präfekt ihnen eine Antwort darauf gab und ob diese nicht sogar nur mündlich erfolgte, ist nicht mehr ersichtlich. Jedenfalls schrieb der Präfekt seinem Vorgesetzten, dem deutschsprachigen Innenminister Wolffradt, in französischer Sprache vom Antrag der Prediger Desca und Provençal der französisch-reformierten Gemeinde in Magdeburg ${ }^{419}$. Die Absage, die der Innenminister in dieser Sache erteilte, ließ er dem Präfekten ebenfalls in französischer Sprache zukommen ${ }^{420}$. Die Prediger gaben ihr Anliegen jedoch nicht auf und wandten sich erneut in französischer Sprache an den Präfekten, der ihnen zum ersten Mal eine Antwort in französischer Sprache $\mathrm{gab}^{421}$.

Die Witwe des Predigers Dihm senior, die sich parallel dazu ebenfalls in französischer Sprache mit ihrem Anliegen um Fortzahlung des Gehalts ihres Mannes ein Jahr nach seinem Ableben an den Präfekten wandte, einmal im April und erneut im August 1809, erhielt vom Präfekten eine Antwort in

der Schulenburg-Emden an die Prediger und den Gemeinderat der französischreformierten Gemeinde in Magdeburg, 1.4. 1808.

417 Vgl. Lha S-A, Wernigerode, B 18 I. 1180., Bl. 5: Schreiben von Dihm junior, Prediger der französisch-reformierten Kirche in Magdeburg, an Grafen P. E. A. von der Schulenburg-Emden, 16.12.1808. Das Schreiben in deutscher Sprache vgl. ibid., Bl. 7: Schreiben von Dihm junior an Grafen P. E. A. von der SchulenburgEmden, 31. 12. 1808. Eventuell ist das Schreiben in der Akte (Bl. 6) die Antwort in deutscher Sprache auf die erste Anfrage in französischer Sprache von Dihm junior, die bei der Aktensichtung nicht mehr registriert werden konnte.

418 Vgl. ibid., Bl. 8: Schreiben der Prediger der französisch-reformierten Gemeinde in Magdeburg an Grafen P.E. A. von der Schulenburg-Emden, 6. 4. 1809; ibid., Bl. 9: Schreiben der Prediger an Grafen P.E. A. von der Schulenburg-Emden, 15. 4.1809.

419 Vgl. Lha S-A, Wernigerode, B 18 I. 1180., Bl. 10: Schreiben von Grafen P.E. A. von der Schulenburg-Emden an G. A. von Wolffradt, 18.4.1809.

420 Vgl. Lha S-A, Wernigerode, B 18 I. 1180., Bl. 13: Schreiben von G. A. von Wolffradt an Grafen P.E. A. von der Schulenburg-Emden, 20. 5. 1809.

421 Vgl. ibid., Bl. 15 f.: Schreiben der Prediger der französisch-reformierten Gemeinde in Magdeburg an Grafen P. E. A. von der Schulenburg-Emden, [5]. 1809; ibid., Bl. 17: Schreiben von Grafen P. E. A. von der Schulenburg-Emden an die Prediger der französisch-reformierten Gemeinde in Magdeburg, [5]. 1809. 
deutscher Sprache ${ }^{422}$. Die Witwe behielt jedoch bei ihren weiteren Anträgen an den Präfekten die französische Sprache bei ${ }^{423}$.

Diese Akte zeigt: Selbst wenn der Präfekt Graf von der SchulenburgEmden bereit war, an den Innenminister Wolffradt Schreiben in französischer Sprache zu adressieren, so wie die Sprachregelung es für diese beiden Amtsträger vorsah - ungeachtet dessen, dass ihrer beider Erstsprache Deutsch war -, so hielt er sich, im Austausch mit den Administrierten, an die deutsche Sprache, selbst wenn diese ihm eine Antwort in französischer Sprache nahelegten. Dem einen, mit dem es ein Leichtes gewesen wäre, auf Deutsch zu korrespondieren, schrieb er auf Französisch, und den anderen, die sich offensichtlich lieber in französischer Sprache artikulierten, pflegte er auf Deutsch zu antworten. Die Sprachwahl orientierte sich offenbar kaum an der Praktikabilität und den Vorlieben der Ansprechpartner, in der sich teilweise die Zwänge der Zeit ausdrückten. Es sieht so aus, als ob der Präfekt der Unannehmlichkeit der wiederholten Gesuche um Gehaltserhöhung oder -fortzahlung mit der Unhöflichkeit eines Sprachwechsels begegnete.

Zieht man weitere Korrespondenzen zwischen den Staatsbeamten heran, so ist in einigen Fällen überliefert, wie die interne Regelung zur Sprachwahl in der Kommunikation zwischen Staatsbeamten oder employésfür Spannungen sorgte.

\subsubsection{Streitigkeiten über die Sprachwahl in Amtskorrespondenzen}

Am 14. April 1808 ließ Finanzminister Jacques Claude Beugnot den Präfekten durch ein Rundschreiben bestellen, sie sollten sich an ihn zukünftig nur noch in französischer Sprache wenden. Unter dem Betreff »Le ministre invite le Préfet à se conformer à la décision de S. M. sur l'usage de la langue française " ging folgendes Rundschreiben beim damaligen Präfekten des Werradepartements, Berlepsch, ein:

je remarque que la Correspondence de quelques fonctionnaires m'est adressée en Langue allemande. Je vous préviens que S. M. a décidé le 21 Mars dernier, que La

422 Vgl. ibid., Bl. 11: Schreiben der Witwe des Predigers Dihm senior der französisch-reformierten Gemeinde in Magdeburg an den Grafen P.E.A. von der Schulenburg-Emden, 29. 4. 1809; ibid., Bl. 18: Schreiben der Witwe des Predigers Dihm senior an den Grafen P.E. A. von der Schulenburg-Emden, 23. 8. 1809; ibid., Bl. 19: Schreiben von Grafen P.E. A. von der Schulenburg-Emden an die Witwe des Predigers Dihm senior, [8]. 1809.

423 Vgl. Lha S-A, Wernigerode, B 18 I. 1180., u.a. Bl. 20: Schreiben der Witwe des Predigers Dihm senior der französisch-reformierten Gemeinde in Magdeburg an den Grafen P.E. A. von der Schulenburg-Emden, 18. 10. 1809; ibid., u.a. Bl.21: Schreiben der Witwe des Predigers Dihm senior an den Grafen P. E. A. von der Schulenburg-Emden, 5. 12. 1809; ibid., u.a. Bl. 23: Schreiben der Witwe des Predigers Dihm senior an den Grafen P. E. A. von der Schulenburg-Emden, 15.3. 1810 . 
langue française continuera d'être employée dans ses conseils d'Etat et privé, à la Trésorerie, dans les Bureaux des quatres ministères, et dans ceux des conseillers d'État chargés de la Direction de quelque partie de l'administration publique. Je vous prie de vouloir bien vous y conformer et de m'accuser reception de la présente ${ }^{424}$.

Der Präfekt des Werradepartements bestätigte den Erhalt des Rundschreibens und versprach, sich für die Einhaltung dieser Sprachregelung einzusetzen $^{425}$.

Zwischen den westphälischen und kaiserlich-französischen Staatsbeamten wurde gelegentlich die Wahl der Kommunikationssprache zum Angelpunkt für Streitigkeiten und Machtkämpfe. Berding berichtet über Streitigkeiten des Präfekten des Werradepartements Trott mit der französischen Domänenbehörde im Jahre 1811:

Der Präfekt des Werra-Departements (von Trott) hatte im November 1811, [...] die Eingabe des Domänendirektors (Tornezy) wiederholt zurückgewiesen mit der Begründung, dass die Eingaben in deutscher Sprache und auf Stempelpapier abgefasst sein müssten. Tornezy wies darauf hin, dass es das Ziel des Pariser Vertrages und der daraus folgenden Übertragung der Rechtsstreitigkeiten an die Präfekturräte gewesen sei, alle Streitsachen ohne Kosten zu entscheiden. Das Ansinnen, Angaben auf Stempelpapier, also gebührenpflichtig vorzubringen, sei ungeheuerlich; ebenso sei es eine unüberbietbare Provokation, den Gebrauch der deutschen Sprache zu verlangen, wo doch auch innerhalb Westfalens zwischen den Ministerien und im Behördenschriftverkehr bis hinab zu den Präfekturen die französische Sprache als Amtssprache gelte ${ }^{426}$.

Die Vermutung liegt nahe, dass der Präfekt, um die Ansprüche der kaiserlich-französischen Vertreter im Königreich Westphalen abzuwehren, die deutsche Sprache als Kommunikationssprache verlangte und so eine Verzögerung im Entscheidungsprozess erzielen und möglicherweise die Souveränität des Königreichs Westphalen gegenüber dem Kaiserreich Frankreich demonstrieren wollte. Der Konflikt wegen der Sprachwahl ergab sich hier nicht innerhalb der westphälischen Behörde, sondern wohlgemerkt im Austausch mit Vertretern von französisch-kaiserlichen Institutionen.

Die obigen Ausführungen haben gezeigt, dass sich im Fall der Sprachwahl ein weites Spektrum von Motivationen für die Kommunikation zwischen Staatsbeamten finden lässt: Auf dieser breiten Skala von Praktiken, die für die einen eng an der offiziellen Sprachregelung blieben und für die anderen in Distanz dazu standen, wird man sowohl pragmatische Handhabungen als auch als Provokation aufgefasste Gebräuche erkennen können. Der Sprachwechsel innerhalb einer Beamtenkorrespondenz konnte für

424 Vgl. StA MR, Best. 77a Nr.473, Akten der Präfektur des Werradepartements über das Ministerialschreiben, dass in den höheren Conseils französisch die Geschäftssprache bleiben soll, 1808: Rundschreiben Nr. 103 von J. C. Beugnot, Finanzminister, an F. L. von Berlepsch, 14. 4. 1808.

425 Vgl. ibid., Schreiben Nr. 166 von F. L. von Berlepsch, an J. C. Beugnot, 16. 4. 1808.

426 BERDING, Napoleonische Herrschafts- und Gesellschaftspolitik, S. 105. 
Irritationen sorgen und barg viel Potential für Unmutsäußerungen. Über die Sprachen führten die »französische Partei« und die »deutsche Partei« zum Teil verdeckt eine Auseinandersetzung, bei der die politische Gesinnung zum eigentlichen Motor wurde.

Relativierend könnte hinzugefügt werden, dass die deutsch-französischen Gegensätze in der administration teilweise von den regionalen Gegensätzen übertroffen wurden. Der Historiker Goecke schreibt dazu:

Im Uebrigen waren die Gegensätze zwischen einer französischen und deutschen Partei nicht die einzigen, welche es in Westphalen gab, sondern die Hessen und besonders die Hannoveraner waren stolz auf ihre vorgebliche Ueberlegenheit über die übrigen Deutschen, und glaubten sich braunschweigischen und preußischen Coterien geopfert und umgekehrt ${ }^{427}$.

Besonders die in Kassel heimischen Hessen empfanden den Zuzug anderer Deutscher als sehr nachteilig:

Diese guten Hessen fanden sich plötzlich fremd in ihrer eignen Stadt und so mächtig wirkte auch hier die Gewohnheit, dass selbst von denjenigen, die noch unter Landgraf Friedrichs Regierung gebildet worden waren, nur die wenigsten sich in den neuen Zustand der Dinge finden konnten. [...] Dieser Fremden-Hass der Hessen traf die Deutschen Ankömmlinge fast noch mehr als die Franzosen und zeigte sich vorzüglich dann, wenn Braunschweiger oder Preussen Stellen im vormaligen Hessen erhielten. [...] Die Eigenthümlichkeiten des Hessenthums waren auf der andern Seite den Fremden Angesiedelten so zuwider und lächerlich, dass diese die Hessen zum beständigen Gegenstand ihrer sarkastischen Unterhaltung machten. [...] Diese Verhältnisse verhinderten denn natürlich ein gesellschaftliches Zusammentreten der Hessen mit den übrigen Deutschen in Kassel ${ }^{428}$.

Über die Vorzugsbehandlung einiger Deutscher, die eher aufgrund ihrer regionalen Herkunft als wegen ihrer Fachkompetenz zustande kam, schreibt Zinserling: "Abgedankte oder reducirte Preussische Offiziere sah man in Menge in Kassel ankommen, einige Wochen lang die Antichambre des Ministers besuchen und dann Stellen erlangen, zu denen sie weder Talente noch Studien hatten ${ }^{429}$. Der Anteil der Preußen in der Verwaltung soll nach dem Eindruck Zinserlings insgesamt höher gewesen sein als der anderer Deutscher ${ }^{430}$. Ein Historiker spricht seinerseits von einem Überhang der Hannoveraner und Braunschweiger ${ }^{431}$.

Trotz Zwiespalt und regionaler Gegensätze sorgte jedoch offenbar die Antipathie gegen das Französische für den Zusammenhalt innerhalb der

427 GoecKe, Das Königreich Westphalen, S. 112; vgl. ZINSERLING, Denkwürdigkeiten, S. 95.

428 Ibid., S. 95.

429 Ibid., S. 40. Die Einflussnahme der deutschen Partei in der Besetzung von Stellen zeigt sich laut Zinserling u.a. im Beharren auf dem »Anciennitäts-Prinzip« und auf dem »Herkunftsprinzip«. Ibid., S. $40 \mathrm{f}$.

430 Vgl. ibid. S. $96 \mathrm{f}$.

431 Vgl. GoECKE, Das Königreich Westphalen, S. 112. 
so genannten deutschen Partei ${ }^{432}$. Die von den Zeitgenossen angesprochenen Schwierigkeiten, die vermeintlich aufgrund des zweisprachigen Verwaltungsapparats entstanden, scheinen jedoch gelegentlich nur als Vorwand angeführt worden zu sein. Folgende Aussage des Geschichtslehrers der Pagen am Hof, Zinserling, legt dies nahe:

Um die Entfernung der Franzosen, die nicht geradezu eine Stütze am Hofe hatten aus ihren bisherigen Stellen vorzubereiten und zu rechtfertigen, musste man zuerst dem Gebrauch der Französischen Sprache in den Geschäften den Krieg erklären. Da die Deutsche Sprache ohnehin vorherrschend war, so wäre es die Pflicht eines Ministers gewesen, in einem Königreich, das von einem Französischen Prinzen beherrscht wurde, das seine Konstitution und Gesetzgebung von Frankreich erhalten hatte, das mit diesem Lande in einer Verbindung stand, die sich zuletzt wahrscheinlich in eine Reunion verwandeln konnte, den Gebrauch der französischen Sprache eher zu befördern als zu hindern. Die seit Ludwig dem XIV. bestehende Universalität dieser Sprache erleichterte dieses Verfahren, und wie weit es von Tyrannei entfernt war, zeigte die Bereitwilligkeit und Leichtigkeit, mit der man anfangs den Französischen Geschäftsstyl adoptirte. [...] In den Central-Administrationen zu Kassel musste man nicht vergessen, dass die Tochter die Sprache der Mutter zu lernen verpflichtet sey. Die Vorwände, diesen Grundsätzen entgegen zu handeln, waren bald gefunden. Wozu, hiess es, bedürfen wir als Deutsche in den Geschäften der Französischen Sprache? Welche Weitläufigkeit! Welche Unmöglichkeit, gewisse Gegenstände im Französischen auszudrücken! Welche Schwierigkeit, so viel geschickte Uebersetzer zu finden. - Und mit diesen Vorwänden gieng man so weit, sogar dem König selbst Deutsch geschriebene Piecen zur Unterschrift vorzulegen, die dieser denn auch zu unterzeichnen nicht ermangelte. So war es denn natürlich, dass man mit scheinbaren Grund gegen die Anstellung derjenigen Franzosen, die in männlichen Jahren nicht mehr vollkommen Deutsch lernen konnten, protestirte. [...] Unaufhörlich wurde der König mit Klagen über die Unbrauchbarkeit der Franzosen in der Administration bestürmt ${ }^{433}$.

Die Ausführungen Zinserlings machen deutlich, wie politisch der Aushandlungsprozess des Gebrauchs der französischen oder deutschen Sprache im öffentlichen Bereich war. Die von den Zeitgenossen angesprochenen Verständigungsschwierigkeiten und vermeintlichen Erschwernisse im Geschäftsgang durch die Verwendung der französischen Sprache erscheinen so zumindest zum Teil vorgetäuscht.

Der hohe Politisierungsgrad der Sprachenfrage in der westphälischen administration lässt sich am folgenden, wahrscheinlich fiktiven Brief deutlich erkennen. Ein westphälischer Beamter schreibt einem anderen über einen dritten, während alle drei anonym bleiben: »Es hat ganz das Ansehen, als ob P. sich selbst eine Grube graben wollte. Seine Wuth, alles zu französiren, muß ihm den Hals brechen, und die deutsche Parthei arbeitet ihm stets entgegen ${ }^{434}$. Diese Aussage macht deutlich, dass der Kampf zwischen der französischen und der deutschen Partei über die Sprachenfrage in der ad-

432 Vgl. ZiNSERLING, Denkwürdigkeiten, S. 22.

433 Ibid., S. 37.

434 Vertraute Briefe, S. 135. 
ministration nicht offen geführt wurde und zudem zum Prinzip geworden war $^{435}$. Das Verwaltungshandeln bestimmter Beamter wurde von dem Moment an, in dem diese als Franzosen oder Franzosenfreunde erkannt worden waren, systematisch abgelehnt, ungeachtet der Inhalte.

Zinserling berichtet, wie beim König gegen die Französischsprachigen in der administration Stimmung gemacht wurde:

Ein Zug, der vieles aufklärt, darf bei dieser Gelegenheit nicht vergessen werden. Der Graf Wolfrath, der bekanntlich weder der feinste Mann noch der feinste Kopf war, und der dem letzteren Umstande vorzüglich seine Ernennung zum Minister des Innern verdankte, hatte einst in einer jener geheimern Zusammenkünfte das Kapitel von Vertreibung der Franzosen besprechen hören. Den Tag darauf findet er den König, umgeben von seinen Französischen Hof-Offizianten, und sagt ihm, ganz voll von der gestrigen Unterhaltung: Sire, j'ai trouvé un excellent moyen, d'eloigner tous les Français. - Mais, mon cher, antwortete ihm der König, Vous oubliez, que je suis aussi Français moi ${ }^{436}$.

Es ist unwahrscheinlich, dass diese Anekdote auf einen tatsächlichen Austausch des Grafen Wolffradt mit dem König zurückgeht. So wie Zinserling sie wiedergibt, hätte sie in dieser Form auch als zeitgenössischer Witz kursieren können ${ }^{437}$. So komisch der wiedergegebene Einwurf Wolffradts auch wirkt, so sollte die Anekdote nicht darüber hinwegtäuschen, dass es einigen Staatsbeamten durchaus ernst war mit dem Ausspielen einer Sprache gegen die andere. Zinserling führt weiter zum Plan der so genannten deutschen Partei in der administration aus:

Wir verdrängen allmählich die Französische Sprache aus den Theilen der Verwaltung, wo sie sich schon eingeschlichen hat, und wo wir sie, ohne zu auffallend zu werden, verdrängen können. Wir entfernen, so viel möglich, alle Franzosen, die Stellen in der Administration erhalten haben, und scheuchen dadurch diejenigen zurück, die noch Lust haben könnten, sich bei uns anzusiedeln ${ }^{438}$.

Zinserling zufolge wurde die Umsetzung dieses Plans durch eine besondere Eigenschaft der so genannten »Französischen Konnexion « erleichtert ${ }^{439}$ :

bei dem Egoismus, den die Franzosen seit der Revolution haben, gelang es der Deutschen Parthei selbst, viele von den Franzosen, die Gönner unter ihren Landsleuten bei Hofe hatten, nach und nach zu entfernen. Dieses war besonders bei der Administra-

435 Einige Akteure der Hofgesellschaft und im Staatsapparat scheinen sich von einem strengen Parteidenken und dem deutsch-französischen Gegensatz emanzipiert zu haben. Bemerkenswerterweise trifft dies z. B. eher auf die Zweisprachigen zu, wie den Generalintendanten des Öffentlichen Schatzes, Pichon. Vgl. ZINSERLING, Denkwürdigkeiten, S. 47-49.

436 Ibid., S. $38 f$.

437 In den Kapiteln B III. (Bittschriften) und B IV. (Karikaturen) werden einige Beispiele von zeitgenössischen Witzen und Rätseln angeführt.

438 ZINSERLING, Denkwürdigkeiten, S. 26.

439 Ibid., S. 40. 
tion der Posten der Fall; [die deutsche Partei suchte] den Franzosen das Geheimniss der Post aus den Händen zu reissen ${ }^{440}$.

Hier schreibt offensichtlich ein erklärter Feind der Französischen Revolution, der ganz dezidierte Vorstellungen über den daraus abzuleitenden Nationalcharakter der Franzosen hatte.

Nichtsdestotrotz ließen sich mindestens zwei Phasen im `Kampf $\triangleleft$ der deutschen und der französischen Partei in der Verwaltung ausmachen: Bis zur Ungnade von Finanzminister Bülow war nach Aussagen von Zeitgenossen die deutsche Partei in einer stärkeren Position. Zinserling beschreibt den Minister metaphorisch als einen Damm gegen Französischen Einfluss « ${ }^{441}$. Nachdem Bülow bei König Jérôme in Ungnade gefallen war, spricht er auch vom »Untergang des Bülowismus ${ }^{442}$. Die Anhänger des Finanzministers vereint er in einer "Klique" und spricht auch anderswo von ihnen als den "Hauptverfechter[n] des Germanismus « ${ }^{443}$. Über die Reorganisation der deutschen Partei nach dem Sturz Bülows schreibt er noch:

Die Zeit war vorbei, wo die Deutsche Parthei ihre Grundsätze laut und öffentlich proklamieren konnte. Sie hatte kein sichtbares Haupt. Der neue Minister der Finanzen hatte Gefälligkeit gegen das Französische System zur Richtschnur seiner Handlungen gemacht. Aber im Stillen suchte man noch immer fort zu wirken, und am Hofe und bei Besetzung der Stellen herrschten, wo nicht eine mächtig Französische Protektion dazwischen kam, die alten Deutschen aristokratischen Principien immer fort ${ }^{444}$.

Auch die Haltung des Königs soll sich gewandelt haben. Anfänglich soll er, wie der ehemalige westphälische Page Lehsten-Dingelstädt berichtet, sich sehr offen gegenüber seinen deutschsprachigen Staatsbeamten gezeigt haben:

er [hat] den Deutschen in allem den Vorzug gegeben. Fast alle Franzosen aus seiner nächsten Umgebung entfernte er. Selbst die Kränkung durch Dörnberg brachte ihn nicht von den deutschen Kavalieren zurück, und er würde dies noch mehr getan haben, wenn ihm nicht vom Kaiser von Zeit zu Zeit Franzosen zugeschickt worden wären, und diese musste er behalten ${ }^{445}$.

Nach Bülows Abgang wurde der König allerdings den Deutschsprachigen gegenüber ungnädig:

Dem König waren die Augen geöffnet worden und voll Zorn, so lange getäuscht worden zu seyn, liess er seinem Unwillen im nächsten Staatsrathe freien Lauf. Als er einige Woche drauf in seinem Vorzimmer Deutsch sprechen hörte, hielt er ebenfalls eine heftige Rede.

440 Ibid., S. 39.

441 Ibid., S. 52.

442 Ibid., S. 50.

443 Ibid., S. 51, 47.

444 Ibid., S. $53 \mathrm{f}$.

445 [LEHSTEN-DingelstäDT], Am Hofe König Jérômes, S. 30. 
Der Graf von Fürstenstein, in gleichem Falle, betrug sich auf gleiche Weise und hielt mehrere privatim starke Strafpredigten ${ }^{446}$.

Bei den deutsch-französischen Fronten, die nach und nach in den Zentralbehörden, aber auch am westphälischen Hof aufgebaut wurden, und teilweise in »Gallomanie« und "Germanomanie « mündeten ${ }^{447}$, wurden die Verständigungsschwierigkeiten zum Teil als Vorwand genutzt, wobei die tatsächlichen deutsch-französischen Verständigungsschwierigkeiten aufgrund der Sprachen wahrscheinlich das geringste Hindernis ausmachten.

Bisher wurde der Fokus dieser Untersuchung auf die Schwierigkeiten gelegt, die die Sprachregelung in der Verwaltung auslösten. Wie sich die sprachlichen und daran anknüpfenden politischen Gegensätze unter den Mitgliedern des westphälischen Hofstaats bemerkbar machten, soll im Folgenden beleuchtet werden.

\subsubsection{Sprachkonflikte am Hof}

Einigen zeitgenössischen Stimmen nach war die Verwaltung im Königreich Westphalen generell stärker deutsch geprägt, während der Hof eher französisch ausgerichtet war. Als Bercagny zum Präfekt des Elbdepartements ernannt und nach Magdeburg versetzt wurde, meldete der kaiserlichfranzösische Vertreter Reinhard missbilligend nach Frankreich, »dass es ratsamer wäre, den alten Grundsatz zu befolgen: >Der Hof ist französisch, aber die Verwaltung deutsch « $^{448}$.

Die sprachlichen Belange innerhalb des Verwaltungsapparats und des Hofstaats flossen in vielerlei Hinsicht ineinander. Gerade was die bereits erwähnte Bildung einer französischen und einer deutschen Partei anging, nahmen die Intrigen am Hof sicherlich Einfluss auf die Organisation im Verwaltungsapparat $^{449}$. Zu den Aktivitäten gegen Finanzminister Bülow schreibt Kleinschmidt beispielsweise, wie bereits erwähnt:

Der französischen Clique am Hofe war Graf Bülow längst ein Stein des Anstoßes, in der gehässigsten Weise wurde seine Thätigkeit kritisiert, und die Intriguen gegen ihn ruhten auch nicht nach der Abreise seines speziellen Verleumders Jollivet ${ }^{450}$.

446 ZINSERLING, Denkwürdigkeiten, S. 53.

447 Ibid., S. 32, 139, vgl. ferner S. 47.

448 KoHL, Die Verwaltung der östlichen Departements, S. 36. Vgl. GoECKE, Das Königreich Westphalen, S. 112; HAVEMANN, Das Kurfürstenthum Hannover, S. 49 .

449 Über das Chaos der Hofintrigen vgl. ANONYMUs, Die entlarvte hohe und geheime Polizei, S. 19f.; GoecKe, Das Königreich Wespthalen, S. 272; KLEINSCHMIDT, Geschichte des Königreichs Westfalen, S. 35, 410-422; KirCHEISEN, König Lustig, S. 89.

450 KLEINSCHMidT, Geschichte des Königreichs Westfalen, S. 410. Zu den Hauptvertretern der deutschen Partei am westphälischen Hof wird oftmals Frau von Truchseß gerechnet. Vgl. KIRCHEISEN, König Lustig, S. 122 f. 
Die Spannungen, die in der administration aufgrund der Sprachen entstanden und die Konflikte, die sich unter dem Vorwand der Sprachen ergaben, finden sich in ähnlicher Form in der Hofgesellschaft wieder. Besonders die Ausführungen des Pagenlehrers Zinserling ermöglichen es, das ambivalente Verhältnis von Hofstaats- und Verwaltungsamtsträgern zu der gesamtgesellschaftlich vorhandenen Diglossie im Königreich Westphalen zu beleuchten. Die "Denkwürdigkeiten" von Zinserling sind vor allem für das höfische Leben in Kassel aufschlussreich.

Im Zusammenhang mit den Sprachkonflikten in der administration konnte bereits angedeutet werden, dass bei den deutsch-französischen Fronten, die nach und nach am westphälischen Hof und in den Zentralbehörden entstanden, die Verständigungsschwierigkeiten zum Teil als Alibi für die Konflikte zwischen den Westphalen französischer und deutscher Herkunft genutzt wurden, wobei die tatsächlichen deutsch-französischen Verständigungsschwierigkeiten wahrscheinlich zweitrangig waren. Die Angaben Zinserlings lassen vermuten, dass das Problem der sprachlichen Verständigung eher einen kulturellen Hintergrund hatte: Die alteingesessenen adligen und bürgerlichen Kreise, die unter der westphälischen Herrschaft Hof und Verwaltungsapparat nahe standen, waren durchaus in der Lage, sich sprachlich mit den französischen Emporkömmlingen zu verständigen ${ }^{451}$. Französisch galt bereits im vorangegangenen Jahrhundert als gängige Kommunikationssprache des Adels in deutschen Hofgesellschaften ${ }^{452}$. Was für die Königin galt, traf auch auf andere Vertreter des Adels am Hof zu:

Die Sitten ihrer Zeit entsprechend, war die Prinzessin ganz nach französischer Art erzogen worden und bediente sich auch weitaus lieber der französischen als der deutschen Sprache. Man hat es ihr später, und zwar mit Recht, zum Vorwurf gemacht, dass sie deutsches Wesen hasse und sich viel lieber mit Franzosen unterhalte als mit ihren Landsleuten. Als am Hofe einst ein deutscher Page eine an ihn gerichtete Frage in seiner Muttersprache beantwortete, erhielt er eine Rüge und die Weisung, mit der Königin stets Französisch zu sprechen ${ }^{453}$.

Die Königin soll sich tatsächlich vorzugsweise der französischen Sprache bedient haben, selbst gegenüber ihren deutschsprachigen Untertanen, zumindest soweit sie zum Hof gehörten ${ }^{454}$. Dies entsprach der Tatsache, dass Französisch gängige Umgangssprache an deutschen Fürstenhöfen war ${ }^{455}$; konform mit der Vorstellung Napoleons, der vor Katharinas Verheiratung mit Jérôme darauf bestanden hatte, dass sie auf ihren württembergischen Hof-

451 ZiNSERLING, Denkwürdigkeiten, S. 18.

452 Vgl. ibid., S. 37.

453 KiRCHEISEN, König Lustig, S. 107.

454 Vgl. MÜlLER, Kassel seit siebzig Jahren, Bd. 1., S. 17.

455 Vgl. u.a. SCHUlze, Die Entstehung des nationalen Vorurteils, S. 32 f. 
staat verzichtete $e^{456}$. Die Tatsache, dass die erste Dame des Landes auf die Benutzung der französischen Sprache Wert legte und dabei ihre deutsche Landessprache verleugnet haben soll, ist symptomatisch für die Verhältnisse am westphälischen Hof.

Einige Vertreter der alten Aristokratie beherrschten das Französische zum Teil fließend und auf hohem Niveau:

Indessen wirkte doch schon die Sprache, dass die Konversation in jenen auf Französischen Fuß lebenden adlichen Deutschen Häusern, eine Lebhaftigkeit und einen tour d'esprit hatte, der sie von der schwerfälligen Plumpheit und Pedanterie der Deutschen bürgerlichen Gesellschaft vortheilhaft unterschied ${ }^{457}$.

Französisch war die »Konversations-Sprache« der höheren Stände im Königreich Westphalen ${ }^{458}$; sie war von jeher die Sprache der Aristokratie in den deutschsprachigen Territorien ${ }^{459}$. Das bereits erwähnte Spottgedicht auf König Jérôme, »Abschied von Cassel«, das wahrscheinlich auf den ehemaligen westphälischen Finanzminister Bülow zurückgeht, wurde bezeichnenderweise in französischer Sprache verfasst ${ }^{460}$.

Es dürfte sogar zutreffen, dass viele Vertreter der alteingesessenen deutschen Aristokratie Französisch auf einem gehobeneren Niveau beherrschten als die französischen so genannten »Emporkömmlinge«. Ein Hauptmotiv für die Rangeleien der vormaligen Elite gegen das Französische und die Franzosen könnte in den unterschiedlichen sozialen Herkünften und Soziolekten des Französischen am westphälischen Hof gründen. Allerdings relativiert Zinserlings Angabe zu den französischen Sprachfertigkeiten der einheimischen Adligen am westphälischen Hof die angebliche Differenz im Sprachniveau zu den eingewanderten Franzosen ein wenig. Über die »Nachahmungssucht des Französischen Tons« dieser Adligen schreibt er, dass sie sich letzten Endes ${ }^{461}$ "auf äussere Form und die Sprache, die gewöhnlich durch ausgewanderte Tanzmeister und Kammermädchen gelehrt, oft ein wahrer Jargon war, beschränk[te] « ${ }^{462}$. Die sprachlichen Differenzen zwischen den deutschen Adligen mit französischen Sprachkompetenzen und den französischen Zuwanderern werden demnach nicht sehr groß gewesen sein; die sozialen und kulturellen dagegen umso deutlicher. Während

456 Vgl. LynCKeR, Historische Skizzen, S. 82; KLEInSCHMIDT, Geschichte des Königreichs Westfalen, S. 33.

457 ZINSERLING, Denkwürdigkeiten, S. 87.

458 Ibid., S. 114, vgl. ferner S. 154.

459 Vgl. SCHLOBACH, Der Einfluß Frankreichs; BÖDEKER, Strukturen der Aufklärungsgesellschaft; KRAMER, WinKELMANN (Hg.), Das Galloromanische; KRAMER, Das Französische in Deutschland; SAUDER, Die französische Sprache in Deutschland; KeIM, »Savoir vivre«, S. 132.

460 ZimmermanN, Graf Bülow, S. 52; vgl. PAYe, Mit Zepter.

461 ZINSERLING, Denkwürdigkeiten, S. 86.

462 Ibid., S. 87. 
sich in der Stadt Kassel die deutsche und die französische Sprachgemeinschaft klarer voneinander trennen ließen, verhielt es sich am Hof anders, so dass die kulturellen und sozialen Differenzen sich dort am spürbarsten manifestierten $^{463}$.

Aus der Perspektive manches Zeitgenossen muss die neu zusammengewürfelte Elite des westphälischen Staates als sehr eklektischer »Haufen« erschienen $\operatorname{sein}^{464}$, in dem sich vielleicht weniger Franzosen gegen Deutsche, Französischsprachige gegen Deutschsprachige gegenüberstanden als vielmehr Vertreter sehr unterschiedlicher Gesellschaftsschichten. Zinserling betont, wenn er auf die »höhere Deutsche Gesellschaft« in Kassel zu sprechen kommt, wie sie »sich [...] mit den Vornehmen Französischen parvenus amalgamirte ${ }^{465}$. Die Aristokratie kann als die »natürliche Feindin « des neuen gouvernement beschrieben werden, so schreibt er noch: »Ihr Stolz musste sich beleidigt fühlen durch die Nothwendigkeit, französische Emporkömmlinge in den bedeutendsten Stellen der Administration und des Hofs neben und über sich zu sehen ${ }^{466}$.

Aus der Sicht mancher brüskierter Adliger waren das Staatsoberhaupt und die Herrschaftsvertreter eine direkte Folge der Französischen Revolution, die sie verabscheuten: »Welche Satire bildete sowohl dieser westfälische als der napoleonische Hof in Paris als Kind einer Revolution für Freiheit und Gleichheit, wo alle königliche Würde mit Füßen getreten und mit königlichem Blut besudelt wurde «, schrieb der Page Lehsten-Dingelstädt im Nachhinein ${ }^{467}$. Mit der neuen Hofgesellschaft taten sich auch nie zuvor so nah erfahrene soziokulturelle Unterschiede auf. Zumal von den 132 Personen, die den Hofstaat bildeten, zwei Drittel deutsche Adlige waren, während das übrige Drittel aus französischen Bürgerlichen bestand ${ }^{468}$.

Eine kurze Betrachtung der veränderten Elite am westphälischen Hof und ihrer Sprachbeherrschung macht diese grundsätzliche Abneigung nachvollziehbar: Manch ein frisch geadelter Abenteurer musste erst die Schreibweise seiner französischen Erstsprache üben und unterschrieb zunächst mit vielen Schwingungen »compte Wellingerode« mit " $\mathrm{p}$ « wie Rechnung, statt »comte« für Graf ${ }^{469}$. Der Wortlaut mag gleich gewesen sein, aber der Titel,

463 Vgl. ibid., S. 86.

464 LUXBURG, zitiert nach: KeIM, »Savoir vivre«, S. 140.

465 ZINSERLING, Denkwürdigkeiten, S. 88.

466 Ibid., S. 18. Über den Adel in Frankreich und Deutschland vgl. FEHRENBACH, Der Adel; ARETIN, Der Adel.

467 [LEHSTEN-DingELSTÄDT], Am Hofe Königs Jérome, S. 15.

468 Vgl. WeSTERBURG, "Sardanapolische Pracht«, S. 198. Über ständisch-soziale Affinität als wesentliche Komponente im Auskommen mit französischen Revolutionstruppen in der Helvetischen Republik vgl. WÜRGLER, Wer hat Angst vor wem?, S. $147 \mathrm{f}$., $151 \mathrm{f}$, passim.

469 KLEINSCHMIDT, Geschichte des Königreichs Westfalen, S. 52. 
so geschrieben, muss auf jeden Fall komisch auf die strengen Wächter des adligen Standes gewirkt haben. Jedenfalls komisch genug, dass die entsprechende Anekdote dazu überliefert wurde.

Ein geadelter Günstling des Königs Jérôme, Graf von Fürstenstein, konnte seinen neuen Titel nicht so recht aussprechen: »Le Camus konnte, da er auch zu den vielen gehörte, die es nicht für nötig hielten, die Sprache des Landes, dem sie ihr Brot verdankten, zu lernen, nicht einmal seinen neuen Namen richtig aussprechen. Es klang wie `Fürchetintin $« \ll^{470}$. Er wurde deswegen sogar von seinen Zeitgenossen belächelt und wiederholt dazu ermutigt, seinen Namen aufzusagen, um alle zu belustigen ${ }^{471}$. Die Akzeptanz für solch arrivierte Persönlichkeiten am westphälischen Hof hielt sich seitens der herkömmlichen Elite der vormaligen Territorien verständlicherweise in Grenzen $^{472}$. Wenn selbst die falsche Aussprache von Nachnamen im Fundus der Memoirenliteratur erhalten geblieben ist, deutet dies darauf hin, wie sehr sich die Zeitgenossen darüber empören konnten. Die Porträtierung des Grafen von Fürstenstein durch den Pagenlehrer Zinserling ist ebenfalls kennzeichnend für die These, dass die soziokulturelle Kluft in der westphälischen Hofgesellschaft viel ausschlaggebender für das erschwerte Zusammenleben war als die tatsächlichen sprachlichen Verständigungsschwierigkeiten:

Sein Aeusseres war der Kälte seines Charakters entsprechend, doch nicht ohne einige Annehmlichkeit, und wenn er länger Graf und Minister geblieben wäre, so würde er im Umgang auch gewisse Manieren seines neuen Standes in grösserer Vollkommenheit erlernt haben, doch nie das, was der Franzose manières grandes et aisées nennt, denn hier standen ihm seine früheren Verhältnisse und sein esprit retreçi im Wege. Als sich zuerst die Nachricht von einer bevorstehenden Verheirathung des Grafen mit der jungen Gräfin $\mathrm{H}^{* * *}$ im Publikum verbreitete, gab es wenige Personen, die ihr Glauben beigemessen hätten. Man hielt diese Familie für zu stolz, um in eine solche Mesalliance einwilligen zu können. Indessen das Unerwartete geschah und die Verblendung des Königs, seines Günstlings, und der Triumph der Deutschen Parthei war hiermit vollendet. Der Graf Fürstenstein wurde germanisirt, ohne es zu wissen, und gefiel sich, wie andere Franzosen, in der Idee nun gleichsam ein Eingeborner, un bon bourgeois de Cassel, geworden zu seyn. Idiot in der Aministration und in den Deutschen Verhältnissen, liess er sich durch des Grafen Versicherung, dass Bülow, sein alter Freund, ein homme universel, und in den Finanzen unvergleichlich sey, zu einem blinden Vertrauen auf diesen hinreissen, und so gehörte nicht einmal mehr Kunst dazu, ihn zu dupiren ${ }^{473}$.

470 KIRCHEISEN, König Lustig, S. 77.

471 FABRE, Jérôme Bonaparte, S. 103. Selbst Namen konnten Gelächter bei den Zeitgenossen hervorrufen. Der provisorische westphälische Kriegsminister d'Albignac musste dies selbst erfahren. Wahrscheinlich wegen seiner mangelnden Kompetenz wurde er, selbst von den Franzosen, mit dem Spitznamen »le ministre Gnic-Gnac« belegt. KLEINSCHMIDT, Geschichte des Königreichs Westfalen, S. 353.

472 KIRCHEISEN, König Lustig, S. 77.

473 ZINSERLING, Denkwürdigkeiten, S. 35 f. 
Der Autor der »Denkwürdigkeiten « vergisst hier nicht zu betonen, dass sich Lecamus die "Manieren seines neuen Standes" gewissenhaft aneignete, obgleich er niemals darin die erwünschte Vollkommenheit erreichen würde. Damit machte er in seinem Kommentar seine Ansicht deutlich, dass der geadelte Graf von Fürstenstein nie ein echter Adeliger sein würde. Dazu waren »seine früheren Verhältnisse und sein esprit retreçi « ein zu schwerwiegendes Hindernis. In diesem Quellenzitat kommt auch der bewusste Standesunterschied zum Vorschein, der bei den alten deutschen Adelsfamilien stark ausgeprägt war, selbst wenn sie sich auf mesalliances mit den Parvenüs am westphälischen Hof einließen.

Die Reaktion der herkömmlichen Elite auf die Standesunterschiede zur zugewanderten Elite aus Frankreich reichte von pikiertem Amüsement bis hin zu grenzenloser Empörung, wobei letztere teilweise geheim gehalten wurde $^{474}$. Es war wieder Zinserling, der sehr präzise die Ursache für den latenten Konflikt der gesellschaftlichen Schichten am westphälischen Hof und für das Problem andeutet, das die vormalige Elite mit den neuen Parvenüs hatte ${ }^{475}$ :

Betrachtete man die Herren und Damen, welche über den Rhein gekommen waren, um eine Zierde des Westphälischen Hofes zu werden, in Hinsicht ihrer gesellschaftlichen Ausbildung, so musste man allerdings selbst das Lächeln gerechtfertigt finden, mit dem manche alte Deutsche Familien [sie] betrachteten ${ }^{476}$.

Auch ein anderer Zeitgenosse entwirft eine Skizze des Hofstaats Jérômes, bei der die vorhandenen Divergenzen in der soziokulturellen Herkunft mehr als deutlich werden. Der Jurist Cramer schreibt:

Dort stand der Thron, für den Fürsten bestimmt, der in der Pracht der Dekoration nicht die dürftige Unbedeutenheit seines Aueßern, und in der Würde der Königsrolle nicht vergessen machen konnte, was er nach seiner Herkunft und nach seiner Verdienstlosigkeit war; abgemessene Etikette ordnete die Stelle jedes für den Augenblick, wo eines Bedienten Ruf, in ausländischer Sprache die Erscheinung des Regenten Deutscher Völker verkündigte. Da stand neben einem Manne, der alle Szenen der französischen Revolution von den philantropischen Grillen an, bis zu den Gräueln der Blutbäder durchgegangen war, neben ihm ein der Zelle entschlüpfter Mönch, dessen lüsterner Blick verrieth, wie er das Weltleben wohl zu nutzen verstand; neben einem Deutschen Fürstensohn drängte sich ein westindischer Pflanzer hervor, ehemals beschäftigt, die Neger zur Arbeit zu treiben; hier buhlte ein vollbürtiger Edelmann um freundliche Worte eines Handwerker Sohnes, den nur die Fähigkeit zu allem in diesen Kreis führte, dort demonstrirte ein Katederheld, der auch am Hofe nicht aufhören wollte, allein zu reden, tauben Ohren, und sein Nachbar, nur im Aktenstile erfahren, verfiel aus diesem in das barbarischste Französische, was noch je der Mund der Sterblichen ausgesprochen; zum Sclaven war hier herabgesunken, wer als Freiherr geboren war und leben konnte, indeß sich ein Staatsmann dort brüstete,

$474 \mathrm{Zu}$ einem ähnlichen Befund über die äußerlich anpassungsfähigen hessischen Adligen kommt MuRK, Der hessische Adel, u.a. S. 257.

475 Vgl. ZINSERLING, Denkwürdigkeiten, S. 81.

476 Ibid., S. 82. 
der in der Liveré sein Leben zubrachte, und hier ein reichdekorirter General erschien, dessen größter Schmuck sonst die Muskete war. Auch der Damen holden Zierde gesellte sich zu der Welt der Münder, und wurde von dem Könige mit besonderem Wohlgefallen betrachtet ${ }^{477}$.

Das Quellenzitat quillt regelrecht über von Vorurteilen und Topoi - nicht zuletzt werden die westphälischen Herrschaftsverhältnisse sogar mit Sklaverei verglichen. Cramer bescheinigte Jérôme unter anderem eine zu fragwürdige soziale Herkunft, um als Staatsoberhaupt des Königreichs Westphalen gelten zu können. Insgesamt zeigt Cramers Skizze, dass es nicht allein eine große Spanne in der sozialen Herkunft der Hofgesellschaftsmitglieder gab, auch ihre Erfahrungswelten waren zum Teil höchst gegensätzlich: Einige hatten an der Zerschlagung des französischen Adels teilgenommen, bevor sie in Westphalen selbst geadelt wurden.

Insgesamt wich Jérôme zudem mit seinem Führungsstil auch vom Habitus eines königlichen Staatsoberhaupts ab. Die Zeitgenossen erzählten sich zahlreiche Anekdoten, wie er in seinem Umfeld durch sein ungewöhnliches Verhalten für Überraschungen sorgte. So berichtet F. Müller, wie einst Königin Katharina ihren königlichen Gemahl mit einem Frühstück im Freien überraschen wollte:

Von einem in dem vorgekommenen Intermezzo [in der den Hofvergnügungen angekauften Hessenstein'sche Villa] sehr unschuldiger Natur hat mir ein dabei gewesener Königlicher Leibpage in seinen reiferen Jahren Mittheilung gemacht. Eines Tags, als der König große Truppeninspection auf dem Forste hielt, hatte sich die Königin in Gesellschaft von einigen Hofdamen und dem Leibpagen nach dieser Besitzung begeben. Sie wollte hier den König bei seiner Rückkehr anhalten und mit einem ländlichen Frühstücke überraschen; es sollte nur in Eierkuchen und gebratenen Kartoffeln bestehen. Das Schälen der Kartoffeln wurde durch die Königin höchsteigenhändig und durch die andern Damen besorgt, nachdem der page erst den größern Schmutz hatte beseitigen müssen. Kaum war man mit backen und braten fertig, so traf der König ein und nahm die ihm bereitete Ueberraschung mit dem besten Humor auf. Es zeigte sich aber bald, dass die hier entwickelten Kochkunst eine sehr unvollkommene gewesen; sowohl der Eierkuchen als die Kartoffeln waren stark angebrannt ${ }^{478}$.

In dieser Situation präsentierte sich Jérôme als erfahrener Koch:

Darum musste das Werk von neuem begonnen werden, wobei der König der kleinen Gesellschaft zeigen wollte, wie viel er in dieser Beziehung einst zu Schiffe gelernt hatte. Er legte seine Uniform ab, band sich eine Küchenschürze um, zerschlug dann kunstgemäß die Eier in die Pfanne und hielt diese so lange über die Kaminflamme bis das Gebäck fertig war; und dieselbe Sorgfalt widmete er auch den Kartoffeln. Herauf setzte er die beiden von ihm zubereiteten Schüsseln mit der Gewandheit eines Kellners den Damen vor, welche die omelette und die pommes de terre frittes nicht

477 CRAMER, Geschichte des Königreichs Westphalen, S. 74f. Vgl. ferner [LEHSTENDINGELSTÄDT], Am Hofe Königs Jerôme, S. 14.

478 MÜlLER, Kassel seit siebzig Jahren, Bd. 1, S. 37; vgl. ferner PrÖHLE, Die Fremdherrschaft, S. 10. 
genug rühmen konnten. So war aus dem geladenen Gäste der eigentliche Bewirther geworden. Man sieht hieraus, dass es dem jungen Manne an Anstelligkeit und Gemüthlichkeit nicht gefehlt hat ${ }^{479}$.

Sicherlich musste nicht nur die Königin über seine Kochtalente staunen. F. Müller selbst, als Sohn eines Handwerkers, der die Anekdote bloß wiedergibt, wird es auch weniger schockiert als belustigt haben, dass der König so talentiert seine Matrosenkochkünste zum Besten gab. Keim weist darauf hin, dass die Kasseler Bürger die Volksnähe ihres Monarchen durchaus zu schätzen wussten: »Die Herzen vieler Bürger gewann er, als er an einem Frühstück ihm zu Ehren auch selbst teilnahm. Sie fühlten sich ernstgenommen ${ }^{480}$. Aber was war mit dem alteingesessenen Adel? Katharina mochte sich für ihren Teil sehr anpassungsfähig zeigen - die von F. Müller wiedergegebene Anekdote beinhaltet im Übrigen womöglich auch eine Kritik an der einstmaligen Königin der Westphalen, die sich auf die Ständegewohnheiten ihres "prince français" aus eigenem Antrieb einließ; den altehrwürdigen Adelsfamilien mag es anders vorgekommen sein. Die Anekdote, wahrhaftig oder nicht, könnte mit einem schockierten bis empörten Ausdruck weitererzählt worden sein. Hier spiegelt sich die Faszination wider, die sich anhand der Gerüchte über König Jérômes soziale Herkunft und seinen plötzlichen Aufstieg zum Monarchen ergab. Wer die Anekdote weitergab, vermittelte womöglich die Botschaft: Wie empörend es doch sei, quasi von einem Kellner regiert zu werden, selbst wenn er gut und gern kochte.

Auch richtete Jérôme Feierlichkeiten und Maskeraden aus, die in großen Volksfeste mündeten und für kurze Zeit für die Kasselaner aus dem Königreich Westphalen ein Schlaraffenland machten ${ }^{481}$. Um einen Mann seiner gardes $d u$ corps vor dem Ertrinken zu retten, sprang er ihm ohne zu zögern selbst nach; diese Heldentat nutzte er zur Pflege seines Ansehens bei seinen Untertanen, indem er den Hofmaler Louis Dupré beauftragte, die Szene zu verewigen ${ }^{482}$. Wie bereits erwähnt, wurde seine Eröffnungsrede vor den Reichsständen besonders bemerkt, weil sie, unabhängig von der französischen Sprache, außerdem auch von der damals üblichen Kanzleisprache abwich $^{483}$.

All diese Eigenschaften und Eigenwilligkeiten des Königs Jérôme bewiesen seinen Untertanen, dass er ein ungewöhnlicher Monarch war, und dies

479 Ibid.

480 KEIM, »Savoir vivre«, S. 139; vgl. ferner S. 144.

481 Vgl. MÜlleR, Kassel seit siebzig Jahren, Bd. 1, S. 26; vgl. ferner WegEner, Die Relationen Napoléons I. zum Königreich Westfalen, S. $57 \mathrm{f}$.

482 "Jérôme rettet einen Gardisten aus der Mulde« von Dupré. Vgl. Boudon, Le roi Jérôme, S. 311; BEYELER, Vom französischen Prinzen zum westphälischen König, S. 70 f., 486f. Der Page Lehsten-Dingelstädt erwähnt ebenfalls Kinson als Maler dieser Szene. Vgl. [LEHSTEN-DinGELSTÄDT], Am Hofe König Jérômes, S. 30.

483 Vgl. AnONYMUS, Regierungs-Geschichte, S. 229. Vgl. oben S. 149. 
war sicherlich in ihrer Wahrnehmung auf seine soziale Herkunft zurückzuführen. Bei der kuriosen Zusammensetzung der Hofgesellschaft, die Cramer sehr deutlich und mit vielen Topoi gesättigt zeichnet, liegt die Vermutung nahe, dass manche Vertreter des einheimischen Adels sich eher widerwillig mit der Gemeinschaft der französischen Einwanderer vereinigten.

Der Historiker Goecke bestätigt die Darstellung des Zeitgenossen Cramer und nuanciert sie zugleich, indem er darauf hinweist, dass die Abneigung gegenüber der neuen Elite nicht von allen geteilt wurde: »Das königliche Haus wies eine Menge von Hofbeamten auf, worunter wir sowohl geadelten französischen Abenteurern als auch redlichen Freunden der neuen Verhältnisse aus dem deutschen Adel begegnen ${ }^{484}$.

Zinserling zufolge bildeten die Einwanderer aus Frankreich im Allgemeinen, insbesondere aber diejenigen, die nicht am Hof oder in der Verwaltung unterkamen, einen unrühmlichen Abglanz der französischen Gesellschaft:

Diejenige Franzosen, welche sich in einer geringeren Sphäre zu Kassel befanden, verdienen in gesellschaftlicher Hinsicht noch weit weniger Beachtung. Es waren größtentheils Leute, die in Frankreich ursprünglich zu den geringeren Klassen gehörten und als Emporkömmlinge der Revolution ihr Glück gemacht hatten ${ }^{485}$.

Wie bereits erwähnt, war die zwielichtige Herkunft manch eines westphälischen Geadelten so bekannt, dass selbst Napoleon Bedenken anmeldete. Am 10. September 1811 wurde auf sein Bestreben der westphälische Adel durch ein Dekret reorganisiert und es wurden Recherchen angestellt, um unredliche Mitglieder des Hofes auszuschließen. Der ehemalige Page Lehsten-Dingelstädt berichtet darüber:

Der Zufluß von Menschen aus aller Herren Ländern nach Westfalen an den üppigen Hof war sehr groß. Viele ließen sich mit Geburtsrechten begrüßen, welche ihnen nicht zukamen. Zweifel über den Stand gar mancher tauchten auf. Man hielt es für angemessen Recherchen anzustellen und die Verhältnisse des Adels zu regeln. Durch ein königliches Dekret vom 10. Sept. 1811 sollte ein neuer westfälischer Adel organisiert werden. Die Mitglieder des alten sowie des neukreierten Adels sollten als Wahrzeichen des westfälischen Adels zwei Fahnen mit dem westfälischen Adler ihren Wappen beifügen, welche als Lanzen über Kreuz gelegt unter dem Wappenschild lagen. Indes wurde diese Maßregel nicht beifällig aufgenommen. Alle vom alten Adel erhielten das Prädikat: Baron ${ }^{486}$.

Mag das Urteil der Historikerin Helene Wegener etwas einseitig erscheinen und teilweise auf unkritischer Quellenauslegung beruhen, dennoch ist es in seiner Grundthese einprägsam: Sie macht den westphälischen Hof für den Untergang des westphälischen Staates mitverantwortlich, da die Zusammensetzung des Hofstaats aus Personen außerordentlich schlechten Leumunds besonders verhängnisvolle Konsequenzen hatte:

484 GoECKE, Das Königreich Westphalen, S. $64 \mathrm{f}$.

485 ZinSERLING, Denkwürdigkeiten, S. 86; vgl. LYNCKER, Historische Skizzen, S. 80 f.

486 [LEHSTEN-DingELSTÄDT], Am Hofe König Jérômes, S. 61. 
Die von Jérôme vorgenommene Auswahl des westfälischen Hofes ist ein Verhängnis während der ganzen Regierungszeit für den westfälischen Staat sowohl wie persönlich für Jérôme und Schuld an dem inneren Verfall des Hofes und Staates. Der westfälische Hof ist [...] ein Hof von Lakaien. Dieser Hof rekrutiert sich grösstenteils aus persönlichen Freunden Jérômes aus der Zeit seines abenteuerlichen Seelebens und der schlesischen Kampagne 1807, unter ihnen haben eine besondere Rolle am Kasseler Hof Lecamus, La Flèche, Meyronnet, die das Jérômes Anerbieten skrupellos angenommen, gespielt; ein geringer Bruchteil hat aus von Napoleon selbst gelieferten Franzosen [...] bestanden, [von denen die meisten nach weniger Zeiten enttäuscht nach Frankreich zurückgingen]. Was nach d[eren] Abzug noch übrig bleibt, ist ein Hofstaat von bedeutungslosen, abenteuerlichen Fremdlingen [...]. Jérôme war hier die für ihn unmöglich lösbare Aufgabe gestellt, einen Hof einzurichten, von dessen Einrichtung er nichts verstehen konnte, da er nie die wahre echte Hofluft genossen $[\text { hatte }]^{487}$.

Sicherlich ist anzumerken, dass Historiker teilweise diejenigen zeitgenössischen Aussagen ohne die nötige Distanz wiedergaben, die sich nach der Auflösung des Königreichs Westphalen dezidiert ablehnend und negativ zeigten. Der Topos vom Königreich Westphalen als »Eldorado für [...] allen Abhub der französischen Nation « wird bei Historikern wie Kleinschmidt, Wegener oder Kircheisen gern wiederholt ${ }^{488}$. Wenn dieses Urteil auch stärker auf die Verhältnisse außerhalb des Hofes zutraf, so wurden auch die Herkunft des Königs und seine Unerfahrenheit mit dem Hofleben als Auslöser eines ungewöhnlichen Herrschaftsrituals kritisiert.

Gelegentlich gaben die Emporkömmlinge Anlass, sich über ihre Manieren zu amüsieren ${ }^{489}$. »Spöttereien und Sarkasmen über die [...] Gaucherien, die anfangs zuweilen beim Cärimoniel vorfielen«, waren an der Tagesordnung $^{490}$. König Jérôme entwickelte tatsächlich eine große Leidenschaft für die neue Hofetikette und das neue Hofzeremoniell ${ }^{491}$. Selbst Napoleon muss Missfallen an der von seinem Bruder eingeführten Hofetikette gehabt haben $^{492}$. Cramer berichtet ausführlich über das "große Staatsspektakel « beim Einzug des Königs und dem dabei entfalteten »Westphälischen Hofzere-

487 WegENER, Die Relationen Napoléons I. zum Königreich Westfalen, S. 56 f. Kleinschmidt betrachtet es ähnlich: »Den König hatten dahin begleitet oder es folgten ihm auf dem Fuße Scharen von Abenteurern [...]; Glücksritter, Roués nahmen bald am Hofe und in der Verwaltung [...] die erste Rolle ein, Westfalen wurde Eldorado für [...] allen Abhub der französischen Nation; [...] manche von ihnen datierten ihr Anrecht an den Königlichen Säckel von Schlesien oder von Paris her «. KLEINSCHMIDT, Geschichte des Königreichs Westfalen, S. $30 \mathrm{f}$.

488 Vgl. ibid., S. 479.

489 Vgl. ZiNSERLING, Denkwürdigkeiten, S. 22.

490 Ibid., S. 22.

491 Vgl. Hilarius, Humoristische Reise, S. 76; [LEHSTEN-DingelSTÄDT], Am Hofe König Jérômes, S. 7; GOECKE, Das Königreich Westphalen, S. 220; WEGENER, Die Relationen Napoléons I. zum Königreich Westfalen, S. 57; KIRCHEISEN, König Lustig, S. 94; FABRE, Jérôme Bonaparte, S. 105 f.; LOSCH, Kurfürst Wilhelm I., S. 282.

492 Vgl. GoECKE, Das Königreich Westphalen, S. 220. 
moniel « ${ }^{493}$. Das Leben in Kassel änderte sich angeblich schlagartig. In der Enthüllungspublizistik sind Vorwürfe über Unzucht mit deutschen Frauen ein häufiger Topos ${ }^{494}$. Die Zeitgenossen berichten über den ausschweifenden Luxus sowie über die Sittenlosigkeit am Hof ${ }^{495}$. Ein asiatischer Luxus herrsche am Hof, schreibt Wilhelm Wagener ${ }^{496}$, F. Müller bemerkt, dass man sich anstrengte, "auf dem [gleichen] Fuße des Kaiserhofs in Paris « zu leben ${ }^{497}$. Der Topos von Kassel als »kleinem Paris« konnte bereits mehrfach in den bisher zitierten Quellenzitaten ausgemacht werden ${ }^{498}$, wobei der Luxus durch Zwangsanleihen finanziert wurde ${ }^{499}$, was für Kassel zeitweilig einen wirtschaftlichen Aufschwung brachte $e^{500}$.

Auch Zinserling gibt seine Sicht über die Umwälzungen preis, die der Strom an Zuwanderern aus Frankreich nach sich zog:

Diess war der gesellschaftliche Geist von Kassel, als es auf einmal von einer Menge Menschen überströmt wurde, die die Welt unter den mannigfaltigsten Verhältnissen gesehen und durch ihre Erfahrungen ein grosses savoir faire erlangt hatten, Geiz in der Regel nur dem Namen nach kannten, als Verschwender erschienen und einen hohen Grad gesellschaftlicher Gewandtheit und Abgeschliffenheit besassen. [...] Diese guten Hessen fanden sich plötzlich fremd in ihrer eignen Stadt und so mächtig wirkte auch hier die Gewohnheit, dass selbst von denjenigen, die noch unter Landgraf Friedrichs Regierung gebildet worden waren, nur die wenigsten sich in den neuen Zustand der Dinge finden konnten ${ }^{501}$.

493 Vgl. Cramer, Geschichte des Königreichs Westphalen, S. 75 f.

494 Vgl. Wagener, Das Königreich Westphalen, S.24f. Faszinierend ist im übrigen die ambivalente Vereinnahmung der Frauen als »Deutschtum« im zeitgenössischen Diskurs der Memorialisten: Auf der einen Seite wurden die deutschen Frauen als Wahrzeichen des Patriotismus eingesetzt, vgl. dazu HAGEMANN, Heldenmütter, S. $185 \mathrm{f}$. Auf der anderen Seite, wie hier, verschränkten sich die Stereotypisierungen von Geschlechts- und Nationalcharakteren, so dass die Frauen sich zuerst mit den feminisierten Franzosen abgaben und für das Verkommen der deutschen Sitten mitverantwortlich gemacht wurden. Die Diskrepanz zwischen den »Patriotinnen« und »Huren der Franzosen« ist eklatant. Vgl. Cöln, zitiert nach: BuCHNeR, Anno Dazumal, Bd. 2, S. 275-279; HAGEMANN, Nation, Krieg und Geschlechterordnung, S. 571; FLORACK, »Weiber sind wie Franzosen geborne Weltleute«, S. 338; OWZAR, Fremde Herrschaft, S. $78 \mathrm{f}$.

495 Vgl. CRAMER, Geschichte des Königreichs Westphalen, S. 75 f.; LUXBURG, zitiert nach: KEIM, »Savoir vivre«, S. 140; vgl. ferner GOECKE, Das Königreich Westphalen, S. $227 \mathrm{f}$.

496 Vgl. Wagener, Das Königreich Westphalen, S. 23; Wegener, Die Relationen Napoléons I. zum Königreich Westfalen, S. 58. Kritisch dazu vgl. OWZAR, Fremde Herrschaft, S. 78. Allerdings werden der Luxus und der Pomp am westphälischen Hof als nicht nur imaginiertes Kontrastprogramm zur Haushaltung unter Kurfürst Wilhelm I. auch von Historikern bestätigt, vgl KeIM, »Savoir vivre«, S. 136.

497 MÜLLER, Kassel seit siebzig Jahren, Bd. 1, S. 16.

498 Vgl. ANONYMUS, Die französische Garküche; WegENER, Die Relationen Napoléons I. zum Königreich Westfalen, S. 57 f.; KIRCHEISEN, König Lustig, S. 84.

499 Vgl. Wegener, Die Relationen Napoléons I. zum Königreich Westfalen, S. 16.

500 Vgl. MÜller, Kassel seit siebzig Jahren, Bd. 1, S. $16 \mathrm{f}$.

501 ZINSERLING, Denkwürdigkeiten, S. $94 \mathrm{f}$. 
In dem sensationellen Wirbel, den die pompöse Lebenshaltung am Hof und die Zuwanderung aus Frankreich in Kassel auslösten, änderte sich die Einstellung der vormaligen adligen Elite zur neuen Herrschaft: »Das Königreich Westphalen ist ein vorübergehendes Phänomen, ein Meteor, das einige Jahre nur am Deutschen Himmel schimmern wird « ${ }^{502}$. Die Haltung einiger Mitglieder der deutschen Partei war dementsprechend: »Alles kommt darauf an, in dieser kurzen Zeit, Deutschen Geist, Deutsche Sprache, Deutsche Sitten, Deutsches Herkommen gegen den Einfluss fremder Konstitutionen, Gesetzgebungen, Sitten und Kolonisten zu retten « ${ }^{503}$. Allen Angaben Zinserlings zufolge waren in diesem Kontext die vielbeschworenen Verständigungsschwierigkeiten eher simuliert ${ }^{504}$.

Alle angeführten Beispiele, wenn sie auch wegen ihrer tendenziösen grundsätzlich antifranzösischen Haltung mit Zurückhaltung aufzunehmen sind, dokumentieren dennoch den Kulturschock für die einheimischen Adligen am Hof $^{505}$. Aber auch von Seiten der Emporkömmlinge wurden die Unterschiede in der soziokulturellen Herkunft durchaus bemerkt, was sich zum Beispiel an diesem zeitgenössischen Kommentar ablesen lässt: »On dit que les Barons allemands savent le latin ${ }^{506}$. Die Begegnung mit der lateinkundigen deutschen Gelehrtenrepublik war für viele offensichtlich eine neue Erfahrung ${ }^{507}$.

Das Vortäuschen von Kommunikationsproblemen, die das Zusammenleben von Westphalen französischer und deutscher Erstsprache angeblich hervorrief, war noch ambivalenter, den Angaben Zinserlings nach zu urteilen:

Mehrere jener alten adlich-deutschen Familien, die in früheren Zeiten nichts als Französisch gesprochen hatten, affektirten jetzt auf einmal eine besondere Vorliebe für Deutsche Sprache und Litteratur, versuchten einzelne Franzosen, denen sie Gutmüthigkeit und Bildungsfähigkeit genug zutrauten, zu germanisiren und sprachen, wenn sie Deutsche Klienten aus der bürgerlichen Mittelklasse mit einem Thee oder Diner beglückten, um den Patriotismus zu verbreiten, Deutsch, während sie unter sich blos Französisch plauderten. Viele junge Leute, die das Glück eines solchen Diners genossen, wurden wirklich die Düpe dieses Stratagems und verbreiteten, durch solche erlauchte Beispiele unterstützt, die Germanomanie weiter unter ihren Umgebungen. Dinge dieser Art scheinen Kleinigkeiten; wir haben uns aber zu sehr von

502 Ibid., S. 25. Zum Topos der Meteoriten als Vorzeichen des Untergangs der napoleonischen Ära vgl. ferner KLEINSCHMIDT, Geschichte des Königreichs Westfalen, S. 439.

503 ZINSERLING, Denkwürdigkeiten, S. 25.

504 Ibid.

505 Über ähnliche soziale Spannungen innerhalb des post-revolutionären Adels in Frankreich vgl. BRELOT, La noblesse au temps de l'égalité, S. 221-224.

506 ZINSERLING, Denkwürdigkeiten, S. 22; vgl. ferner SCHELLER, Jeromiade, S. 47.

507 Vgl. BÖNING, Weltaneignung, S. 119. 
ihrem Einflusse zu überzeugen Gelegenheit gehabt, um sie mit Stillschweigen übergehen zu können ${ }^{508}$.

Seitens des alteingesessenen Adels wurde gegenüber der neuen französischen Elite beklagt, wie die französische Sprache die Kommunikation erschwere, und gegenüber der »bürgerlichen Mittelklasse« mit der Pflege der deutschen Sprache kokettiert, obgleich Französisch für den Privatgebrauch unter den meisten Adligen nach wie vor spontan gewählt wurde. Die Ambivalenz der herkömmlichen adligen Elite in Bezug auf ihre Sprachwahl hätte nicht offensichtlicher sein können. Die Sprachenfrage wurde als Feld definiert, um sich demonstrativ von den Franzosen zu distanzieren, unabhängig von den tatsächlichen Sprachfertigkeiten, -gewohnheiten und -neigungen.

Michaele Siebe erläutert die Hintergründe dieses Phänomens. Der Gegensatz von Bürgertum und Adel könne die Bildung von nationalen Gegensätzen verstehen helfen ${ }^{509}:$ »In Frankreich berief sich die höfische Gesellschaft auf ihre edleren germanischen Ursprünge, um sich von der Bourgeoisie und dem Rest der Bevölkerung als auserwählte Rasse abzugrenzen. In Deutschland ist die Abgrenzung der Bourgeoisie gegenüber dem >Adel « eng mit der Abgrenzung zur Nation Frankreich verknüpft « ${ }^{510}$. Die gegenseitigen und komplexen Abgrenzungs- und Einbeziehungstendenzen, die zu Beginn des 19. Jahrhunderts unter der napoleonischen Ära verstärkt einem nationalen Projekt dienen sollten, manifestierten sich zum Teil über die Sprachwahl oder wurden über diese demonstriert. Der deutsche Adel, wegen seiner Verwendung der französischen Sprache bereits Ende des 18. Jahrhunderts zunehmend kritisiert, bemühte sich demnach unter der westphälischen Herrschaft und noch stärker ab 1813, die kritisierte Gewohnheit abzulegen, um vom Nationalstiftungsprojekt einer kleinen intellektuellen Elite nicht ausgeschlossen zu bleiben ${ }^{511}$.

Die Sprachenfrage in der westphälischen Gesellschaft, versucht man sie über die überlieferten Aussagen der Zeitgenossen zu eruieren, erfordert strenge Quellenkritik: Wegen der vielfältigen Strategien, die im Spiel waren, darf aus den negativen Aussagen der Zeitgenossen nicht darauf geschlossen werden, dass das, worüber sie sich in Bezug auf die Sprachen beklagten, direkt die reale Situation der Sprachen reflektierte. Hinter den überlieferten zeitgenössischen Verlautbarungen über das Verhältnis der Sprachen in der westphälischen Gesellschaft stecken zum Teil komplexe Vorgänge der Abgrenzung, die hier angedeutet werden konnten. Die Sprachenfrage war unter den Westphalen ein höchst politisches Thema.

508 ZINSERLING, Denkwürdigkeiten, S. $89 \mathrm{f}$.

509 SIEBE, Von der Revolution zum nationalen Feindbild, S. 8 f.

510 Ibid., S. 10.

511 Zur Adelsfeindlichkeit vgl. u.a. PRÖHLE, Die Fremdherrschaft, S. 28; ARETIN, Der Adel; FeHrenbaCH, August Wilhelm Rehbergs Adelskritik. 
Zusammenfassend kann festgehalten werden, dass einheimische Adlige zum Teil über Französischsprachkenntnisse verfügten, die auf einem höheren Niveau lagen als das der französischsprachigen Zuwanderer, die zu Mitgliedern der Hofgesellschaft wurden. Die Sprachverständigungsschwierigkeiten am Hof waren zweitrangig, die soziokulturellen Unterschiede dafür um so gravierender. Deswegen kann davon ausgegangen werden, dass bei der Thematisierung die Sprachenfrage als Problem durch die Zeitgenossen zum Teil etwas vorgetäuscht wurde, das auf einer grundsätzlicheren Abneigung beruhte und nicht auf eine rein sprachliche Kommunikationsschwierigkeit reduziert werden kann. Das Problem der vorwestphälischen Elite mit den Vertretern der neuen Herrschaft war nicht so sehr ein sprachliches, wie öffentlich bekundet, sondern vielmehr ein kulturelles. Die Akzeptanzbereitschaft für eine Elite, die auch als »Abenteurer« bezeichnet wurde, war aus der eigenen Herkunft und Identität heraus verständlicherweise begrenzt ${ }^{512}$.

Aus den obigen Ausführungen lässt sich der Schluss ziehen, dass die sprachlichen Gemeinsamkeiten und Differenzen in der westphälischen Gesellschaft anders gelagert waren als es aus dem heutigen europäischen Selbstverständnis vermutet werden könnte. Dialekt sprechende Bauern wurden zum Teil von Hochdeutsch sprechenden Staatsvertretern nicht verstan$\operatorname{den}^{513}$, während Franzosen, die in sieben Jahren westphälischer Herrschaft kaum ein Wort Deutsch gelernt hatten, sich mit Französisch sprechenden Deutschen gut verständigen konnten. In der Alltagspraxis hatten die regionalen Sprachbarrieren eine weitaus größere Bedeutung als die Barriere zwischen Franzosen, die kein Deutsch konnten, und Deutschen, die Französisch beherrschten. Die neue Elite aus französischen Zuwanderern teilte wahrscheinlich, trotz der schwer überwindlichen sprachlichen Barrieren, mit den königlich-westphälischen Untertanen aus den Unterschichten zum Teil stark übereinstimmende Erfahrungswelten und Wahrnehmungsmuster. Auch stellt die Vertrautheit frühneuzeitlicher europäischer Hofkreise mit der französischen Sprache einen entscheidenden Faktor dar ${ }^{514}$. Nicht zuletzt wiesen manche französische Erstsprachler, die aus den französischen Unterschichten stammten und zu Angehörigen der neuen westphälischen Elite wurden, Schwächen in französischer Schrift- und Regierungssprache

512 KLEINSCHMIDT, Geschichte des Königreichs Westfalen, S. 30.

513 Vgl. Ruthe, Auf der Flucht vor den Strickreitern, S. 45; FABRE, Jérôme Bonaparte, S. 138.

514 Schulze stützt sich auf Zahlen: "An deutschen Fürstenhöfen des 18. Jh. wird eindeutiger und besser Französisch gesprochen als in Frankreich, wo 1867 10\% aller Franzosen noch kein Französisch sprechen können. Französisch wird in den besseren Kreisen Europas populärer als in Frankreich selbst. [...] Erst im späten 18. Jh. beginnt die englische Sprache in Europa Boden zu gewinnen, ohne freilich schon die Vorherrschaft des Französischen in Diplomatie und Wissenschaft brechen zu können«. SCHULZE, Die Entstehung des nationalen Vorurteils, S. 32 f. 
auf, die für die Herrschaftspraxis möglicherweise erschwerend wirkten ${ }^{515}$. Auch was ihre Aufnahme durch die in französischer Regierungssprache beflisseneren Hofkreise aus vorwestphälischen Verhältnissen anbelangt, hatte diese Schwäche oft ein erhebliches Gewicht in der Aushandlung der neuen Herrschaftsverhältnisse.

Weiter zugespitzt kann folgende These formuliert werden: Wenn Personen sich sprachlich verständigen konnten, bedeutete dies noch nicht, dass sie sich kulturell und sozial nahe standen, während Personen, die über keine gemeinsame sprachliche Verständigungsmöglichkeit verfügten, durchaus ähnliche Erfahrungswelten und kulturelle Hintergründe miteinander teilten.

Im Kontext des Hofes und des höheren Verwaltungsapparats wurden offenbar rein sprachliche Verständigungsprobleme hochstilisiert, wo eigentlich kulturelle oder soziale Abneigung herrschte. Diese Differenzen waren vermutlich weniger nationalkulturell als ein soziales Akzeptanzproblem, dem soziokulturelle Unterschiede zugrunde lagen.

Die Kohärenz von Sprach-, National- und Kulturgemeinschaften, wie im intellektuellen zeitgenössischen Diskurs propagiert, scheint nicht unbedingt mit der Alltagsrealität der Westphalen in Übereinstimmung gewesen zu sein.

Die Konstruktion des nationalen Feindbilds Frankreich im 19. Jahrhundert in den deutschen Territorien war unter anderem im Gegensatz von Bürgertum und Aristokratie in Deutschland begründet. Weil sich der deutsche Adel frankophil und frankreichorientiert zeigte, gaben sich bürgerliche Kreise wiederum frankreichfeindlich, um sich demonstrativ vom Adel zu distanzieren. Die sozialen Gegensätzen bildeten die Basis für die Konflikte, die später "als Ausdruck >nationaler`, >kultureller` Gegensätze zwischen Deutschland und Frankreich« aufkommen sollten ${ }^{516}$.

515 Vgl. AnOnymus, Sind die Teutschen, S. 11; LosCH, Kfm. Hessen, S. 51.

516 SIEBE, Von der Revolution zum nationalen Feindbild, S. 10. Vor ihm hatte bereits der Historiker Losch diese Tendenz im Königreich Westphalen so beschrieben: »Daß Gesetze und Verordnungen doppelsprachig erlassen, daß die Geschäftssprache der höchsten Verwaltungsbehörden französisch war, daß der König dieses im Herzen Deutschlands gelegenen Landes selbst die Sprache seiner Untertanen nicht verstand, ließ man sich in [den] Kreisen [der Anhänger der neuen Zeit aus dem Beamtenstand und in der gebildeten Welt] willig gefallen. War doch französisch von jeher die Sprache der feinen Welt gewesen «. LOSCH, Kfm. Hessen, S. 50 f. Demnach hätte die Franzosenzeit im Nachhinein die Kluft zwischen gehobenen bürgerlichen Schichten und Adel sowie den weniger gebildeten Schichten geschürt. 


\subsection{Sprachenfrage aus der Sicht der Sprachreiniger, Memorialisten und Historiker}

»Hier ist die Zeit und der Ort nicht für den Beweis, dass es nur eine wahrhaft natürliche Gränze der Völker gebe, dass nur die Sprache, an sich und als Ausdruck der Volks-Eigenthümlichkeit, befriedigend diesem Begriffe entspreche«, schrieb im Jahre 1814 Richard Harnier ${ }^{517}$.

Alle zeitgenössischen Urteile aus westphälischer Zeit über die aus dem Sprachkontakt resultierenden Schwierigkeiten in der Kommunikation, die bisher zitiert wurden, erscheinen gemäßigt, wenn man ihnen die Kommentare der Flugschriftautoren und Memoirenschreiber nach 1813 gegenüberstellt. Im intellektuellen Diskurs Anfang des 19. Jahrhunderts war die konstitutive Kraft von Sprache für die nationale Identitätsstiftung unbestritten, und die Nationalsprachen sollten als Hebel der Nationsbildung par excellence dienen ${ }^{518}$.

Ernst Moritz Arndt, der im Folgenden als Vertreter eines frühen deutschen Nationalismus mit seiner Ansicht über die Sprachenfrage zitiert wird, war im Gegensatz zu Harnier bemüht, unter Beweis zu stellen, wie Sprachen die Völker voneinander trennten. Er ging von einer biologischen Unmöglichkeit aus, die vollkommene Beherrschung einer Fremdsprache zu erreichen, selbst bei einem Kleinkind, das sehr früh damit in Kontakt gewesen sei ${ }^{519}$. Auch sich in eine fremde Sprache zu verlieben sei sehr

517 HARNIER, Bildet der Rhein, S. 4.

518 Im Folgenden wird vorwiegend anhand von Arndts Schrift »Ueber Volkshaß und über den Gebrauch einer fremden Sprache« argumentiert. In einer weiter angelegten Analyse wären noch u.a. folgende Schriften von »Sprachreinigern « und »Sprachbereicherern « zu berücksichtigen: CAMPE, Versuche von deutscher Sprachbereicherung; DERS., Zweiter Versuch deutscher Sprachbereicherungen; DERS., Über die Reinigung und Bereicherung der deutschen Sprache; DERS., Wörterbuch zur Erklärung und Verdeutschung, 1801; DERS., Versuch einer genauen Bestimmung und Verdeutschung; DERS., Wörterbuch der deutschen Sprache; DERS., Wörterbuch zur Erklärung und Verdeutschung, 1808; DERS., Wörterbuch zur Erklärung und Verdeutschung, 1813; [HEINSIUS], Der Sprach-Gerichtshof; RADLOF, Frankreichs Sprach- und Geistestyrannen. Weiterführend vgl. SPILLNER, Der Sprach-Gerichtshof von 1814; KRAMER, Das Französische in Deutschland, S. 118-121. Über die Ideologen und Sprachwissenschaftler um 1800 vgl. KIRKNESS, Zur Sprachreinigung; OESTERREICHER, Ère française et Deutsche Bewegung; SCHLIEBEN-LANGE, Les Idéologues; DIES. (Hg.), Europäische Sprachwissenschaft um 1800; HAGEMANN, Nation, Krieg und Geschlechterordnung, S. 570; SCHLIEBEN-LANGE, DRÄXLER, Die Französische Revolution und das deutsche Sprachdenken; Tintemann, Trabant (Hg.), Sprache und Sprachen um 1800. Über Campes Wörterbuchsprojekt im Jahre 1807 vgl. u.a. KEIM, »Savoir vivre«, S. 152; LÜSEBRINK, REICHARDT, Einleitung, in: DIES., »Kauft schöne Bilder, Kupferstiche...«, S. 20, 22.

519 ARNDT, Ueber Volkshaß, S. 35 f., vgl. ferner S. 14. Arndts »Volkshaß« ist synonym mit »Nationalhaß«. Vgl. ibid., S. 3. Über Arndt vgl. LÜSEBRINK, Ernst Moritz Arndt. Über die eher ethnische Bedeutung der Begriffe »Volk« und »Vater- 
schwer $^{520}$. Von allen Verschiedenheiten zwischen den Völkern, so Arndt, siegten die sprachlichen Unterschiede:

Das Größte und Bedeutendste aber liegt in der Verschiedenheit der Sprachen, weil jede Sprache das äußere Abbild des innersten Gemüthes eines Volkes ist, weil sie die Form ist, welche sich von Kind auf des ganzen Menschen, der sie spricht, am gewaltigsten bemeistert, und seinem Geiste und seiner Seele das Gepräge giebt, womit er empfinden, denken, lieben, und leben soll: sie ist der erstarrte Geist der vergangenen Geschlechter, den die Lippe aufthaut, wie sie die Worte erfasst. Darum ist nichts trauriger und gefährlicher, als wenn ein Volk seine Sprache für eine fremde vergisst; dann begehrt es Sklav der Fremden zu werden. Aus dieser Verschiedenheit der Sprachen, und aus der eigenthümlichen Bildung, die mit einer jeden Sprache verknüpft ist, und aus manchen theils sichtbaren, theils unsichtbaren früheren oder späteren Ursachen erwächst der Widerwille und die Abneigung, welche die Völker in einzelnen Punkten gegen einander haben, und welche ihre Unabhängigkeit und Freiheit besser sichern, als noch so viele befestigte Städte und gezückte Schwerdter ${ }^{521}$.

Die Überzeugung, die Sprache eines Menschen sei identitätsstiftend und präge Geist und Seele ganzheitlich, sollte eindeutig dazu dienen, an der Schwelle zum Nationalzeitalter den nationalen Geist in Deutschland zu entfachen und zu verankern. Zur Unterstützung verwendet Arndt starke kämpferische Metaphern und Topoi: Er warnt vor der Sklaverei, die aus einer Sprachdominanz resultiere, und stellt die Sprache als besseres Schwert zur Behauptung der Unabhängigkeit und Freiheit dar ${ }^{522}$.

Zum identitären Charakter von Sprachen sagt Arndt: »Die Sprache ist ein Spiegel des Volkes, das sie spricht ${ }^{523}$. Seiner Ansicht nach gründe in einer Sprache der Ursprung eines Volkes und Sprache und Volk seien innerlich eins, was auch bedeute, dass, wer nicht zu seiner Sprache halte, auch kein Volk werden oder bleiben könne ${ }^{524}$.

Diese Grundposition hilft einige der tendenziösen Kommentare zu erklären, die vorwiegend aus gebildeten Kreisen stammen und dazu neigen, den Sprachkontakt mit dem Französischen als die schlimmste Misshandlung der Franzosenzeit darzustellen ${ }^{525}$.

Eines der vielfach heraufbeschworenen Schreckensbilder in diesem Kontext betrifft die vermeintliche Gefahr der Verschmelzung mit der Sprache des Unterdrückers. Vor diesem Hintergrund lässt sich erklären, dass der anonyme Autor der Schrift "Die entlarvte hohe und geheime Polizei« mit Bedauern schreibt, zu den

land « bei Arndt, Körner und Jahn, vgl. LÜSEBRINK, REICHARDT, »Kauft schöne Bilder, Kupferstiche...«, S. 10.

520 Vgl. ARNDT, Ueber Volkshaß, S. 38.

521 Ibid., S. 12.

522 Das kriegerische Element der Sprache als Schwert findet sich u.a. auch bei Grimm, vgl. Kummer, Sprache und kulturelle Identität, S. $274 \mathrm{f}$.

523 ARNDT, Ueber Volkshaß, S. 33.

524 Vgl. ibid., S. 34, 77.

525 Vgl. Kummer, Sprache und kulturelle Identität, S. $274 \mathrm{f}$. 
Titeln, diesem allgemein verehrten National-Spielwerke, und [...] von [den] Schauspielen in der Muttersprache. Allein nichts von dem allen wurde ausgelassen, und wir sollten schlechterdings schon in den ersten Jahren das seyn, was andere eroberte Staaten in Jahrhunderten nicht geworden sind, nicht haben werden wollen und können - verschmelzt in den Geist, in die Sprache und Sitten der Unterdrücker ${ }^{526}$.

Ein weiterer Topos, neben der Verschmelzung, ist der einer über die Sprache entstehenden Versklavung. Der Versuch, sich in der fremden Sprache zu artikulieren, komme einem Akt der Versklavung nahe. So schreibt Scheller in seiner »Jeromiade« folgende Verse:

So musst' man uns das Fransche lehren,

Damit wir Frankenknechte wären ${ }^{527}$.

Und auch Arndt warnt vielfach vor Sklaverei, Tyrannei und Knechtschaft, wie in der bereits oben zitierten Quelle, in der er betont, dass ein Volk, das bereit sei, seine Sprache aufzugeben, eigentlich begehre, „Sklav der Fremden zu werden ${ }^{528}$. Die Bereitschaft der Deutschen, sich die französische Sprache anzueignen und somit zum "Sklav der Fremden zu werden«, wird von Arndt problematisiert und zum Teil damit begründet, die deutsche Sprache habe dadurch viel an ihrer ursprünglichen Lebendigkeit eingebüßt. Das Problem des deutschen Volkes sei, dass es von einem lebenden und redenden Volk zu einem grübelnden und schreibenden Volk geworden sei ${ }^{529}$. Dieser Vorwurf findet sich auch in den bereits oben besprochenen Bemerkungen der westphälischen Zeitgenossen, allen voran Siméon, über die mangelnde Redekultur der Deutschen. Arndt vergleicht die Franzosen und die Deutschen in ihrem Verhältnis zur eigenen Sprache und konstatiert die überwiegende Neigung der Franzosen zum Sprechen und die der Deutschen zum Denken, was er an der Geselligkeit der Franzosen und dem Rückzug der Deutschen in die Privatsphäre festmacht ${ }^{530}$.

Wenn Arndt sich gegen das Franzosentum und die Franzosen ereifert, gilt sein giftiger Ausspruch zuerst den "Sprachmeistern", die er samt den »Tanzmeistern, Abbés, Kammerdienern, Köchen, Salbenkrämern, Kammerzofen, und Gouvernantinnen « in Gedanken nach Frankreich zurückbefördert:

Die beiden Völker haben bei einander nichts zu thun, die Franzosen haben bei ihnen selbst Landes genug, wir haben es auch bei uns, und es wird kein großer Verlust für uns seyn, wenn die französischen Sprachmeister, Tanzmeister, Abbés, Kammerdiener, Köche, Salbenkrämer, Kammerzosen, und Gouvernantinnen unserer Töchter

526 AnONymus, Die entlarvte hohe und geheime Polizei, S. 30.

527 SCHELLER, Jeromiade, S. 8.

528 ARNDT, Ueber Volkshaß, vgl. S. 11, hier S. 12.

529 Vgl. ibid., S. 45; HagemanN, Nation, Krieg und Geschlechterordnung, S. 571.

530 Vgl. ARNDT, Ueber Volkshaß, S. $50 \mathrm{f}$. 
und unserer Bordelle das grobe Allemannien als ein unausstehliches und abscheuliches Land künftig fliehen ${ }^{531}$.

Ihre Sprache zählt nach Ansicht Arndts zu den tückischsten Gaben, die die französischen Einwanderer den Deutschen mitbrachten. Deswegen rangieren die »Sprachmeister« an vorderster Stelle, wenn Arndt sich anschickt, eine Liste der unerwünschten Zuwanderer aufzustellen.

Das Motiv des Turmbaus zu Babel wird in der Argumentation gegen die napoleonischen Staatsgründungen auf deutschen Territorien ebenfalls mehrfach bemüht. Arndt erinnert an den Willen Gottes:

Gott hat diese Verschiedenheit auch unter den Menschen gewollt, und deswegen hat er sie gestiftet: darum die verschiedenen Völker, Länder, und Sprachen, und was sich draus wieder für eine Unendlichkeit von Verschiedenheiten erzeugt.

Wer also von Einer Religion, von Einem Staate, von Einer Sprache, von Einem gebietenden Volke spricht, der spricht gegen Gott und seinen ewigen Willen ${ }^{532}$.

Damit wird Napoleons Expansionspolitik in Europa als Blasphemie dargestellt. Arndt sieht freilich in der nach der biblischen Erzählung eingetretenen Sprachverwirrung eine große Chance:

Was in der Bibel als ein Babel, als eine Verwirrung geschildert wird, was den einfältigen Menschen der Urwelt so erscheinen musste, das ward eine Erhellung der kindischen Dumpfheit, eine Erlösung des Menschengeschlechts von unbewusster Träumerei ${ }^{533}$.

Das Motiv des Turmbaus zu Babel wird auch in der burlesken Satire von Hilarius erwähnt, allerdings mit einem ironischen Unterton. Die Umgangsformen in der westphälischen Gesellschaft kritisiert der Autor so:

es [ist] doch wohl eine grobe Lüge, wenn sich so viele Menschen >Herr Bruder nennen, die doch keine Verwandtschaft weiter haben, als die von Adam her, oder die aus den Weinhäusern, oder die aus der großen Hornspitzenfabrik, oder endlich die aus der großen politischen Unfabrik. - Vielleicht aber liegt doch einige Wahrheit in dem `Herr Bruder , denn es soll jetzt mitunter eine Blutsverwirrung unter den Menschen seyn, wie zu den Zeiten des babilonischen Thurmbaues eine Sprachverwirrung war ${ }^{534}$.

Nicolai, der sich hinter dem Pseudonym Hilarius verbarg, erschien offenbar in seinem Text die »Sprachverwirrung " Anfang des 19. Jahrhunderts weniger bedeutsam als die »Blutsverwirrung «. Die Frage, ob die Zugehörigkeit zu einem Volk beziehungsweise zu einer Nation mehr auf der Bluts- als auf der Sprachverwandtschaft basierte, klingt hier mit an. Das Werden der Nation, so reflektierten die gebildeten Zeitgenossen, war abhängig von der Entscheidung der Sprachenfrage. Der Autor der burlesken Satire nimmt möglicher-

531 Ibid., S. 19.

532 Ibid., S. 11.

533 Ibid., S. $30 \mathrm{f}$.

534 HilariUs, Humoristische Reise, S. 9 f. 
weise wie Arndt selbst eine unterschwellig ironische Haltung zu den Vertretern des Frühnationalismus in Deutschland ein, wenn er bemerkt, dass eigentlich alle aus der napoleonischen Ära sehr blutsverwirrt herausträten und die Sprachverwirrung demgegenüber gar nicht so bedeutend sei.

Insgesamt klingen die Angriffe gegen das Französische aus gebildeten Kreisen höchst widersprüchlich, wenn man bedenkt, wie stark diese Kreise sich selbst geistig an Frankreich orientierten ${ }^{535}$. Um den Widerspruch wieder aufzulösen, in den sich ein Intellektueller wie Arndt mit seiner Abwehrhaltung gegen die französische Sprache bei aller Vertrautheit mit den französischen Gelehrtenschriften verstrickte, nahm er kurzerhand die hohe geistige Literatur und Philosophie von der Notwendigkeit des »Volkshasses« aus:

St. Bernhard, Ludwig der Heilige, Duguesclin, Bayard, Turenne, du Thou, de l'Hopital, Pascal, Montesquieu. [...] Auf dieser Höhe hört der Volkshaß auf; da beginnt die große Gemeinschaft der Völker, die allgemeine Menschheit, und da wird die Menschlichkeit und Liebe nimmer fehlen, die uns alle zu Kindern Eines Gottes und Einer Erde macht ${ }^{536}$.

Arndt warnt zwar alle vor dem gefährlichen Sprachkontakt mit dem Französischen und der daraus drohenden Verschmelzung mit dem Deutschen, behält sich jedoch selbst vor, weiterhin seinen Geist an französischen Schriften zu formen.

Interessant ist auch, auf die Illusion des Deutschen als Nationalsprache hinzuweisen, wie sie im Zuge der Restauration in den nach 1813 erschienenen Schriften vertreten wird. Nicolai lässt seinen westphälischen Antihelden zwar lautstark herausposaunen: "Ich bin geboren in Deutschland, also in einem Lande, wo durchgängig ein' und dieselbe Sprache geredet wird ${ }^{537}$. An anderer Stelle verrät er aber, es sei mit der Einigkeit der deutschen Sprache noch nicht so weit her, und spricht ironisch, wie oben bereits zitiert, vom Trugbild des Deutschen als Nationalsprache des deutschen Reiches ${ }^{538}$. Nicolai hebt unter anderem die vielen Dialekte sowie die kulturellen regionalen Unterschiede hervor. Damit betont er, wie illusorisch das Programm mancher Zeitgenossen war, die deutsche Sprache als Nationalsprache zum Fundament der deutschen Nation zu küren ${ }^{539}$.

Aus der Perspektive von Charles J. Bail, eines französischen Zuwanderers, der 1809 ein statistisches Werk über das Königreich Westphalen verfasste, bildete für die Stiftung von nationalen Gefühlen historisch gesehen

535 LÜSEBRINK, Ernst Moritz Arndt.

536 ARNDT, Ueber Volkshaß, S. 21.

537 Hilarius, Humoristische Reise, S. 25

538 Vgl. ibid., S. $15 \mathrm{f}$.

539 Über den frühaufklärerischen Patriotismus-Diskurs, der Reichsidentität mit regionaler Identität verband vgl. NORTH, Das Reich als kommunikative Einheit, S. $240 \mathrm{f}$. 
nicht so sehr die gemeinsame Sprache ein Hindernis, sondern die kulturellen regionalen Unterschiede:

Quoique Maximilien eut tenté en Allemagne ce que Richelieu exécuta si heureusement en France quelques siècles après lui, il ne put jamais annéantir la puissance des grands vassaux; en France ils avaient été sournis aux Rois, en Allemagne ils le furent à peine aux loix; ainsi les allemands formaient un corps de nation, et ils n'avaient pas d'esprit national; ils parlaient la même langue et restaient étrangers les uns aux autres, ils vivaient sous le gouvernement d'un même chef et obeissaient à plusieurs; ils jouissaient enfin des mêmes droits sans êtres liés par le même intérêt; voilà pourquoi ils n'avaient ni tranquillité au dedans, ni considération au dehors. [Leurs] loix [...], elles étaient en effet si compliquées [...] que peu de nationaux pouvaient se vanter de les connaitre [...], il faut $<y>$ ajouter le mauvais emploi des forces nationales ${ }^{540}$.

Eine solche Aussage seitens eines Befürworters der westphälischen Herrschaft, welche die Wichtigkeit einer nationalen Sprache für einen Staat in Abrede stellt, überrascht nicht weiter: Die Konzeptionalisierung des Königreichs Westphalen, der Projekte zur Bildung der westphälischen Nation zugrunde lagen $^{541}$, musste Abstand nehmen von einer einzigen Nationalsprache. Tatsächlich wurde bereits 1807 der Mindener Gelehrte Christoph Heinrich Wermuth von den französisch-kaiserlichen Vertretern beauftragt, das Wesen der westphälischen Nation historisch zu eruieren. In seinem Legendenangebot schaffte er es, Wedekind und Karl den Großen als westphälische Nationsbrüder zu versöhnen und für die westphälische Staatsgründung Pate stehen zu lassen ${ }^{542}$.

In Bezug auf die gemeinsame deutsche Sprache, die Nicolai belächelt, zeigt sich Scheller in seiner »Jeromiade« nicht weniger skeptisch gegenüber der Ursprache Deutsch aus »Rein'kens« Zeit, die die wenigsten eigentlich noch verstehen würden:

540 BAIL, Statistique générale, S. XVIII.

541 Vgl. OWZAR, Schlendrian, S. 308; SPEITKAMP, Unruhe, Protest, Aufstand, S. 149.

542 Vgl. SHAT Vincennes, Akte 1 M 1526: Notice historique sur la Westphalie, par Wermuth, de Minden, le 22 août 1807 (43 pages), dort S. 4: »une chose est certaine, toute la Westphalie avait pour écusson principal un cheval sautant, libre et sans bride: il fut la bannière de Wittekind comme de tous ses ancêtres«; S. 21: »Maintenant je parle des deux grands hommes contemporains: a. Charle Magne, b. Wittekind le Grand, ils etaients tous deux Westphaliens tant: 1. par naissance que, 2. par possessions provinciales et territoriales «; S. 41: »Aucune nation a des tels princes [Wittekind et Charlemagne], on peut donc dire ce qu'on voudra, l'attachement d'un Westphalien à la posterité de Wittekind ne pourra jamais cesser parmi la partie cultivée de la nation«. Auch der »Westphälische Moniteur" bewies mit dem Abdruck einer Art Leserbrief an den Redakteur des »Moniteur «, zugeschickt durch den Leser »H.« aus »Cassel, de l'Imprimerie du Gouvernement « zum Thema "Sur les monuments d'une partie de l'ancienne Westphalie» diese Verbindungslinie Wedekind-Jérôme de Westphalie, vgl. Le Moniteur westphalien, Nr. 31, 8. März 1808, S. 125 f. Dort auf S. 125: »Wittekind, [...] déja un Roi ou un Duc de Westphalie«. 
Desselben, den bis diesen Tag

Kein Schreiber übersetzen mag,

Weil Alemannen mit den Sassen

Sich schwer zusammen reimen lassen.

Mir wars, als schrieb' ich einen neu'n,

Und kam im vollen Sprung hinein

In Rein'kens alte Deutsche Zung',

So wie sie mir die Mutter sung.

Nun steht es da, und mancher mag

Es nicht verstehn am heut'gen Tag.

Wenn er's nicht thut, ists eigne Schuld,

Und muss ein solcher han Geduld,

Bis ihm ein andrer übersetzt

Was bass uns in der Ursprach' letzt ${ }^{543}$.

Aber selbst Arndt räumt in seiner Schrift »Ueber Volkshaß und über den Gebrauch einer fremden Sprache« bei aller Sympathie für den Einheitscharakter der deutschen Sprache ein, diese sei von zwei Hauptdialekten beherrscht, nämlich dem »Sassischen « und dem »Allemannischen " ${ }^{544}$. Er stellt sie allerdings über die französische Sprache hinsichtlich ihres edlen Wesens und ihres Reichtums ${ }^{545}$. Allerdings schreibt er an anderer Stelle ganz diplomatisch auch zur Wertung beider Sprachen: »welche von beiden Sprachen die beste sey, die französische oder die teutsche? Die Antwort giebt sich von selbst: sie sind beide die besten, die französische Sprache für die Franzosen und die teutsche Sprache für die Teutschen $\aleph^{546}$.

Arndt belässt es allerdings nicht bei der Konstatierung der Vorzüge der deutschen Sprache für die Deutschen, er geht weiter und definiert ein Programm zur sprachlichen Abschottung. Im Kern erscheint es ihm notwendig, sich vor dem Gebrauch anderer Sprachen, besonders der Nachbarvölker, zu schützen, um sich seine Freiheit als Volk zu sichern ${ }^{547}$ :

Daher sollte jedes Volk, welchem seine Eigenthümlichkeit und Freiheit lieb ist, das Gesetz machen, dass die lebende Sprache eines Nachbarvolkes bei ihm nimmer gesprochen werden dürfte, so dass man $\mathrm{z}$. B. in Teutschland wohl russisch und spanisch und englisch sprechen dürfte, aber nicht polnisch, italiänisch, noch französisch, weil man durch den Gebrauch der benachbarten Sprachen die Schlagbäume niederwirft, welche die Völker für das Glück und die Bildung der Welt wohlthätig und weise von einander trennen.

Man sieht jetzt, wohin ich will. Ich will die Uebung und den Gebrauch der französischen Sprache in Teutschland abgeschafft wissen. Man mag die französische Sprache lesen und verstehen wie andere Sprachen, damit man der Bildung, Wissenschaft, Kunst, und Art auch des französischen Lebens genießen könne; aber sprechen soll man sie nicht ${ }^{548}$.

543 SCHELLER, Jeromiade, S. 204.

544 Vgl. ARNDT, Ueber Volkshaß, S. $71 \mathrm{f}$.

545 Vgl. ibid., S. 71.

546 Ibid., S. 70.

547 Vgl. ibid., S. 21.

548 Ibid., S. $38 \mathrm{f}$. 
Diese Abwehrhaltung gegenüber jeglichem mündlichen Sprachkontakt mit dem Französischen ist am Ende der napoleonischen Ära auf deutschen Territorien bezeichnend. Deutschland als »Mittelpunktsvolk« und »Mittelpunktsland « bedürfe nicht des Französischen ${ }^{549}$. Französisch als diplomatische Sprache sei, nach Ansicht von Arndt, ebenfalls kein Muss, denn »die wirksamste geistige Gewalt, [sei] die Gewalt der Sprache «550. Deswegen rät er dazu, in der Diplomatie mehr Dolmetscher zu verwenden, was alle Unterhändler sprachlich gleich stellen würde ${ }^{551}$. Auch die Einführung des Lateinischen als Diplomatiesprache erscheint ihm angebracht ${ }^{552}$.

Das Ziel sollte nach Arndts Meinung sein, die Volksverschiedenheiten der Franzosen und der Deutschen zu kultivieren ${ }^{53}$. Die Hauptmotivation dahinter war die Stärkung der nationalen Unterschiede über die Abgrenzung der Sprachen:

wir [haben] dahin zu trachten und Alt und Jung, Vornehm und Gering zu ermahnen, die Herrschaft der französischen Sprache bei uns für alle Zeiten zu vertilgen, damit wir künftig politisch frei und innerlich und äußerlich ächt teutsch leben können, was nicht allein uns selbst heilsam und ersprießlich, sondern auch den Franzosen das wohlthätigste seyn wird ${ }^{554}$.

Arndt fordert eine allgemeine Pflicht, sich der französischen Sprache in $\mathrm{Zu}$ kunft zu enthalten, und plädiert dafür, den deutschen Fürsten- und Bürgersöhnen solle weder Französisch, noch Latein und Griechisch beigebracht werden ${ }^{55}$. An dieser Stelle appelliert er besonders an die deutschen Frauen, denen als Bildnerinnen der künftigen Geschlechter eine besondere Aufgabe in Bezug auf die Vorrangstellung der deutschen Sprache gebühre ${ }^{556}$.

Zusammen mit dem Ruf zu den Waffen, um sich von der "französischen Tyrannei« zu befreien, ruft Arndt dazu auf, sich von der französischen Sprache loszusagen:

Aber wir haben nichts gethan, wenn wir nicht auch die ungebührliche Herrschaft der französischen Sprache aus unsern Gränzen treiben, wenn wir nicht durch lauten Ausspruch und stille Uebereinkunft das Gesetz gegen, die französische Sprache soll in Teutschland keine sprechende Sprache mehr seyn. Sobald wir diesen Sieg über verjährten Land und buhlerische Eitelkeit errungen haben, bricht der Tag unser Glorie wieder an, und nach wenigen Geschlechtern werden wir wieder ein teutsches Volk, eine teutsche Art, und ein teutsches Leben sehen. [...] Arbeiten die Franzosen, wo sie die Herren sind, nicht planmäßig, unsre Sprache allmälig zu vertilgen und auszutreffen ${ }^{557}$ ?

549 Ibid., S. 47, 61.

550 Ibid., S. 48.

551 Vgl. ibid., S. $48 \mathrm{f}$.

552 Vgl. ibid., S. 49.

553 Vgl. ibid., S. $49 \mathrm{f}$.

554 Ibid., S. 66.

555 Vgl. ibid., S. 73.

556 Vgl. ibid., S. 78 f.; HagemanN, Heldenmütter, S. 185 f.

557 ARNDT, Ueber Volkshaß, S. 70. 
Mit einem solchen ablehnenden Programm gegenüber der französischen Sprache im Hintergrund überrascht nicht weiter das Aufkommen der Sprachgesellschaften nach 1813, die sich gegen die vermeintliche französische Fremdwörterflut in der deutschen Sprache wandten ${ }^{558}$.

Selbst wenn bei Arndt die Terminologie »Nation« keine Erwähnung findet, wird die deutsche Sprache doch an das Nationalprojekt angebunden. Diese latente Verbindung wird in den Memoiren eines westphälischen Zeitgenossen ganz deutlich: »indem alle Vorkehrungen getroffen wurden, um eine ausländische Sprache zur öffentlichen Geltung zu bringen, legte man die Axt an die Wurzel des nationalen Lebens « ${ }^{559}$. Während Arndt die Sprache als Schwert definiert und Jakob Grimm sie als »schimmernde Waffe gegen den feindlichen Übermut« bezeichnet, wird hier für die französische Sprache die Metapher der Axt verwendet ${ }^{560}$.

Die starke Ideologisierung der Sprachenfrage in der Zeit unmittelbar nach Ende des Königreichs Westphalen mag auch erklären helfen, weshalb es in den Darstellungen der Historiker zur unreflektierten Übernahme von kämpferischen und tendenziösen zeitgenössischen Aussagen über die Sprachen kam.

Französisch wurde als Sprache des Siegers hingestellt; mit dieser Grundeinstellung konnte man in erster Linie mit der vermeintlichen Dominanz der französischen Sprache über die deutsche in Verwaltung und Gesellschaft beziehungsweise mit der angeblichen Oktroyierung der französischen Sprache ins Gericht gehen ${ }^{561}$. Es wurde teilweise behauptet, die Amtssprache im Königreich Westphalen sei ausschließlich Französisch gewesen, aber nicht mehr erwähnt, dass weite Bereiche der Verwaltung auch in deutscher Sprache geführt wurden ${ }^{562}$. Die Sprachenfrage wurde als ein grundsätzliches Mittel zur Festigung der westphälischen Herrschaft thematisiert:

In fremder Sprache rathschlagte man über das Wohl und Wehe des neuen Königreichs. [...] So bequemten sich denn die Deutschen, französisch zu lernen, da die Franzosen, trotz des königlichen Versprechens, nicht Deutsch lernen mochten.

Mit dieser friedfertigen Lösung des Sprachconflictes allein war jedoch das Glück Westphalens noch nicht gegründet ${ }^{563}$.

Selbst in jüngeren Beiträgen gilt die Tatsache, dass die Amtssprache Französisch war, häufig als Hauptmotiv für die Wahrnehmung der westphälischen

558 Vgl. ibid., S. 84f.; KIRKNESS, Zur Sprachreinigung; FlAMM, Eine deutsche Sprachakademie; SCHMIDT, Geschichte des Alten Reiches, S. 146-149.

559 Havemann, Das Kurfürstenthum Hannover, S. 55.

560 Grimm, zitiert nach: KuMMER, Sprache und kulturelle Identität, S. 274.

561 LosCH, Kfm. Hessen, S. 51.

562 Vgl. Treitschke, zitiert nach: KoHL, Die Verwaltung der östlichen Departements, S. 37; LÜNSMANN, Die Armee des Königreichs Westfalen, S. 10.

563 LYNCKER, Historische Skizzen, S. $84 \mathrm{f}$. 
Herrschaft als Fremdherrschaft ${ }^{564}$. Auch französische Historiker sahen in der Regelung der Sprachenfrage im Königreich Westphalen eine existentielle Bedingung für das Fortbestehen des neuen Staates: »Placer sur un trône allemand un prince français de sa maison fut sans nul doute la première erreur de Napoléon. L'entourer de conseillers, dont Siméon, qui ne parlait pas allemand, en était une autre«, schreibt Tulard ${ }^{565}$.

\section{Fazit: die soziokulturelle und politische Relevanz der Sprachenfrage}

Insgesamt lässt sich aus allen Ausführungen über die verschiedenen Grade des Sprachbewusstseins, die zeitgenössischen Reflexionen über die Sprachen und deren ambivalente Hintergründe ableiten, dass die Sprachenfrage auf jeden Fall als zentral für das Verständnis der westphälischen Gesellschaft einzustufen ist. Auch wenn das Thema zunächst kulturhistorisch anmutet, so führt es doch zum konstitutiven Kern der westphälischen Gesellschaftsrealität, da die Sprachenfrage auf vielen Ebenen relevant war, so für die soziale, kulturelle und politische Abgrenzung.

Hält man sich eng an die offiziellen Verlautbarungen, kann der westphälischen Herrschaft keine offenkundige Sprachdominanz durch das Französische vorgehalten werden. Allerdings mussten die Westphalen mittels vieler individueller und kollektiver Erfahrungen erleben, dass jenseits der offiziellen Sprachpolitik die französische Sprache sehr wohl an vielen Stellen ihrer Gesellschaft den Vorzug erhielt, da Französisch von 1807 bis 1813 zweifellos das sozial höhere Prestige besaß. Die Einführung der französischen Sprache neben der deutschen im Verwaltungsbereich verursachte durchaus grundlegende Veränderungen der Kommunikationspraktiken.

Im dritten Teil wurde zunächst die paradoxe Situation bestätigt, die als linguistisches Rätsel in der Einleitung dargestellt wurde: Nebeneinander existierten gleichzeitig zeitgenössische Kommentare, die das Sprachproblem hochstilisierten, wie auch Kommentare, die die mehrsprachige Kommunikation als scheinbar selbstverständlich erscheinen ließen. Auf der einen Seite sind Indizien dazu überliefert, wie selbstverständlich die Zeitgenossen sich jenseits der Sprachunterschiede verständigten, wenn sie beispielsweise versuchten, auch Aussagen in fremden Sprachen mit Sinn zu füllen. Dennoch überwogen im Diskurs über die Sprachen ganz dezidierte Urteile und Vorurteile. Es konnte festgestellt werden, dass die zeitgenössischen Erklärungen über die Sprachen quellenkritisch behandelt werden müssen, da sie häufig eine subjektive oder parteiische Sicht reflektieren. Oft wurden

564 Vgl. Kahmann, Die Geschichte des J. F. A. Lampe, S. 343.

565 Tulard, Siméon, S. 567. 
angebliche Sprachverständigungsschwierigkeiten, die nicht unbedingt relevant oder existent waren, politisch funktionalisiert, um daran die Forderung nach Abgrenzung anzuknüpfen. Aus den zeitgenössischen reflexiven Aussagen über die Sprachen und die Sprachenfrage lässt sich schwer rekonstruieren, inwieweit die Sprachenvielfalt im Alltag die Kommunikation tatsächlich erschwerte. Allerdings konnte gezeigt werden, dass die Grenzziehung zwischen den Sprachgemeinschaften zum Teil ganz entgegen anderer Zugehörigkeitsprinzipien verlief. So bestätigt sich die Feststellung von Schulze:

Ständische Solidaritäten [...] wogen in dieser [europäischen] `Gemeinschaft` noch schwerer als beginnende nationale Differenzierungen, auch die Beschäftigung Fremder in den nationalen Bürokratien war etwas durchaus Gewöhnliches, auch wenn der einheimische Adel immer deutlicher auf sein Indigenat pochte ${ }^{566}$.

Zum Schluss kristallisierte sich insbesondere bei eingehenderer Betrachtung der Hofgesellschaft heraus, dass, wenn Personen sich sprachlich verständigen konnten, dies noch nicht bedeutete, dass sie sich kulturell und sozial nahe standen. Gleichzeitig teilten Personen, die über keine gemeinsame sprachliche Verständigungsmöglichkeit verfügten, durchaus ähnliche Erfahrungswelten und kulturelle Hintergründe. Die Kohärenz von Sprach-, National- und kulturellen Gemeinschaften, wie im intellektuellen zeitgenössischen Diskurs propagiert, stimmte somit mit der Alltagsrealität der Westphalen nicht überein. 